\title{
Application of a Decomposition Strategy to the Optimal Synthesis/Design of a Fuel Cell Sub-system
}

\section{Borja Oyarzábal Alonso}

\author{
Thesis Submitted to the Faculty of \\ Virginia Polytechnic Institute and State University \\ in partial fulfillment of the requirements for the degree of \\ MASTER OF SCIENCE \\ in \\ Mechanical Engineering \\ Dr. Michael von Spakovsky, Chair \\ Dr. Michael Ellis \\ Dr. Douglas Nelson \\ Dr. Ricardo Muñoz \\ Dr. Benoit Olsommer
}

Blacksburg, VA

$6^{\text {th }}$ August 2001

Keywords: Optimization, decomposition, fuel cell. 
Application of a Decomposition Strategy to the Optimal Synthesis/Design of a Fuel Cell Sub-system

\section{Borja Oyarzábal Alonso}

\section{Abstract}

The application of a decomposition methodology to the synthesis/design optimization of a stationary cogeneration fuel cell sub-system for residential/commercial applications is the focus of this work. To accomplish this, a number of different configurations for the fuel cell sub-system are presented and discussed. The most promising candidate configuration, which combines features of different configurations found in the literature, is chosen for detailed thermodynamic, geometric, and economic modeling both at design and off-design. The case is then made for the usefulness and need of decomposition in large-scale optimization. The types of decomposition strategies considered are time and physical decomposition. Specific solution approaches to the latter, namely Local-Global Optimization (LGO) and Iterative Local-Global Optimization (ILGO) are outlined in the thesis. Time decomposition and physical decomposition using the LGO approach are applied to the fuel cell sub-system. These techniques prove to be useful tools for simplifying the overall synthesis/design optimization problem of the fuel cell sub-system.

Finally, the results of the decomposed synthesis/design optimization of the fuel cell subsystem indicate that this sub-system is more economical for a relatively large cluster of residences (i.e. 50). To achieve a unit cost of power production of less than 10 cents/kWh on an exergy basis requires the manufacture of more than 1500 fuel cell sub-system units per year. In addition, based on the off-design optimization results, the fuel cell subsystem is unable by itself to satisfy the winter heat demands. Thus, the case is made for integrating the fuel cell sub-system with another sub-system, namely, a heat pump. 


\section{Acknowledgements}

In the time I have spent at Virginia Tech for my Master of Science degree, I have had the opportunity to grow in a personal and a professional way. Many persons have contributed in order to make my experience at Virginia Tech an important reference point in my life. I would like to thank them for making this possible.

First, I would like to thank my advisor Professor von Spakovsky. He trusted my capabilities, and he took the time to teach me when it was necessary.

I am very grateful to have had the opportunity of working with Dr. Ricardo Muñoz. He has all my admiration as an engineer and as a person.

I would like to thank Nikos Georgopoulos, Casper Jorgensen and Jeroen Dekkers for their contributions to my work.

The advise at different stages of my project from Dr. Benoit Olsommer, Professor Michael Ellis and Professor Douglas Nelson have been of tremendous help.

I would like to thank as well my friends in Blacksburg. They have always been an important source of support.

Finalmente me gustaría agradecer el apoyo de mi familia y de mi novia, Maria. En especial a mis padres: Esteban y Alicia, siempre han sabido darme la libertad y el apoyo para conseguir mis metas. 


\section{Table of contents}

Acknowledgements

iii

Table of contents iv

List of figures . vii

List of Tables xii

Nomenclature $\mathrm{XV}$

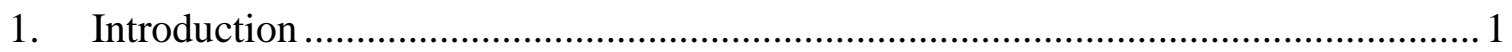

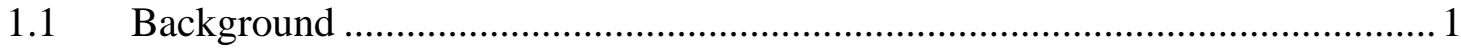

1.2 Fuel Cells and Stationary Applications ................................................ 2

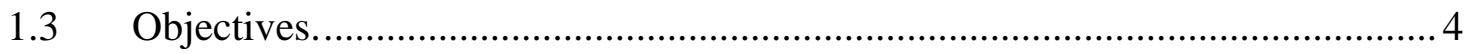

2. General Description of the PEM Fuel Cell Sub-system and its Objectives ............... 6

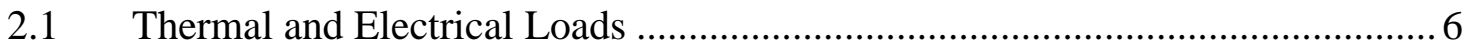

2.2 The Stationary PEMFC Sub-system for Residential Cogeneration Applications.

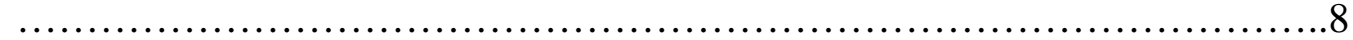

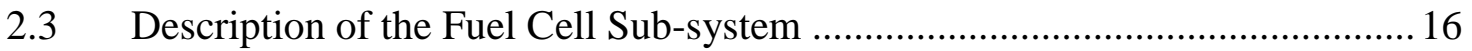

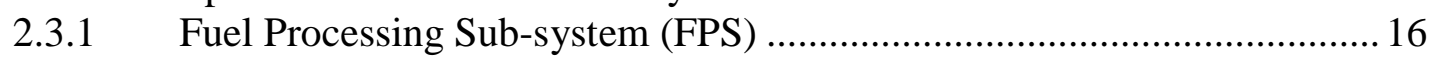

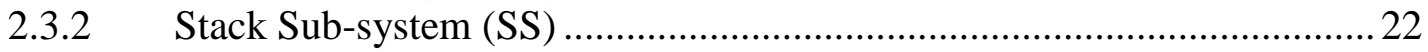

2.3.3 Thermal Management Sub-system (TMS).........................................29

3. Modeling for Synthesis/Design and Off-Design ............................................. 31

3.1 Thermodynamic, Geometric and Cost Models of the FPS ...................... 31

3.1.1 Thermodynamic and Geometric Model for the SR Reactor .................... 31

3.1.2 Thermodynamic and Geometric Model for the SG................................ 41 
3.1.3 Outline of the Principal Features of the Thermodynamic and Geometric Models for the FPS.

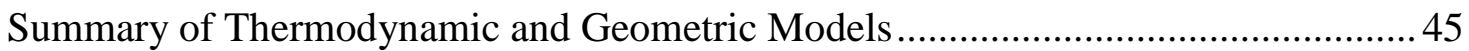

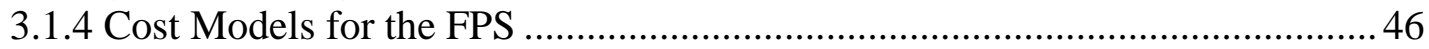

3.2 Thermodynamic, Geometric and Cost Models of the SS ....................... 49

3.2.1 Thermodynamic and Geometric Model for the PEMFC Stack.................49

3.2.2 Outline of the Principal Features of the Thermodynamic and Geometric

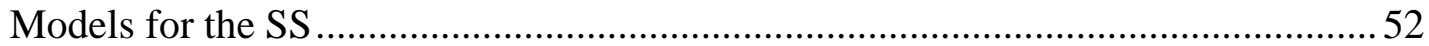

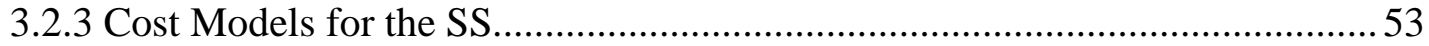

4. Decomposition for the Large-Scale Optimization of Energy System

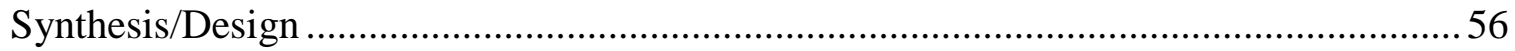

4.1 The Dynamic, Nonlinear Mixed Integer Programming Problem..........................56

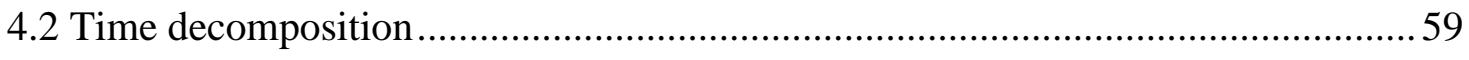

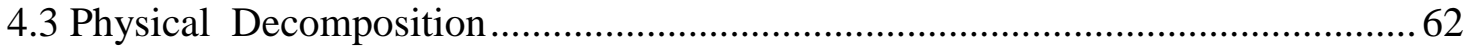

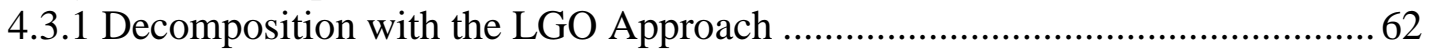

4.4 Iterative Local-Global Optimization (ILGO) Approach........................................ 67

4.4.1 Version A of the Iterative Local-Global Optimization (ILGO-A) Approach . 68

4.4.2 Version B of the Iterative Local-Global Optimization (ILGO-B) .................... 72

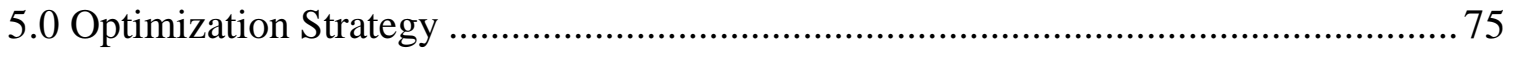

5.1 Definition of the Synthesis/Design Optimization Problem Using Time

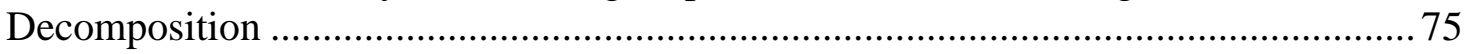

5.2 Synthesis/Design Optimization Problem Using Physical Decomposition..............78

5.2.1 Physical (Unit) Decomposition of the Fuel Cell Sub-system ......................... 78

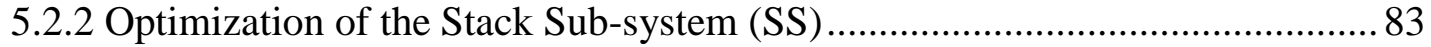

5.2.3 Combined FPS Unit-level/System-level Optimization .................................. 87

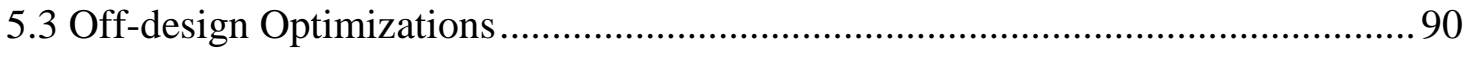

5.4 Algorithm for the Optimization Procedure. ..................................................... 94

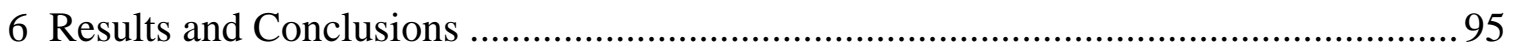

6.1 Results for the Unit-level Optimization of the SS.............................................. 95 
6.2 Results for the Optimization of the Fuel Cell Sub-system for a Variable Number of

Residences

6.3 Results for the Optimization of the Fuel Cell Sub-system for a Variable Number of Units Manufactured per Year. 116

6.4 Thermodynamics and Geometry Characteristics of the Optimal Fuel Cell Subsystem at the Synthesis/Design Point for 50 Residences and 1482 Units.................... 121

6.4.1 Thermodynamic Characteristics.................................................................... 121

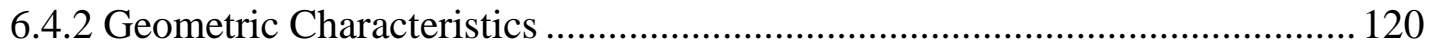

6.5 Off-design Optimization of the Most Promising Syntheses/designs (50 Residences, 1482 Units).....

7. Conclusions and Recommendations for Future work

References

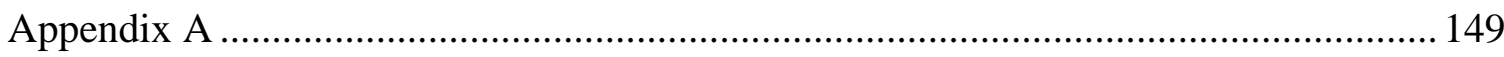

Heat exchangers model …………................................................................. 149

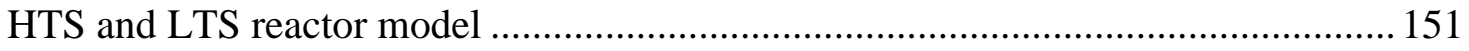

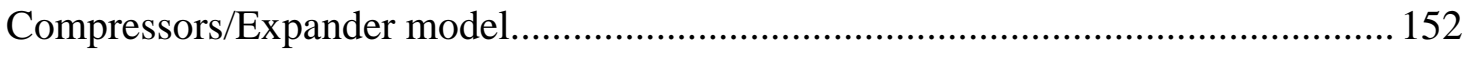

Vita 154 


\section{List of figures}

Figure 2. 1:Winter electrical and thermal load profiles for locations in the northeastern

U.S. (Gleason et al., 1999).................................................................. 7

Figure 2. 2: Summer electrical and thermal load profiles for locations in the northeastern

U.S. (Gleason et al., 1999).................................................................. 7

Figure 2. 3: Conventional fuel steam reforming sub-system with shift and PROX reactors

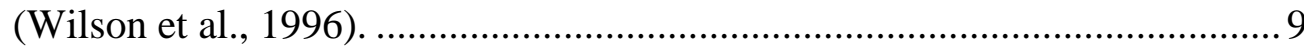

Figure 2. 4: Alternative fuel steam reforming sub-system with a perm-selective hydrogen separator (Wilson et al., 1996).............................................................. 9

Figure 2. 5: PEMFC sub-system for cogeneration presented by Kordesch et al. (1996).. 11

Figure 2. 6: The methane steam reforming PEMFC sub-system presented by Arthur D. Little (1994) ................................................................................................ 12

Figure 2. 7: TES options for cogeneration in residential applications (Gunes, 2001).... 14

Figure 2. 8: Fuel cell sub-system (components are summarized in Table 2.2)............... 19

Figure 2. 9: General view of a fuel cell unit made up of collector plates, flow channels, backing layers, and membrane electrode assembly (i.e. the anode/ and cathode/catalyst layers and membrane) (Barbir, 1999).

Figure 2. 10: Polymer electrolyte membrane with porous electrode / catalyst layers

(Thomas et al., 2000).

Figure 2. 11: Chemical structure of the Nafion ${ }^{\mathrm{TM}}$ membrane material (Thomas et al., 2000)

Figure 2. 12: General overview of a membrane electrode assembly (MEA) and the electrode backing layers (Thomas et al., 2000)...........................................26

Figure 2. 13: Polarization curve

Figure 2. 14: Fuel cell stack with 3 MEAs plus collector plates (Thomas et al., 2000)... 28 
Figure 3. 1: Equilibrium compositions at the outlet of the SR reformer reactor calculated using the SR model above (outlet pressure $3 \mathrm{~atm}$; steam to methane ratio of 3)

Figure 3. 2: a) Double countercurrent-flow SR tube (Murray et al., 1985); and b) a flat slab single countercurrent-flow SR tube (Murray et al., 1985). .38

Figure 3. 3: Example of a baffled, single-pass shell and tube heat exchanger (Liu et al., 1998).

Figure 3. 4: Plot of FPS capital cost as a function of volumetric flow rate. 47

Figure 3. 5: Plot of the unit price of natural gas over a twelve-month period. 48

Figure 3. 6: Family of polarization curves for the PEMFC stack model. .50

Figure 4. 1: Dynamic Mixed Integer Non-linear Programming (MINLP) Problem......... 58

Figure 4. 2: Physical decomposition of a 2-unit system.

Figure 4. 3: Local (unit) and global (system) optimizations. .66

Figure 4. 4: Initial restricted unit or local optimum points used in the construction of the system-level ORS and in the Taylor series expansions about the point for unit 1 and that for unit 2 .

Figure 4. 5: The restricted system-level optimum point on the system-level ORS for the initial values $\xi_{o}$ and $\psi_{o}$

Figure 5. 1: Optimum Response Surface for the SS at $200 \mathrm{kPa}$ and for 50 houses. 86

Figure 6. 1: a) Unit-level ORSs for the SS at stack operating pressures of 200, 250 and $300 \mathrm{kPa}$. b) Unit-level ORSs for the SS at stack operating pressures of 350 and $400 \mathrm{kPa}$; In both cases the number of residences is set to 50.

Figure 6. 2: a) Frontal view of the unit-level ORS for the SS for 50 residences and at a stack pressure of $300 \mathrm{kPa}$; b) stack power density versus hydrogen feed for a gross power output of $149 \mathrm{kWe}$ and a stack pressure of $300 \mathrm{kPa}$.

Figure 6. 3: Power density versus hydrogen feed for a gross power output of $149 \mathrm{kWe}$ and stack pressures of $200 \mathrm{kPa}, 300 \mathrm{kPa}$ and $400 \mathrm{kPa}$.

Figure 6. 4: Lateral view of the unit-level ORS for the SS for 50 residences and $200 \mathrm{kPa}$. 
Figure 6. 5: Optimum costs of the fuel cell sub-system versus the number of residences.

Figure 6. 6: Optimum unit cost of production at the synthesis/design point for the fuel cell sub-system in $\$ / \mathrm{kWh}$ on an energy basis versus the number of residences.

Figure 6. 7: Optimum unit cost of production at the synthesis/design point for the fuel cell sub-system in $\$ / \mathrm{kWh}$ on an exergy basis versus the number of residences.

Figure 6. 8: Costs of the fuel cell sub-system for a single residence in millions of dollars versus system efficiency for a complete range of feasible fuel cell subsystem simulations.

Figure 6. 9: Costs of the fuel cell sub-system for 50 residences in millions of dollars versus system efficiency for a complete range of feasible fuel cell subsystem simulations.

Figure 6. 10: Costs of the fuel cell sub-system for 100 residences in millions of dollars versus system efficiency for a complete range of feasible fuel cell subsystem simulations.

Figure 6. 11: System efficiency of the optimum synthesis/design versus the number of residences.

Figure 6. 12: Optimum net power output at the synthesis/design point of the fuel cell sub-system versus the number of residences.

Figure 6. 13: Optimum rate of methane consumption at the synthesis/design point versus the number of residences.

Figure 6. 14: Characteristic lengths of the a) steam generator, c) steam reformer reactor and d) heat exchangers as well as b) the number of cells of the stack versus the number of residences for which the fuel cell sub-system is synthesized/designed.

Figure 6. 15: Optimum costs at the synthesis/design point of the fuel cell sub-system in $\$$ /unit versus the number of units manufactured per year.

Figure 6. 16: Costs of the fuel cell sub-system for 100 units manufactured per year in millions of dollars versus system efficiency for a complete range of feasible fuel cell sub-system simulations. 
Figure 6. 17: Costs of the fuel cell sub-system for 1482 units manufactured per year in millions of dollars versus system efficiency for a complete range of feasible fuel cell sub-system simulations. 120

Figure 6. 18: Costs of the fuel cell sub-system for 10,000 units manufactured per year in millions of dollars versus system efficiency for a complete range of feasible fuel cell sub-system simulations.

Figure 6. 19: Thermodynamic details of the configuration for the optimal fuel cell subsystem at the synthesis/design point. 123

Figure 6. 20: Mechanical/electrical exchanges and thermal energy exchanges within and from the configuration for the optimal fuel cell sub-system at the synthesis/design point (50 residences, 1482 units manufactured per year).

Figure 6. 21: Conversion of the methane to reformate in the FPS for the optimum fuel cell sub-system at the synthesis/design point (50 residences, 1482 units manufactured per year).

Figure 6. 22: Graphical representation of the geometric data of Table 6.12 for the heat exchanger prior to the steam reformer reactor (component 3 in Fig 2.8). 124

Figure 6. 23: Graphical representation of the geometric data of Table 6.12 for the heat exchanger prior to the LTS reactor (component 6 in Fig 2.8).

Figure 6. 24: Graphical representation of the geometric data of Table 6.12 for the heat exchanger prior to the PROX reactor (component 8 in Fig 2.8).

Figure 6. 25: Graphical representation of the geometric data of Table 6.13 for the steam generator (component 25 in Fig 2.8).

Figure 6. 26: Graphical representation of the geometric data of Table 6.14 for the steam reformer reactor (component 4 in Fig 2.8).

Figure 6. 27: System electrical efficiency based on LHV versus gross power of the stack for the optimum synthesis/design at the different summer load conditions.

Figure 6. 28: System electrical efficiency (LHV) versus gross power of the stack for the optimum synthesis/design at the different winter load conditions. 133 
Figure 6. 29: Total cost versus power sold for all the feasible runs at the summer offpeak electric load condition for the optimum synthesis/design shown in Table 6.21

Figure 6. 30: Comparison of the electrical production and the electrical demand over the entire environmental/load profile.

Figure 6. 31: Comparison of the heat production and the heat demand over the entire environmental/load profile.

Figure 6. 32 System electrical efficiency based on LHV versus gross power of the stack for the optimum synthesis/design and off-design at the different summer load conditions.

Figure 6. 33 System electrical efficiency (LHV) versus gross power of the stack for the optimum synthesis/design and off-design at the different winter load conditions. 


\section{List of Tables}

Table 2 1: Electrical and thermal loads used in the simulation and optimization of the PEM fuel cell sub-system........................................................... 8

Table 2 2: Some typical compositions of natural gas (mol\%) (Farry, 1998).................. 17

Table 2 3: Components of the configuration given in Fig. 2.8 ................................... 18

Table 2 4: Possible reactions in the methane steam reformer reactor (Jianguo et al., 1989).

Table 2 5: Reactions promoted by the catalyst in the methane steam reformer reactor (Adelman et al., 1995)............................................................................. 20

Table 3. 1: Outline of FPS's thermodynamic and geometric models. .......................... 45

Table 3. 2: Summary of parameters and constants for the thermodynamic and geometric

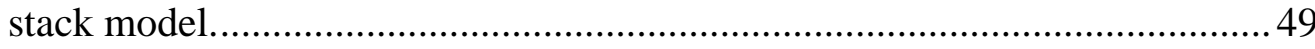

Table 3. 3: Outline of the SS's thermodynamic and geometric models..........................52

Table 3. 4: Capital cost in $\$$ / kWe predicted by Eq. (3.74) and Eq. (3.66) for various combinations of the active area and number of cells and a gross power output of $126 \mathrm{kWe}$

Table 5. 1: Environmental conditions used in the modeling, simulation, and optimization of the PEM fuel cell sub-system.

Table 5. 2: Independent and coupling function variables for the PEM fuel cell subsystem.

Table 5. 3 Parameters held constant during the optimization of the fuel cell sub-system.81

Table 5. 4: Limits on coupling function values as a function of the number of houses.... 85

Table 5. 5: Inequality constraints imposed in Problem (5.12) in order to guarantee a feasible solution

Table 5. 6: Range of the independent variables of the FPS for which the system level optimization problem is evaluated. 
Table 5. 7: Independent/dependent synthesis/design variables held constant during the off-design optimization.

Table 5. 8: Description of the independent (operational) variables for the off-design....93

Table 6. 1: Optimum costs for the fuel cell sub-system for different number of residences.

Table 6. 2: Costs on an energy basis with respect to the electrical and thermal products delivered by the fuel cell sub-system for different number of residences at the synthesis/design point.

Table 6. 3: Costs on an exergy basis with respect to the electrical and thermal products delivered by the fuel cell sub-system for different number of residences at the synthesis/design point.

Table 6. 4: Optimum work and heat interactions of the fuel cell sub-system at the synthesis/design point.

Table 6. 5: Optimum synthesis/design values of the independent variables for 1, 50 and 100 residences.

Table 6. 6: Optimum cost at the synthesis/design point of the fuel cell sub-system for different number of fuel cell sub-system units manufactured per year.

Table 6. 7: Costs on an energy basis with respect to the electrical and thermal products delivered by the fuel cell sub-system for different number of fuel cell subsystem units manufactured per year.

Table 6. 8: Costs on an exergy basis with respect to the electrical and thermal products delivered by the fuel cell sub-system for different number of fuel cell subsystem units manufactured per year.

Table 6. 9: Optimum work and heat interactions of the fuel cell sub-system for different number of fuel cell sub-system units manufactured per year.

Table 6. 10: Optimum molar flow rates, temperatures, and pressures for streams 1 to 20 of Fig. 6.19.

Table 6. 11: Optimum molar flow rates, temperatures and pressures for streams 21 to 29 in Fig. 6.19.

Table 6. 12: Geometry for the heat exchangers of the optimal fuel cell sub-system at the synthesis/design point. 
Table 6. 13: Optimum geometry for the steam generator based only on the synthesis/design point.

Table 6. 14: Optimum geometry for the steam reformer reactor based only on the synthesis/design point.

Table 6. 15: Optimum geometry for the fuel cell stack based on the synthesis/design point only.

Table 6. 16: Geometry for the heat exchangers of the optimal fuel cell sub-system determined based on the synthesis/design point and off-design information.

Table 6. 17: Optimum geometry for the steam generator based on the synthesis/design point and off-design.

Table 6. 18: Optimum geometry for the steam reformer reactor based on the synthesis/design point and off-design.

Table 6. 19: Optimum geometry for the fuel cell stack based on the synthesis/design point and off-design

Table 6. 20: Most promising syntheses/designs.

Table 6. 21: Summary of performance for the optimum synthesis/design over the entire environmental/load profile.

Table 6. 22: Summary of performance for the $2^{\text {nd }}$ best synthesis/design over the entire environmental/load profile.

Table 6. 23: Summary of performance for the fifth best synthesis/design over the entire environmental/load profile.

Table 6. 24: Total unit costs on an energy basis for the most promising synthesis/designs.

Table 6. 25: Total unit costs on an exergy basis for the most promising synthesis/designs.

Table 6. 26 Optimum values of the operational variables for the fifth design. 134 


\section{Nomenclature}

$A_{\text {act }} \quad$ Active area

$A_{\text {cross }}$ Cross-sectional area

$A_{f f} \quad$ Free flow area

$A_{\text {wetted }}$ Wetted area

$B \quad$ Baffle spacing

$c_{n g} \quad$ Unit price of the natural gas

$c_{p} \quad$ Specific heat at constant pressure

$C$ Clearance between adjacent tubes

$C_{\text {component/subsystem }}$ Capital cost

$C_{r} \quad$ Heat capacity ratio

$D_{h} \quad$ Hydraulic diameter

$D_{p} \quad$ Characteristic catalyst diameter

$D_{t} \quad$ Tube diameter

$\dot{E} \quad$ Electrical power

$f(\vec{x}, \vec{y})$ Figure of merit or objective

F Faraday's constant

$\vec{G} \quad$ Set of inequality constraints

$\dot{G} \quad$ Mass velocity $h \quad$ Convection coefficient for the combustion gases

$h_{i} \quad$ Total enthalpy

$\vec{H} \quad$ Set of equality constraints

$J \quad$ Current density

$k \quad$ Thermal conductivity

$k_{i} \quad$ Unit cost of the $\mathrm{i}^{\text {th }}$ resource

$K_{p}(T)$ Chemical equilibrium constant at standard pressure

L Characteristic length

$\dot{m}_{i} \quad$ Mass flow rate

$n_{e^{-}} \quad$ Number of moles of electrons per mole of $\mathrm{H}_{2}$

$\dot{n}_{i} \quad$ Molar flow rate

$n_{\text {month }}$ Number of the month

$n_{t} \quad$ Number of tubes

$n_{\text {units }} \quad$ Number of stacks manufactured per year

NTU Number of transfer units

$\mathrm{Nu} \quad$ Nusselt number

$P_{\text {component }}$ Pressure 


\begin{tabular}{|c|c|c|c|}
\hline$P_{i}$ & Partial pressure & $\dot{W}_{\text {elec }}$ & $\begin{array}{l}\text { Electric power produced by the } \\
\text { stack }\end{array}$ \\
\hline$P_{o}$ & Standard pressure & & \\
\hline$P_{r}$ & Prandtl's number & $y_{i}$ & $\begin{array}{l}\text { Mole fractions of reactants or } \\
\text { products in the stoichiometric } \\
\text { equilibrium reactions }\end{array}$ \\
\hline$Q_{\max }$ & Maximum possible heat transfer & & \\
\hline$Q$ & Actual heat transfer & $\Delta G^{o}$ & $\begin{array}{l}\text { Standard Gibbs free energy of } \\
\text { reaction }\end{array}$ \\
\hline $\mathrm{r}_{\mathrm{CH} 4}$ & $\begin{array}{l}\text { Fraction of the total methane that } \\
\text { enters the combustion chamber }\end{array}$ & Greek & \\
\hline $\mathrm{r}_{\mathrm{H} 2 \mathrm{O} / \mathrm{CH}}$ & $\begin{array}{l}\text { Moles of methane to moles of } \\
\text { steam }\end{array}$ & $\delta$ & Pitch \\
\hline$r_{\text {dist }}$ & Distance between the ratio of the & $\varepsilon$ & Effectiveness \\
\hline & $\begin{array}{l}\text { pressure ratios at off-design and } \\
\text { at design and the surge line on }\end{array}$ & $\mu$ & Viscosity \\
\hline & the compressor map & $\rho$ & Density \\
\hline $\mathrm{R}$ & Universal gas constant & $\chi$ & Valve setting \\
\hline$\dot{R}_{i}$ & $\begin{array}{l}\text { Rate of consumption of a } \\
\text { resource }\end{array}$ & $\dot{\Omega}$ & Rate of exergy \\
\hline $\operatorname{Re}$ & Reynolds number & $\Delta \mathrm{T}$ & Temperature difference \\
\hline$s_{i}^{o}$ & Absolute entropy & Subscr & ripts \\
\hline $\mathrm{T}$ & Temperature & $c g$ & Combustion gases \\
\hline$u$ & Gas velocity & design & Short for synthesis/design \\
\hline$u_{i j}$ & Coupling function & FPS & Fuel processing sub-system \\
\hline$U$ & Overall heat transfer coefficient & HTS & High temperature shift \\
\hline \multirow[t]{3}{*}{$V_{\text {cell }}$} & Voltage in v/cell & LTS & Low temperature shift \\
\hline & & $\max$ & Maximum \\
\hline & & MEA & Membrane electrode assembly \\
\hline
\end{tabular}




\begin{tabular}{|c|c|c|c|}
\hline & & SS & Stack sub-system \\
\hline PROX & Preferential oxidation & Super & cripts \\
\hline $\min$ & Minimum & inlet & \\
\hline oper & Operational & FPS & Fuel processing sub-system \\
\hline$r f m$ & Reformate & outlet & \\
\hline $\mathrm{S}$ & Shell side & SS & Stack sub-system \\
\hline SR & Steam reformer & & \\
\hline
\end{tabular}




\section{Introduction}

In this chapter, a brief overview of fuel cell types and their state of development is given as is a brief introduction to the decomposition optimization strategy, which is applied in this work to the synthesis I design of a Proton Exchange Membrane (PEM) fuel cell sub-system. It is envisioned using such a subsystem as the basis of a total energy system for residential / commercial cogeneration applications. The overview and introduction is followed by a presentation of the goal and objectives of this thesis work.

\section{$1.1 \quad$ Background}

There have been many important contributions to the field of thermoeconomics since its origins in the late 1950's. An important line of research has been the effort begun in the 1970's on cost assignment, i.e. the rational distribution of cost among the different streams of an energy system and the use of such a cost assignment for decomposition methodologies (e.g., Valero et al. (1994), Frangopoulos (1994), von Spakovsky (1994), Tsatsaronis and Pisa (1994), El-Sayed (1989)). Over the past few years, the Energy Management Institute (EMI) at the Virginia Polytechnic Institute and State University (Virginia Tech) has focused some of its effort on applying thermoeconomics and, in particular, decomposition concepts to the optimization of the synthesis, design and operation of energy systems. In particular, Muñoz and von Spakovsky (2000a,b,c,d; 2001a,b) have developed a general methodology for the decomposed synthesis / design optimization of highly coupled, highly dynamic energy systems. Their work shows that their decomposition technique is an extremely useful tool 
that not only permits the solution of the overall synthesis / design optimization problem for highly complex systems by dividing the problem into smaller sub-problems but also facilitates the difficult task of sub-system integration.

The research work presented in this thesis is based on the application of a decomposition methodology to the synthesis / design optimization of a stationary cogeneration fuel cell sub-system for residential/commercial applications. This work provides the basis for ongoing and future work, which couples the fuel cell sub-system with heat pump and storage sub-systems into an overall total energy system for cogeneration purposes. The usefulness of this decomposition strategy for the detailed conceptual synthesis / design of energy systems is demonstrated.

\subsection{Fuel Cells and Stationary Applications}

Intensified research into fuel cell stacks and systems has been ongoing for the last forty years. The first application of this technology in the 1960's was in the American Manned Space Program, the Gemini project. At present, the most developed or mature of all fuel cell technologies is the Phosphoric Acid Fuel Cell (PAFC) system which has reached the stage of commercial use for stationary applications, e.g., the $200 \mathrm{kWe}$ system produced by ONSI, a division of International Fuel Cells. Molten Carbonate Fuel Cell (MCFC) and Solid Oxide Fuel Cell (SOFC) systems are currently entering the demonstration phase. Polymer Electrolyte Membrane Fuel Cell (PEMFC) systems have been successfully implemented for aerospace applications (Wilson et al., 1996), and their use is being extended not only to transportation but to stationary applications as well in an attempt to increase their market and, thus, lower their manufacturing costs.

PEMFCs and PAFCs are competing ${ }^{1}$ for the stationary power market both for utility peak power and distributed power generation (an important trend in the utility market). In this competition, PEMFC systems appear to have some important advantages over PAFC systems in the short to mid term (Cleghorn et al., 1996). They are as follows:

\footnotetext{
${ }^{1}$ Note that another quite viable competitor is the SOFC, which has advantages and disadvantages visa vie the PEMFC. These, however, are not developed here.
} 


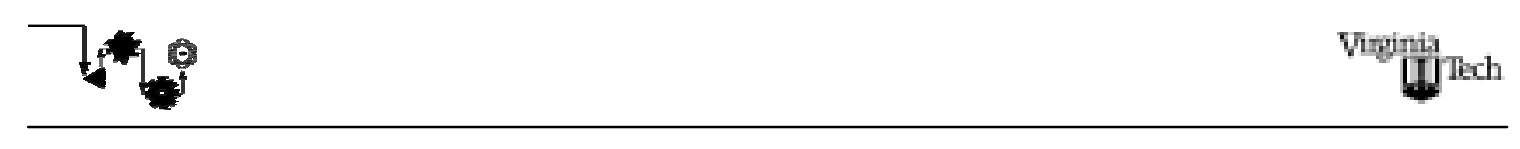

- PEMFCs have higher energy conversion efficiencies and power densities.

- PEMFCs have a stable, inert polymer electrolyte and easier and faster startup and shutdown leading to higher reliability and longevity.

The present work is, thus, focused on the use of PEMFC technology for stationary cogeneration applications, in particular residential/commercial applications. At present, there are no commercially available systems, although intensive research is underway to achieve this goal. Commercialization of at least the first generation of such systems seems feasible in the short term, e.g., Plug Power's 7000 residential fuel cell system scheduled for mass production towards the beginning of 2002 (Plug Power LLC, 2001). Nonetheless, considerable research is still needed to significantly improve them for a broader, more competitive market. In fact, a review of recent publications ${ }^{2}$ shows that there is no general agreement for these types of applications on the most important design features of these systems (e.g., design pressure, system size, system configuration, etc.). Even manufacturers that are well advanced with such systems seem far from having an integrated platform for the synthesis / design optimization of these systems. This lack of a set of comprehensive synthesis / design tools is not particular to just fuel cells since they are generally lacking in the development of all types of new, non-state-of-the-art energy conversion technologies. In fact, today's engineers are forced to rely heavily on rules-ofthumb, individual experience and a fairly non-integrated, non-interdisciplinary approach of basic calculations, i.e. simple trade-off analysis. In cases where optimization is considered, partially due to the fact that new and more powerful computers have become available and optimization tools more popular, it is seen as a straightforward mathematical problem, which for large-scale, highly non-linear optimization problems can be very limiting to say the least. Even significant increases in computational power are not sufficient to offset the ever-increasing complexity of energy systems and the ensuing synthesis / design problem. Therefore, the need for methods that permit effective solutions of large-scale optimization problems is still an area of research, which generates

\footnotetext{
${ }^{2}$ Note that much of on-going fuel cell research is under proprietary restrictions so that any conclusion made here must be prefaced by this fact.
} 
great interest. Muñoz and von Spakovsky (2000a,b) present two general approaches to address this need for large-scale, non-linear optimization: Local-Global Optimization (LGO) and Iterative Local Global Optimization (ILGO). A number of versions of LGO can be found in the aerospace and thermoeconomics literature including the one presented in Muñoz and von Spakovsky (2000a). ILGO, which in fact consists of two versions (ILGO-A and ILGO-B), is a completely original development by Muñoz and von Spakovsky (2000a). In the research presented here, a LGO based method is used to resolve the complex problem of optimizing the synthesis / design of a cogeneration PEM fuel cell system for residential / commercial applications. However the ILGO-A and ILGO-B methods are presented and their advantages with respect to LGO discussed.

\subsection{Objectives.}

The goal of the work proposed for this thesis research is to demonstrate the feasibility of using LGO for the thermoeconomic optimization of the fuel cell sub-system (includes the stack sub-system (SS), the fuel processing sub-system (FPS), and the thermal management sub-system (TMS)), which might be used in a fuel cell based total energy system. This requires the development of a general thermoeconomic model for the fuel cell sub-system, which itself is based on PEMFC technology as well as steam reforming of methane. It furthermore requires the application of a decomposition strategy (LGO) for dynamically optimizing each of the sub-systems' syntheses/designs, taking into account the optimal behavior of each sub-system at off-design as well as at its synthesis / design point. Such a tool will enhance any integrated synthesis / design environment through a systematic and efficient selection of the best set of configurations (syntheses) and designs which comprise a system's synthesis/design space.

The following is a list of the major objectives envisioned:

1) Gain a fundamental understanding of how PEMFC stacks, sub-systems and systems operate and a general comprehension of the fundamental phenomena present in each part of the process (i.e. electrochemical conversion, fuel processing, air delivery, stack cooling, and load management). 
2) Create the thermodynamic models for components and sub-systems and in turn describe their connectivities. Include models for off-design behavior, which will lead to the full simulation and optimization of the system over an entire operational cycle (i.e. four seasons).

3) Develop appropriate component cost functions, which relate cost to appropriate decision (synthesis / design and operational) variables.

4) Apply a decomposition strategy, which permits both local/unit (i.e. component and sub-system) and global/system (i.e. fuel cell sub-system) optimizations and provides for an on-going communication between these levels of optimization.

5) Define the computational tools necessary for solving the set of mathematical optimization problems created.

6) Use the models and computational tools for both optimizing the system locally (i.e. at the component and sub-system levels) and globally (i.e. at the system level).

7) Document and analyze the results for the optimal synthesis / design of the PEMFC sub-system. 


7.0

\section{General Description of the PEM Fuel Cell Sub- system and its Objectives}

In this chapter, the thermal and electrical loads that the PEMFC sub-system must meet per house or per cluster of homes are presented. A number of different configurations for the fuel cell sub-system are presented and discussed and the most promising candidate chosen for detailed modeling and evaluation. The final section of the chapter presents the most important concepts of sub-system technology and operation.

\subsection{Thermal and Electrical Loads}

The PEM fuel cell sub-system's ability to cogenerate is used to satisfy the electrical and heating demands for a cluster of homes in a residential complex ${ }^{1}$. The geographical location of the residences plays an important role in setting the loads. The loads presented here are based on average data from northeastern US locations. The different loads profiles shown in Figs. 2.1 and 2.2 were developed by the Gas Research Institute and TDA Research (Gleason et al., 1999).

Since determining feasibility of the tool being developed here was of primary interest, it was decided to simplify these profiles for summer and winter. All the loads were, thus, characterized by only four load conditions: peak and off-peak for summer and winter. In future work, detailed load profiles for different US locations will be implemented. These profiles will increase the number of degrees of freedom for synthesizing and designing a fuel cell based total energy system (i.e. significantly

\footnotetext{
${ }^{1}$ Note that this could just as well be conceived as a commercial complex provided that representative load profiles were used.
} 
increase the number of operational variables during the off-design optimization). The actual load conditions used in this work are given in Table 2.1 and were determined from the load profiles in Figs. 2.1 and 2.2.

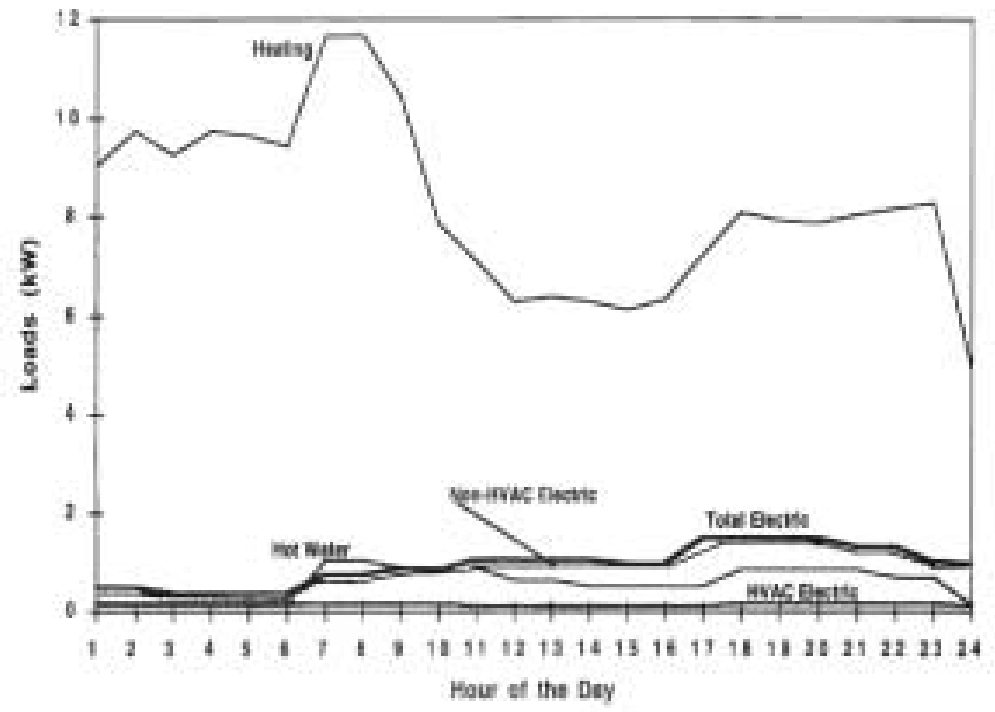

Figure 2. 1:Winter electrical and thermal load profiles for locations in the northeastern U.S. (Gleason et al., 1999).

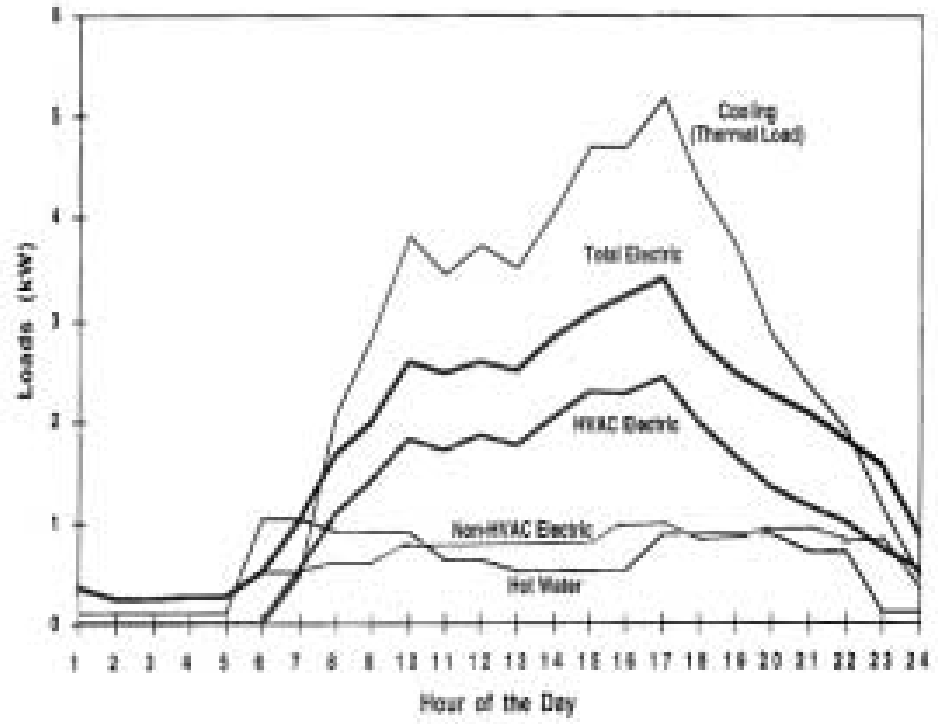

Figure 2. 2: Summer electrical and thermal load profiles for locations in the northeastern U.S. (Gleason et al., 1999). 
Table 2 1: Electrical and thermal loads used in the simulation and optimization of the PEM fuel cell sub-system.

\begin{tabular}{|l|c|c|}
\hline \multicolumn{1}{|c|}{ Load conditions } & $\begin{array}{c}\text { Electric loads per } \\
\text { house (W) }\end{array}$ & $\begin{array}{c}\text { Thermal loads } \\
\text { per house (W). }\end{array}$ \\
\hline Summer peak electric load condition. & 2700 & 700 \\
\hline Winter peak heat load condition. & 500 & 10200 \\
\hline Summer off-peak electric load condition & 1000 & 500 \\
\hline Winter off-peak heat load condition & 1600 & 7200 \\
\hline
\end{tabular}

All the load conditions in Table 2.1 are considered to have equal time duration along the lifetime of the fuel cell sub-system ${ }^{2}$. Note that the summer peak electric load condition is taken as an average of the highest demand in summer, which gives one a more characteristic load for a peak condition than the absolute peak. This is due to the fact that absolute peak demand is only reach in a small period of time.

\subsection{The Stationary PEMFC Sub-system for Residential Cogeneration Applications.}

There are a wide variety of PEMFC sub-system configurations for stationary applications in the literature. The present work has focused on PEMFC technologies coupled to the steam reforming of natural gas since this combination seems to be the most prevalent and promising based on the literature (e.g., Jianguo, 1989).

The fuel cell sub-system, which is one of several sub-systems that comprise the total energy system ${ }^{3}$, is itself made up of four major sub-systems:

- $\quad$ Stack sub-system (SS).

\footnotetext{
${ }^{2}$ The lifetime of the fuel cell sub-system is considered to be 10 years.

${ }^{3}$ The fuel cell based total energy system can be broken down into, for example, a fuel cell sub-system, a vapor compression and/or absorption heat pump sub-system, a thermal storage sub-system, and an electric storage sub-system. Obviously, each of these sub-systems can undergo a further breakdown as is done for the fuel cell sub-system above.
} 


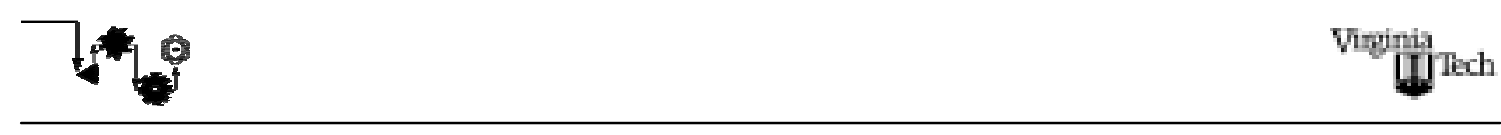

- Fuel processing sub-system (FPS).

- Thermal management sub-system (TMS).

- $\quad$ Load management sub-system (LMS).

The focus here will be on the detailed modeling, simulation, and optimization of the first two sub-systems, namely, the SS and the FPS.

Two conceptual depictions of the primary processes comprising an FPS based on steam reforming are shown in Figs. 2.3 and 2.4. Both have proven their efficacy in

$\begin{array}{lll}\text { STEAM AIR INJECTION AIR BLEED } & \text { AIN }\end{array}$

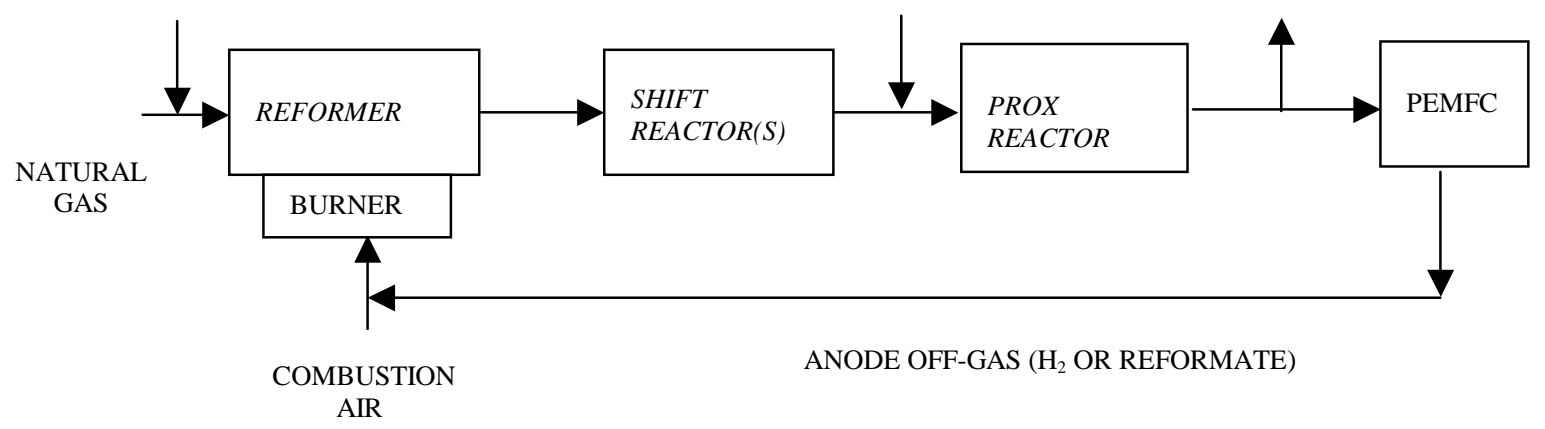

Figure 2. 3: Conventional fuel steam reforming sub-system with shift and PROX reactors

(Wilson et al., 1996).

STEAM

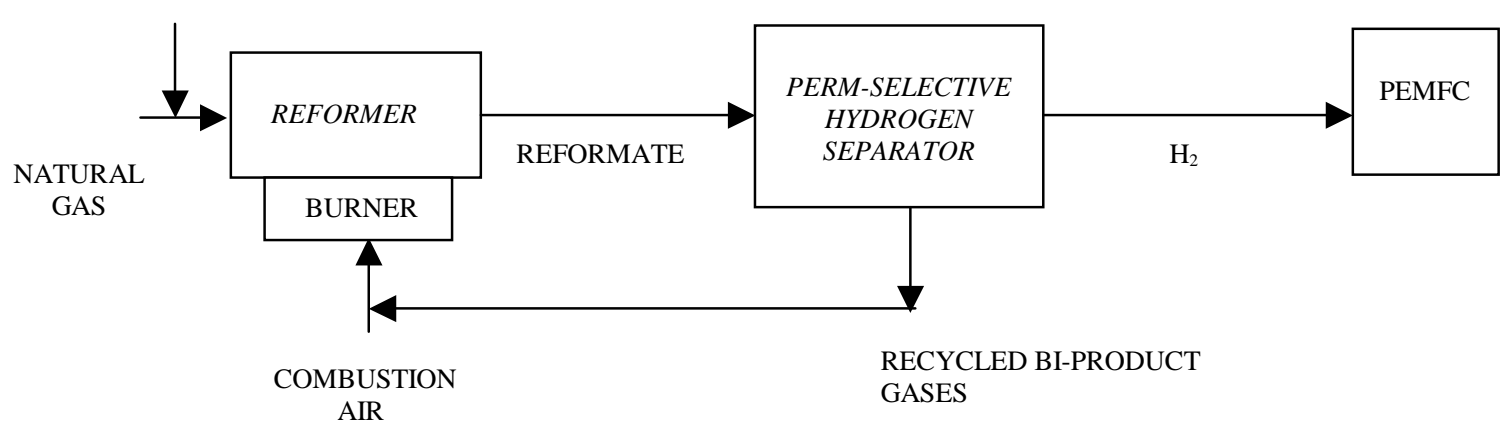

Figure 2. 4: Alternative fuel steam reforming sub-system with a perm-selective hydrogen separator (Wilson et al., 1996). 
commercial applications for the steam reforming of natural gas (Wilson et al., 1996). The concept shown in Fig. 2.3 is a conventional system with preferential oxidation (PROX) and high and low temperature water-gas shift (SHIFT) reactors. Fig. 2.4 shows an alternative concept in which reformate downstream of the reformer enters a permselective $^{4}$ hydrogen separation process (e.g., a pressure swing absorption (PSA) process, a metallic membrane process, or a polymer membrane process) and is separated into $\mathrm{H}_{2}$ ( $<97 \%$ purity) and bi-product gases, the former continuing on to the PEMFC stack and the latter to the combustor of the fuel reformer ${ }^{5}$. The disadvantages of using metallic membranes are that they are subject to mechanical degradation over time resulting in a loss of performance and their cost is high, i.e. they are typically made of palladium. Polymer membranes, on the other hand, cannot operate at the high temperatures typical of natural gas steam reforming while limiting purities at useful recovery levels are less than 97\% using typical feed conditions (Lomax, 2001). Existing PSA systems are costly, with system costs increasing as target purity goes up. They are also temperature limited. For these reasons, the more conventional approach shown in Fig. 2.3 is used for the FPS developed in this study ${ }^{6}$. However, it should be noted that much promising research into hydrogen separation technologies is underway and could lead to significant and important improvements in these processes and in turn in the overall reforming process for natural gas.

\footnotetext{
${ }^{4}$ The term "perm-selective" refers to, for example, membranes which permeate many or all substances at a finite rate. However, the permeance of certain molecules is much higher than that of others. This difference in permeation rate allows the more permeable constituent of a mixture to be separated from the less permeable ones by simple diffusion. Unfortunately, this means that limiting product purity is inversely proportional to hydrogen recovery, as the relative driving force for impurity permeation increases as the hydrogen is withdrawn, and that the limiting purities at useful recovery levels are less than $97 \%$ using typical feed conditions (Lomax, 2001).

${ }_{5}$ The bi-product gases consist of $\mathrm{CO}_{2}, \mathrm{CO}, \mathrm{H}_{2} \mathrm{O}$, and possibly small amounts of $\mathrm{H}_{2}$ and $\mathrm{CH}_{4}$ or other hydrocarbons, which comprise the natural gas feed to the steam reformer. These gases are the ones absorbed by the PSA bed and released during bed regeneration or the gases, which are selectively retarded from diffusing at sufficiently high rates through the membrane in a metallic or polymer membrane separation process.

${ }^{6}$ Note that even in the conventional approach, some type of final purification (perm-selective process) might be required in order to get down to the $<10 \mathrm{ppm} \mathrm{CO}$ levels required for robust operation of the PEMFC stack, i.e. to avoid poisoning of the catalyst in the stack.
} 
For the conceptual FPS shown in Fig. 2.3 combined with a SS and TMS (the LMS is not considered here), a wide range of possible detailed fuel cell sub-system configurations exits (i.e. Fig. 2.5 in Kordesch et al. (1996) and Fig. 2.6 in Arthur D. Little (1994)).

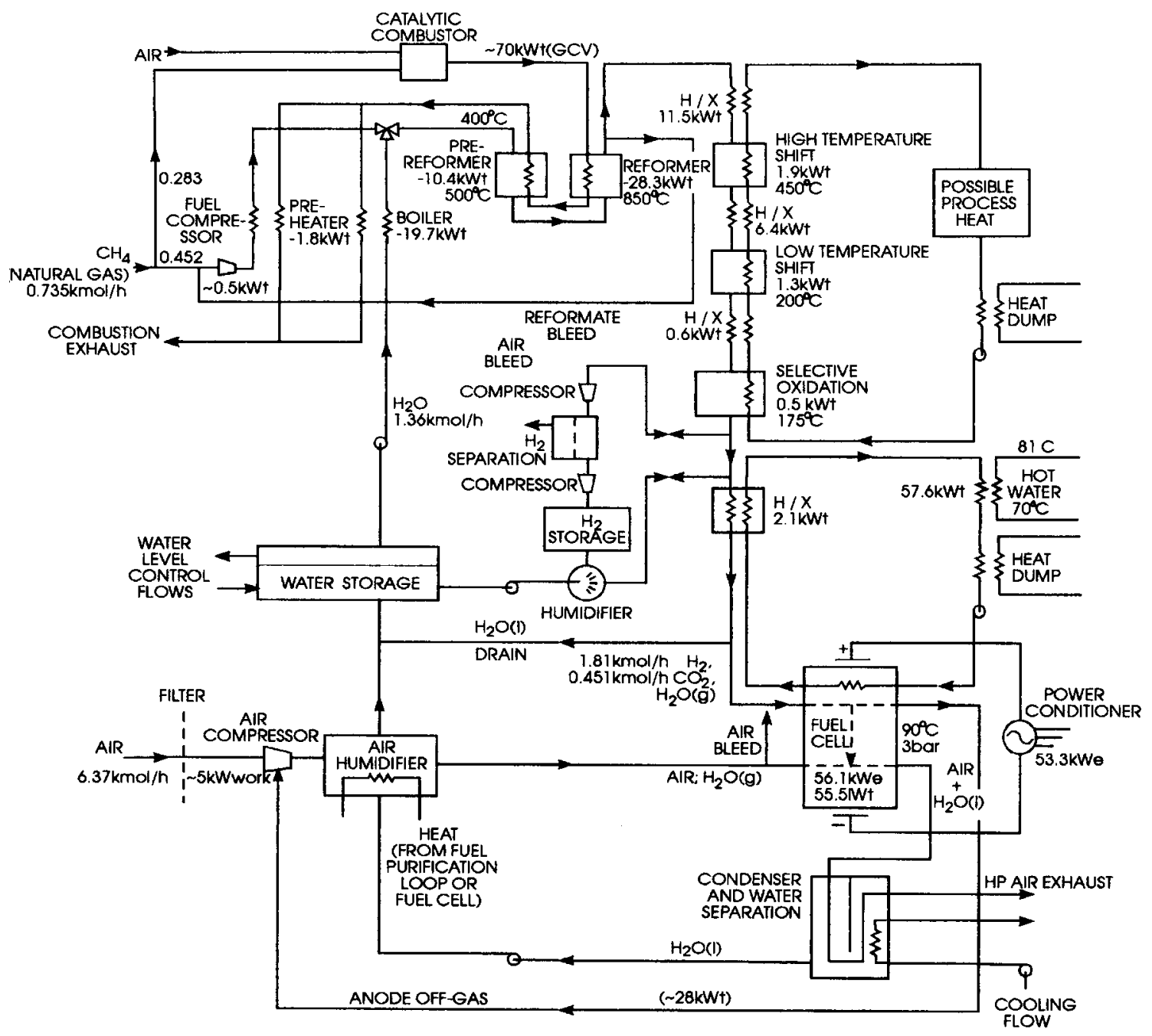

Figure 2. 5: PEMFC sub-system for cogeneration presented by Kordesch et al. (1996).

The configuration depicted in Fig. 2.5 is an example of the conceptual depiction presented in Fig. 2.3 (Reformer Reactor, Shift Reactors (High Temperature Shift (HTS) and Low Temperature Shift (LTS)), Selective Oxidation (PROX) and PEMFC). A 
particular characteristic of this configuration is that the heat recovery done in the exothermic processes of the FPS (HTS, LTS and PROX) is not used within the configuration. Instead it offers the possibility of using this energy to couple the configuration with other sub-systems (e.g. a vapor compression or an absorption heat pump sub-system). The energy required by the endothermic processes in the FPS (steam generator and steam reformer reactor) is provided by a combustor. The combustion gases,

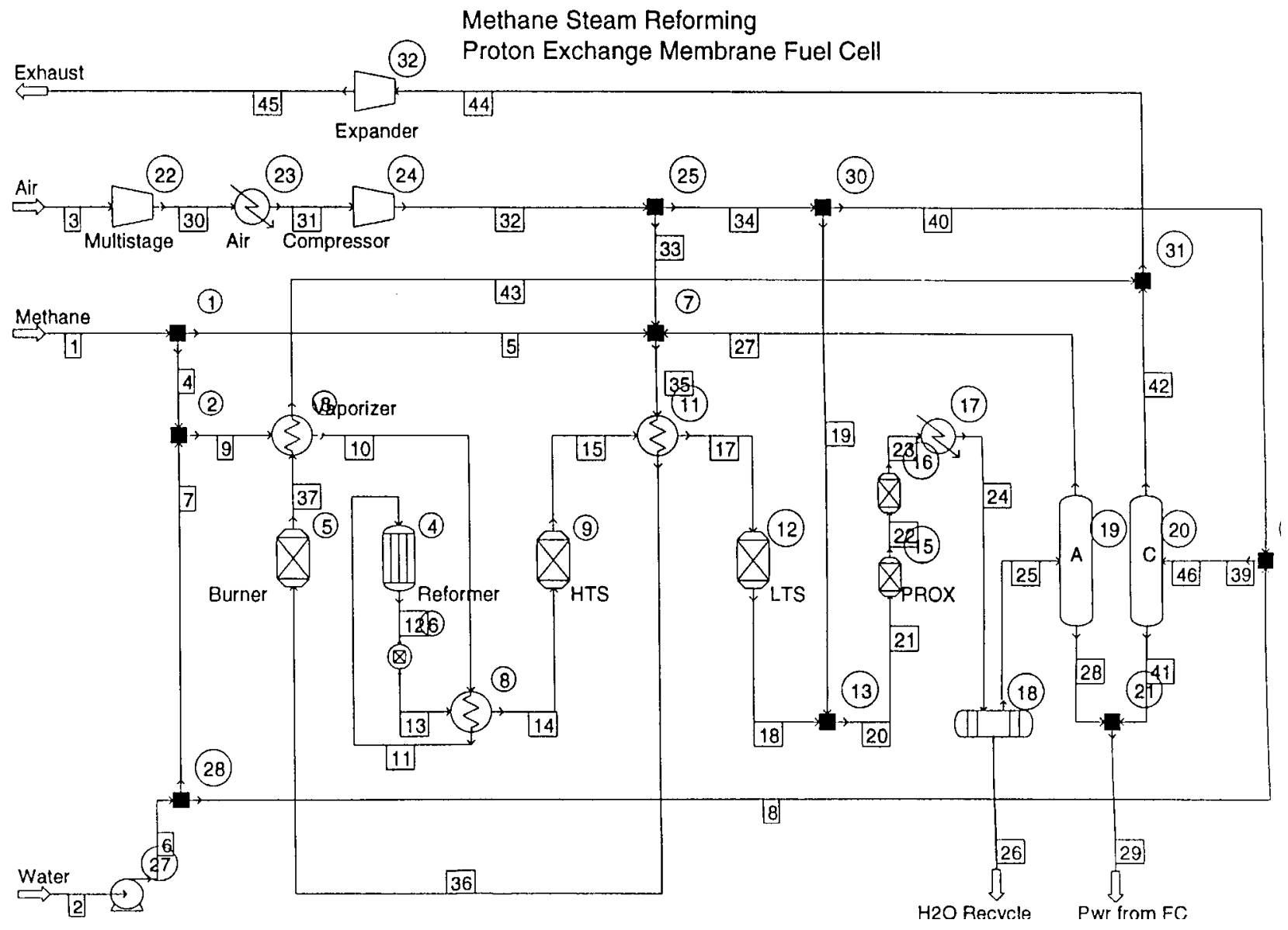

Figure 2. 6: The methane steam reforming PEMFC sub-system ${ }^{7}$ presented by Arthur D. Little (1994).

\footnotetext{
${ }^{7}$ The number in each box indicates the stream number. The number in each circle is the component number.
} 
close to atmospheric pressure, preheat and heat the methane and the reformate prior to and in the reformer reactor and are used to provide steam for the reforming process.

In Fig. 2.6, a different concept for the PEMFC sub-system (SS and FPS) is presented. This configuration is another example of the conceptual depiction of Fig. 2.3 but represents a different philosophy in thermal management than the configuration shown in Fig. 2.5. In this case, the heat recovered in the exothermic processes of the FPS is used for energy recovery purposes within the configuration. A heat exchanger located between the HTS and the LTS preheats the combustion gases. Another example of internal energy recovery is the fact that the reformate stream that exits the steam reformer reactor preheats the methane stream entering the reactor. There is no heat exchanger between the LTS and the PROX, which forces both reactors to operate at almost the identical temperature. In order to provide heat for the endothermic processes of the FPS, a burner is added. The combustion gases in this case are compressed and, therefore, before being exhausted to the atmosphere, are expanded in an expander to recover part of the energy used in the compression process. In this configuration, no source of heat, which couples the configuration with other sub-systems, is specified.

To develop the configuration used in this study (Fig. 2.8), four key factors were taken into account. They are as follow:

- Thermal management: An efficient fuel cell sub-system must be thermally well integrated. Thus, the use of internal heat recovery and the selection of the appropriate streams for satisfying the thermal load requirements is extremely important for developing a good overall sub-system configuration. A Second Law analysis of possible sub-system configurations can provide the basis for this type of integration.

- Flexibility: A stationary fuel cell sub-system for residential applications must satisfy a wide variety of loads. In summer, electrical loads may be three times as high as the thermal loads (see Table 2.1 and Figs. 2.1 and 2.2). This situation changes dramatically in winter when thermal loads are ten times larger than electrical ones. It will be shown in the results given in Chapter 6 that a PEM fuel 


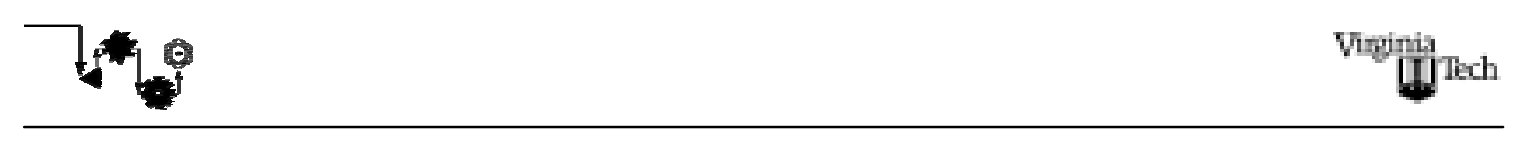

cell sub-system by itself (unless sized for this) is unable to satisfy all of these loads. Therefore, combining the fuel cell sub-system with a vapor compression or an absorption heat pump sub-system and possibly some thermal storage might be necessary. Another option would be to allow a two-way connection to the utility grid for buying and selling power. The combination of some or all of these options constitutes the total energy systems (TESs) depicted in Fig. 2.7. Nonetheless, even with these other options for development flexibility, the design and operation of the fuel cell sub-system itself is important for the development of the most efficient and economical TES.

- Reducing capital cost: Due to the basic complexity of the fuel cell sub-system and even more so of the TES, capital cost can easily skyrocket. Thus, it is important to avoid creating complicated heat exchanger networks when dealing with the issues of flexibility and thermal management.

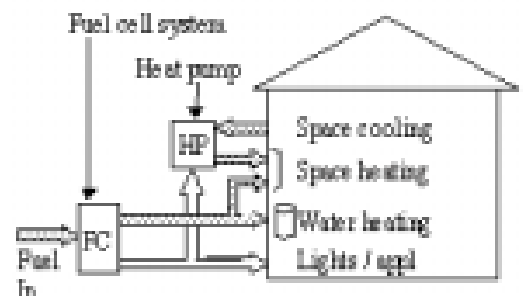

Fig a Fuel cell wh beat recovery for water and space heating

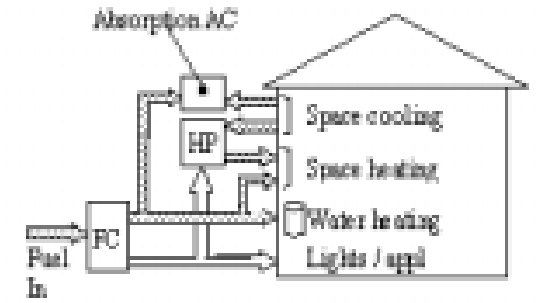

Fig, b. Fuel cell with heal recovery foe water beating, space heating and absorption cooling

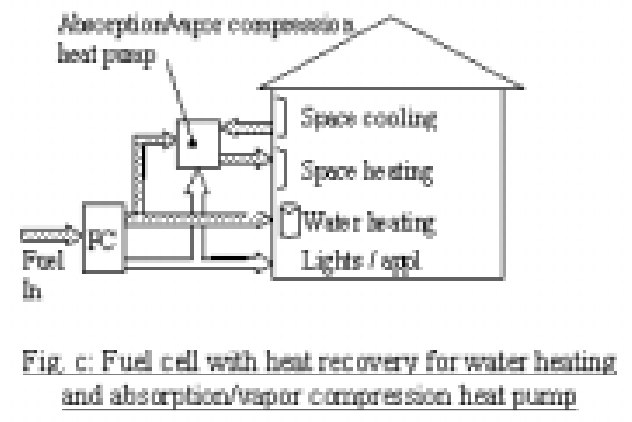

Figure 2. 7: TES options for cogeneration in residential applications (Gunes, 2001). 


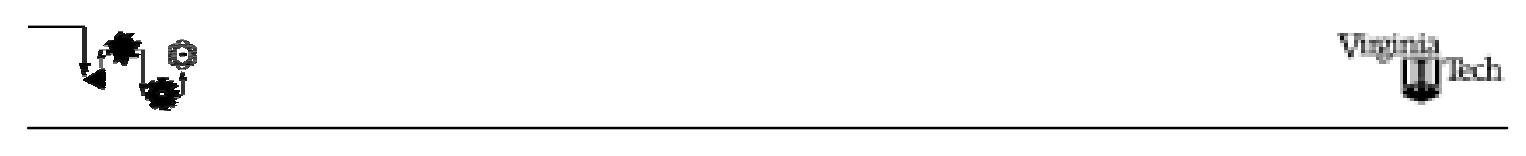

- Control: In determining the synthesis and design of the fuel cell sub-system, a number of important control parameters must be kept within specified ranges during operation at all off-design conditions. Appropriate consideration of these control parameters must be given in the development of any configuration (synthesis) and design.

Based on these four factors, the configuration shown in Fig. 2.8 was developed and is the fuel cell sub-system configuration used in the modeling, simulation, and optimization presented in subsequent chapters. Table 2.2 lists the components used in this configuration. Like the configuration presented in Fig. 2.6, the configuration used in this thesis work (Fig. 2.8) uses the heat generated in the exothermic processes (LTS, HTS and PROX) for energy recovery purposes. This feature improves the thermal management within the configuration and increases the efficiency of the sub-system. On the other hand, the possibility of including a source coupling the configuration with other subsystems is an important feature that should be included in the configuration, therefore, a source of heat is added by including a heat exchanger in the combustion gas stream before it is exhausted to the atmosphere. Thus, the configuration used in this thesis work combines the thermal management features of Fig. 2.6 while at the same time keeping the possibility offered in Fig. 2.5 of coupling with other sub-systems.

In order to improve the flexibility of the sub-system, a heat exchanger is added between the LTS and PROX reactor, a feature that is included as well in Fig. 2.5. In addition, in the configuration of Fig. 2.8, the combustion gases are used to satisfy the endothermic processes of the FPS; and as in Fig. 2.6 the combustion chamber operates with compressed gases, which allows one to use the compressed air leaving the SS. Finally, another important feature of Fig. 2.8 is that the anode-off gases are burned in the combustion chamber, decreasing, therefore, the amount of additional methane that must be burned and increasing the efficiency of the sub-system. 


\subsection{Description of the Fuel Cell Sub-system}

The following sections give a brief overview of the function of the various components, which comprise the FPS, the SS, and the TMS.

\subsubsection{Fuel Processing Sub-system (FPS)}

The natural gas enters the fuel cell sub-system (at (1) in Fig. 2.8) from a natural gas pipeline. For this thesis work, the natural gas is assumed to be $100 \%$ methane $\left(\mathrm{CH}_{4}\right)$. This assumption does not introduce significant error as is seen in Table 2.3, which contains a number of different commercially available natural gas compositions (Farry, 1998).

The first step in the processing of fuel is methane compression to a pressure that meets the operational requirements of the fuel cell stack. This ranges from 2 to $4 \mathrm{~atm}$. It is assumed that such a compressor (see component (1), Fig. 2.8) exhibits a design isentropic efficiency of 0.7 .

Once the methane is compressed, it is mixed with steam. This mixing process has two primary purposes: to increase the temperature of the fuel and to promote the start of the reforming process, i.e. conversion of the mixture to reformate which is a gas with a high concentration of hydrogen. The mixing takes place in the mixing chamber (component (2) of Fig. 2.8).

Component (3), the heat exchanger to the left of the steam reformer reactor, is used to pre-heat the steam-methane mixture before entering the steam reformer reactor since hydrogen formation is promoted at higher temperatures. Once the steam reforming process has taken place, the same heat exchanger cools the exiting stream, initiating the heat recovery process. This particular component is a good example of the thermal integration, which has been applied to the present configuration. 
Table 2 2: Some typical compositions of natural gas (mol\%) (Farry, 1998).

\begin{tabular}{|c|c|c|c|}
\hline & $\begin{array}{c}\text { Non-associated gas } \\
\text { (independent of crude oil } \\
\text { production) }(\%)\end{array}$ & $\begin{array}{c}\text { Condensate } \\
(\%)\end{array}$ & $\begin{array}{c}\text { Associated gas } \\
\text { (in conjunction with } \\
\text { crude oil production) (\%) }\end{array}$ \\
\hline Carbon dioxide & 0.5 & 2.5 & 1.0 \\
\hline Nitrogen & 1.1 & 1.0 & 1.0 \\
\hline Methane & 94.4 & 86.5 & 68 \\
\hline Ethane & 3.1 & 5.5 & 15 \\
\hline Propane & 0.5 & 3.0 & 9.0 \\
\hline Iso-butane & 0.1 & 0.3 & 2.0 \\
\hline Normal-butane & 0.1 & 0.7 & 3.0 \\
\hline Pentanes plus & 0.2 & 0.5 & 1.0 \\
\hline Total & 100 & 100 & 100 \\
\hline
\end{tabular}

In the steam reformer reactor itself, component (4), up to 11 possible reactions can take place between the constituents involved in the steam reforming process (Jianguo et al., 1989). Table 2.4 lists these. However, the steam reforming process is catalytic and uses catalysts such as $\mathrm{Ni} / \mathrm{MgAl}_{2} \mathrm{O}_{4}$ or $\mathrm{Ru} / \mathrm{ZrO}_{2}$ to significantly increase the rate of conversion of some of the reactions (Kordesch et al., 1996). Thus, a simple kinetic analysis leads to the conclusion that the only reactions that need be considered in the modeling process are those given in Table 2.5 (Adelman et al., 1995).

\footnotetext{
${ }^{8}$ Condensate means those hydrocarbons, regardless of gravity, that occur naturally in the liquid phase in the reservoir and are produced and recovered at the well head in the liquid form.
} 
Table 2 3: Components of the configuration given in Fig. 2.8 .

\begin{tabular}{|c|l|}
\hline $\begin{array}{c}\text { Component } \\
\text { numbers }\end{array}$ & \multicolumn{1}{|c|}{ Component descriptions } \\
\hline 1 & Natural gas compressor \\
\hline 2 & Mixer for natural gas and steam \\
\hline 3 & Heat exchanger prior to the steam reformer reactor \\
\hline 4 & Steam reformer reactor \\
\hline 5 & High temperature shift reactor (HTS) \\
\hline 6 & Heat exchanger prior to the low temperature shift reactor \\
\hline 7 & Low temperature shift reactor (LTS) \\
\hline 8 & Heat exchanger prior to the preferential oxidation reactor \\
\hline 9 & Preferential oxidation reactor (PROX) \\
\hline 10 & Heat exchanger prior to the PEMFC Stack \\
\hline 11 & PEMFC stack \\
\hline 12 & Water separator for the reformate stream leaving the PEMFC stack \\
\hline 13 & Mixer for the reformate and methane entering the combustor \\
\hline 14 & Heat exchanger providing heat to the house or to other sub-system. \\
\hline 15 & Heat exchanger providing heat to the house or for water heating \\
\hline 16 & Heat rejection \\
\hline 17 & Pump \\
\hline 18 & Compressor for the air intake \\
\hline 19 & Heat exchanger for preheating the air \\
\hline 20 & Water injection (humidifier) \\
\hline 21 & $\begin{array}{l}\text { Expander for power recovery from the air and combustion gas } \\
\text { streams }\end{array}$ \\
\hline 22 & Water separator for the air exhaust \\
\hline 23 & Water tank \\
\hline 24 & Steam generator \\
\hline 25 & Combustor \\
\hline Va1 & Mixer for the air and the combustion gases \\
\hline Va2 & $\begin{array}{l}\text { Valve for the recirculation of methane } \\
\text { expander }\end{array}$ \\
\hline & Valve for the recirculation of air \\
\hline & \\
\hline & \\
\hline & \\
\hline &
\end{tabular}




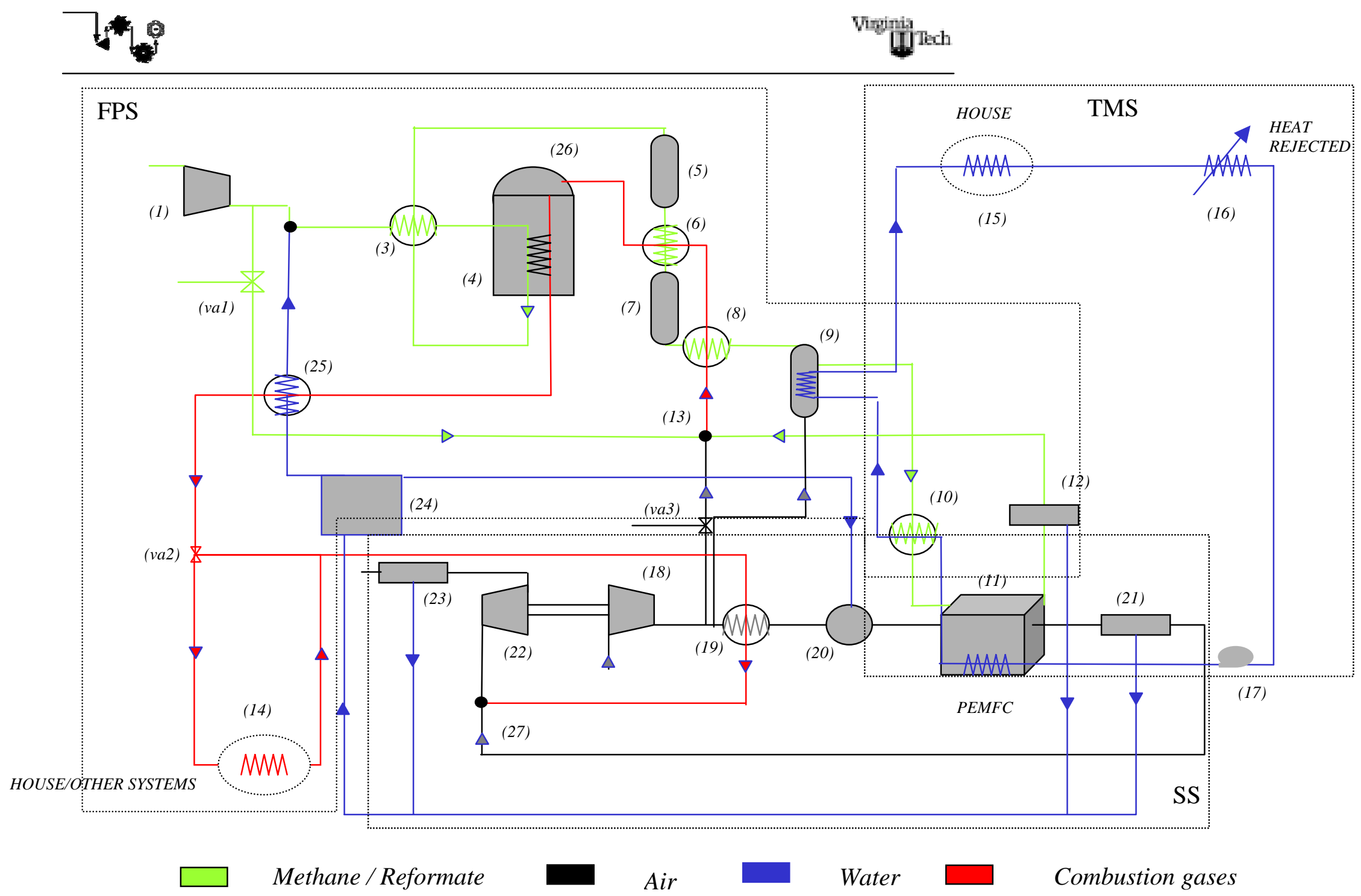

Figure 2. 8: Fuel cell sub-system (components are summarized in Table 2.2). 


7.0

Table 2 4: Possible reactions in the methane steam reformer reactor (Jianguo et al., 1989).

\begin{tabular}{|l|c|}
\hline \multicolumn{1}{|c|}{ Reactions } & $-\Delta \mathrm{H}_{298,}, \mathrm{~kJ} / \mathrm{mol}$ \\
\hline $\mathrm{CH}_{4}+\mathrm{H}_{2} \mathrm{O} \Leftrightarrow \mathrm{CO}+3 \mathrm{H}_{2}$ & -206.1 \\
\hline $\mathrm{CO}+\mathrm{H}_{2} \mathrm{O} \Leftrightarrow \mathrm{CO}_{2}+\mathrm{H}_{2}$ & +41.15 \\
\hline $\mathrm{CH}_{4}+2 \mathrm{H}_{2} \mathrm{O} \Leftrightarrow \mathrm{CO}_{2}+4 \mathrm{H}_{2}$ & -165.0 \\
\hline $\mathrm{CH}_{4}+\mathrm{CO}_{2} \Leftrightarrow 2 \mathrm{CO}+2 \mathrm{H}_{2}$ & -247.3 \\
\hline $\mathrm{CH}_{4}+3 \mathrm{CO}_{2} \Leftrightarrow 4 \mathrm{CO}+2 \mathrm{H}_{2} \mathrm{O}$ & -330.0 \\
\hline $\mathrm{CH}_{4} \Leftrightarrow \mathrm{C}+2 \mathrm{H}_{2}$ & -74.82 \\
\hline $2 \mathrm{CO} \Leftrightarrow \mathrm{C}+\mathrm{CO}_{2}$ & +173.3 \\
\hline $\mathrm{CO}+\mathrm{H}_{2} \Leftrightarrow \mathrm{C}+\mathrm{H}_{2} \mathrm{O}$ & +131.3 \\
\hline $\mathrm{CO}+2 \mathrm{H}_{2} \Leftrightarrow \mathrm{C}+2 \mathrm{H}_{2} \mathrm{O}$ & +90.13 \\
\hline $\mathrm{CH}_{4}+2 \mathrm{CO} \Leftrightarrow 3 \mathrm{C}+2 \mathrm{H}_{2} \mathrm{O}$ & +187.6 \\
\hline $\mathrm{CH}_{4}+\mathrm{CO}_{2} \Leftrightarrow 2 \mathrm{C}+2 \mathrm{H}_{2} \mathrm{O}$ & +15.3 \\
\hline
\end{tabular}

If the steam-methane mixture ratio is sufficiently low (i.e. 1.5 moles of water per mole of methane), carbon formation may occur (Arthur D. Little, 1994). In order to avoid this effect, the steam-methane ratio must always be kept above 2. The steam-methane ratio is, thus, constrained here to be equal to or greater than 2 so that carbon formation need not be considered in the present thesis work.

Table 2 5: Reactions promoted by the catalyst in the methane steam reformer reactor (Adelman et al., 1995).

\begin{tabular}{|c|c|c|}
\hline & Reactions & $-\Delta \mathrm{H}_{298,} \mathrm{~kJ} / \mathrm{mol}$ \\
\hline Steam reforming & $\mathrm{CH}_{4}+\mathrm{H}_{2} \mathrm{O} \Leftrightarrow \mathrm{CO}+3 \mathrm{H}_{2}$ & -206.1 \\
\hline Water-gas shift & $\mathrm{CO}+\mathrm{H}_{2} \mathrm{O} \Leftrightarrow \mathrm{CO}_{2}+\mathrm{H}_{2}$ & +41.15 \\
\hline
\end{tabular}




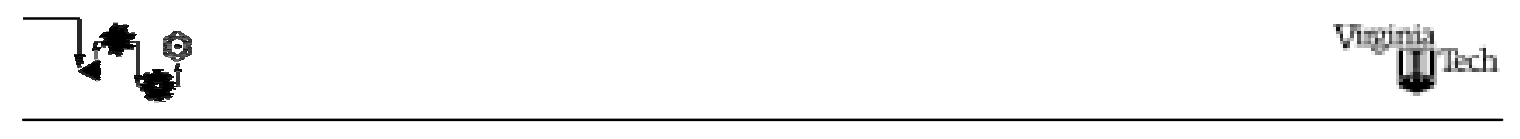

The next two principal components in Fig. 2.8 are the high temperature shift (HTS) and the low temperature shift (LTS) reactors. These are packed bed reactors that slow down the gases in the presence of a catalyst. The principal reaction taking place in these processes, due to the relatively low temperatures present and the type of catalyst used, is the water-gas shift reaction (see Table 2.5). Examples of commercial water-gas shift catalysts are the chromia-promoted iron catalyst similar to the Fischer-Tropsch catalyst $\left(400^{\circ} \mathrm{C}-500^{\circ} \mathrm{C}\right)$, the copper mixed oxide catalysts used for desulfurized feeds (low temperatures), and the sulfided cobalt-molybdenum alloy catalysts (Newsome, 1980). The best new alternatives to these water-gas shift catalysts are ruthenium, rhenium, and platinum (Lomax, 2001).

The HTS and the LTS reactors increase the concentration of hydrogen in the reformate gases produced by the steam reforming reactor. After the LTS process, the gases have a high concentration of hydrogen and a remarkable amount of water and carbon dioxide. The amounts of methane and carbon monoxide are relatively small. Typical concentrations (based on simulations performed in this thesis work) on a molar basis of hydrogen and carbon monoxide entering and exiting the HTS reactor are 55\% and $10 \%$ and $60 \%$ and $4 \%$, respectively. Those exiting the LTS are on the order of $65 \%$ and $1 \%$. However, at this concentration level of carbon monoxide, further conversion is required since even a few ppm (parts per million) of carbon monoxide in the gas stream (reformate) will adversely affect the operation of the PEMFC stack. The carbon monoxide poisons the catalyst in the fuel cell, preventing the electrochemical reactions that power the fuel cell.

In order to decrease carbon monoxide concentrations, additional clean-up of the reformate is required. Thus, a preferential oxidation (PROX) reactor (component (9) in Fig. 2.8) is used. In such a reactor, a small amount of air is injected which preferentially combusts with the $\mathrm{CO}$, converting it to $\mathrm{CO}_{2}$. PROX reactors usually have three catalyst stages each provided with air injection mainfolds, which typically employ Platinum $(\mathrm{Pt})$ (Inbody et al, 1998).

There are consequences, however, to decreasing the concentration of carbon monoxide to a few ppm in the reformate, consequences in terms of cost and lost 
efficiency in the system. For example, the hydrogen burned in the PROX process is an important loss that could be avoided if the PEMFC were more resistant to carbon monoxide concentrations. One way of increasing the tolerance of the PEMFC to CO could be achieved by increasing the operational temperature of the PEMFC since the Pt catalyst used in the stack increases its tolerance to $\mathrm{CO}$ as the temperature of operation increases. Researchers are working on this issue by modifying the chemical composition of the electrolyte. Experimental work (e.g., Honma et al., 2000; McGrath et al., 2001) has in fact already produced some promising new directions for material development. For example, the work by Honma et al. (2000) has produced new materials, which can operate at $100^{\circ} \mathrm{C}$ without sacrificing ion conductivity in the membrane. Work by McGrath et al. (2001) on new materials, which could operate between $120^{\circ} \mathrm{C}$ to $150^{\circ} \mathrm{C}$ without sacrificing ion conductivity or the ability to remain hydrated, looks promising. Not only would operation at higher stack temperatures improve stack resistance to CO poisoning, but it could as well lead to the elimination of at least one or more of the PROX reactor stages and to the complete elimination of the need for any perm-selective processes.

Finally, as already mentioned above, additional clean-up stages not considered here involve various technologies such as pressure swing absorption (PSA), metallic membranes, and polymer membranes. Of these three processes, the advantages/disadvantages of PSA seem to outweigh those for the other processes in terms of product purity, hydrogen recovery, tolerance to impurities, reliability, and costs (Lomax, 2001).

\subsubsection{Stack Sub-system (SS)}

\subsubsection{The PEMFC Stack}

There are two primary electrochemical half reactions taking place within the electrode/catalyst layers of the PEMFC (see Fig. 2.9). Electrochemical oxidation half reactions occur in the anode catalyst layer converting the hydrogen provided by the FPS to hydrogen protons $\left(\mathrm{H}^{+}\right)$and electrons $\left(\mathrm{e}^{-}\right)$. The positive $\mathrm{H}^{+}$ions released move through 


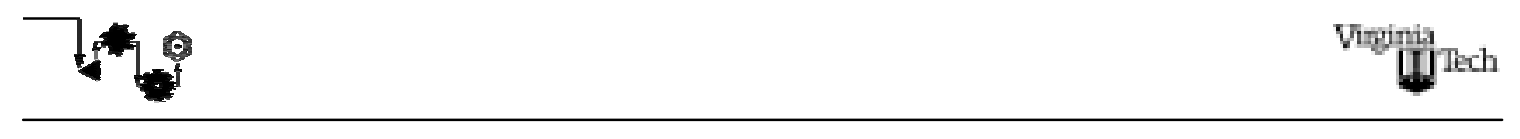

the membrane to the cathode side of the fuel cell. The electrons produced flow through an external load, combining with the $\mathrm{H}^{+}$ions and $\mathrm{O}_{2}$ in an electrochemical reduction half reaction in the cathode/catalyst layer. $\mathrm{O}_{2}$ is provided by the air supplied to the fuel cell stack. Liquid water, which results from the electrochemical reaction in the cathode, is removed from the fuel cell stack with the air stream as it exits the stack.

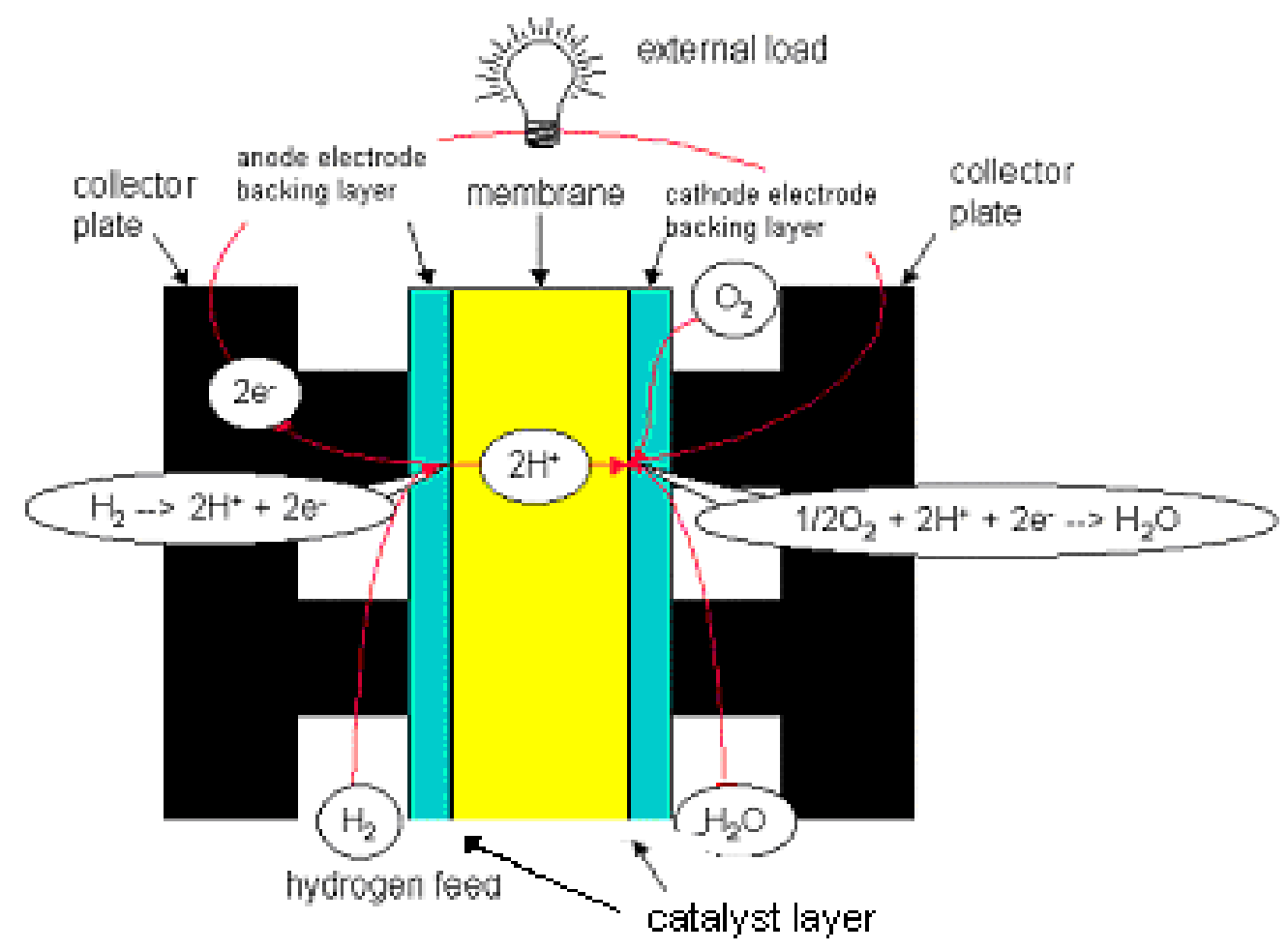

Figure 2. 9: General view of a fuel cell unit made up of collector plates, flow channels, backing layers, and membrane electrode assembly (i.e. the anode/ and cathode/catalyst layers and membrane) (Barbir, 1999).

Since the PEMFC operates at low temperature (e.g., $60{ }^{\circ} \mathrm{C}$ to $80{ }^{\circ} \mathrm{C}$ ), the rate of reaction of the electrochemical half reactions is too small and, therefore, a catalyst such as platinum $(\mathrm{Pt})$ or some alloy of platinum must be used to accelerate the process. Taking 


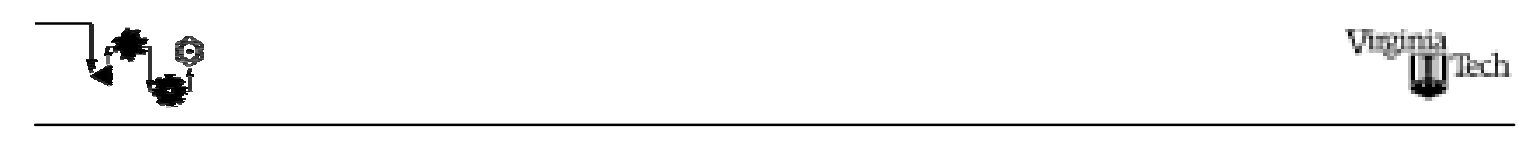

the platinum catalyst into account, the oxidation process, which takes place at the anode, is expressed in the following terms (Thomas et al., 1998):

$$
\begin{aligned}
& \mathrm{H}_{2}+2 \mathrm{Pt} \rightarrow 2 \mathrm{Pt}-2 \mathrm{H} \\
& 2 \mathrm{Pt}-2 \mathrm{H} \rightarrow 2 \mathrm{H}^{+}+2 e^{-}+2 \mathrm{Pt}
\end{aligned}
$$

As can be seen by the above expressions, the heterogeneous conversion takes place in two steps. First, the hydrogen molecule bonds with the catalyst in a surface (or chemical adsorption) reaction (Eq. (2.1)) that increases the rate of the overall process. Second, each hydrogen atom is desorbed from the catalyst and separated into a proton and an electron (Eq. (2.2)). The importance of available or active catalyst area becomes apparent. This active catalyst area, of course, is directly related to the active area of the polymer membrane electrolyte since contact of the reaction site with the membrane is required in order to transport the $\mathrm{H}^{+}$released away from each reaction site.

The Pt catalyst strongly affects the oxidation taking place at the anode electrode. It has less of an effect on the rate of the reduction reaction, taking place at the cathode electrode. Therefore, the loading of Pt is typically higher on the cathode side by as much as a factor of two. However, even with the higher loading, it turns out that the reduction half reaction at the cathode is the limiting reaction for fuel cell stack operation.

A description of the physical makeup of the electrode/catalyst layers is given in Fig. 2.4. The catalyst is spread in small particles throughout these layers as are both membrane and electrode materials. Pathways in the polymer membrane material allow the $\mathrm{H}^{+}$ions released to cross from the anode/catalyst layer to cathode/catalyst layer 

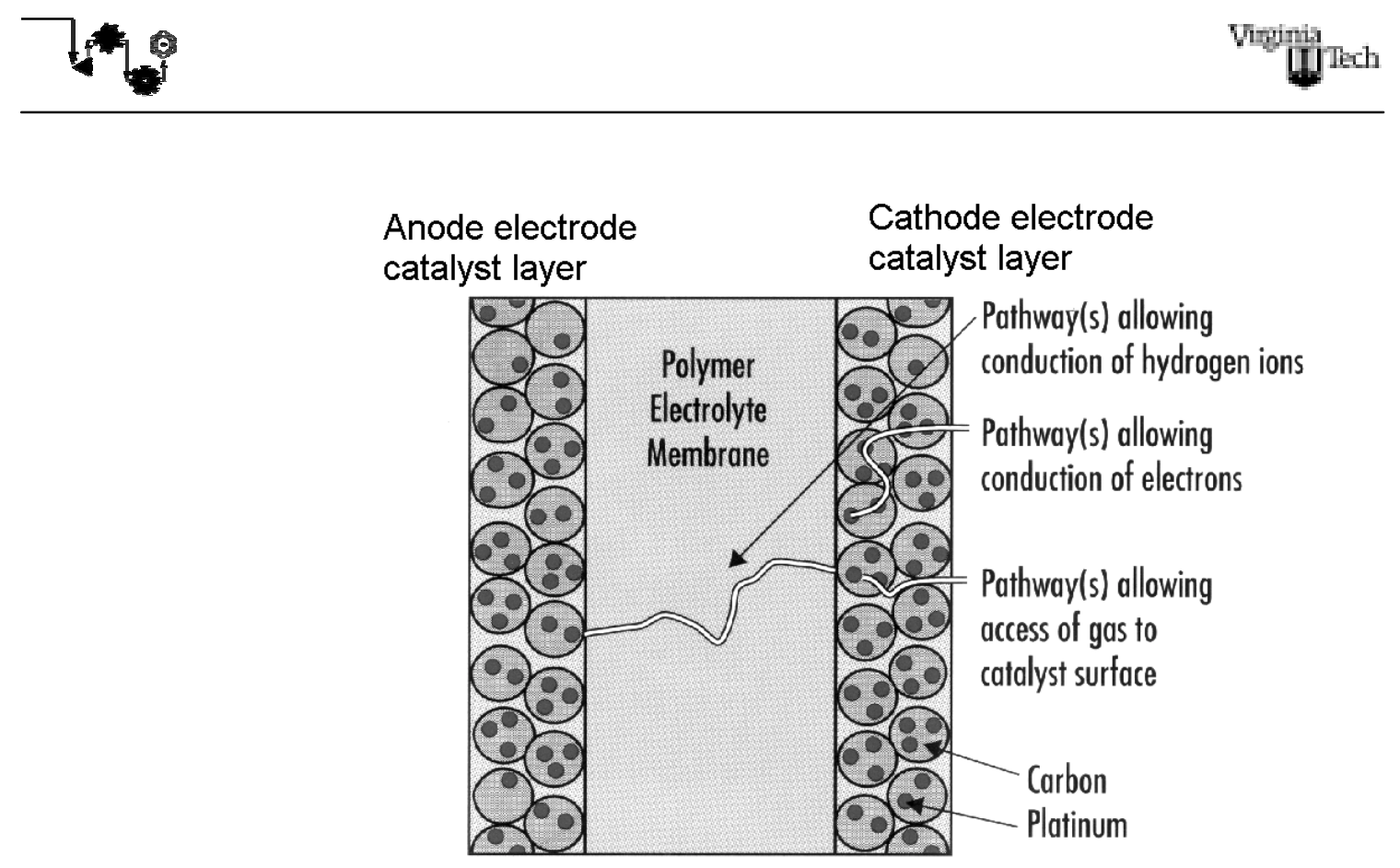

Figure 2. 10: Polymer electrolyte membrane with porous electrode / catalyst layers

(Thomas et al., 2000).

where the $\mathrm{H}^{+}$ions combine with the $\mathrm{O}_{2}$ and the $\mathrm{e}^{-}$, which arrive through an alternate pathway furnished by the electrode material.

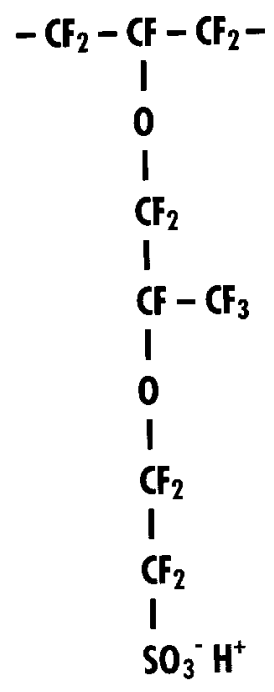

Figure 2. 11: Chemical structure of the Nafion ${ }^{\mathrm{TM}}$ membrane material (Thomas et al., 2000). 


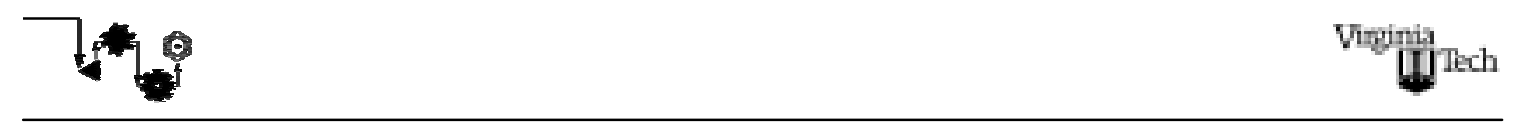

The most common membrane material used in PEMFCs is Nafion ${ }^{\mathrm{TM}}$. Its chemical structure is shown in Fig. 2.11. The primary function of the membrane is to allow the movement of $\mathrm{H}^{+}$ions, while at the same time barring the movement of electrons, $\mathrm{H}_{2}$, and air $\left(\mathrm{O}_{2}\right)$ directly from anode to cathode or vice versa. Such movement either short-circuits

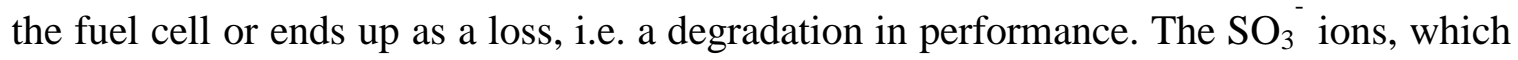
form part of the Nafion ${ }^{\mathrm{TM}}$ material structure, provide the pathways for the $\mathrm{H}^{+}$ions through the membrane. Figure 2.12 shows a membrane as part of a MEA (membrane electrode assembly, i.e. electrode/catalyst layers and membrane) with electrode backing layers on both sides of the MEA. This construction along with the collector plates forms an elemental unit that is repeated to form multiple cell stacks.

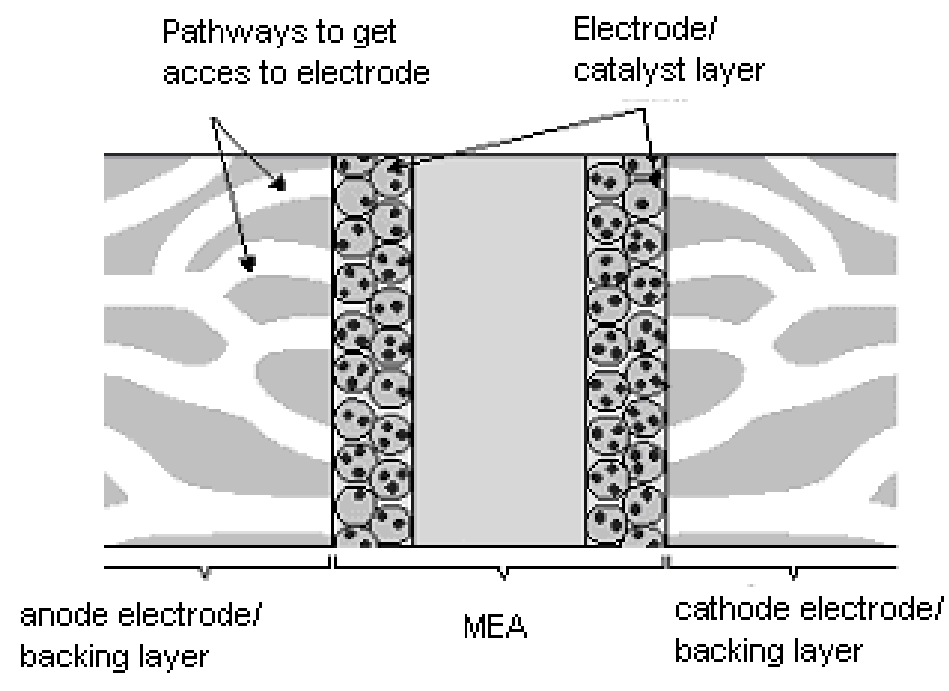

Figure 2. 12: General overview of a membrane electrode assembly (MEA) and the electrode backing layers (Thomas et al., 2000).

The performance map of a fuel cell which at a minimum includes all the elements shown in Fig. 2.12 is characterized by what is called a family of polarization curves. A single polarization curve relates the voltage per cell $(\mathrm{V})$ with current density $\left(\mathrm{A} / \mathrm{cm}^{2}\right)$ at a given temperature, pressure, and composition of the reactant streams. Figure 2.13 gives 


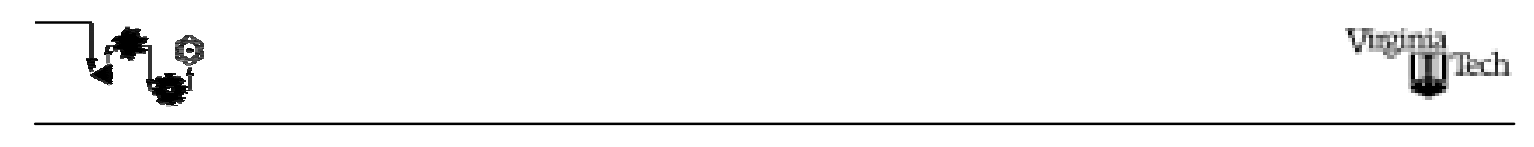

an example of a polarization curve with both actual and ideal open circuit voltages indicated as well as the regions where different types of losses (i.e. polarizations or overpotentials) dominate. Some of the principal parameters other than materials and geometry that influence cell performance and, thus, the shape of the polarization curve are as follow:

- Partial pressure of the oxygen: this pressure depends on the total pressure of operation of the PEMFC.

- Temperature of operation of the PEMFC.

- Relative humidity of the air and reformate streams entering the PEMFC: these relative humidities should be kept within in a range of 85 to $95 \%$.

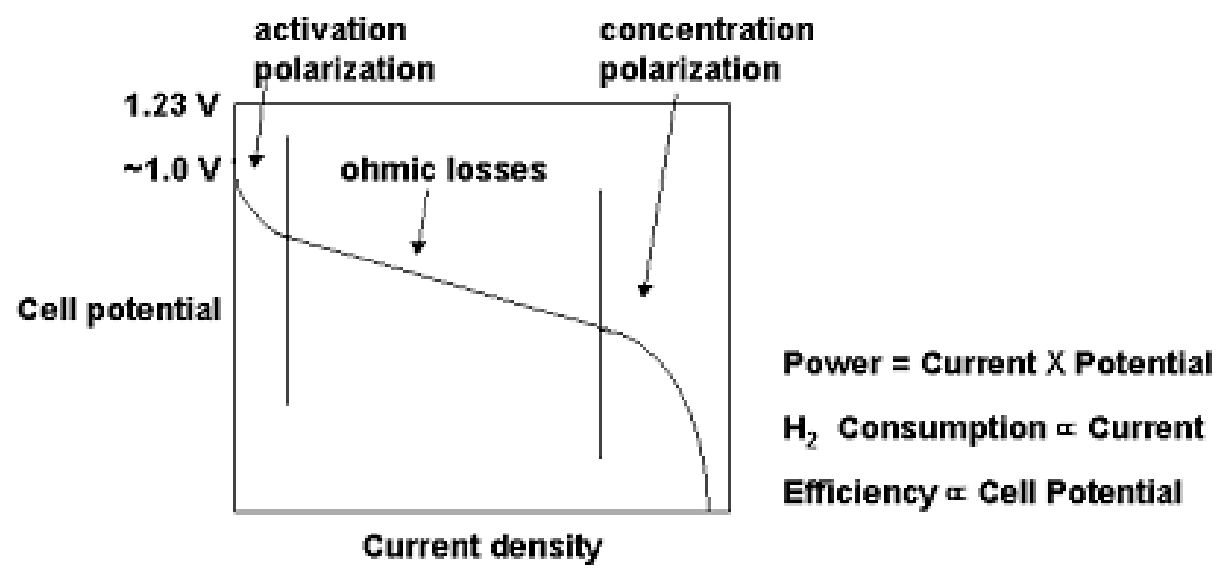

Figure 2. 13: Polarization curve.

Within the stack, cells are electrically connected in series as is shown in Fig. 2.14. The flow channels for the reformate and air, however, are typically set up in parallel through the use of manifolds which distribute the reactant flows to the various cells in the stack. This is done for reasons of performance since, in general, the more uniform the 

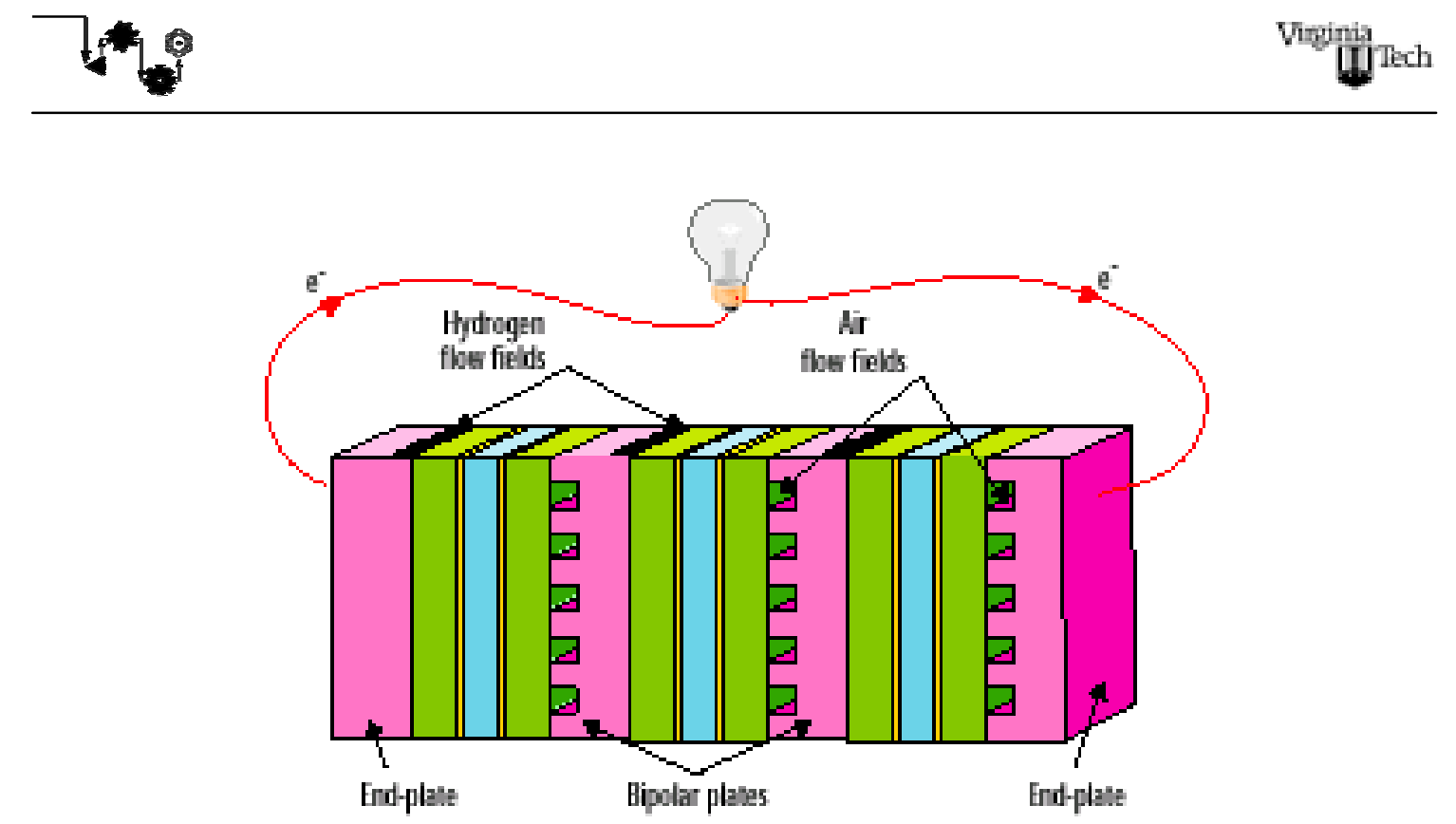

Figure 2. 14: Fuel cell stack with 3 MEAs plus collector plates (Thomas et al., 2000).

flow fields, the higher the performance of the stack, i.e. cell performance is determined by the weakest point in the cell.

In the following chapters, more details about the behavior of the PEMFC are presented along with the simulation details.

\subsubsection{Balance of Components in the SS}

The SS includes the air circuit of the fuel cell sub-system. The primary goal of the air circuit is to provide the oxygen to the fuel cell stack. It as well plays an important role in terms of power consumption and recovery within the SS.

Before entering the stack, the air is compressed to avoid a significant pressure difference between the air and the hydrogen streams in the stack (see component (18) in Fig. 2.8) and to increase the partial pressure of the oxygen. The heat exchanger and the humidifier (components (19) and (20)) bring the air stream at the inlet of the stack to the operating temperature $\left(70^{\circ} \mathrm{C}-90^{\circ} \mathrm{C}\right)$ and to a relative humidity between $85 \%$ and $95 \%$. Downstream of the fuel cell stack, two water separators (see components (21) and (23)) recover any liquid water in the air stream. The water typically used in the stack for humidification and cooling is de-ionized water and an overall positive water balance is 
kept within the sub-system (i.e. the water added, produced, and recovered is greater than the water consumed) so that no water need be added to the sub-system. At the tail end of the air circuit, there is an expander (see component (22) in Fig. 2.8), which recovers part of the power used in compressing the air to the stack pressure. According to the results presented in chapter 6 , the power consumed by the air compressor in a fuel cell subsystem with a net power output of $135 \mathrm{kWe}$ and an operating pressure close to $2.2 \mathrm{~atm}$ could be as much as $27 \mathrm{kWe}$, almost $20 \%$ of the net power output. Less than half of this power is usually recovered by the expander.

\subsubsection{Thermal Management Sub-system (TMS).}

In the operation of the fuel cell sub-system, the thermal management sub-system (TMS) plays an important role. However, even though its operation is taken into account in this thesis work, its detailed synthesis / design is not and instead left for future work.

With respect to its operation, it plays two separate roles within the fuel cell subsystem. The first is that it must remove thermal energy from the SS. This energy is lowgrade $\left(60^{\circ} \mathrm{C}\right.$ to $\left.80^{\circ} \mathrm{C}\right)$ thermal energy released in the PEMFC stack. It must be removed by the TMS in order to maintain the stack's operating temperature at a fixed value and to ensure that the stack temperature does not exceed $80^{\circ} \mathrm{C}$ plus some small delta.

The second role played by the TMS is that of cogeneration since the thermal energy released in the stack can be recovered and used for space heating and/or hot water in the residences. However, due to the amount and quality available, the results presented in the final chapter of this thesis show that it is insufficient even in conjunction with sources in the FPS to satisfy winter heating loads since the fuel cell sub-system is designed to satisfy the electrical loads at all load conditions. This suggests that the fuel cell sub-system must be coupled with another complementary cycle such as an absorption heat pump to be able to fully satisfy both the heating and electrical loads of the residences. Such heat pumps require thermal energy of sufficient quality (i.e. high enough temperature) to be able to operate. The low-grade thermal energy of the SS is insufficient for these purposes; and, thus, a source must be found elsewhere in the fuel 


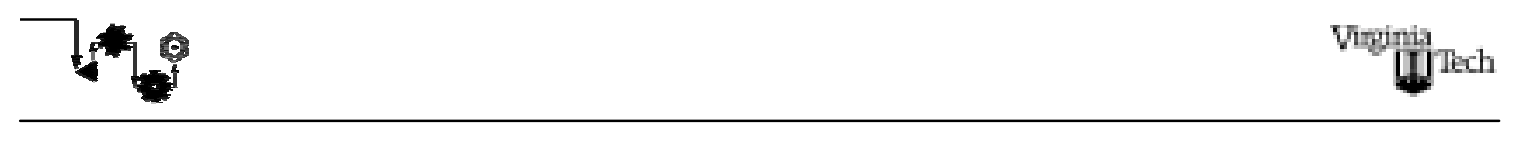

cell sub-system, namely the waste thermal energy at $200{ }^{\circ} \mathrm{C}$ to $300{ }^{\circ} \mathrm{C}$ in the combustion gas stream exiting the FPS (see Fig. 2.8). 


\section{Modeling for Synthesis/Design and Off-Design}

In this chapter, the thermodynamic, geometric, and cost component synthesis / design and off-design models are presented and discussed. They form the basis of the fuel cell sub-system and component optimizations presented in succeeding chapters. Only modeling details of some of the principal fuel cell sub-system components are presented here for illustration purposes. All remaining models appear in Appendix A.

\subsection{Thermodynamic, Geometric and Cost Models of the FPS}

In this section the thermodynamic, geometric, and cost models for two of the principal components of the FPS are detailed: the steam reformer (SR) reactor and the steam generator $(\mathrm{SG})$. The SR reactor is representative of the models for all of the other reactors of the FPS, i.e. the high temperature shift (HTS), low temperature shift (LTS), and preferential oxidation (PROX) reactors. The SG, on the other hand, is representative of the component modeling for the heat transfer present in most of the components of the FPS. The modeling for both synthesis / design and off-design is presented. This section ends with an outline of the principal features of all of the thermodynamic and geometric models for the FPS as well as a presentation of the cost models used. Details of the former are presented in Appendix A.

\subsubsection{Thermodynamic and Geometric Model for the SR Reactor}

In Chapter 2, Table 2.5 summarizes the reactions that dominate in the SR reactor due to the presence of a catalyst. This catalyst, for example, $\mathrm{Ni} / \mathrm{MgAl}_{2} \mathrm{O}_{4}$, significantly increases the kinetic rates of reaction for inverse methanation and water-gas shift over 


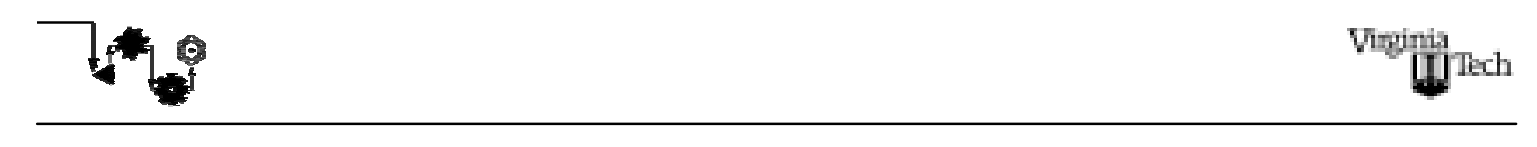

those for all of the other reactions present. It is further assumed that thermodynamic equilibrium is achieved at some point within the SR reactor so that an equilibrium mixture of gases exits the SR. Based on this last assumption, an equilibrium model as opposed to a kinetic rate model is chosen for the SR. As will be discussed in Chapter 6, such an equilibrium model leads to an oversizing of the reactor component. Subsequent work presently underway at Virginia Tech has moved to a kinetic rate based model, which in turn will lead to a more realistic sizing of reactor components since thermodynamic equilibrium will be achieved at the outlet of the reactor instead of somewhere within its interior.

Whether the reactor model is kinetically or equilibrium based, thermodynamic equilibrium calculations that determine the composition of gases leaving the reactor must be made. The overall reaction according to the reactions described in Table 2.5 is

$$
x \mathrm{CH}_{4}+y \mathrm{H}_{2} \mathrm{O} \Rightarrow a \mathrm{CH}_{4}+b \mathrm{H}_{2} \mathrm{O}+c \mathrm{CO}_{2}+d \mathrm{CO}+e \mathrm{H}_{2}
$$

where $x$ and $y$ are the number of moles entering the reactor and $a, b, c, d$, and $e$ are the moles of product for the equilibrium composition at the outlet conditions of the reactor. The latter represent five unknowns whose determination requires a system of five linearly independent equations. Three of these are formed by the three atomic balances, which result from the overall reaction, namely,

$$
\begin{aligned}
& x=a+c+d \\
& 4 x+2 y=4 a+2 b+2 e \\
& y=b+2 c+d
\end{aligned}
$$

The two additional equations required are those based on the conditions of thermodynamic chemical equilibrium associated with the stoichiometric equilibrium reactions of inverse methanation and water-gas shift taking place in the SR reactor. These thermodynamic chemical equilibrium conditions are given in general terms by

$$
K_{p}(T)=\prod_{i=1}^{r}\left(y_{i}\right)^{v_{i}}\left(\frac{P_{i}}{P_{o}}\right)^{\sum_{i=1}^{r} v_{i}}
$$




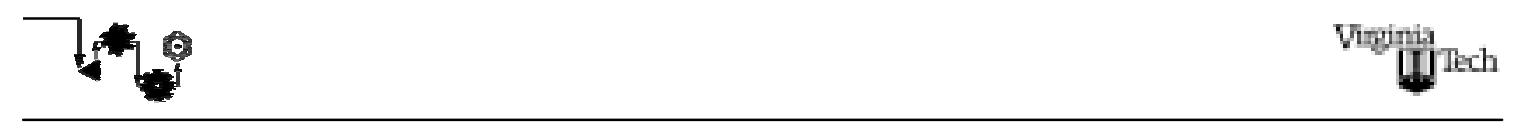

where $K_{p}(T)$ is the chemical equilibrium constant at standard pressure $\left(P_{o}\right)$, the $y_{i}$ are the mole fractions of reactants or products in the stoichiometric equilibrium reactions, the $v_{i}$ are the associated stoichiometric coefficients, $P$ is the equilibrium mixture pressure, and $r$ the total number of reactants and products. The equilibrium constant at standard pressure is defined as

$$
K_{p}(T) \equiv e^{-\Delta G^{o} / R T}
$$

where $\mathrm{T}$ is the equilibrium mixture temperature, $\mathrm{R}$ the universal gas constant, and $\Delta G^{o}$ the standard Gibbs free energy of reaction.

For the inverse methanation reaction, $\Delta G^{o}$ is determined as follows:

$$
\left.\Delta G^{o}(T)\right|_{i m}=\left(h_{C O}+3 h_{H_{2}}-h_{C_{4}}-h_{H_{2} O}\right)-T\left(s_{C O}^{o}+3 s_{H_{2}}^{o}-s_{C H_{4}}^{o}-s_{H_{2} O}^{o}\right)
$$

where $h_{i}$ and $s_{i}^{o}$ are the total enthalpy and the absolute entropy for the $\mathrm{i}^{\text {th }}$ component of the reformate exiting the reactor. The equilibrium constant can then be determined from Eq. (3.6) and substituted into Eq. (3.5) along with the mole fractions and stoichiometric coefficients for this reaction to yield the following equilibrium equation:

$$
\left.K_{p}(T)\right|_{i m}=\left(\frac{y_{\mathrm{CO}}^{1} y_{\mathrm{H}_{2}}^{3}}{y_{\mathrm{CH}_{4}}^{1} y_{\mathrm{H}_{2} \mathrm{O}}^{1}}\right)\left(\frac{P}{P_{o}}\right)^{1+3-1-1}
$$

In a similar fashion, the chemical equilibrium equation for the stoichiometric equilibrium water gas-shift reaction taking place in the SR reactor is expressed as

$$
\left.K_{p}(T)\right|_{w g s}=\left(\frac{y_{\mathrm{CO}_{2}} y_{\mathrm{H}_{2}}}{y_{\mathrm{CO}} y_{\mathrm{H}_{2} \mathrm{O}}}\right)\left(\frac{P}{P_{o}}\right)^{1+1-1-1}
$$

where in this case the Gibbs free energy of reaction used to determine $\left.K_{p}(T)\right|_{w g s}$ is given by

$$
\left.\Delta G^{o}(T)\right|_{w g s}=\left(h_{\mathrm{CO}_{2}}+h_{\mathrm{H}_{2}}-h_{\mathrm{CO}}-h_{\mathrm{H}_{2} \mathrm{O}}\right)-T\left(s_{\mathrm{CO}_{2}}^{o}+s_{\mathrm{H}_{2}}^{o}-s_{\mathrm{CO}}^{o}-s_{\mathrm{H}_{2} \mathrm{O}}^{o}\right)
$$




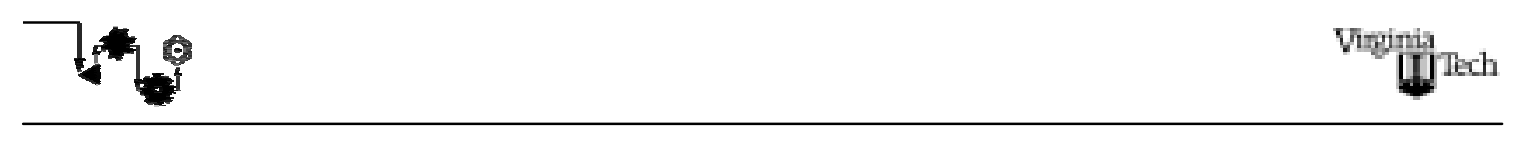

and again $h_{i}$ and $s_{i}^{o}$ are the total enthalpy and absolute entropy for the $\mathrm{i}^{\text {th }}$ component of the reformate exiting the reactor.

For a given outlet SR temperature $T$ and pressure $P$ as well as inlet composition $x$ and $y$, the outlet composition $a, b, c, d$, and $e$ for the SR reactor is calculated using Eqs. (3.2) through (3.10). As an illustration, Fig. 3.1 shows the results of a set of chemical equilibrium equations for a SR reactor with an inlet steam to methane ratio of 3 and a mixture pressure of $3 \mathrm{~atm}$ for a range of outlet temperatures from about $530{ }^{\circ} \mathrm{C}$ to $800{ }^{\circ} \mathrm{C}$.

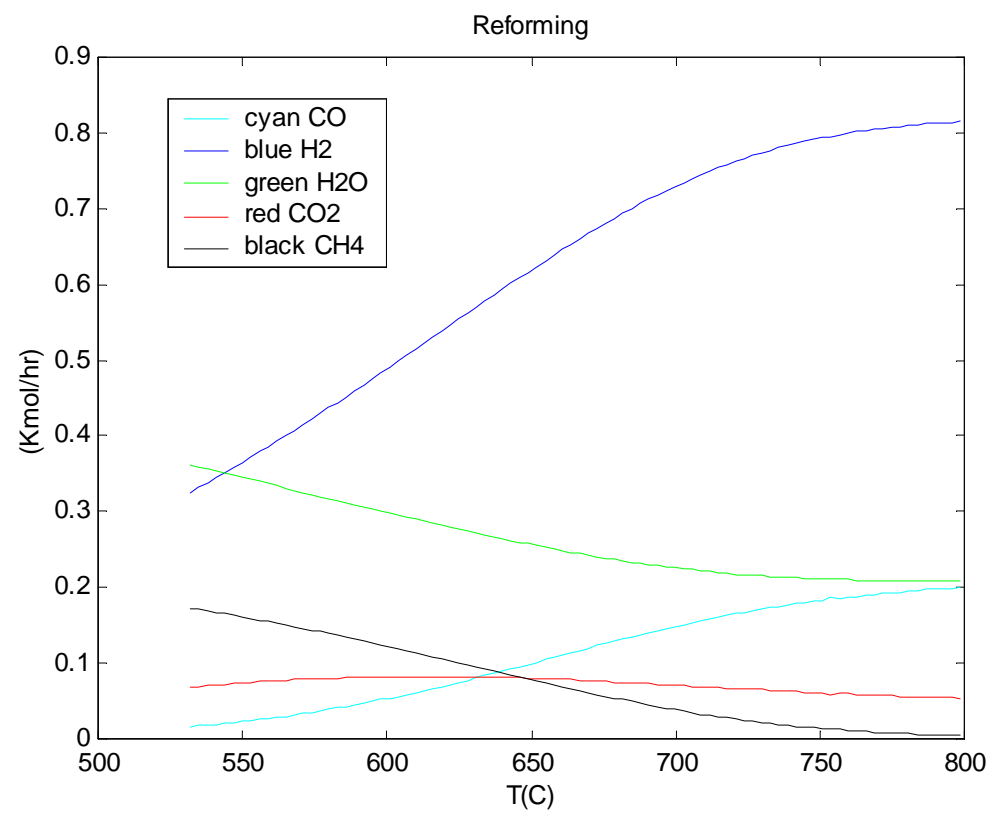

Figure 3. 1: Equilibrium compositions at the outlet of the SR reformer reactor calculated using the SR model above (outlet pressure 3 atm; steam to methane ratio of 3 ).

Thermal energy must be transferred in a heat interaction to the reactor for the reaction to proceed and for the $\mathrm{H}_{2}$ conversion rate to increase, which from the figure above can be seen to increase with temperature. Combustion gases from an auxiliary combustor flow counter currently to the reformate, providing the necessary thermal energy for the SR reactor. 


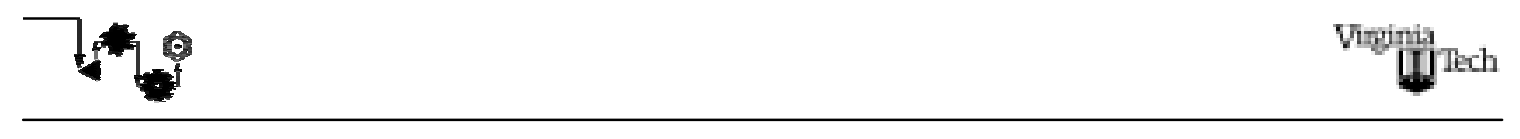

The SR reactor model uses the compositions calculated in Eqs. (3.2) through (3.10) together with the temperatures and pressures assumed in those calculations to characterize the geometry and the heat transfer of the SR reactor. These temperatures, pressures and compositions will have a different value for the different environmental/load conditions in which the model of the SR reactor is evaluated (design and three off-design conditions, see Table 2.1). The SR reactor uses the thermal energy as a driving force for the conversion of the methane and steam mixture into reformate (mixture of gases rich in hydrogen). The strong analogy between the behavior of the SR reactor and the behavior of a heat exchanger suggested the possibility of applying some of the techniques for the design of heat exchangers to the design of the SR reactor. The model presented in this section characterizes the heat transfer of the SR reactor at the synthesis/design point and at off-design by the calculation of the effectiveness of the SR reactor. The effectiveness of the SR reactor is defined as

$$
\varepsilon=\frac{Q_{S R}}{Q_{\max }}
$$

where $Q_{S R}$ is the actual heat transfer and $Q_{\max }$ the maximum possible heat transfer in the SR reactor. The actual heat transfer is defined as

$$
Q_{S R}=\sum_{\text {reformate }} n_{i}^{\text {outlet }} h_{i}^{\text {outlet }}\left(T_{\text {reformate }}^{\text {outlet }}\right)-\sum_{\text {reformate }} n_{i}^{\text {inlet }} h_{i}^{\text {inlet }}\left(T_{\text {reformate }}^{\text {inlet }}\right)
$$

where $n_{i}$ is the molar flow rate of the $\mathrm{i}^{\text {th }}$ component of the reformate at the outlet $\left(n_{i}^{\text {outlet }}\right)$ or inlet $\left(n_{i}^{\text {inlet }}\right)$ of the SR reactor and $h_{i}$ the corresponding enthalpy on a molar basis evaluated at the outlet temperature $\left(T_{\text {reformate }}^{\text {outet }}\right)$ and at the inlet $\left(T_{\text {reformate }}^{\text {inlet }}\right)$ of the reformate, respectively. The maximum possible heat transfer is defined in the same fashion, namely, as

$Q_{\max }=\sum_{\text {reformate }} n_{i}^{\text {outlet }} h_{i}^{\text {outlet }}\left(T_{\text {comb.gases }}^{\text {outlet }}\right)-\sum_{\text {reformate }} n_{i}^{\text {inlet }} h_{i}^{\text {inlet }}\left(T_{\text {reformate }}^{\text {inlet }}\right)$ 


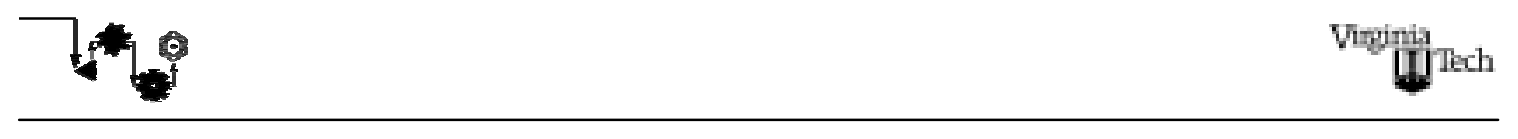

where the outlet molar flow rates are evaluated at the theoretical maximum temperature, that is to say, the inlet temperature of the combustion gases $\left(T_{\text {comb.gases }}^{\text {outlet }}\right)$ that heat the SR reactor.

The geometry of the SR reactor is calculated at the synthesis/design point and fixed at off-design. This geometry is related to the effectiveness through the number of transfer units (NTU) and the heat capacity ratio $\left(C_{r}\right)$ in the following terms (flow arrangement relation for counter flow, Incropera and Dewitt (1990)) :

$\varepsilon=\frac{1-\exp \left[-N T U\left(1-C_{r}\right)\right]}{1-C_{r} \exp \left[-N T U\left(1-C_{r}\right)\right]}$

where the heat capacity ratio is express as

$$
C_{r}=\frac{C_{\min }}{C_{\max }}
$$

and where $C_{\min }$ and $C_{\max }$ are the minimum and maximum heat capacities of the reformate and the combustion gases in the steam reformer, Eqs. (3.16) and (3.17), respectively, i.e. (see Eqs 3.16 and 3.17).

$C_{\min }=\min \left(C_{c g}, C_{\text {reformate }}\right)$

$C_{\max }=\max \left(C_{c g}, C_{\text {reformate }}\right)$

The expression to calculate the heat capacity of the reformate, $C_{\text {reformate }}$, is

$C_{\text {reformate }}=\frac{\dot{m}_{\text {reformate }} c_{p, \text { reformate }}^{\text {inlet }}+\dot{m}_{\text {reformate }} c_{p, \text { reformate }}^{\text {outlet }}}{2}$

where $\dot{m}_{\text {reformate }}$ is the total mass flow rate of the reformate, $c_{p, \text { reformate }}^{\text {inlet }}$ is the specific heat at constant pressure on a mass basis at the temperature and composition of the reformate at the inlet of the SR reactor, and $c_{p, r e f o r m a t e}^{\text {outle }}$ is the specific heat at constant pressure on a 


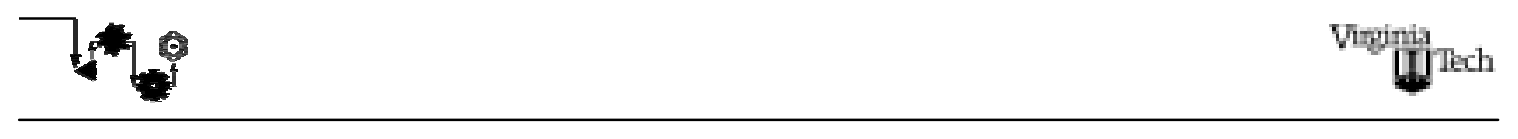

mass basis at the temperature and composition of the reformate at the outlet of the SR reactor. Note that the compositions and temperatures of the reformate at the inlet and outlet of the SR reactor are sensibly different; and, therefore, the arithmetic mean of the inlet and outlet values needs to be considered. For the heat capacity of the combustion gases, the heat capacity is determined as follows

$C_{c g}=\dot{m}_{c g} c_{p, c g}$

where $\dot{m}_{c g}$ is the mass flow rate of combustion gases in the SR reactor and $c_{p, c g}$ the specific heat at constant pressure on a mass basis for the combustion gases evaluated at the arithmetic mean of the inlet and outlet temperatures of the combustion gases in the reactor. Note that for the combustion gases the composition does not change, only the temperature.

The number of transfer units is calculated as

$$
N T U=\frac{U A}{C_{\min }}
$$

where $U$ and $A$ are evaluated with respect to a counter-flow geometric arrangement. Examples of different configurations of SR reactor tubes in a counter-flow configuration are depicted in Figs. 3.2 a and 3.2 b. In particular the geometry chosen for this model of the SR tubes is a single countercurrent flow configuration similar to that of Fig. 3.2 b, but with a circular cross-section. An important advantage of the single counter current flow is hat it is easier to control at off-design (Murray et al., 1985). 


7.0

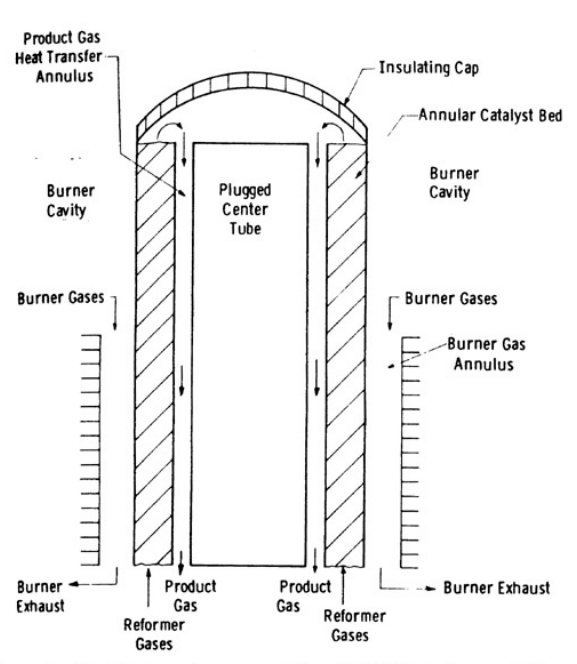

a)

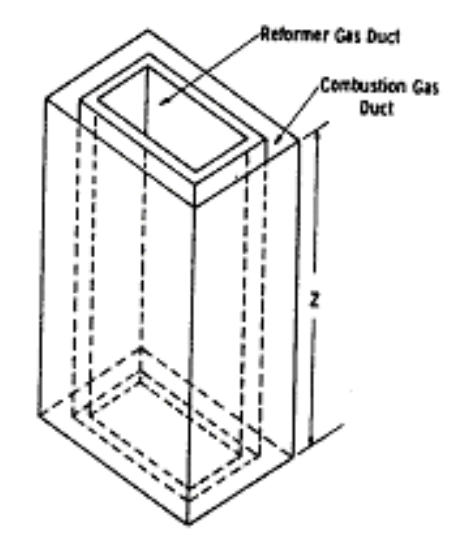

b)

Figure 3. 2: a) Double countercurrent-flow SR tube (Murray et al., 1985); and b) a flat slab single countercurrent-flow SR tube (Murray et al., 1985).

Thus, the total heat transfer area $A$ is expressed as

$$
A=\left(\pi D_{t S R} n_{t S R}\right) L_{S R}
$$

where $n_{t S R}$ is the number of SR tubes, $D_{t S R}$ the tube diameter, and $L_{S R}$ the tube length. Now, as to $U$, it is expressed as a function of the heat transfer coefficient of the combustion gases $U_{g a s}$ and the reformate $U_{r f m}$ such that 


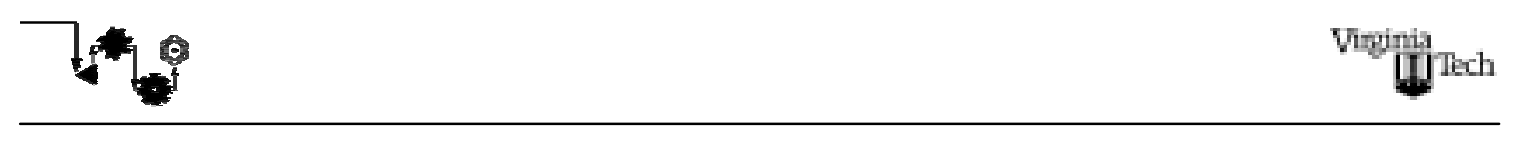

$$
\frac{1}{U}=\frac{1}{U_{g a s}}+\frac{1}{U_{r f m}}
$$

The heat transfer coefficient for the combustion gases is defined as

$$
U_{\text {gas }}=\frac{k_{\text {gas }}}{D_{h_{\text {gas }}} N u_{\text {gas }}}
$$

where $D_{h_{\text {gas }}}$ is the hydraulic diameter for the combustion gases given by

$$
D_{\text {has }}=\frac{4 A_{\text {cross }}}{A_{\text {wetted }}}
$$

$A_{\text {cross }}$ is the cross-sectional area expressed as

$$
A_{\text {cross }}=(\delta)^{2}-\frac{\pi D^{2}{ }_{t S R}}{4}
$$

with $\delta$ the pitch of the tubes of the SR reactor based on a triangular pitch-tube layout. $A_{\text {wetted }}$ is the wetted area defined as

$$
A_{\text {wetted }}=4 \delta+\pi D_{t S R}
$$

Other terms in Eq. (3.23) above are $k_{\text {gas }}$, the thermal conductivity of the combustion gases evaluated for a particular gas composition at the arithmetic mean of the inlet and outlet gas temperatures, and the Nusselt number, $\mathrm{Nu} u_{\text {gas }}$, for the combustion gases at low Reynolds number ( $\operatorname{Re}_{\text {gas }} \leq 10,000$ ) expressed as:

$N u_{\text {gas }}=4.562+0.8 \delta$

Equation (3.27) is a correlation developed from data found in Table 8.3 of Incropera and Dewitt (1990).

For turbulent flow ( $\operatorname{Re}_{\text {gas }}>10,000$ ), the classic Dittus-Boelter correlation is used and is given by

$$
N u_{\text {gas }}=0.023 \operatorname{Re}_{\text {gas }}^{0.8} \operatorname{Pr}_{\text {gas }}^{0.4}
$$

where the Reynolds number for the combustion gases is defined as 


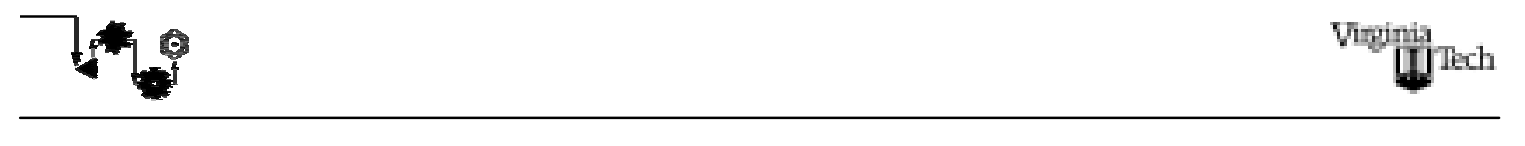

$\operatorname{Re}_{\text {gas }}=\frac{\rho_{\text {gas }} D_{\text {hgas }} u_{\text {gas }}}{\mu_{\text {gas }}}$

and $\rho_{\text {gas }}, u_{\text {gas }}$ and $\mu_{\text {gas }}$ are the density, velocity and viscosity of the combustion gases, respectively. All properties for both correlations (Eqs. (3.27) and (3.28)) as well as Eq. (3.29) are evaluated at the arithmetic mean of the inlet and outlet gas temperatures.

Now, on the reformate-side of the SR reactor, the heat transfer coefficient, $U_{r f m}$, is expressed as

$$
U_{r f m}=\frac{k_{r f m}}{D_{t_{S R}} N u_{r f m}}
$$

where $k_{r f m}$ is the thermal conductivity of the reformate gases. The Nusselt number for the reformate $N u_{r f m}$ is a Leva packed-bed correlation from Adelman et al. (1995). The correlation is as follows:

$$
N u_{r f m}=1.26 R e_{r f m}^{0.95} \exp \left(-6 \frac{D_{p}}{D_{t S R}}\right)
$$

where $D_{p}$ is the characteristic catalyst diameter and $R e_{r f n}$ is defined in the same fashion as Eq. (3.29), namely,

$$
\operatorname{Re}_{r f m}=\frac{\rho_{r f m} D_{h r f m} u_{r f m}}{\mu_{r f m}}
$$

All thermodynamic properties for the heat transfer coefficient on the reformate side are evaluated at the arithmetic mean of the inlet and outlet temperatures of the reformate, while the values of each of these two temperatures are used for the remainder of the calculations (e.g., for calculating the effectiveness of the reactor). The correlation used to calculate the Nusselt number for the reformate, Eq. (3.31), applies to a number of counter-flow configurations for SR tubes (i.e. double counter current flow (see Fig 3.2 a) or single counter current flow (see Fig. 3.2 b). However, other assumptions made with regards to this model make it applicable specifically to a single counter current flow 


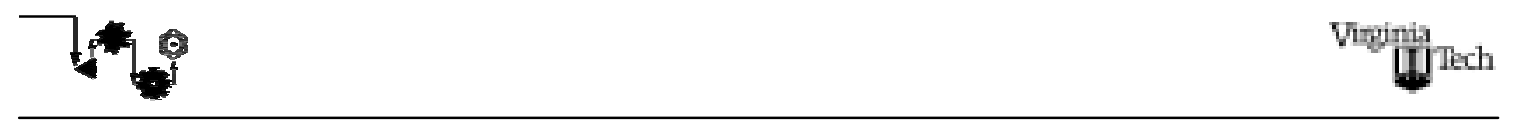

circular tube configuration. The model described in Eqs (3.1) through (3.32) is applied at both the synthesis/design point and at off-design, the difference, of course, being that the independent variables for one are different from those for the other during the optimization procedure.

\subsubsection{Thermodynamic and Geometric Model for the SG}

The steam generator (SG) plays a strategic role within the configuration. It provides the steam for mixing with the methane at a variable temperature and flow rate, both of which are important parameters in the reforming process. The model of the SG is based in a cross-flow heat exchanger configuration (see Fig. 3.3). The SG is divided into three sub-models:

- economizer

- evaporator

- $\quad$ superheater

The main features of the sub-models are the characterization of the convection heat transfer coefficients on the steam and combustion gas sides, both of which are required for calculating the overall heat transfer coefficient.

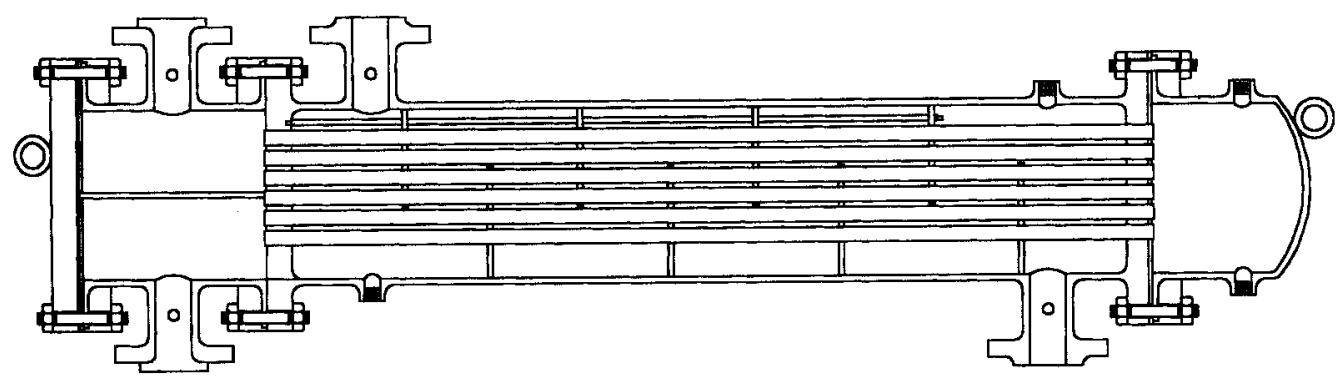

Figure 3. 3: Example of a baffled, single-pass shell and tube heat exchanger (Liu et al., 1998). 


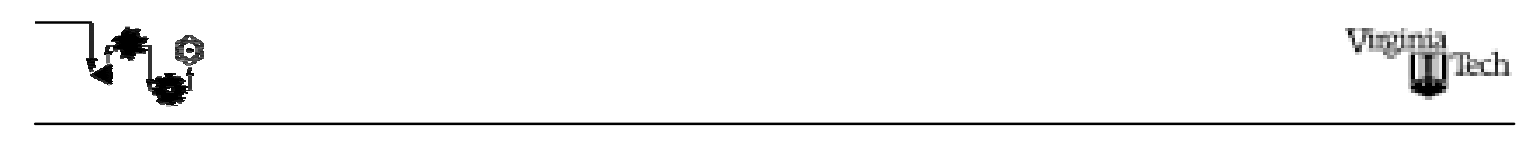

The economizer heats the liquid water that enters the steam generator until saturation is reached. The overall heat transfer coefficient for the economizer is expressed as follows:

$$
U_{\text {eco }}=\frac{1}{\frac{1}{h_{\text {eco }}}+\frac{1}{h_{\text {gases }}}}
$$

The convection coefficient on the combustion gas side, $h_{\text {gases }}$, is based on a correlation by Liu et al. , (1998), namely,

$$
h_{\text {gases }}=0.36\left(\frac{k_{\text {avg }}}{L_{e}}\right)\left(R e_{\text {gases }}\right)^{0.55}\left(\frac{C_{p} \mu_{\text {avg }}}{K_{\text {avg }}}\right)^{0.33}\left(\frac{\mu_{\text {avg }}}{\mu_{\text {gas }}}\right)^{0.14}
$$

where $k_{\text {avg }}, \mu_{a v g}$ and $C_{p}$ are, respectively, the average thermal conductivity, average viscosity, and the specific heat at constant pressure of the combustion gases at the arithmetic mean of the inlet and outlet temperatures of the combustion gases. $L_{e}$ is a characteristic length of the heat exchange area available to the combustion gases and $\operatorname{Re}_{\text {gases }}$ is the Reynolds number of the combustion gases for a given geometry given by

$$
\operatorname{Re}_{\text {gases }} \equiv \frac{G_{s} D_{e}}{\mu_{\text {avg }}}
$$

where $G_{s}$ is the shell-side mass velocity and $D_{e}$ the equivalent diameter of the shell. The shell side mass velocity is express as

$$
G_{s}=\frac{\dot{m}_{\text {gases }}}{A_{s}}
$$

where $\dot{m}_{\text {gases }}$ is the mass flow rate of the gases and $A_{s}$ the cross flow area calculated as

$$
A_{s}=\frac{D_{s} C B}{\delta}
$$

In this equation, $\delta$ is the pitch, $D_{s}$ the diameter of the shell, $C$ the clearance between adjacent tubes and $B$ the baffle spacing.

The equivalent diameter in $\mathrm{Eq}$ (3.35) is expressed as 


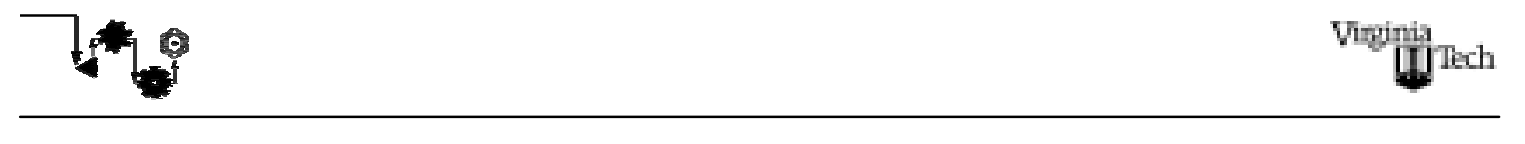

$D_{e}=\frac{4 A_{f f}}{P_{w}}$

where $A_{f f}$ is the free flow area and $P_{w}$ the wetted perimeter. Since a square pitch configuration is assumed here Eq. (3.38) can be rewritten as

$D_{e}=\frac{4\left(\delta^{2}-\pi d_{o}^{2} / 4\right)}{\pi d_{o}}$

where $d_{0}$ is the external tube diameter.

The convection coefficient on the water-side of the economizer, $h_{\text {eco }}$, is based on an analytical derivation of the Nusselt number for fully developed laminar flow in a circular tube with uniform surface heat flux. Under these conditions,

$N u_{e c o}=4.66$

and $\quad h_{e c o}=\frac{N u_{e c o} k_{e c o}}{d_{i}}$

where $k_{e c o}$ is the thermal conductivity of the water and $d_{i}$ is the internal diameter of the tubes.

Now, turning to the other sub-models, the overall heat transfer coefficient for the evaporator and the superheater are given by Eqs. (3.42) and (3.43), i.e.

$$
\begin{gathered}
U_{\text {evap }}=\frac{1}{\frac{1}{h_{\text {evap }}}+\frac{1}{h_{\text {gases }}}} \\
U_{\text {shtr }}=\frac{1}{\frac{1}{h_{\text {shtr }}}+\frac{1}{h_{\text {gases }}}}
\end{gathered}
$$

The convection coefficients on the combustion gas side of the evaporator and superheater appearing in the above expressions are determined using the same correlation introduced earlier, namely, Eq. (3.34). On the water side, on the other hand, the classic correlation for fully developed turbulent flow in circular tubes is used to characterize the Nusselt number for the superheater, i.e. 


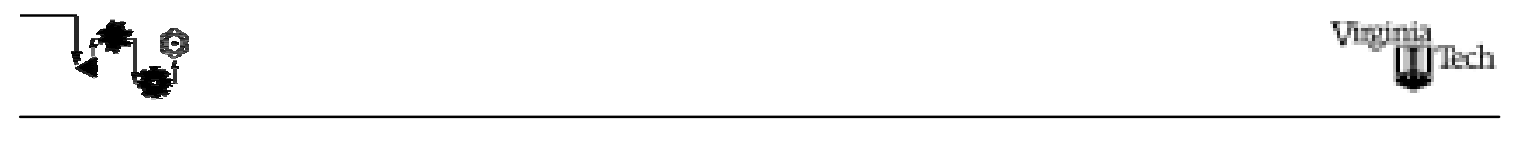

$N u_{s h t r}=0.023 \operatorname{Re}_{\text {shtr }}^{0.8} \operatorname{Pr}^{0.33}$

and using this expression, the convection coefficient is determined from

$h_{\text {shtr }}=\frac{N u_{\text {shtr }} k_{\text {shtr }}}{d_{i}}$

For the evaporator, the water-side convection coefficient is determined from a regression analysis of data found in Fig 7.3 in Liu et al. (1998) where it is tabulated as a function of the water mass flow rate $\dot{G}_{\text {evap }}$ expressed in $\mathrm{kg} / \mathrm{m}^{2} \mathrm{~s}$. The resulting equation is

$h_{\text {evap }}=40.7875 \dot{G}_{\text {evap }}+441.675$

The same model for the steam generator, Eqs (3.33) through (3.46), is used at the synthesis/design point and at off-design the difference again being that the independent variables for one are different than those for the other during the optimization procedure. Generally the same is true for all the models of the fuel cell sub-system that include geometric parameters (SR, SG, heat exchangers and stack).

\subsubsection{Outline of the Principal Features of the Thermodynamic and Geometric Models for the FPS}

In this section, an outline of the principal features of all of the thermodynamic and geometric models for the FPS is given in Table 3.1. Further details for each component model other than those already presented above can be found in Appendix A. 
Table 3. 1: Outline of FPS's thermodynamic and geometric models.

\begin{tabular}{|c|c|}
\hline Components & Summary of Thermodynamic and Geometric Models \\
\hline Compressor & $\begin{array}{l}\text { Model consists of an energy balance and an assumed fixed isentropic } \\
\text { efficiency of } 0.7 \text {. Psychometric calculations are included. To evaluate } \\
\text { the basic properties of the gas mixtures, the ideal gas mixture (Gibbs- } \\
\text { Dalton mixture) assumption is made. }\end{array}$ \\
\hline $\begin{array}{l}\text { HTS and LTS } \\
\text { reactors }\end{array}$ & $\begin{array}{l}\text { Chemical equilibrium calculations are made at the exit temperature of } \\
\text { each reactor. The role of the catalyst is modeled by assuming that only } \\
\text { the water-gas shift reaction contributes significantly. Each reactor's } \\
\text { energy balance is solved iteratively in conjunction with its chemical } \\
\text { equilibrium equations to determine the composition and temperature } \\
\text { at the outlet. To evaluate the basic properties of the gas mixtures, the } \\
\text { ideal gas mixture (Gibbs-Dalton mixture) assumption is made. }\end{array}$ \\
\hline PROX & $\begin{array}{l}\text { The model assumes that the dominant reactions are those for } \mathrm{H}_{2} \text { and } \\
\mathrm{CO} \text { combustion. The } \mathrm{CO} \text { and } \mathrm{O}_{2} \text { concentrations are assumed to be } \\
\text { zero at the outlet of the reactor and the overall process is assumed to } \\
\text { be isothermal. An energy balance is used to calculate the heat rejected. } \\
\text { To evaluate the basic properties of the gas mixtures, the ideal gas } \\
\text { mixture (Gibbs-Dalton mixture) assumption is made. }\end{array}$ \\
\hline Water separators & $\begin{array}{l}\text { Calculation of the water balance in the separator is based on an } \\
\text { assumed efficiency for the process, i.e. } 90 \% \text { of the liquid water is } \\
\text { assumed removed. }\end{array}$ \\
\hline Heat exchangers & $\begin{array}{l}\text { Thermodynamic as well as geometrically based energy balances are } \\
\text { used. To evaluate the basic properties of the gas mixtures, the ideal } \\
\text { gas mixture (Gibbs-Dalton mixture) assumption is made. }\end{array}$ \\
\hline Combustor & $\begin{array}{l}\text { Energy and mass balances that calculate the exit temperature and } \\
\text { combustion gas composition are employed. To evaluate the basic } \\
\text { properties of the gas mixtures, the ideal gas mixture (Gibbs-Dalton } \\
\text { mixture) assumption is made. }\end{array}$ \\
\hline Mixing points & $\begin{array}{l}\text { To evaluate mixer exit conditions, energy and mass balances are used. } \\
\text { To evaluate the basic properties of the gas mixtures, the ideal gas } \\
\text { mixture (Gibbs-Dalton mixture) assumption is made. }\end{array}$ \\
\hline $\begin{array}{l}\text { Steam reformer } \\
\text { reactor }\end{array}$ & $\begin{array}{l}\text { As described in section 3.1.1. Note that each reactor's energy balance } \\
\text { is solved iteratively in conjunction with its chemical equilibrium } \\
\text { equations to determine the composition and temperature at the outlet. } \\
\text { To evaluate the basic properties of the gas mixtures, the ideal gas } \\
\text { mixture (Gibbs-Dalton mixture) assumption is made. }\end{array}$ \\
\hline Steam generator & As described in section 3.1.1. \\
\hline
\end{tabular}




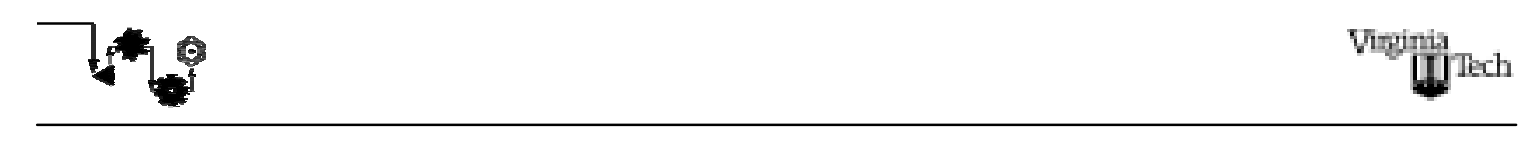

\subsubsection{Cost Models for the FPS}

The capital cost model for the FPS is based on hydrogen production, i.e.

$$
C_{F P S_{\text {line }}}=f\left(\dot{G}_{H_{2}}\right)
$$

where $C_{F P S_{\text {line }}}$ is the capital cost of the FPS reforming line and $\dot{G}_{H_{2}}$ the volumetric flow rate of hydrogen produced by the FPS. This type of model instead of one based on the geometry of the principal components involved was assumed due to the limited information available in the open literature at the time. Currently, however, the FPS cost model is being modified at Virginia Tech to reflect a geometric basis since new information has become available. This model will be featured in future thesis work along with the kinetic as opposed to equilibrium-based model mentioned earlier in section 3.1.1.

Now, returning to the production-based model implied by Eq. (3.47), the relation between hydrogen production and the capital cost of the FPS reformer line varies in the open literature. Two basic relations were considered here, i.e.

- the model based on Ogden et al. (1996) which suggests that

$$
C_{F P S_{\text {line }}}=6.408\left(\dot{G}_{H_{2}}\right)^{0.7}
$$

where the volumetric flow rate of hydrogen is expressed in millions of standard cube meters per day and the capital cost in millions of dollars; this cost model assumes that the cost of the PROX reactor is $20 \%$ of the cost of the rest of the fuel processing line; this model is valid for relatively small values of $\mathrm{H}_{2}$ production (i.e. 3 to $9 \mathrm{kmols} / \mathrm{hr}$ )

- the model in Jorgensen (2000) is based on data found in the literature on steam reforming plants; this model was built for relatively large-scale steam methane reformer plants and is given by 


$$
C_{F P S_{\text {line }}}=41.766\left(\dot{G}_{H_{2}}\right)^{1.173}
$$

where the units are the same as those given for Eq. (3.48).

The first of these two relations was chosen for the FPS reformer line cost model since it better reflects the sizes of the fuel cell sub-system considered in this work. In both cases, the capital cost of the FPS reforming line is multiplied times a cost escalation factor that coverts the dollars calculated in Eqs. (3.48) and (3.49) from 1996 year dollars to 2000 year dollars. Figure 3.4 shows the FPS reforming line cost calculated with Eq. 3.48 as a function of the molar flow rate of hydrogen processed. Note that this is not the trend that one would expect when geometry instead of flow rate is used to define variations in cost. Further discussion of this point is given in the Chapter 6.

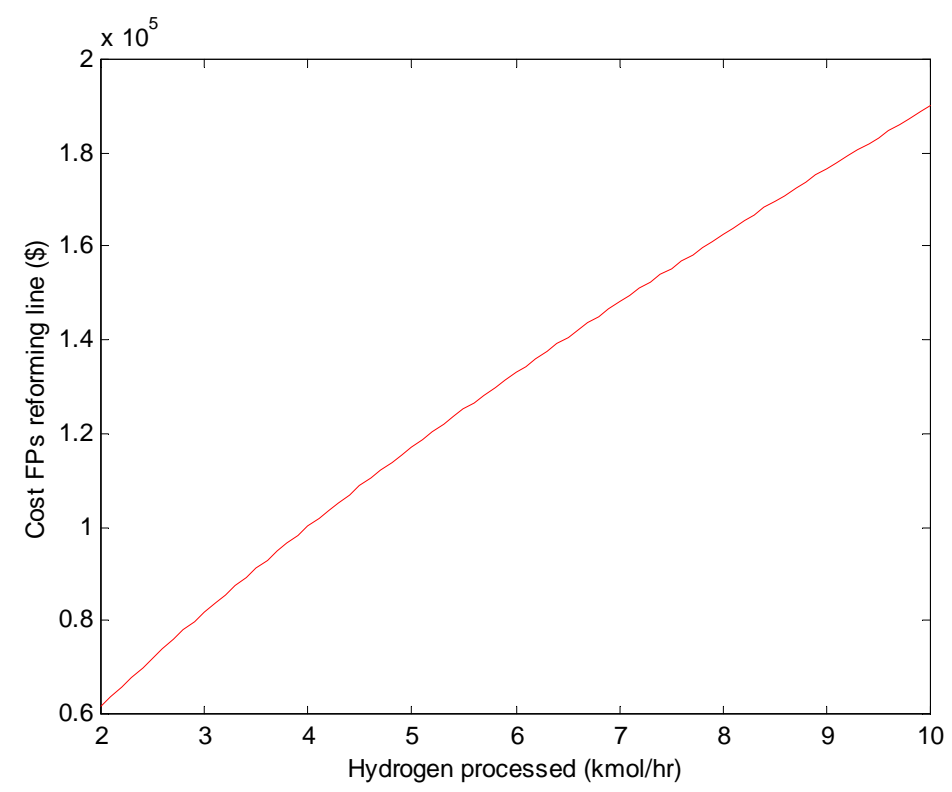

Figure 3. 4: Plot of FPS capital cost as a function of volumetric flow rate ${ }^{1}$.

Another important component of the FPS cost model is the operating cost associated with the use of natural gas. This cost was tabulated for a twelve-month period

\footnotetext{
${ }^{1}$ The cost of the FPS is extrapolated for hydrogen productions out of the range of 3 to $9 \mathrm{kmols} / \mathrm{hr}$.
} 
based on data from the Energy Information Administration $\left(2000^{2}\right)$. A plot of this data appears in Fig. 3.5. A regression analysis of this data resulted in the following equation:

$$
\begin{aligned}
& \begin{array}{l}
c_{n g}=-127.24 x^{6}+396.26 x^{5}-412.91 x^{4}+140.87 x^{3} \\
+5.4238 x^{2}-2.3984 x+6.7196
\end{array} \\
& \text { where } \quad x=\left(n_{\text {month }}-1\right) / 12
\end{aligned}
$$

and $n_{\text {month }}$ is the number of the month in question and $c_{n g}$ the unit price of the natural gas expressed in $\$ / \mathrm{kft}^{3}$.

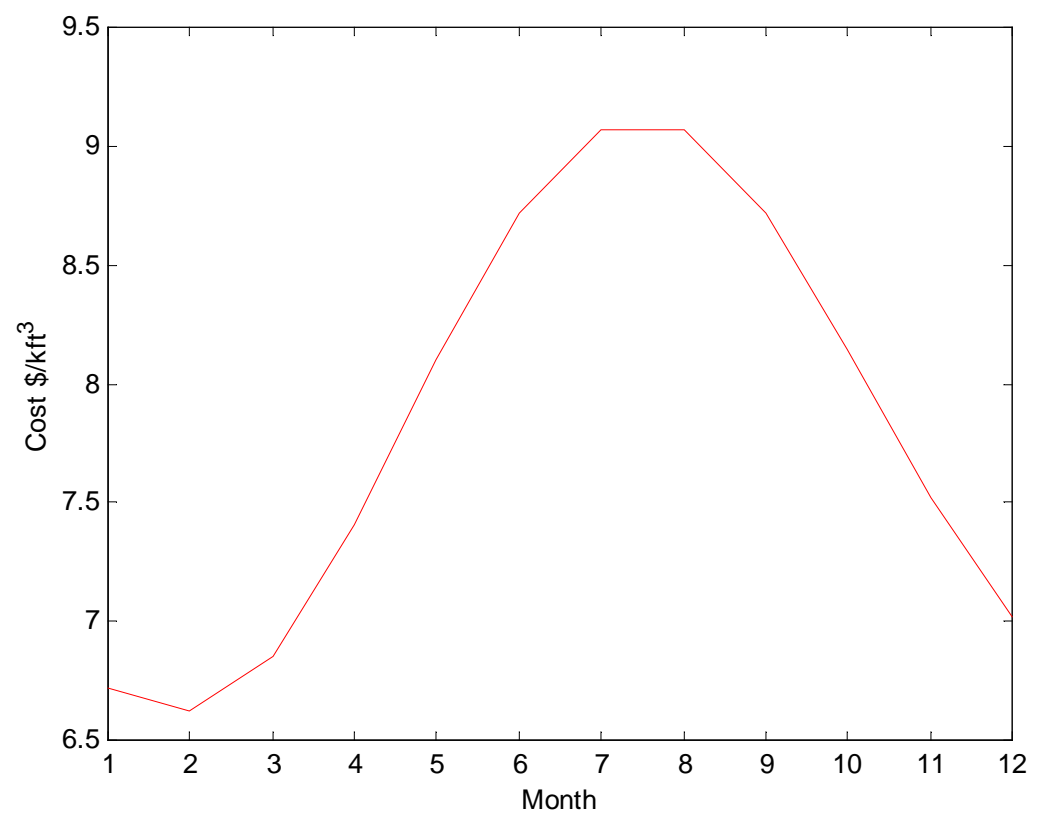

Figure 3. 5: Plot of the unit price of natural gas over a twelve-month period.

\footnotetext{
${ }^{2}$ This data is available at www.eia.doe.gov
} 


$70^{\circ}$

\subsection{Thermodynamic, Geometric and Cost Models of the SS}

The main component of the stack sub-system (SS) is the PEMFC stack. The operation of the stack determines the operation of the SS since the other SS components play a supporting role for the stack, i.e. they ensure the correct air mass flow rates as well as relative humidities, temperatures and pressures at the inlets and outlets of the stack. The modeling for both synthesis / design and off-design is presented. This section ends with an outline of the principal features of all of the thermodynamic and geometric models for the SS as well as a presentation of the cost models used. Details of the former are presented in Appendix A.

\subsubsection{Thermodynamic and Geometric Model for the PEMFC Stack}

The model of the PEMFC is a lumped-parameter model. Elements of Barbir et al. (1999) and classic equations in fuel cell design are used. The input and output model parameters as well as a number of constants are summarized in Table 3.2.

Table 3. 2: Summary of parameters and constants for the thermodynamic and geometric stack model.

\begin{tabular}{|c|c|c|}
\hline Input parameters & Constants & Output parameters \\
\hline $\begin{array}{l}\text { - mass flow rate of } \mathrm{H}_{2} \\
\text { entering on the anode-side } \\
\text { - work of the compressors } \\
\text { and expander of the fuel } \\
\text { cell sub-system (SS and } \\
\text { FPS combined) } \\
\text { - active area } \\
\text { - operating pressure } \\
\text { - operating temperature } \\
\text { - number of houses }\end{array}$ & $\begin{array}{l}\text { - molar fraction of oxygen } \\
\text { in the air } \\
\text { - fuel }\left(\mathrm{H}_{2}\right) \text { utilization fac- } \\
\text { tor } \\
\text { - molar masses of the } \\
\text { reformate components } \\
\text { - temperature rise through } \\
\text { the stack of the streams } \\
\text { - atmospheric conditions } \\
\text { of temperature, pressure } \\
\text { and relative humidity }\end{array}$ & $\begin{array}{l}\text { - number of cells in the } \\
\text { stack } \\
\text { - mass flow rate of air } \\
\text { entering on the cathode } \\
\text { side } \\
\text { - heat rejected by the } \\
\text { coolant of the stack }\end{array}$ \\
\hline
\end{tabular}




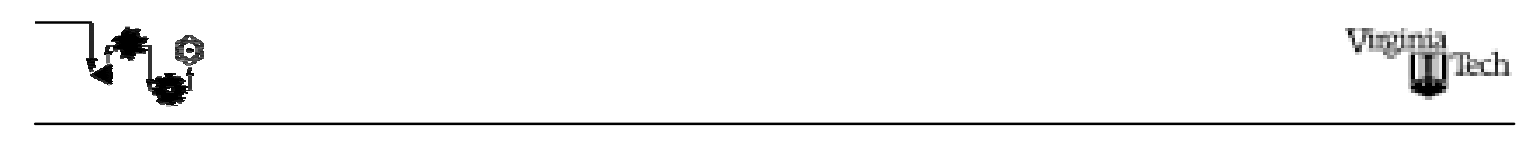

Operation of a PEMFC stack is characterized by a polarization curve, which shows the relationship between the current density and the voltage drop for the stack. The polarization curve accounts for the concentration, activation, and ohmic polarizations or losses, which occur within the stack. For more details see section 2.3.2.1. The polarization curve used for the stack model is based on the GC tools (1998) and represents a family of curves (see Fig. 3.6) depending on temperature and pressure and given by the following expressions:

For $J \geq 0.001 \mathrm{~A} / \mathrm{cm}^{2}$ and $T>303.15^{\circ} \mathrm{K}$ :

$$
V_{\text {cell }}=1.05-0.055 \log _{10}(1000 \mathrm{~J})-(1.064-0.002493 T) \mathrm{J}+0.055 \log _{10}\left(P_{O_{2}}\right)
$$

For $J \geq 0.001 \mathrm{~A} / \mathrm{cm}^{2}$ and $T \leq 303.15^{\circ} \mathrm{K}$ :

$$
V_{\text {cell }}=1.05-0.055 \log _{10}(1000 \mathrm{~J})-(8.966-0.02857) \mathrm{J}+0.055 \log _{10}\left(P_{O_{2}}\right)
$$

For $J<0.001 \mathrm{~A} / \mathrm{cm}^{2}$ :

$$
V_{\text {cell }}=1+0.055 \log _{10}\left(P_{O_{2}}\right)
$$

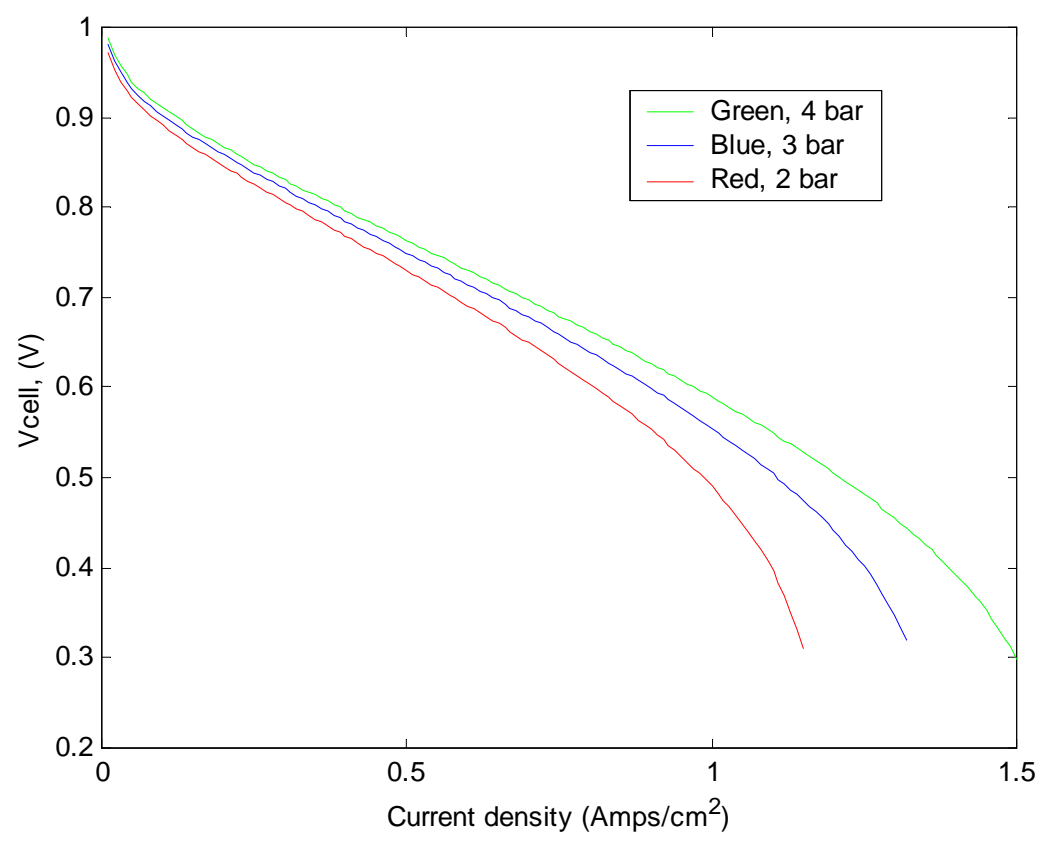

Figure 3. 6: Family of polarization curves for the PEMFC stack model. 


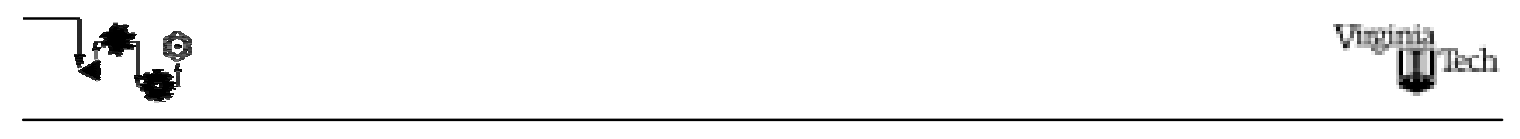

Here $J$ is the current density expressed in $\mathrm{A} / \mathrm{cm}^{2}, V_{\text {cell }}$ the voltage in v/cell, and $P_{\mathrm{O}_{2}}$ the partial pressure of oxygen in atm. Once the voltage per cell is calculated, it is corrected to the actual voltage based on the limiting current, $J_{\max }$. The expression for the actual voltage is

$V_{\text {cell } a c t}=V_{\text {cell }}+0.1 \log _{10}\left(1-\frac{J}{J_{\max }}\right)$

where $J_{\max }=1.4+0.2\left(\frac{P_{\text {stack }}}{101,325}-3\right)$

and $P_{\text {stack }}$ is the operating pressure for the stack.

Once the current density is known, the mole flow rate of hydrogen entering the stack can be found using the Faradaic efficiency, which here is assumed to be $100 \%$ (typically it varies between $95 \%$ and $100 \%$ ). In equation form, this is expressed as

$\dot{n}_{H_{2}}=\frac{n_{\text {cell }} J_{S_{H_{2}}}}{n_{e^{-}} F}$

where $s_{H_{2}}$ is the ratio of actual moles of $\mathrm{H}_{2}$ to the stoichiometric moles of $\mathrm{H}_{2}, n_{e^{-}}$the number of moles of electrons per mole of $\mathrm{H}_{2}$, F Faraday's constant, and $n_{\text {cell }}$ the number of cells. From the flow rate of $\mathrm{H}_{2}$ entering the cell and a fixed fuel utilization factor (e.g., $85 \%$ ), the input and output flow rates of the air can be determined from the stoichiometry and mass balances.

Finally, the rate of thermal energy rejected to the coolant in the stack, $\dot{Q}_{\text {stack }}$,is found using the following expression

$\dot{Q}_{\text {stack }}=\dot{W}_{\text {elec }}+\sum_{i}^{\text {out }} \dot{m}_{i} h_{i}-\sum_{i}^{i n} m_{i} h_{i}$

where $\dot{W}_{\text {elec }}$ is the electric power produced by the stack, $\dot{m}_{i}$ the mass flow rate of the $\mathrm{i}^{\text {th }}$ component, and $h_{i}$ the corresponding enthalpy. 


\subsubsection{Outline of the Principal Features of the Thermodynamic and Geometric Models for the SS}

In this section, an outline of the principal features of all of the thermodynamic and geometric models for the SS is given in Table 3.3. Further details for each component model other than those already presented above can be found in Appendix A.

Table 3. 3: Outline of the SS's thermodynamic and geometric models.

\begin{tabular}{|l|l|}
\hline Components & \multicolumn{1}{c|}{ Summary of the model } \\
\hline $\begin{array}{l}\text { Compressors and } \\
\text { turbine }\end{array}$ & $\begin{array}{l}\text { Models consist of an energy balance and an assumed fixed isentropic } \\
\text { efficiency of 0.7 for the compressor and 0.8 for the expander (turbine) } \\
\text { Psychometric calculations to evaluate the condensation of water are } \\
\text { included. To evaluate the basic properties of the gas mixtures, the } \\
\text { ideal gas mixture (Gibbs-Dalton mixture) assumption is made. }\end{array}$ \\
\hline Water separators & $\begin{array}{l}\text { Calculation of the water balance in the separator is based on an } \\
\text { assumed efficiency for the process, i.e. 90\% of the liquid water is } \\
\text { assumed removed. }\end{array}$ \\
\hline Mixing points & $\begin{array}{l}\text { Thermodynamic as well as geometrically based energy balances are } \\
\text { used. To evaluate the basic properties of the gas mixtures, the ideal } \\
\text { gas mixture (Gibbs-Dalton mixture) assumption is made. }\end{array}$ \\
\hline $\begin{array}{l}\text { The number of mixing points within the configuration is minimized in } \\
\text { order to avoid unnecessary irreversibilities. To evaluate mixer exit } \\
\text { conditions, energy and mass balances are used. To evaluate the basic } \\
\text { properties of the gas mixtures, the ideal gas mixture (Gibbs-Dalton } \\
\text { mixture) assumption is made. }\end{array}$ \\
\hline PEMFC & $\begin{array}{l}\text { As described in section 3.2.1 the model of the PEMFC is a lumped } \\
\text { parameter model based on Barbir et al. (1999) and classic equations } \\
\text { for fuel cell design. The family of polarization curves is based on } \\
\text { Geyer et al. (1998). }\end{array}$ \\
\hline
\end{tabular}




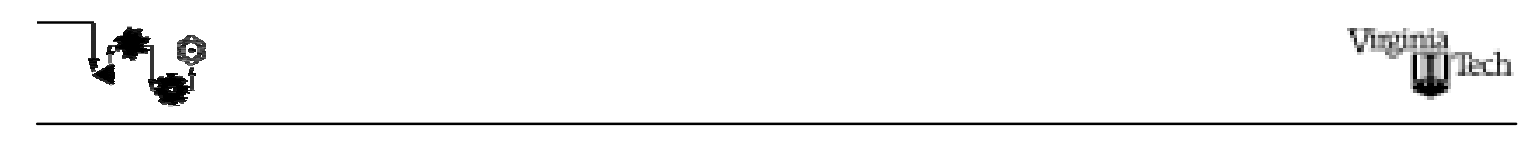

\subsubsection{Cost Models for the SS}

There are two cost functions available for the capital cost of the stack. The first cost function is based on the data for the cost of the materials of the stack found in Ekdunge et al. (1998) and relates the capital cost of the stack (in \$) to the gross power produced, $\dot{E}_{\text {stack }}($ in $\mathrm{kW})$. Thus,

$$
C_{\text {stack }}=f\left(\dot{E}_{\text {stack }}\right)
$$

The breakdown of this function follows:

$$
\begin{aligned}
& C_{\text {membrane }}=120 \dot{E}_{\text {stack }} \\
& C_{\text {electrode }}=31.16 \dot{E}_{\text {stack }} \\
& C_{\text {catalyst }}=243.2 \dot{E}_{\text {stack }} \\
& C_{\text {bipolar }}=825 \dot{E}_{\text {stack }} \\
& C_{\text {endplates }}=0.24 \dot{E}_{\text {stack }} \\
& C_{\text {plasticframe }}=0.105 \dot{E}_{\text {stack }} \\
& C_{\text {stack }}=C_{\text {membrane }}+C_{\text {electrode }}+C_{\text {catalyst }}+C_{\text {bipolar }}+C_{\text {endplates }}+C_{\text {plassicframe }}=1219.7 \dot{E}_{\text {stack }}
\end{aligned}
$$

where $C_{\text {membrane }}, C_{\text {electrode }}, C_{\text {catalyst }}, C_{\text {bipolar }}, C_{\text {endplates }}$ and $C_{\text {plasticframe }}$ are the capital cost of the membrane, electrodes, catalyst, bipolar plates, end plates and plastic frames, respectively. A cost escalation factor of 1.042 was applied to Eq. (3.66) in order to change 1998 year dollar to 2000 year dollars.

A second function for calculating the capital cost of the stack (in \$) was built as a function of the active area, $\mathrm{A}_{\text {act }}$, (in $\mathrm{m}^{2}$ ); the number of cells, $n_{\text {cells }}$; and the number of stacks manufactured per year $\left(n_{\text {units }}\right)$. This cost function is an extrapolation of data found in Oei et al. (1997). Thus,

$$
C_{\text {stack }}=f\left(n_{\text {cells }}, A_{\text {act }}, n_{\text {units }}\right)
$$

The breakdown of this function follows:

$$
\begin{aligned}
& C_{\text {MEA }}=\left(0.00777 A_{\text {act }}+0.0616\right) n_{\text {cells }} \\
& C_{\text {bipolar }}=\left(0.0013841 A_{\text {act }}+0.154\right) n_{\text {cells }}
\end{aligned}
$$




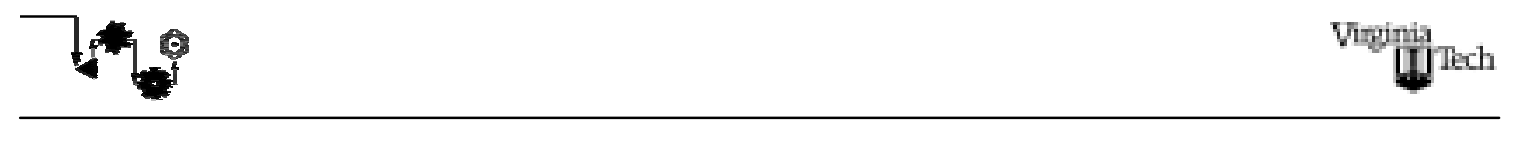

$$
\begin{aligned}
& C_{\text {cooling }}=\left(0.000692 A_{a c t}+0.154\right) n_{\text {cells }} \\
& C_{\text {mix }}=124.48 \\
& C_{\text {assembly }}=\left(15.4+0.17325 n_{\text {cells }}\right)
\end{aligned}
$$

where $C_{M E A}$ is the capital cost of the membrane electrode assemblies; $C_{\text {cooling }}$ the capital cost associated with the cooling system in the stack; $C_{m i x}$ is the capital cost of the endplates, plastic insulators, current collectors, plastic housing, and the tie bolts; and $C_{\text {assembly }}$ the part of the capital cost associated with assembly. Before adding all the capital cost terms together, it is necessary to scale the data since it is based on the manufacture of 500,000 stack units per year. The scale factor applied is

$\gamma=\frac{500,000}{\text { units }}$

so that the capital cost of the stack becomes

$$
C_{\text {stack }}=\gamma\left(C_{M E A}+C_{\text {bipolar }}+C_{\text {cooling }}+C_{\text {mix }}+C_{\text {assembly }}\right)
$$

As with Eq. (4.66), a cost escalation factor of 1.058 is applied to Eq. (3.74) in order to change 1997 year dollars to 2000 year dollars. In Table 3.4 some of the capital costs of the stack predicted with Eq. (3.74) is summarized as a function of the active area, number of cells, and number of units manufactured. The data provided in Table 3.4 shows how for a given value of the number of units manufactured, the price of the stack predicted by Eq. (3.74) for various combinations of active area and number of cells and a gross power output of $126 \mathrm{kWe}^{3}$ compares well with the cost predicted by Eq. (3.66) for an active area of about $500 \mathrm{~cm}^{2}$, i.e. the average value for the range of active areas considered (400 to $600 \mathrm{~cm}^{2}$ ). For this reason 1482 units was chosen as the reference number of units manufactured. The results given in Chapter 6, nonetheless include a sensitivity study of the influence of this parameter on the synthesis/design optimization of the fuel cell sub-system.

\footnotetext{
${ }^{3}$ The average gross power produced over the entire environmental/profile for the optimum synthesis/design of the fuel cell sub-system for 50 residences is close $100 \mathrm{kWe}$, with a peak electric gross power of 149 $\mathrm{kWe}$.
} 
Table 3. 4: Capital cost in $\$$ / kWe predicted by Eq. (3.74) and Eq. (3.66) for various combinations of the active area and number of cells and a gross power output of $126 \mathrm{kWe}$.

\begin{tabular}{|c|c|c|c|c|}
\hline Units & Active area $\left.\mathbf{( c m}^{\mathbf{2}}\right)$ & Number of cells & $\begin{array}{l}\text { Capital cost } \\
\text { (Eq.(3.74)) }\end{array}$ & $\begin{array}{l}\text { Capital cost } \\
(\mathbf{E q . ( 3 . 6 6 )})\end{array}$ \\
\hline 1482 & 500 & 539 & $\$ 154,430$ & $\$ 153,669$ \\
\hline 1482 & 550 & 490 & $\$ 144,940$ & $\$ 153,669$ \\
\hline 1482 & 600 & 449 & $\$ 137,000$ & $\$ 153,669$ \\
\hline
\end{tabular}




\section{Decomposition for the Large-Scale Optimization of Energy System Synthesis/Design}

The case is made for the need of decomposition in the large-scale optimization of energy system synthesis/design. The problem in its full complexity is defined as a dynamic, non-linear, mixed, integerprogramming problem. A brief introduction to the two types of decomposition, i.e. time decomposition and physical decomposition, is presented. Specific solution approaches to the latter, namely Local-Global optimization (LGO) and Iterative Local-Global Optimization (ILGO) are outlined. These presentations set the theoretical foundation for the work given in Chapters 5 and 6. For a deeper understanding of the concepts presented in this chapter, the reader is referred to the work by Muñoz and von Spakovsky (2000a,b,c,d,; 2001a,b).

\subsection{The Dynamic, Nonlinear Mixed Integer Programming Problem}

The synthesis/design optimization of the fuel cell sub-system and by extension the total energy system (TES) is a nonlinear mixed integer optimization problem with equality and inequality constraints. In general terms, this is expressed as

$$
\begin{aligned}
& \text { Minimize } f(\vec{x}, \vec{y}) \\
& \text { w.r.t } \vec{x}, \vec{y} \\
& \text { subject to } \\
& \qquad \vec{H}(\vec{x}, \vec{y})=\overrightarrow{0} \\
& \vec{G}(\vec{x}, \vec{y}) \leq \overrightarrow{0}
\end{aligned}
$$

where $f(\vec{x}, \vec{y})$ represents the figure of merit or objective of the optimization ${ }^{1}$; $\vec{H}(\vec{x}, \vec{y})=\overrightarrow{0}$ the set of equality constraints which represent, for example, mass and energy

\footnotetext{
${ }^{1}$ In the field of thermoeconomics this is the total cost of the system.
} 


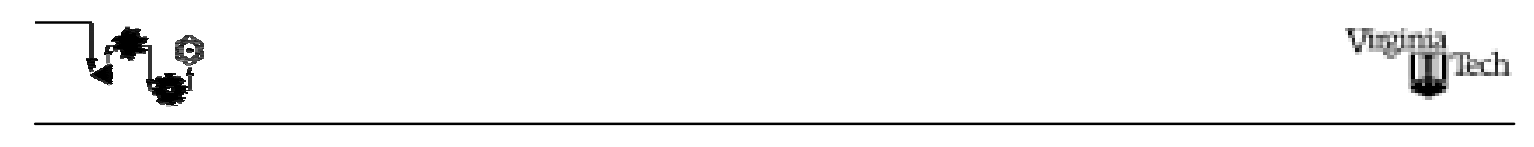

balances as well as performance constraints which the fuel cell subsystem must obey (e.g., the equations presented in sections 3.1 and 3.2 of chapter 3 ); $\vec{G}(\vec{x}, \vec{y}) \leq \overrightarrow{0}$ the set of inequality constraints which, for example, represent any physical limits to which the fuel cell sub-system must conform; and $\vec{x}$ the set of independent synthesis/design variables (degrees of freedom) and $\vec{y}$ the set of operational variables that minimize $f(\vec{x}, \vec{y})^{2}$. Examples of synthesis/design and operational variables are shown on Fig. 4.1 below for the nonlinear mixed integer programming problem associated with TESs.

The vectors of equality and inequality constraints $\vec{H}$ and $\vec{G}$, respectively, are composed of sub-vectors $\vec{h}_{i}$ and $\vec{g}_{i}$ each of which mathematically describes phenomena usually within the realm of a particular discipline (e.g., thermodynamics, aerodynamics, etc.). $\vec{H}$ is written in terms of its sub-vectors as

$$
\vec{H}(\vec{x}, \vec{y})=\left\{\begin{array}{c}
\vec{h}_{1}(\vec{x}, \vec{y}) \\
\vec{h}_{2}(\vec{x}, \vec{y}) \\
\vec{h}_{3}(\vec{x}, \vec{y}) \\
: \\
\vec{h}_{n}(\vec{x}, \vec{y})
\end{array}\right\}=\overrightarrow{0}
$$

while the vector $\vec{G}$ is expressed as

$$
\vec{G}(\vec{x}, \vec{y})=\left\{\begin{array}{c}
\vec{g}_{1}(\vec{x}, \vec{y}) \\
\vec{g}_{2}(\vec{x}, \vec{y}) \\
\vec{g}_{3}(\vec{x}, \vec{y}) \\
: \\
\vec{g}_{n}(\vec{x}, \vec{y})
\end{array}\right\} \leq \overrightarrow{0}
$$

In the case of energy systems, $\vec{H}$ and $\vec{G}$ represent the thermodynamic, geometric and/or cost models of the system which in our case are for the FPS, SS and TMS that comprise the fuel cell sub-system. These models are described in Chapter 3 and in Appendix A.

\footnotetext{
${ }^{2}$ Note that the objective or figure of merit of the system could be expressed as the sum of the objectives of the different sub-systems that form the system. This fact will be discussed in more detail in the following sections.
} 


7.0

\section{Synthesis/ Design Variables $\{x\}$}

- Geometry (e.g., length, width of a HX)

- Design Thermodynamic Variables

(e.g., pressure ratio)

- Integer Variables related to configuration (e.g., existence / nonexistence of component)

\section{Operational Variables $\left\{y_{i}\right\}$}

- Flowrates

- Valves settings

- Integer Variables

(component on-off)

- Sell/ Buy products

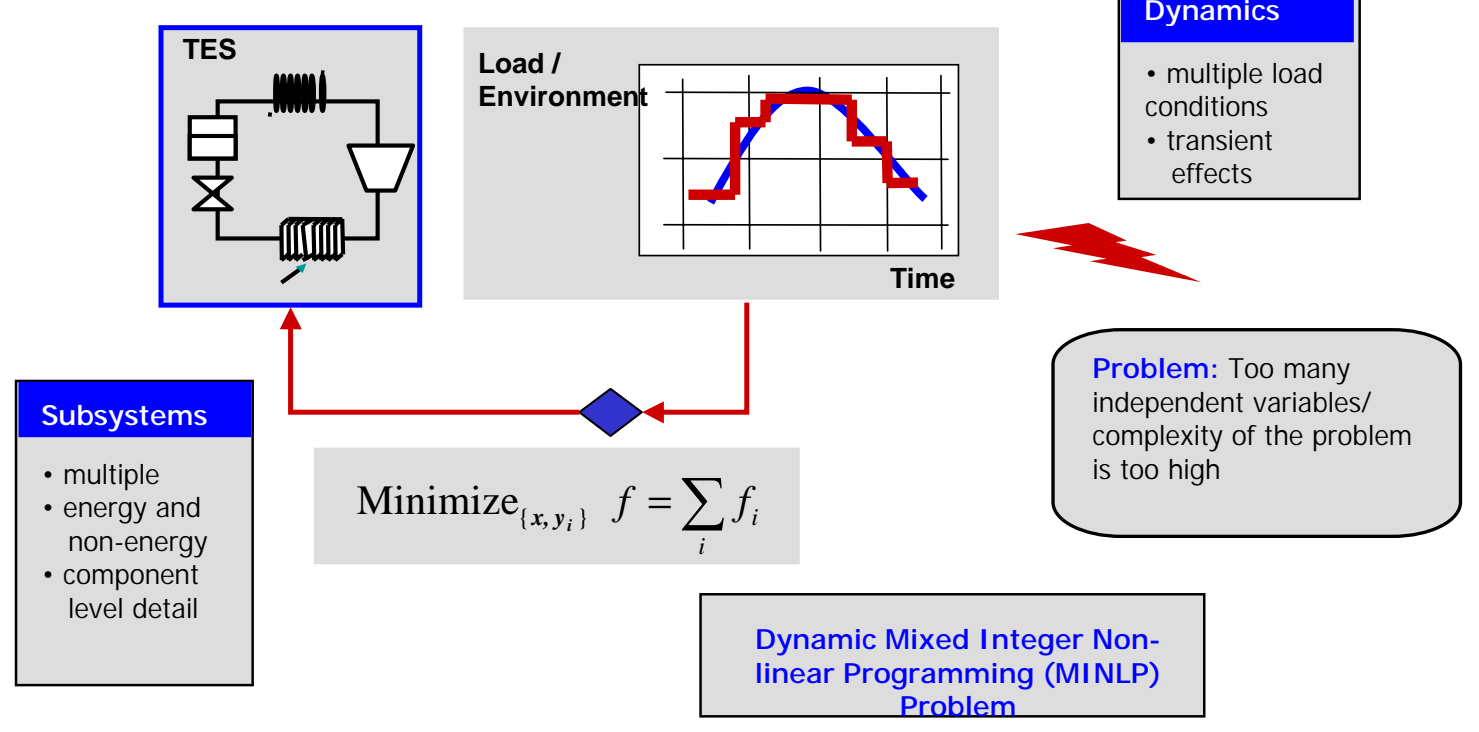

Figure 4. 1: Dynamic Mixed Integer Non-linear Programming (MINLP) Problem.

The general mixed integer non-linear programming (MINLP) problem for TESs and by implication for other dynamic, complex energy systems is depicted in Fig. 4.1. As is shown here, the MINLP can be a highly complex problem which may not just be difficult to solve but may in fact be impossible to solve given the usual techniques of applied optimization. The complexity arises by virtue of the fact that a large number of degrees of freedom (both synthesis/design and operational variables) might be involved due to a desire to simultaneously optimize not only at a system level but at a detailed component/sub-system level. The complexity also arises because of detailed load profiles, of highly non-linear models, and of a mix of discrete and continuous variables. 


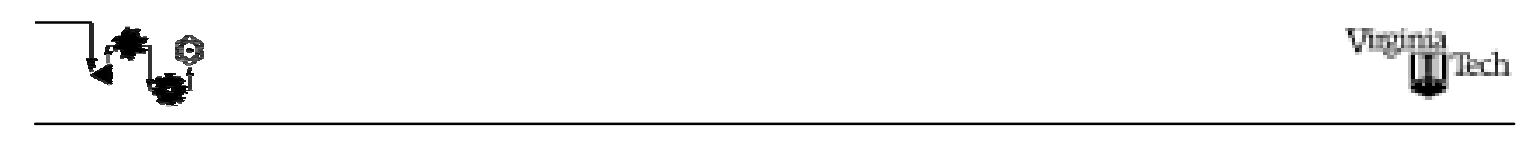

One option is to simplify the MINLP problem greatly by, for example, reducing the number of independent variables, considering only a single instant in time (i.e. only part of the load profile) or perhaps even linearizing certain or all the aspects of the problem. The drawback, of course, to any of these measures is a loss of information, which may in fact not be necessary if the problem can be decomposed into a set of smaller problems, the solution to which closely approximates the solution to the combined problem.

The types of decomposition considered here are time decomposition and physical decomposition and two different solution approaches for the latter, i.e. Local-Global Optimization (LGO) and Iterative Local-Global Optimization (ILGO), based on the work by Muñoz and von Spakovsky (2000 a,b,c,d; 2001 a,b). Both LGO and ILGO are explained in some detail in the following sections. However, the next section begins with a description of time decomposition,

\subsection{Time decomposition}

Most if not all energy systems must meet a set of loads (e.g., electricity and heat) under a varying set of environmental conditions (e.g., ambient temperature and pressure). Thus, the synthesis/design optimization of the system must be done in such a way that the system is able to meet the most stringent load(s) and set of conditions as well as all other loads and conditions in the most efficient or cost effective manner. However, considering all load points simultaneously, especially for a very detailed load profile over a long period of time, further complicates an already complex problem. Time decomposition surmounts this particular difficulty by decomposing the time variant features of synthesis/design into the synthesis/design at the most stringent load point followed by that at all other load points and conditions, i.e. a set including the optimum and a number of near optimum synthesis/designs at the most stringent load point are evaluated at all other load points in order to determine the optimal synthesis/design at all points ${ }^{3}$. The

\footnotetext{
3 Obviously, time decomposition makes the assumption that the global optimum found in this way approximates what would be found without time decomposition. This is an assumption made on physical
} 


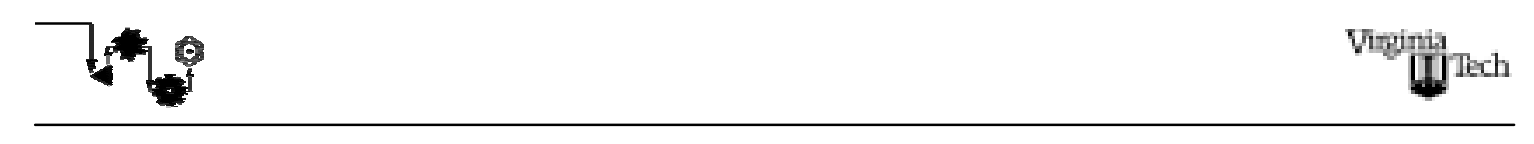

most stringent time segment (i.e. load point and set of environmental conditions) depends on the purpose of the system. In particular, in a cogeneration system the most stringent time segment would be the one with the peak electrical demand or that with the peak heating demand. The synthesis/design of the system is initially optimized with respect to this particular point that mathematically and on a thermoeconomic (thermodynamic and economic) basis is expressed in the following terms:

$$
\begin{aligned}
& \text { Minimize } C_{\text {design }}=\left[\left(\sum_{i=1}^{r} k_{i} \dot{R}_{i}\right) \cdot \tau\right]_{\text {design }}+\sum_{i=1}^{m} C_{i}^{p} \\
& \text { w.r.t. } \quad \tilde{X}_{\text {design }}=\left\{\vec{X}_{1}, \vec{X}_{2}, \cdots, \vec{X}_{m}\right\}_{\text {design }} \quad \tilde{Y}_{\text {design }}=\left\{\vec{Y}_{1}, \vec{Y}_{2}, \cdots, \vec{Y}_{m}\right\}_{\text {design }}
\end{aligned}
$$

subject to

$$
\begin{aligned}
& {[\vec{H}]_{\text {design }}=\overrightarrow{0}} \\
& {[\vec{G}]_{\text {design }} \leq \overrightarrow{0}}
\end{aligned}
$$

where $\tau$ is the length of time considered for all time segments and $m$ the number of units (sub-systems or components) in the system. The subscript "design" is short for "synthesis/design". $C_{m}^{p}$ is the capital cost for each component and $\dot{R}_{i}$ and $k_{i}$ represent the rate of consumption and unit cost of the $\mathrm{i}^{\text {th }}$ resource, respectively.

The combinations of values of the vectors $\tilde{X}_{\text {design }}$ and $\tilde{Y}_{\text {design }}{ }^{4}$ that result in the global plus a set of near global minimum values of the objective $C_{d e s i g n}$ (synthesis/design total cost) are then used to minimize the total cost $C_{T}$ over the entire load/environmental profile, i.e.

not mathematical reasoning, a discussion of which is beyond the scope of this thesis work. However, even if in certain cases this assumption is not true, the likelihood of a good solution is high (Muñoz and von Spakovsky, $2001 \mathrm{a}, \mathrm{b})$.

${ }^{4}$ Note that for decomposition, the $\vec{x}$ and $\vec{y}$ notation (Eq. 4.1) has been changed to $\tilde{X}$ and $\tilde{Y}$ with associated $\tilde{X}_{i}$ and $\tilde{Y}_{i}$ representing the independent and dependent variable vectors for each unit of the physical decomposition discussed later in this chapter. 


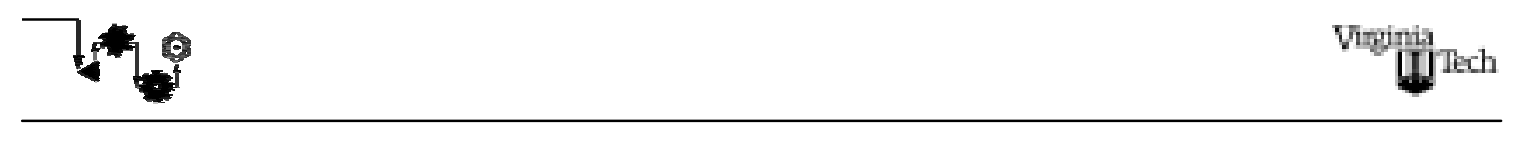

Minimize $\quad C_{\text {oper }}=\sum_{j=1}^{t-1}\left(\sum_{i=1}^{r} k_{i} \dot{R}_{i}\right) \Delta t_{j}+\sum_{i=1}^{m} C_{i}^{\text {maint enence }}$

w.r.t. $\quad \tilde{Y}_{j}=\left\{\vec{Y}_{1}, \vec{Y}_{2}, \cdots, \vec{Y}_{m}\right\}_{j} \quad j=1, \ldots, t-1$

subject to

$$
\begin{aligned}
& {[\vec{H}]_{o f f-d e s i g n}=\overrightarrow{0}} \\
& {[\vec{G}]_{o f f-d e s i g n} \leq \overrightarrow{0}} \\
& \tilde{X}-\tilde{X}_{d e s i g n}=\overrightarrow{0}
\end{aligned}
$$

Thus, Problem (4.7) is repeated for each promising solution of the synthesis/design problem (Problem (4.6)). The first term in Eq. (4.7) is used to evaluate the remaining (off-design) time segments of the load/environmental profile, while the second term in Eq. (4.7) accounts for the maintenance costs which vary from one time segment to the next. The solution to Problem (4.7) results effectively in a set of optimal control or operational variable values $\tilde{Y}_{j}$ for each time segment and an optimal total $\operatorname{cost} C_{T}^{*}$ for each promising solution from which the final synthesis/design for the system is chosen, i.e.

$$
C_{T}^{*}=C_{\text {design }}^{*}+C_{\text {oper }}^{*}
$$

where

$$
C_{\text {design }}^{*}=\left[\left(\sum_{i=1}^{r} k_{i} \dot{R}_{i}^{*}\right) \cdot \Delta t\right]_{\text {design }}+\sum_{i=1}^{m} C_{i}^{p^{*}}
$$

and Eq. (4.8) is valid for each promising solution.

As mentioned earlier, time decomposition transforms the overall time-dependent problem of synthesis/design into two separate but linked problems (Problems (4.6) and (4.7). In particular, it decomposes a problem with $d+o t$ variables ( $d$ design variables, $o$ operational variables, and $t$ time segments) into two smaller problems of $d+o$ and $o(t-1)$ variables, respectively. However, as a trade-off for reducing the number of variables which must be handled by any one problem, the expense of possibly having to carry out 


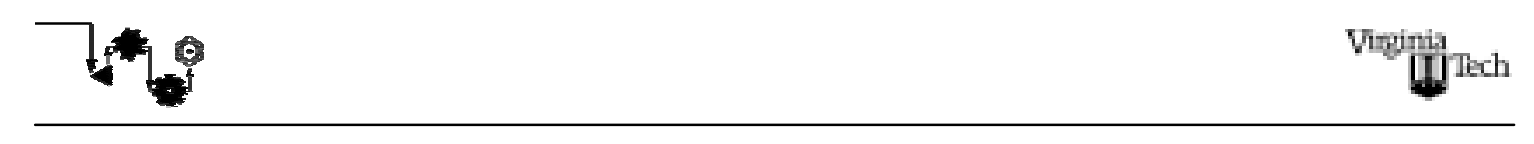

the optimization represented by Problem (4.7) for several possible promising solutions, i.e. those chosen in the synthesis/design optimization (Problem (4.6)), arises. In adition, even with time decomposition, further decomposition for a very complex problem of synthesis/design optimization may be needed. Thus, physical decomposition is considered next.

\subsection{Physical Decomposition}

Most energy systems can be decomposed into a set of units (sub-systems and/or components), each of which must have a clearly defined set of feedback or coupling functions with the other units of the system. Such a physical decomposition reduces the overall system optimization problem of synthesis/design into a number of unit optimization sub-problems. Two main approaches to physical (unit) decomposition are presented in this section. The first is the Local-Global Optimization (LGO) approach and the second the Iterative Local-Global Optimization (ILGO) approach found in Muñoz and von Spakovsky (2000 a,b,c,d; 2001 a,b).

\subsubsection{Decomposition with the LGO Approach}

LGO approach gets its name from the fact that two levels of optimization instead of one are used. At the local or unit level, an optimization for each unit and each set of values of the coupling functions between units (disciplines) is carried out. These optimum results are then used at a global or system level at which the system synthesis/design is optimized with respect to the coupling functions values.

In order to get a better understanding of the LGO approach, let us consider the following optimization problem applied to the system decomposed into two units shown in Fig 4.2, i.e. 


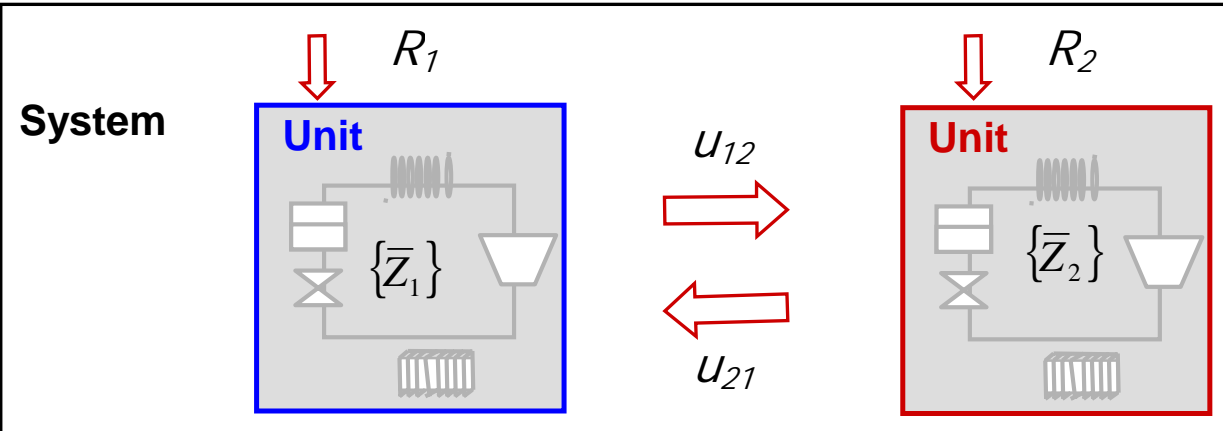

Figure 4. 2: Physical decomposition of a 2-unit system.

Minimize

$C=k_{1} R_{1}\left(\vec{Z}_{1}, u_{12}\left(\vec{Z}_{1}, \vec{Z}_{2}\right), u_{21}\left(\vec{Z}_{1}, \vec{Z}_{2}\right)\right)+k_{2} R_{2}\left(\vec{Z}_{2}, u_{12}\left(\vec{Z}_{1}, \vec{Z}_{2}\right), u_{21}\left(\vec{Z}_{1}, \vec{Z}_{2}\right)\right)$

w.r.t. $\vec{Z}_{1}, \vec{Z}_{2}$

subject to the primary constraints

$$
\begin{gathered}
\vec{H}=\left[\begin{array}{l}
\vec{h}_{1} \\
\vec{h}_{2}
\end{array}\right]=\overrightarrow{0} \\
\vec{G}=\left[\begin{array}{l}
\vec{g}_{1} \\
\vec{g}_{2}
\end{array}\right] \leq \overrightarrow{0}
\end{gathered}
$$

and to the additional (secondary) constraints

$$
\begin{aligned}
& u_{12}\left(\vec{Z}_{1}, \vec{Z}_{2}\right)-\xi=0 \\
& u_{21}\left(\vec{Z}_{1}, \vec{Z}_{2}\right)-\psi=0
\end{aligned}
$$

where $R_{1}$ and $R_{2}$ are the resources used by units 1 and 2, respectively, $k_{1}$ and $k_{2}$ their respective unit costs, and $Z_{1}$ and $Z_{2}$ the set of independent variables for each unit used in 


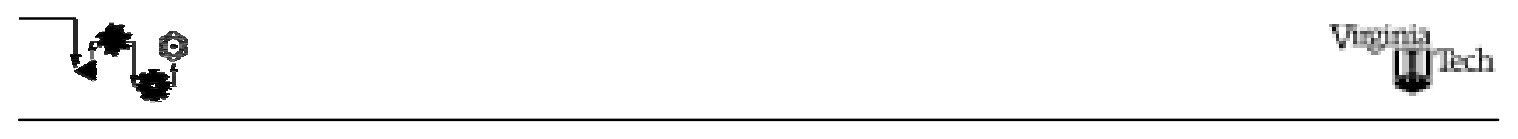

the optimization of the system. Constraints (4.9.3) and (4.9.4) require that the coupling functions take on values of $\xi$ and $\psi$ such that

$$
\begin{aligned}
& u_{12 \max } \leq \xi \leq u_{12 \min } \\
& u_{21 \max } \leq \psi \leq u_{21 \min }
\end{aligned}
$$

The cost of operating each unit is clearly identified in Problem (4.9). The contribution of each unit to the overall objective $C$ is a function of the variables of each unit and the values $\xi$ and $\psi$ of the coupling functions. Therefore, for a given set of values $\xi$ and $\psi$ of the coupling functions, Problem (4.9) can easily be decomposed into two sub-problems, one for each of the units, i.e.

\section{Sub-problem 1:}

$$
\begin{array}{ll}
\text { Minimize } & C_{1}=k_{1} R_{1}\left(\vec{Z}_{1}, \xi, \psi\right) \\
\text { w.r.t. } \vec{Z}_{1} & \\
\text { subject to } & \vec{h}_{1}=\overrightarrow{0} \\
& \vec{g}_{1} \leq \overrightarrow{0}
\end{array}
$$

\section{Sub-problem 2:}

$$
\begin{aligned}
& \text { Minimize } \\
& \text { w.r.t. } \vec{Z}_{2}=k_{2} R_{2}\left(\vec{Z}_{2}, \xi, \psi\right) \\
& \text { subject to } \\
& \qquad \vec{h}_{2}=\overrightarrow{0} \\
& \\
& \vec{g}_{2} \leq \overrightarrow{0}
\end{aligned}
$$

where for purposes of simplification it has been assumed that the capital cost are zero. Thus, Problem (4.9) is effectively reduced to two smaller problems (Problems (4.10) and (4.11)) by physical decomposition. Problems (4.10) and (4.11) have to be solved several 


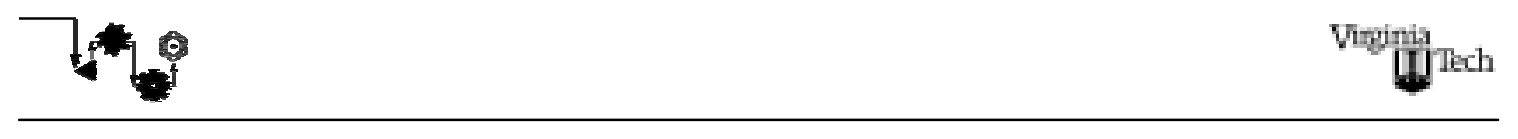

times for different values of $\xi$ and $\psi$ of the coupling functions $u_{12}$ and $u_{21}$. The values selected for the coupling functions must be included within the limits expressed by Eqs. (4.9.5) and (4.9.6). It is assumed in using LGO that it is possible to find different sets of values for the independent variable vectors $\vec{Z}_{1}$ and $\vec{Z}_{2}$ which correspond to particular values $\xi$ and $\psi$ of $u_{12}$ and $u_{21}$.

The results for sub-problems 1 and 2 are a set of optimum values for each objective as a function of the coupling functions such that

$$
\begin{aligned}
& C_{1}^{*}=\min \left(k_{1} R_{1}\left(\vec{Z}_{1}, \xi, \psi\right)\right) \\
& C_{2}^{*}=\min \left(k_{2} R_{2}\left(\vec{Z}_{2}, \xi, \psi\right)\right)
\end{aligned}
$$

Equations (4.12) and (4.13) imply that there exists a set of unit optimum independent variable vectors $\vec{Z}_{1}^{*}$ and $\vec{Z}_{2}^{*}$ that satisfy

$$
C_{1}^{*}=k_{1} R_{1}\left(\vec{Z}_{1}^{*}, \xi, \psi\right)
$$

and $C_{2}^{*}=k_{2} R_{2}\left(\vec{Z}_{2}^{*}, \xi, \psi\right)$

for each set of values $\xi$ and $\psi$ of the coupling functions $u_{12}$ and $u_{21}$. Graphically this is shown in Fig. 4.3 where each local or unit optimum of the local objectives $C_{1}$ and $C_{2}$ are plotted as a function of the coupling functions $u_{12}$ and $u_{21}$. In fact, every point of $C_{1}^{*}$ and $C_{2}^{*}$ versus $u_{12}$ and $u_{21}$ represents a local or unit optimum. When these two surfaces (unit-level ORSs) are combined, they form what is called the system-level Optimum Response Surface (system-level ORS) ${ }^{5}$ for the system as a whole (see Fig. 4.3). The system-level ORS defines the global or system-level problem given by

\footnotetext{
${ }^{5}$ For a system with more than two coupling functions, the ORS is in fact a hyper-surface.
} 

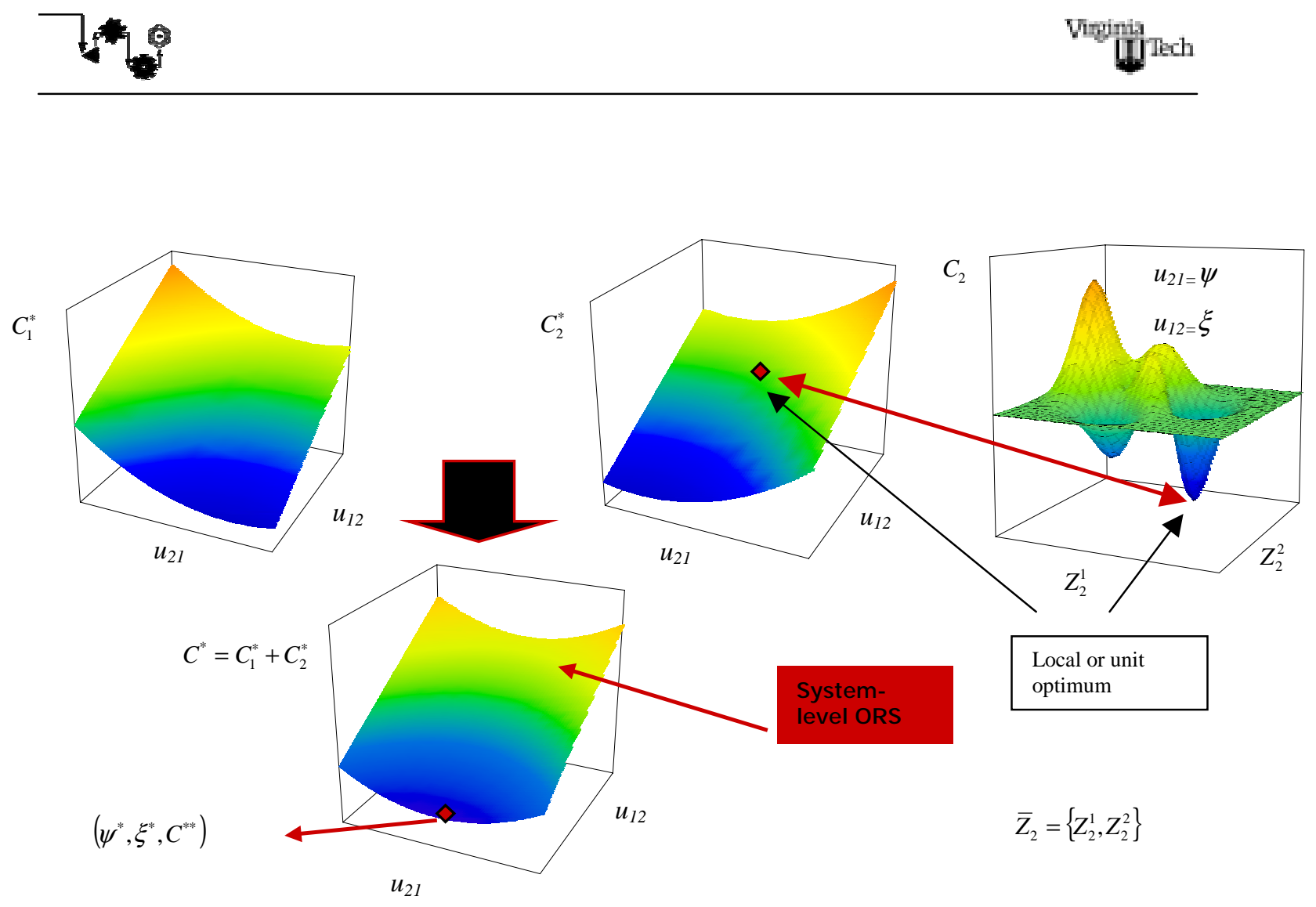

Figure 4. 3: Local (unit) and global (system) optimizations.

Minimize $C^{*}=k_{1} R_{1}(\xi, \psi)+k_{2} R_{2}(\xi, \psi)$

w.r.t. $\xi, \psi$

subject to

$$
\vec{G}=\left[\begin{array}{c}
\xi-u_{12 \max } \\
-\xi+u_{12 \min } \\
\psi-u_{21 \max } \\
-\psi+u_{21 \min }
\end{array}\right] \leq \overrightarrow{0}
$$

This system-level optimization problem consists of finding the optimum values of the coupling functions that minimize the global or system-level objective. At the systemlevel, the independent variable vectors $\vec{Z}_{1}$ and $\vec{Z}_{2}$ of each unit do not appear. This is 


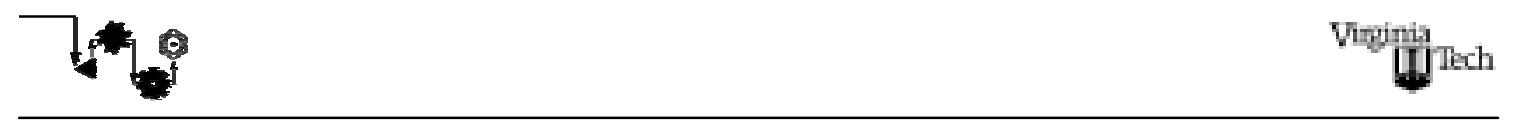

because of the assumption made earlier that there are a unique set of local or unit optimum values $\vec{Z}_{1}^{*}$ and $\vec{Z}_{2}^{*}$ for every combination of $\xi$ and $\psi$.

The LGO technique has the advantage of breaking a large problem into smaller sub-problems that can be solved simultaneously. The drawback is the computational burden that this approach has for large, complex systems since each sub-problem must be solved independently many times in order to generate the ORS. This is further compounded by the need for heuristic algorithms to deal with a mix of real and integer variables in the optimization and by the use of computationally expensive (unit) analyzers. To circumvent these drawbacks Muñoz and von Spakovsky (2000 a,b,c,d; 2001 a,b) develpoped the Iterative Local-Global Optimization (ILGO) approach. There are two complementary versions of this approach: ILGO-A and ILGO-B. Both are presented in the following sections. However, before proceeding, the algorithm for LGO is summarized as follows:

1- Identify the independent variable vectors $\left(\vec{Z}_{1}\right.$ and $\left.\vec{Z}_{2}\right)$ and the coupling functions $\left(u_{12}\right.$ and $\left.u_{21}\right)$.

2- Define and solve the unit-level optimization problems (Problems (4.10) and (4.11)) for different values of $\xi$ and $\psi$ of the coupling functions $u_{12}$ and $u_{21}$ and find a set of local or unit optimum values $\vec{Z}_{1}^{*}$ and $\vec{Z}_{2}^{*}$ for every combination of $\xi$ and $\psi$.

3- Define and solve the system-level optimization problem (Problem (4.16)).

\subsection{Iterative Local-Global Optimization (ILGO) Approach.}

In addition to not having the drawbacks outlined in the previous section for LGO, the ILGO decomposition strategy makes possible the decentralized, integrated synthesis/design optimization of systems by allowing multiple platforms and software tools as well as geographically dispersed and discipline diverse teams of engineers to effectively interact both at the unit (local) and the system (global) levels. This 


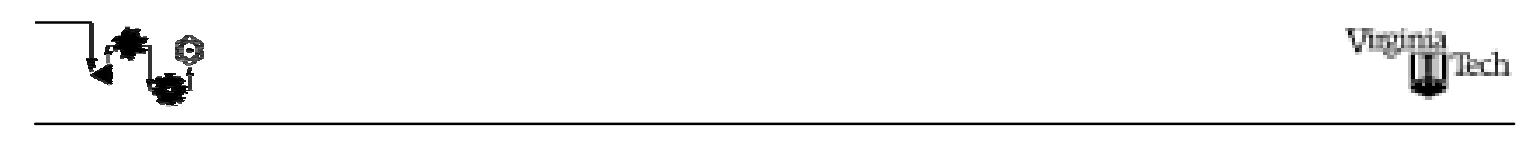

decomposition approach is an advance over other decomposition approaches in the literature (i.e. LGO) in that it

- eliminates the nested optimizations required in standard local-global decomposition approaches;

- uses an intelligent search based on shadow prices to effectively search the system-level Optimum Response Surface(s) - ORS(s) without having to actually generate the $\operatorname{ORS}(\mathrm{s})$;

- assures consistency between all local objectives and the system-level objective;

- introduces no constraint inconsistencies from one sub-problem to another;

- is conducive to the parallelization of the various sub-problem optimizations.

In the following sections, two variations of the ILGO approach (ILGO-A and ILGO-B) are presented. Even though as with the LGO approach the presentation is only given for a two unit system, both approaches are completely general and applicable to any multiple unit system. In addition, they are applicable whether or not a system is hierarchical $^{6}$ or non-hierarchical.

\subsubsection{Version A of the Iterative Local-Global Optimization (ILGO-A) Approach .}

Version A of the Iterative Local-Global Optimization (ILGO-A) approach simplifies the process of LGO by eliminating the need to create the ORSs. In particular, for the twounit system of Fig. 4.2, the same two sub-problems as before (Problems (4.12) and (4.13)) are solved for particular values $\xi_{o}$ and $\psi_{o}$ of the coupling functions $u_{12}$ and $u_{21}$, i.e.

\footnotetext{
${ }^{6}$ Hierarchical, all the components flow from a principal component.
} 


70

\section{Sub-problem 1:}

$\operatorname{Minimize} C_{1}=k_{1} R_{1}\left(\vec{Z}_{1}, \xi_{o}, \psi_{o}\right)$

w.r.t. $\vec{Z}_{1}$

subject to $\vec{h}_{1}=\overrightarrow{0}$

$$
\vec{g}_{1} \leq \overrightarrow{0}
$$

\section{Sub-problem 2:}

Minimize $C_{2}=k_{2} R_{2}\left(\vec{Z}_{2}, \xi_{o}, \psi_{o}\right)$

w.r.t. $\vec{Z}_{2}$

subject to $\vec{h}_{2}=\overrightarrow{0}$

$$
\vec{g}_{2} \leq \overrightarrow{0}
$$

The optimization progresses by selecting a new combination of values $\xi$ and $\psi$ for the coupling functions that guarantees an improved restricted optimum system-level solution $^{7}$. This selection is done intelligently by studying the local behavior of the system-level ORS. The process is guided by the partial derivatives of the local or unit objective functions with respect to a set of values for the coupling functions. For example, an initial set of values $\xi_{o}$ and $\psi_{o}$ are selected for Problems (4.17) and (4.18). The resulting restricted values for the optimum solutions are $\left(C_{1}^{*}\right)_{o}$ and $\left(C_{2}^{*}\right)_{o}$ with corresponding independent variable vectors $\left(\vec{Z}_{1}^{*}\right)_{o}$ and $\left(\vec{Z}_{2}^{*}\right)_{o}$. At this point, only one point of the system-level ORS is known. In order to find the next, a first order Taylor series expansion of each of the restricted optimum solutions is performed. The terms in

\footnotetext{
${ }^{7}$ The term 'restricted' refers to the fact that even though each point on the system-level ORS represents a system-level optimum constructed from a set of local or unit optimums, each point as an optimum is restricted to a given set of values $\xi$ and $\psi$ of the coupling functions. Of course the set of restricted system-level optimums contains the global optimum sought.
} 
these expansions are, thus, linear with small deviations $\Delta u_{12}$ and $\Delta u_{21}$ about $\xi_{o}$ and $\psi_{o}$. In equation form,

$$
\begin{gathered}
C_{1}^{*}=\left(C_{1}^{*}\right)_{o}+\left(\frac{\partial C_{1}^{*}}{\partial u_{12}}\right)_{o} \Delta u_{12}+\left(\frac{\partial C_{1}^{*}}{\partial u_{21}}\right)_{o} \Delta u_{21} \\
C_{2}^{*}=\left(C_{2}^{*}\right)_{o}+\left(\frac{\partial C_{2}^{*}}{\partial u_{12}}\right)_{o} \Delta u_{12}+\left(\frac{\partial C_{2}^{*}}{\partial u_{21}}\right)_{o} \Delta u_{21}
\end{gathered}
$$
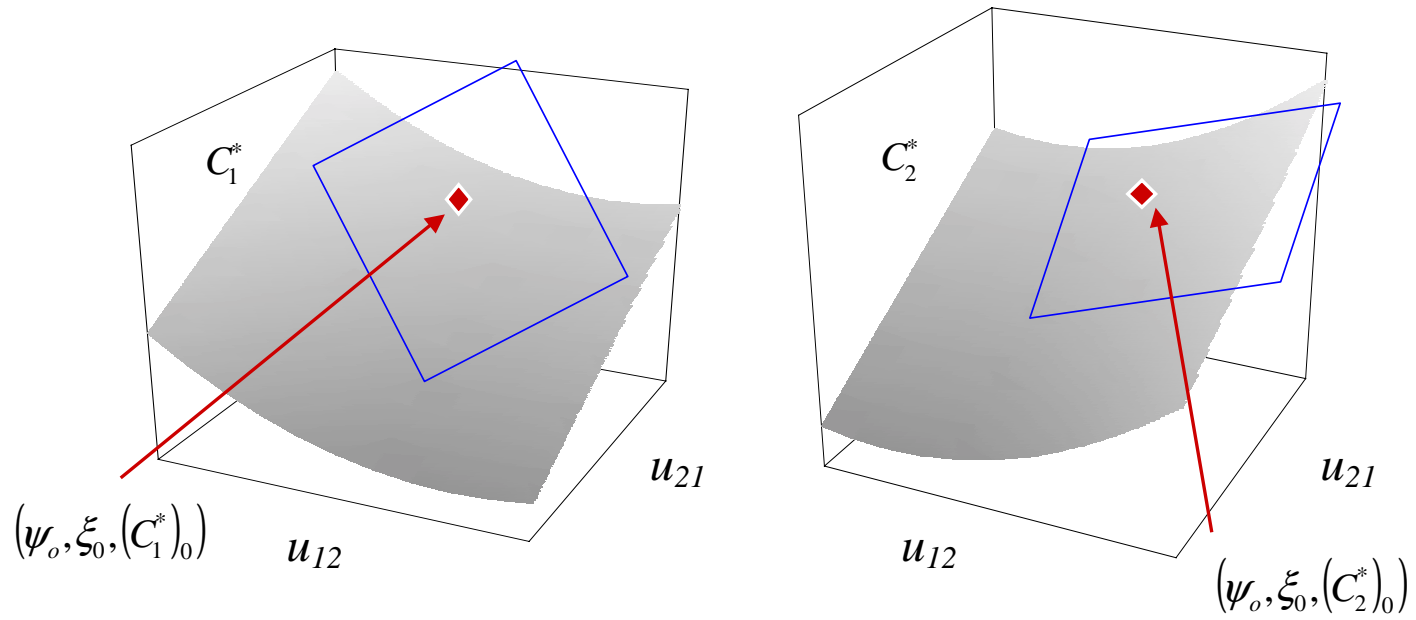

Figure 4. 4: Initial restricted unit or local optimum points used in the construction of the system-level ORS and in the Taylor series expansions about the point for unit 1 and that for unit 2.

As shown in Fig. 4.4 for unit one, partial derivatives, which are in fact "shadow prices" ${ }^{\prime \prime}$, are evaluated at the optimum value $C_{1}^{*}$ of the objective for sub-problem 1 based on the choice of $\xi_{o}$ and $\psi_{o}$ for $u_{12}$ and $u_{21}$, respectively. These partial derivatives or

\footnotetext{
8 "shadow prices" is a type of "marginal cost" since it represents the marginal cost associated with marginal changes in a unit or local objectives optimum value with respect to marginal changes in the value of an associated coupling function.
} 


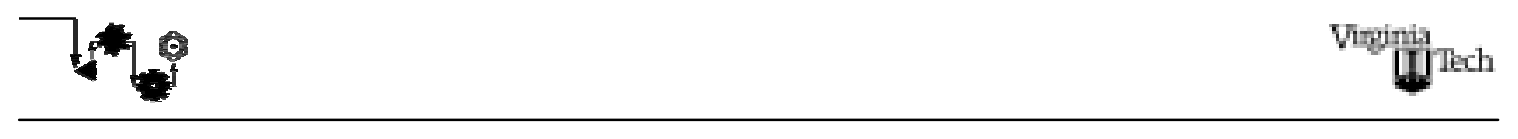

shadow prices are in fact the slopes of the surface shown in Fig. 4.4 in the $u_{12}$ and $u_{21}$ directions. Similarly, for sub-problem 2, a set of shadow prices, i.e. slopes, of the surface for unit 2 at $\xi_{o}$ and $\psi_{o}$ can be found.

Depending on the sign and absolute value of the partial derivatives or shadow prices for units 1 and 2, an improved restricted optimum value of the system-level objective given by

$$
C^{*}=\left(C_{1}^{*}\right)_{o}+\left(C_{2}^{*}\right)_{o}+\left(\frac{\partial C_{2}^{*}}{\partial u_{12}}+\frac{\partial C_{1}^{*}}{\partial u_{12}}\right)_{o} \Delta u_{12}+\left(\frac{\partial C_{2}^{*}}{\partial u_{21}}+\frac{\partial C_{1}^{*}}{\partial u_{21}}\right)_{o} \Delta u_{21}
$$

can be obtained by changing the values of the coupling functions in the directions and with the magnitudes indicated by the shadow prices. Equation (4.21) is obviously a construction of the restricted optimum local objectives, Eqs (4.19) and (4.20), and furthermore represents the restricted system-level optimum point which appears on the ORS for the system-level optimization given in Fig. 4.5. Thus, an iterative procedure called ILGO-A is established where by starting with random values of the coupling functions, new values for these functions $\left(\xi_{o}\right.$ and $\left.\psi_{o}\right)$ are selected based on the slopes. ILGO-A, therefore, moves intelligently using the shadow prices towards global systemlevel optimum without having to actually create the ORS in Fig. 4.5 or any of the local

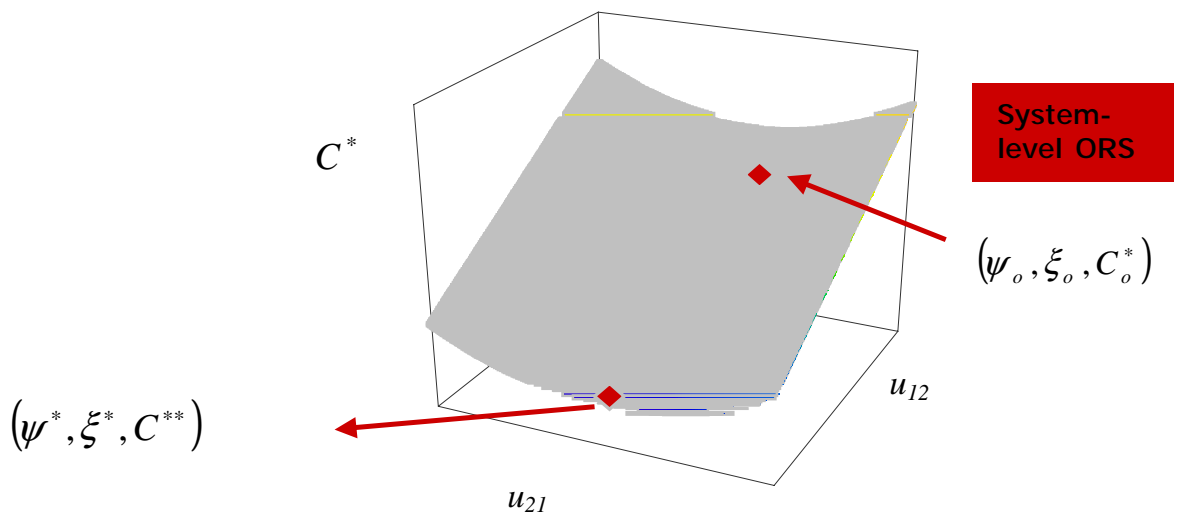

Figure 4. 5: The restricted system-level optimum point on the system-level ORS for the initial values $\xi_{o}$ and $\psi_{o}$. 


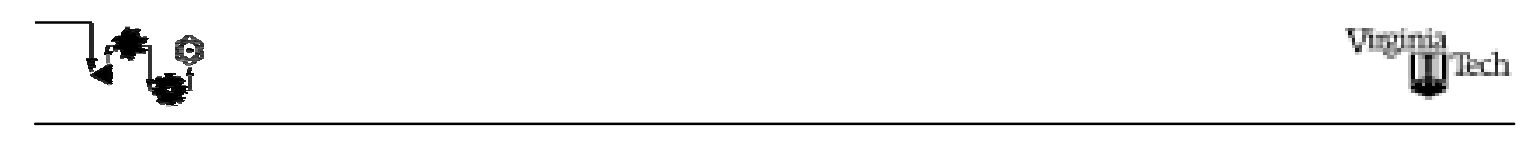

surfaces shown in Fig. 4.4. This and the fact that no nested optimizations of local within the global are required prove to be major advantages of ILGO-A over LGO.

\subsubsection{Version B of the Iterative Local-Global Optimization (ILGO-B)}

The feasibility of the ILGO-A approach presented in the previous section is based on the existence of a set of vectors $\vec{Z}_{1}^{*}$ and $\vec{Z}_{2}^{*}$ for each set of values $\xi$ and $\psi$ that minimize equations (4.17) and (4.18) and satisfy the unit constraints. However, this assumption, that every combination of $\xi$ and $\psi$ leads to a feasible solution, may not be warranted for some systems. In fact, it is possible that the ILGO-A approach may point towards simultaneous increases in $u_{12}$ and $u_{21}$, which due to the characteristics of the units is not physically possible. For such cases, Muñoz and von Spakovsky (2000 a,b,c,d; 2001 a,b) propose an alternative version of ILGO-A called ILGO-B. The latter redefines the local or unit objectives so that each sub-problem is formulated as follows:

\section{Sub-problem $1^{9}$ :}

Minimize $C_{1}^{\prime}=C_{1}+\left(C_{2}^{*}\right)_{o}+\left(\frac{\partial C_{2}^{*}}{\partial u_{12}}\right)_{o} \Delta u_{12}{ }^{(1)}+\left(\frac{\partial C_{2}^{*}}{\partial u_{21}}\right)_{o} \Delta u_{21}{ }^{(1)}$

w.r.t. $\vec{Z}_{1}$ and subject to the same constraints as in problem (4.17)

\section{Sub-problem 2:}

$$
\text { Minimize } C_{2}^{\prime}=C_{2}+\left(C_{1}^{*}\right)_{o}+\left(\frac{\partial C_{1}^{*}}{\partial u_{12}}\right)_{o} \Delta u_{12}^{(2)}+\left(\frac{\partial C_{1}^{*}}{\partial u_{21}}\right)_{o} \Delta u_{21}{ }^{(2)}
$$

w.r.t. $\vec{Z}_{2}$ and subject to the same constraints as in problem (4.18). Variations in the coupling functions are given by

\footnotetext{
${ }^{9}$ Note that this problem is the minimization of cost in unit 1 plus the projected change in cost in the rest of the system (in this case, unit 2) as a consequence of the variation of the local independent variables.
} 


$$
\begin{gathered}
\Delta u_{12}=\frac{\partial u_{12}}{\partial \vec{Z}_{1}} \Delta \vec{Z}_{1}+\frac{\partial u_{12}}{\partial \vec{Z}_{2}} \Delta \vec{Z}_{2}=\sum_{i=1}^{n} \frac{\partial u_{12}}{\partial Z_{i 1}} \Delta Z_{i 1}+\sum_{i=1}^{m} \frac{\partial u_{12}}{\partial Z_{i 2}} \Delta Z_{i 2} \\
\Delta u_{21}=\frac{\partial u_{21}}{\partial \vec{Z}_{1}} \Delta \vec{Z}_{1}+\frac{\partial u_{21}}{\partial \vec{Z}_{2}} \Delta \vec{Z}_{2}=\sum_{i=1}^{n} \frac{\partial u_{21}}{\partial Z_{i 1}} \Delta Z_{i 1}+\sum_{i=1}^{m} \frac{\partial u_{21}}{\partial Z_{i 2}} \Delta Z_{i 2}
\end{gathered}
$$

Note that in Eqs. (4.22) and (4.23), the superscripts (1) and (2) indicate the fact that the variations in the coupling functions given by Eqs. (4.24) and (4.25) are caused by changes in the unit or local independent variables specific to the unit being optimized, i.e. $\vec{Z}_{1}$ for unit 1 and $\vec{Z}_{2}$ for unit 2. Thus, $\Delta u_{12}{ }^{(1)}$, for example, is that part of $\Delta u_{12}$ pertaining to changes in $u_{12}$ due to $\vec{Z}_{1}$. It is important to note that sub-problems $(4.22)$ and (4.23) are not strictly speaking local problems because they include part of the objective functions of other units. The above sub-problems, however, have the advantage that only values of the independent variables close to $\left(\vec{Z}_{1}^{*}\right)_{o}$ and $\left(\vec{Z}_{2}^{*}\right)_{o}$, which lead to feasible solutions, are allowed to participate in the optimization, thus, circumventing the physically infeasible solutions which the ILGO-A approach could produce in its search for the global optimum.

The algorithm for versions A and B of the ILGO approach as given in Muñoz and von Spakovsky (2000 a,b,c,d; 2001 a,b) is as follows:

1- Obtain an initial point of the optimum response surface with $u_{i j}$ and $u_{j i}$ equal to $\xi_{o}$ and $\psi_{o}$ by solving the optimization sub-problems (ILGO-A and -B).

2- Calculate the partial derivatives (shadow prices) of the restricted optimum values of the local objective functions $C_{1}^{*}$ and $C_{2}^{*}$ with respect to $\xi$ and $\psi$ (ILGO-A and -B).

3- For ILGO-A, update the values of $\xi$ and $\psi$ based on

$$
\left(\xi_{o}\right)_{n e w}=\left(\xi_{o}\right)_{\text {old }}-\alpha\left(\frac{\partial C_{i}^{*}}{\partial \xi}\right)_{o}
$$




\section{$\frac{\left(\psi_{o}\right)_{\text {new }}=\left(\psi_{o}\right)_{\text {old }}-\alpha\left(\frac{\partial C_{i}^{*}}{\partial \psi}\right)_{o}}{}$}

where the partial derivatives of the Eqs. (4.26) and (4.27) are selected in order to decrease the total system-level objective (Eq. (4.21)).

For ILGO-B, estimate the maximum allowable values of $\Delta \mathrm{u}_{\mathrm{ij}}$ and $\Delta \mathrm{u}_{\mathrm{ji}}{ }^{10}$. If no information is available, assume that the partial derivatives are constant over most of the optimum response surface.

4- For ILGO-A, once the value of the coupling functions have been updated, steps 1 through 3 are repeated until no improvement in the unit optimizations is achieved or until the coupling functions have reached the minimum allowable values.

For ILGO-B, the unit-based system optimization Problems (4.22) and (4.23) are defined and solved subject to the additional constraint that the values of the increment have to be constrained by a maximum.

5- Finally, for ILGO-B, the solutions from the previous step are used to update $\left(\vec{Z}_{1}^{*}\right)_{o},\left(\vec{Z}_{2}^{*}\right)_{o}$ and $\xi_{o}$ and $\psi_{o}$. Repeat the procedure until no improvement is achieved or until the coupling functions have reached the minimum allowable values.

\footnotetext{
${ }^{10}$ Note that the values of the coupling function could be limited by physical constraints within the system.
} 


7.0

\subsection{Optimization Strategy}

In this chapter, the LGO synthesis/design optimization strategy outlined in the previous chapter is applied to the fuel cell sub-system of Fig. 2.8. This application as well as the coupled off-design procedure are explained in detail. Both physical and time decomposition are used for this application.

\subsection{Definition of the Synthesis/Design Optimization Problem Using Time Decomposition}

As indicated in Chapter 2, the load/environmental profiles of Fig. 2.1 and 2.2 are simplified into the four time segments for winter and summer given in Table 2.1. These time segments are characterized by particular electric and heat load conditions (see Table 2.1) as well as the environmental conditions given in Table 5.1 below.

Table 5. 1: Environmental conditions used in the modeling, simulation, and optimization of the PEM fuel cell sub-system.

\begin{tabular}{|l|c|c|}
\hline \multicolumn{1}{|c|}{ Load conditions } & $\begin{array}{c}\text { Atmospheric } \\
\text { Pressure (Pa) }\end{array}$ & $\begin{array}{c}\text { Atmospheric } \\
\text { Temperature }\left({ }^{\circ} \mathbf{C}\right)\end{array}$ \\
\hline Summer peak electric load condition & 101325 & 25 \\
\hline Winter peak head load condition & 101325 & 5 \\
\hline Summer off-peak electric load condition & 101325 & 25 \\
\hline Winter off-peak head load condition & 101325 & 5 \\
\hline
\end{tabular}




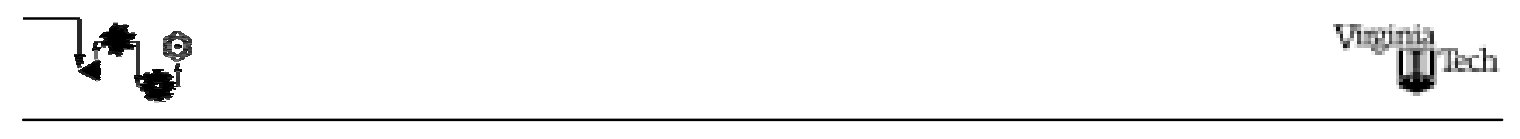

From these four time segments, one was selected for determining the set of best (including the global optimum) feasible synthesis/design solutions which are then further evaluated optimally with respect to the other time segments in order to determine the final optimal synthesis/design solution. The particular load/environmental values of this so-called synthesis/design time segment are used to define the synthesis/design optimization problem. As was explained in Chapter 4, the criterium used in order to choose the synthesis/design point (time segment) is the one with the most stringent electrical load conditions, since the principal product of the fuel cell sub-system is electricity and not heat. The most stringent or demanding time segment is, thus, the peak electric load condition for summer. Synthesizing and designing with respect to this load condition guaranties that all electrical loads over the entire environmental/load profile will be met by the fuel cell sub-system. Therefore, in the context of the time decomposition, the system-level synthesis/design optimization problem for the fuel cell sub-system configuration given in Fig. 2.8 is defined with respect to the summer peak load condition, i.e.

Minimize $C_{\text {design }}=\left(k_{\text {fuel }} \dot{R}_{\text {fuel }}\right) \tau+C_{S S}+C_{F P S}$

w.r.t $\vec{X}_{\text {design }}$

subject to

$$
\begin{aligned}
& {[\vec{H}]_{\text {design }}=\overrightarrow{0}} \\
& \mid \vec{G}]_{\text {design }} \leq \overrightarrow{0}
\end{aligned}
$$

where $C_{\text {design }}$ is the synthesis/design total cost which consists of three components. The first is the cost of the fuel (methane) given by the cost of methane per unit volume of fuel, $k_{f u e l}$; the volumetric flow rate of fuel consumed, $\dot{R}_{\text {fuel }} ;$ and the length of time of all time segments, $\tau$. The second component of the total cost is $C_{S S}$ which is the capital cost of the stack sub-system (SS) while the third component, $C_{F P S}$, is the capital cost of the fuel processing sub-system (FPS). The total cost or objective function is minimized with respect to the set of independent variables $\vec{X}_{\text {design }}$ for the synthesis/design problem. This 


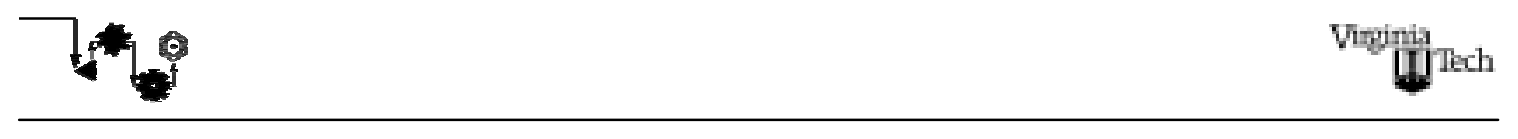

problem is subject to a set of equality and inequality constraints (Eqs. (5.1.1) and (5.1.2)) represented by the various thermodynamic and cost models presented earlier as well as by any physical limitations imposed on the fuel cell sub-system.

Once a set of "best" feasible synthesis/design solutions are determined for Problem (5.1), off-design conditions are taken into account by optimizing this set of 'best' solutions over the remaining environmental/load profile. This off-design or operational optimization problem is defined as follows:

$$
\begin{aligned}
& \text { Minimize } C_{\text {oper }}=\sum_{j}\left(k_{\text {fuel }} \dot{R}_{\text {fuel }}-k_{\text {sale }} \dot{E}_{\text {sale }}\right)_{j} \Delta t_{j} \\
& \text { w.r.t } \vec{Y}_{\text {oper }} \\
& \text { subject to }
\end{aligned}
$$

$$
\begin{aligned}
& {[\vec{H}]_{\text {oper }}=\overrightarrow{0}} \\
& {[\vec{G}]_{\text {oper }} \leq \overrightarrow{0}} \\
& \vec{X}^{\bullet}-\vec{X}_{\text {design }}=\overrightarrow{0}
\end{aligned}
$$

where $C_{o p e r}$ is the operational cost over the off-design conditions $(j=$ summer off-peak, winter peak, winter off-peak). For every time segment $\left(\Delta t_{j}\right)$, there are two contributions to the objective function. The first is the cost of the methane consumed during the time segment. The second is the possibility of selling electricity $\dot{E}_{\text {sale }}$ to the grid at a particular unit price $k_{\text {sale }}$. The problem is subject to the equality and inequality constraints Eqs. (5.2.1) and (5.2.2) imposed by the thermodynamic models for off-design, An additional constraint to the problem is the fact that solutions to the synthesis/design problem (Problem (5.1)) fix the values of the synthesis/design variables $\vec{X}_{d e s i g n}$. Constraint Eq. (5.2.3) ensures that these variables are held constant during the off-design optimization.

Once solutions are found to Problems (5.1) and (5.2), the optimal solution emerges as the minimum of the total cost given by 


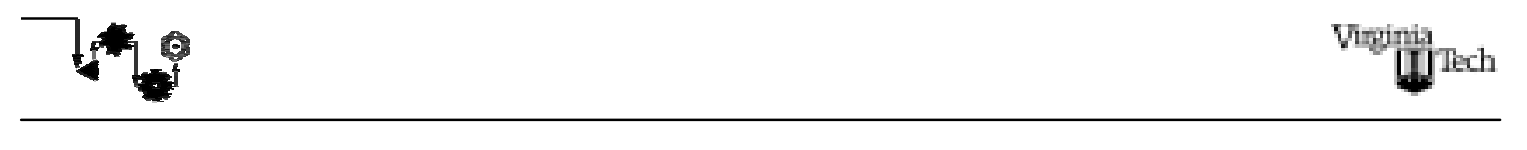

$C_{T}=C_{\text {design }}^{\prime}+C_{\text {oper }}$

where $C_{\text {design }}^{\prime}=\left(k_{\text {fuel }} \dot{R}_{\text {fuel }}\right) \Delta t_{\text {design }}+C_{S S}+C_{F P S}$

In the following sections, the synthesis/design optimization problem (Problem (5.1)) as well as the operational or off-design optimization problem (Problem (5.2)) for the fuel cell sub-system are explained in detail in the context of physical decomposition using the LGO approach described in Chapter 4.

\subsection{Synthesis/Design Optimization Problem Using Physical Decomposition}

\subsubsection{Physical (Unit) Decomposition of the Fuel Cell Sub-system}

In order to simplify the synthesis/design optimization problem, the fuel cell subsystem is decomposed into four major sub-systems, i.e.

- $\quad$ stack sub-system (SS)

- fuel processing sub-system (FPS)

- $\quad$ thermal management sub-system (TMS)

- $\quad$ load management sub-system (LMS).

As indicated in Chapter 2, for purposes of this thesis work, the synthesis/design optimization problem for the fuel cell sub-system will be solved taking into account only the detailed modeling and simulation of the SS and the FPS. The decomposition of the fuel cell sub-system into two major units leads to a decomposition of the fuel cell subsystem synthesis/design optimization problem (Problem (5.1)) into two smaller optimization problems. This process is detailed in section 4.3 (see Eqs. (4.8), (4.9), and (4.10)). In order to define these optimization sub-problems, the independent variables of the major sub-systems (the SS and the FPS) must be identified, as must the coupling functions that connect both sub-systems. The variables chosen as independent variables for the sub-systems as well as the coupling functions are listed in Table 5.2. In Table 5.3 


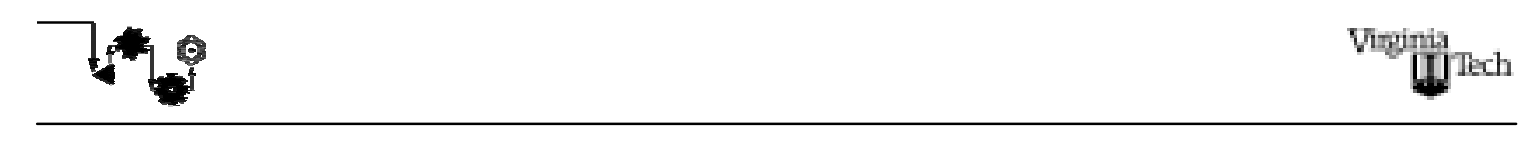

the parameters held constant during optimization are listed. A description of the coupling functions is as follows:

- Rate of hydrogen produced by the FPS $\left(\dot{n}_{\mathrm{H}_{2}}\right)$ : The hydrogen consumed in the SS must be produced in the FPS (no hydrogen storage is considered in the configuration shown in Fig. 2.8). Therefore, the flow rate of hydrogen couples both sub-systems since the value of this parameter must be consistent when both sub-systems are simulated independently.

- Power required by the FPS $\left(\dot{E}_{f p s}\right)$ : The power consumed in order to operate the FPS (electric power consumed by the compressors) must be provided by the fuel cell stack in the SS. Thus, the power required by the FPS couples both sub-systems since the fuel cell stack gross power must be sufficient for powering the SS plus the external load demand as well as the FPS.

- Pressure of operation of the stack $\left(P_{\text {stack }}\right)$ : The pressure at which the hydrogen exits the FPS and the pressure at which the air enters the stack in the SS must equal the operational pressure of the stack. This is an important constraint since the anode and cathode pressure of each cell must be equal or exhibit only a limited pressure difference ${ }^{1}$.

\footnotetext{
${ }^{1}$ Normal forces applied to the membrane due to pressure differences between anode and cathode can cause structural failure of the membranes.
} 


$70^{\circ}$

Table 5. 2: Independent and coupling function variables for the PEM fuel cell subsystem.

\begin{tabular}{|c|c|c|}
\hline $\begin{array}{c}\vec{X}_{d e s i g n}^{F P S} \\
\text { (7 independent variables) }\end{array}$ & $\begin{array}{c}\vec{X}_{d e s i g n}^{\text {COUPING }} \\
\text { (3 coupling functions) }\end{array}$ & $\begin{array}{c}\vec{X}_{d e s i g n}^{S S} \\
\text { (1 independent variable) }\end{array}$ \\
\hline $\begin{array}{c}\mathrm{r}_{\mathrm{H} 2 \mathrm{O} / \mathrm{CH} 4:} \text { Moles of methane to } \\
\text { moles of steam }\end{array}$ & $\begin{array}{r}\dot{n}_{H_{2}}: \begin{array}{c}\text { Rate of hydrogen } \\
\text { produced by the FPS }\end{array}\end{array}$ & $\mathrm{A}_{\mathrm{act}}$ : Active area. \\
\hline $\begin{array}{l}\mathrm{T}_{\text {steam: }} \text { Temperature of the steam } \\
\text { at the exit of the steam } \\
\text { generator } \\
\mathrm{T}_{\text {PROX }} \text { : Temperature at the inlet } \\
\text { to the PROX reactor }\end{array}$ & $\begin{aligned} \dot{E}_{F P S}: & \text { Power required to } \\
& \text { operate the FPS } \\
\mathrm{P}_{\text {stack}}: & \begin{array}{l}\text { Pressure of operation } \\
\text { of the stack }\end{array}\end{aligned}$ & \\
\hline $\begin{array}{l}\mathrm{T}_{\mathrm{LTS}} \text { : Temperature at the inlet to } \\
\text { the LTS reactor. }\end{array}$ & & \\
\hline $\begin{array}{l}\mathrm{T}_{\text {reformer: }} \text { : Temperature at the exit } \\
\text { of the steam reformer } \\
\text { reactor }\end{array}$ & & \\
\hline $\begin{array}{l}\mathrm{r}_{\mathrm{CH} 4}: \text { Fraction of the total } \\
\text { methane that enters the } \\
\text { combustion chamber }\end{array}$ & & \\
\hline $\begin{array}{l}\Delta \mathrm{T}_{\text {ref: }} \text { Temperature difference } \\
\text { on the reformate side in } \\
\text { the steam reformer } \\
\text { reactor. }\end{array}$ & & \\
\hline
\end{tabular}


Table 5. 3 Parameters held constant during the optimization of the fuel cell sub-system.

\begin{tabular}{|l|c|}
\hline \multicolumn{1}{|c|}{ Parameters } & Value \\
\hline Isentropic efficiency of the compressors & 0.7 \\
\hline Isentropic efficiency of the expanders & 0.85 \\
\hline Temperature entering the stack & $70{ }^{\circ} \mathrm{C}$ \\
\hline Temperature raise in the stack & $10^{\circ} \mathrm{C}$ \\
\hline Fuel utilization & $85 \%$ \\
\hline Ambient pressure & $101.325 \mathrm{kPa}$ \\
\hline Pressure drop in the HXs & $2 \%$ \\
\hline Efficiency water separators & $90 \%$ \\
\hline Stoichiometric ratio of hydrogen & 1.17 \\
\hline Stoichiometric ratio of oxygen & 2 \\
\hline
\end{tabular}

The physical decomposition approach used to establish the optimization subproblems corresponding to the independent variables groups listed in Table 5.2 is the LGO approach. The reason why this technique was used instead of the ILGO approach is due to the fact that the SS has a small enough number of variables (1 independent variable and 3 coupling functions) so that the local or unit-level optimum response surfaces (ORSs) can easily be generated. As it turned out, generation of the local or unitlevel ORSs for the SS resulted in quite a heavy computational burden due to the fact that the hyper-surface that defines the unit-level ORSs had to be repeated for the sensitivity study done on how the number of houses affects the optimal synthesis/design of the fuel cell sub-system. The number of houses considered was 1, 50 and 100 houses and the number of optimizations required to define the unit-level ORSs was about $450^{2}$. Using the ILGO approach would in hindsight have saved considerable computational time.

\footnotetext{
${ }^{2}$ The problem was solved for 30 optimum combinations of the rate of hydrogen produced and the power consumed for 5 different pressures and 3 different values of the number of houses. Thus, 450 different optimizations were required. Also, note that an additional impetus for using LGO was being able to visually depict the behavior of the unit-level ORSs and, therefore, provide further justification for the convergence assumptions made with ILGO.
} 


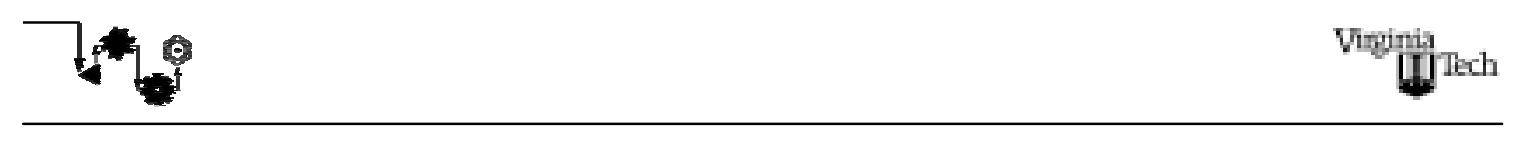

In order to formulate the unit-level objective function for each of the optimization sub-problems, the objective function of the system-level optimization (Problem (5.1)) is broken down into the sum of the contributions from each sub-system, namely,

$$
C_{\text {design }}=C_{\text {design }}^{S S}+C_{\text {design }}^{F P S}
$$

where the SS contribution is its capital cost, i.e.

$C_{\text {design }}^{S S}=C_{S S}$

and the FPS is the cost of the fuel plus its capital cost, i.e.

$$
C_{\text {design }}^{F P S}=\left(k_{\text {fuel }} \dot{R}_{\text {fuel }}\right) \tau+C_{F P S}
$$

The first optimization sub-problem resulting from this breakdown is that of minimizing the cost of the SS with respect to its independent variables (see Table 5.2), namely

Minimize $C_{\text {design }}^{S S}$

$$
\text { W.r.t } \quad \vec{X}_{\text {design }}^{S S}
$$

subject to a set of unit-level constraints for the SS as well as fixed values for the coupling functions. The result of this minimization is $C_{\text {design }}^{* S S}$ for given values of $\vec{X}_{\text {design }}^{\text {CoUPING }}$. The second optimization sub-problem is that of

Minimize $C_{d e s i g n}^{F P S}$

$$
\text { W.r.t } \quad \vec{X}_{\text {design }}^{F P S}
$$

subject to a set of unit-level constraints for the FPS as well as fixed values for the coupling functions. The result of this minimization is $C_{\text {design }}^{* F P S}$ for given values of $\vec{X}_{\text {design }}^{\text {COUPING }}$.

The system-level optimization problem now becomes

$$
\begin{gathered}
\text { Minimize } C_{\text {design }}=C_{\text {design }}^{* S S}+C_{\text {design }}^{* F P S} \\
\text { w.r.t } \quad \vec{X}_{\text {design }}^{\text {COUPLING }}
\end{gathered}
$$

subject to a set of system-level constraints.

The classical LGO approach to solve these two sub-problems as well as the systemlevel problem (Problem (5.9)) is executed in three distinct steps: 
1- Solve the SS optimization sub-problem (Problem (5.7)).

2- Solve the FPS optimization sub-problem (Problem (5.8)).

3- Solve the system-level problem (Problem (5.9)) if steps 1 and 2 have been solved multiple times in order to create the local-level $\mathrm{ORSs}^{3}$ used at the system-level or iterate the system-level problem looping back to steps 1 and 2 after each iteration until a solution to the system-level problem is found ${ }^{4}$.

In this thesis work, the three-step procedure above is collapsed for convenience into a two-step procedure by combining steps 2 and 3 .

What follows are details of the problem definitions for the SS unit-level optimization problem (Problem (5.7)) and the combined FPS unit-level/system-level optimization problem (Problems (5.8) and (5.9)).

\subsubsection{Optimization of the Stack Sub-system (SS)}

The definition of the SS unit-level optimization problem (Problem (5.7)) is as follows:

Minimize $C_{\text {design }}^{S S}=\alpha C_{\text {stack }}\left(A_{a c t}, \dot{n}_{H_{2}}, \dot{E}_{F P S}, P_{\text {stack }}\right)$

w.r.t $A_{\text {act }}$

subject to

$$
\begin{gathered}
\vec{h}_{S S}=\overrightarrow{0} \\
{\left[\begin{array}{l}
\dot{n}_{H_{2}}-\xi=0 \\
\dot{E}_{F P S}-\phi=0 \\
P_{\text {stack }}-\psi=0
\end{array}\right]} \\
\vec{g}_{S S} \leq \overrightarrow{0}
\end{gathered}
$$

\footnotetext{
${ }^{3}$ In Muñoz and von Spakovsky (2001a), the authors refer to this approach as Off-line LGO.

${ }^{4}$ In Muñoz and von Spakovsky (2001a), the authors refer to this approach as Real-time LGO.
} 
where $C_{d e s i g n}^{S S}$ is the total cost of the SS. This cost is assumed to be the capital cost of the fuel cell stack itself plus the capital cost of all the other components in the SS. There are no resource costs since no resources are required for the SS from outside the fuel cell sub-system. It is furthermore assumed for purposes of simplification and for the reason that in the present thesis work details of the designs of the other more conventional components in the SS are not of primary interest that the capital cost of these components represents a cost equal to $30 \%$ of the capital investment for the fuel cell stack. Thus, the proportionality constant $\alpha$ appearing in Eq. (5.10) is set to 1.3.

The equality constraints (Eq. (5.10.1)) represent the set of equations appearing in Chapter 3 and Appendix A which comprise the thermodynamic model for the SS. Equations (5.10.3) represent physical constraints or limits such as those placed on the active area $A_{\text {act }}$ which is allowed to vary from 0.04 to $0.06 \mathrm{~cm}^{2}$ per cell, while Eqs. (5.10.2) provide the coupling function values for each solution of Problem (5.10). These values depend on a number of factors including the number of houses for which the SS is being optimized. As will be shown in Chapter 6, the synthesis/design optimization of the fuel cell sub-system is carried out for three different values of the number of houses (1, 50 and 100). The applicable ranges on coupling function values for the SS for different values of the number of houses are summarized in Table 5.4. The optimization problem is solved for several combinations of coupling function values that fall within the limits defined in Table 5.4. The result of this process are three hyper-surfaces, one per the number of houses. The hyper-surface, mathematically and graphically represented by 
Table 5. 4: Limits on coupling function values as a function of the number of houses.

\begin{tabular}{|c|c|c|c|c|c|c|}
\hline Number of houses & \multicolumn{2}{|c|}{1} & \multicolumn{2}{c|}{50} & \multicolumn{2}{c|}{100} \\
\hline Limits & Lower & Upper & Lower & Upper & Lower & Upper \\
\hline $\begin{array}{c}\text { Rate of hydrogen production } \\
\left(\dot{n}_{H_{2}}\right), \mathrm{kmol} / \mathrm{hr}\end{array}$ & 0.09 & 0.24 & 4.55 & 12 & 9 & 23.8 \\
\hline $\begin{array}{c}\text { Power required by the FPS } \\
\left(\dot{E}_{F P S}\right), k W\end{array}$ & 0.06 & 1 & 5 & 50 & 7 & 100 \\
\hline Stack pressure $\left(P_{\text {stack }}\right), k P a$ & 200 & 400 & 200 & 400 & 200 & 400 \\
\hline
\end{tabular}

Eqs. (4.14) or (4.15) and Fig. 4.3, has for this particular application four dimensions, i.e. cost and the three coupling functions. This hyper-surface or unit-level ORS contains all the information necessary for optimizing at the system-level requiring no further evaluations or optimizations of the SS. Every point on the hyper-surface is formally expressed as

$C_{\text {design }}^{* S S}=\alpha C_{\text {stack }}\left(A A^{*}, \dot{n}_{\mathrm{H}_{2}}, \dot{E}_{F P S}, P_{\text {stack }}\right)$

where the superscript "*" in Eq. (5.11) indicates that the objective function of the SS has been optimized with respect to the variable $A_{a c t}$ for many values of the coupling functions $\dot{n}_{\mathrm{H}_{2}}, \dot{E}_{F P S}$, and $P_{\text {stack }}$. Graphical representations of the three hyper-surfaces for different number of houses will be shown in Chapter 6 and Appendix B. An example of the shape of these surfaces in 3D is shown in Fig. 5.1. The surface is for a fixed stack pressure of $200 \mathrm{kPa}$ and 50 houses. Clearly, an overall unit-level optimum at fixed pressure can be seen for low power and medium hydrogen production.

Now, in order to solve this problem and all of the optimization problems, a commercial optimization package iSIGHT (2000) was used. This software provides a number of different algorithms from gradient based methods such as generalized reduced gradient, sequential quadratic programming, etc. to heuristic based methods such as simulated annealing, genetic algorithms, etc. The latter are more advantages even though more computationally intensity when optimizing with a large number of degrees of 
freedom and when the solution space is highly non-linear and/or a mix of discrete and continuous decision variables are employed. In the case of the Problem (5.7) with its single degree of freedom, a gradient based method sufficed and was, therefore, used.

Once the unit-level optimizations for the SS are concluded and all the unit-level ORSs generated, all the information needed to solve the combined FPS unit-level/systemlevel optimization problem is at hand. Details of this final optimization process are explained in the following section.

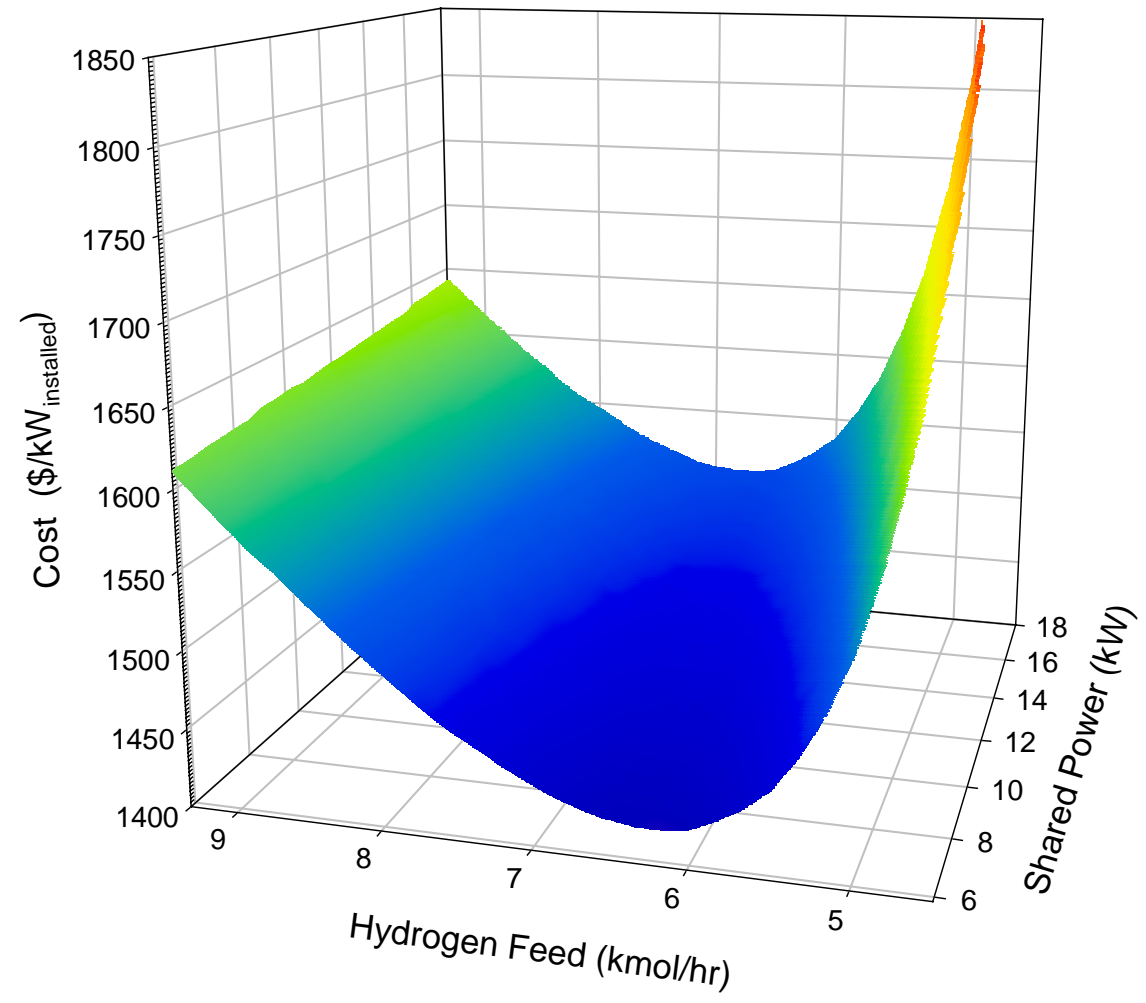

Figure 5. 1: Optimum Response Surface for the SS at $200 \mathrm{kPa}$ and for 50 houses. 


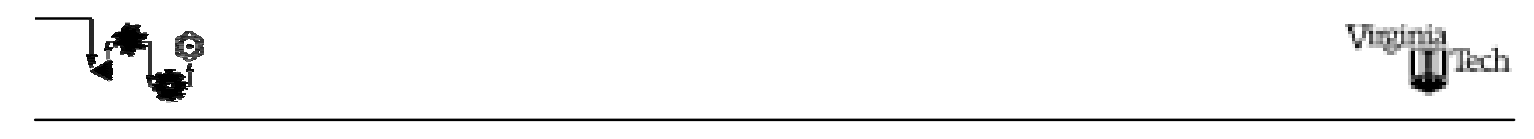

\subsubsection{Combined FPS Unit-level/System-level Optimization}

The combined FPS unit-level/system-level optimization problem is defined as

Minimize $C_{\text {design }}=C_{\text {design }}^{* S S}+\left(k_{\text {fuel }} \dot{R}_{\text {fuel }}\right) \tau+\beta C_{F P S_{\text {line }}}$

W.r.t $r_{\mathrm{H}_{2} \mathrm{O} / \mathrm{CH}_{4}}, T_{\text {steam }}, T_{P R O X}, T_{L T S}, T_{\text {reformer }}, n_{\mathrm{CH}_{4}}, r_{\mathrm{CH}_{4}}, r_{\text {air }}, \Delta T_{\text {ref }}, P_{\text {stack }}$

subject to

$$
\begin{gathered}
\vec{h}_{F P S}=\overrightarrow{0} \\
\vec{g}_{F P S} \leq \overrightarrow{0}
\end{gathered}
$$

where $C_{\text {design }}$ is the total synthesis/design cost for the fuel cell sub-system and where $n_{\mathrm{CH}_{4}}$ (total amount of $\mathrm{CH}_{4}$ entering the fuel cell sub-system) and $r_{\text {air }}$ (ratio of air in the combustion chamber to the reformate in the steam reformer) have been substituted for $\dot{n}_{H_{2}}$ and $\dot{E}_{F P S}$ as independent variables or degrees of freedom since in combining the FPS unit-level optimization with that for the system, the former variables turn out to be more convenient for the simulations. The total cost (Eq.(5.12)) consists of three terms to the right of the equals. The first, $C_{\text {design }}^{* S S}$, is the contribution of the optimized SS with respect to the coupling function variables. The second and third terms are the contributions of the FPS (see Eq (5.6)) to the total cost. It is assumed that the capital cost of the FPS, $C_{F P S}$, is proportional to the capital cost of the fuel processing line. The constant of proportionality $\beta$ accounts for the heat exchanger network used in the thermal management of this sub-system. As in the previous problem, the equality constraints, Eqs. (5.12.1), represent the thermodynamic model of the FPS discussed in Chapter 3 and in Appendix A. The inequality constraints, Eqs. (5.12.2), represent the set of physical constraints imposed on the system in order to ensure a feasible solution with every simulation. The latter are summarized in Tables 5.5 and 5.6.

As with Problem (5.10), iSIGHT is used to solve (5.12). However due to the significantly greater complexity of the latter, a heuristic method, i.e. a genetic algorithm (GA), is used in order to effectively deal with the local minima problems. The GA 


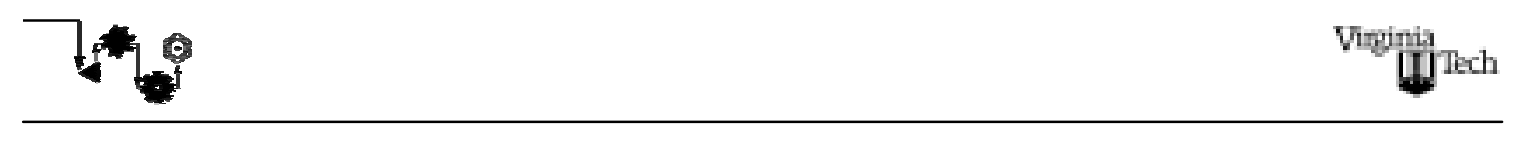

optimization runs utilize a population of 150 while the minimum number of iterations (generations) for the GA is set between 100 and 1000. Once the GA finds a solution close to the global optimum, a gradient-based method is used to refine this solution to the global optimum ${ }^{5}$.

Table 5. 5: Inequality constraints imposed in Problem (5.12) in order to guarantee a feasible solution.

\begin{tabular}{|l|c|}
\hline $\begin{array}{l}\text { - Pinch temperature difference in the heat exchanger prior to the PROX } \\
\text { reactor }\end{array}$ & $\geq 25^{\circ} \mathrm{C}$ \\
\hline $\begin{array}{l}\text { - Temperature difference between the reformate and the combustion } \\
\text { gases evaluated at the exit of the steam reformer reactor }\end{array}$ & $\geq 25^{\circ} \mathrm{C}$ \\
\hline - Pinch temperature difference in the steam generator & $\geq 25^{\circ} \mathrm{C}$ \\
\hline $\begin{array}{l}\text { - Pinch temperature difference in the heat exchanger between the HTS } \\
\text { and LTS reactors }\end{array}$ & $\geq 25^{\circ} \mathrm{C}$ \\
\hline $\begin{array}{l}\text { - Pinch temperature difference in the heat exchanger prior to the steam } \\
\text { reformer reactor }\end{array}$ & $\geq 25^{\circ} \mathrm{C}$ \\
\hline $\begin{array}{l}\text { - Temperature difference between the reformate and the combustion } \\
\text { gases evaluated at the exit of the steam reformer reactor. }\end{array}$ & $\geq 25^{\circ} \mathrm{C}$ \\
\hline $\begin{array}{l}\text { - Ratio between the hydrogen generated by the FPS and the minimum } \\
\text { amount of hydrogen required by the SS to satisfy the electric demand }\end{array}$ & $\geq 1$ \\
\hline
\end{tabular}

\footnotetext{
${ }^{5}$ Obviously, it is often times debatable in non-linear problems whether a global optimum has actually been found since a mathematical proof is either not practical or simply not available, Conclusions of globality, thus, rely on a physical understanding of the problem and of its solution space.
} 


$70^{\circ}$

Table 5. 6: Range of the independent variables of the FPS for which the system level optimization problem is evaluated ${ }^{6}$.

\begin{tabular}{|c|c|c|}
\hline $3 \leq$ & $r_{\mathrm{H}_{2} \mathrm{O} / \mathrm{CH}_{4}}$ & $\leq 6$ \\
\hline $350^{\circ} \mathrm{C} \leq$ & $T_{\text {steam }}$ & $\leq 600^{\circ} \mathrm{C}$ \\
\hline $150^{\circ} \mathrm{C} \leq$ & $T_{P R O X}$ & $\leq 200^{\circ} \mathrm{C}$ \\
\hline $200^{\circ} \mathrm{C} \leq$ & $T_{L T S}$ & $\leq 250^{\circ} \mathrm{C}$ \\
\hline $600^{\circ} \mathrm{C} \leq$ & $T_{\text {reformer }}$ & $\leq 900^{\circ} \mathrm{C}$ \\
\hline $0 \leq$ & $r_{C H_{4}}$ & $\leq 1$ \\
\hline $3 \leq$ & $r_{\text {air }}$ & $\leq 7$ \\
\hline $150^{\circ} \mathrm{C} \leq$ & $\Delta \mathrm{T}_{\text {ref }}$ & $\leq 300^{\circ} \mathrm{C}$ \\
\hline $0.0243 \mathrm{kmol} / \mathrm{hr} \leq$ & $\mathrm{n}_{\mathrm{CH} 4}(1$ house $)$ & $\leq 0.0645 \mathrm{kmol} / \mathrm{hr}$ \\
\hline $0.5 \mathrm{kmol} / \mathrm{hr} \leq$ & $\mathrm{n}_{\mathrm{CH} 4}(50$ house $)$ & $\leq 3 \mathrm{kmol} / \mathrm{hr}$ \\
\hline $2.3 \mathrm{kmol} / \mathrm{hr} \leq$ & $\mathrm{n}_{\mathrm{CH} 4}(100$ houses $)$ & $\leq 6.1 \mathrm{kmol} / \mathrm{hr}$ \\
\hline
\end{tabular}

Explanations of how GAs work abound in the literature. As explained in Charbonneau (2001), a GA starts by generating a set or population of trial solutions to the optimization problem by choosing random values for the independent variables. Then the following steps are executed:

1- The 'goodness' or fitness of each member of the population with respect to the objective of the optimization is evaluated.

2- Pairs of solutions ('parents') from the current population are selected with the probability of being selected made proportional to each solution's fitness.

3- Pairs of solutions are combined to breed or produce new solutions ${ }^{7}$.

\footnotetext{
${ }^{6}$ This range are set on the basis of classical values found in the literature for fuel cell sub-systems. Furthermore they comprise a wider range that allows to find every possible realistic combination of independent variables.
} 


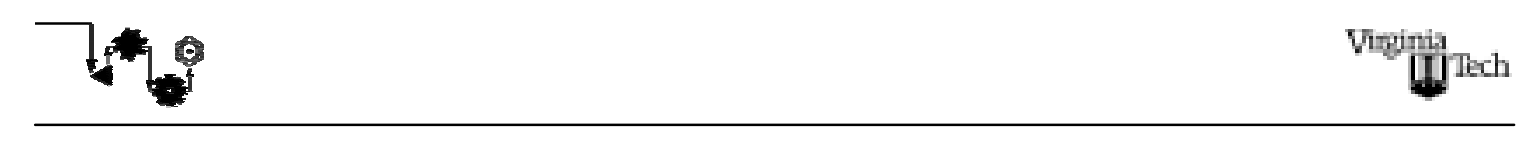

4- Steps 2 and 3 are repeated until the new population has the same members as the original population.

5- The new population replaces the old population.

6- Steps 1 to 5 are repeated until the criterion for stopping the process is achieved (i.e. the maximum number of iterations or generations has been reached or the GA has converged to the desired solution).

Finally, upon finding a solution to Problem (5.12), several sets of values for the independent variables for both sub-systems exists, one of which (i.e. the optimum synthesis/design) clearly minimizes the total cost of the fuel cell sub-system at the synthesis/design point while the others (i.e. the other most promising syntheses/designs) almost minimize this cost. With each set of values, one can, of course, associate a particular but not necessarily unique geometry ${ }^{8}$ for the principal components of the fuel cell sub-system. Once calculated, this geometry as well as the values of the independent variables are used to determine the optimum behavior of these promising syntheses/designs at off-design. The off-design optimizations provide additional information which helps in choosing between the various promising syntheses/designs. A discussion of the off-design optimizations is presented in the following section.

\subsection{Off-design Optimizations}

The off-design optimization problem given generally by Problem (5.2) is written in more specific terms as

\footnotetext{
${ }^{7}$ This step comprises the possible binary encoding of each solution (although there maybe benefits to dropping this part of the step), the crossover of the 'parents', the random mutation of solutions, and the decoding of the new population (again, this part may be by-passed). For more details, the reader is referred to Charbonneau (2001).

${ }^{8}$ The reason that one unique geometry does not exist in this case goes back to the fact that thermodynamic as opposed to geometric variables were used as independent variables. Obviously, if geometric variables had been used, a unique geometry would have resulted. Work along these lines is currently underway at Virgina Tech.
} 


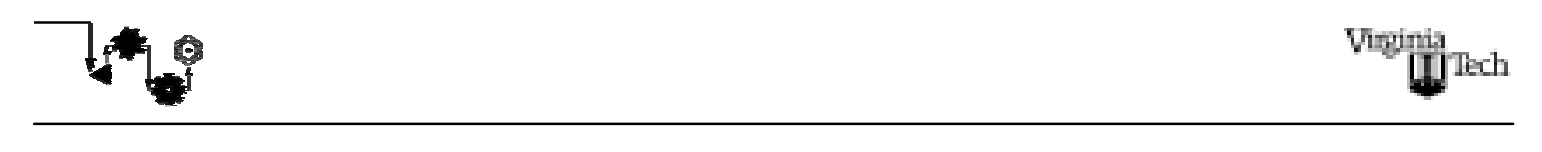

Minimize $C_{\text {oper }}=\sum_{j}\left(k_{\text {fuel }} \dot{R}_{\text {fuel }}-k_{\text {sale }} \dot{E}_{\text {sale }}\right)_{j} \Delta t_{j}$

w.r.t $\chi_{\text {air } j}, \chi_{\mathrm{CH}_{4 j}}, \chi_{\text {exhaust } j}, V_{\text {cell } j}, r_{\dot{m}_{\text {air } j}}, r_{\text {dist } j}, r_{\mathrm{H}_{2} \mathrm{O} / \mathrm{CH}_{4 j}}$

subject to

$$
\begin{aligned}
& {[\vec{H}]_{\text {oper }}=\overrightarrow{0}} \\
& {[\vec{G}]_{\text {oper }} \leq \overrightarrow{0}} \\
& \vec{X}^{*}-\vec{X}^{*}{ }_{\text {design }} \leq \overrightarrow{0}
\end{aligned}
$$

where as explained in section 5.1, Eqs. (5.13.3) ensure that certain independent/dependent variable values determined by the synthesis/design optimization remain fixed. These variables are summarized in Table 5.7. A description of the operational variables used to minimize the objective (Eq.(5.13)) as well as a range of values for each appear in Table 5.8.

Once a solution of Problem (5.13) is found for each of the optimum or nearoptimum solutions of Problem (5.12), the optimal solution for the synthesis/design of the fuel cell sub-system emerges as outlined at the end of section 5.1. Any changes to this solution depend on increasing the degree of fidelity of the thermodynamic and cost models so that a larger number of degrees of freedom reflecting the increased detail can be employed. Work along these lines is currently under way as part of another masters thesis in which significant improvements primarily to the cost and thermodynamic/kinetic models of the FPS are being made. This on-going work will also couple an absorption heat pump sub-system with the fuel cell sub-system to see what effects the additional sub-system has on the optimal synthesis/design of the fuel cell sub-system. 


7.0

Table 5. 7: Independent/dependent synthesis/design variables held constant during the off-design optimization.

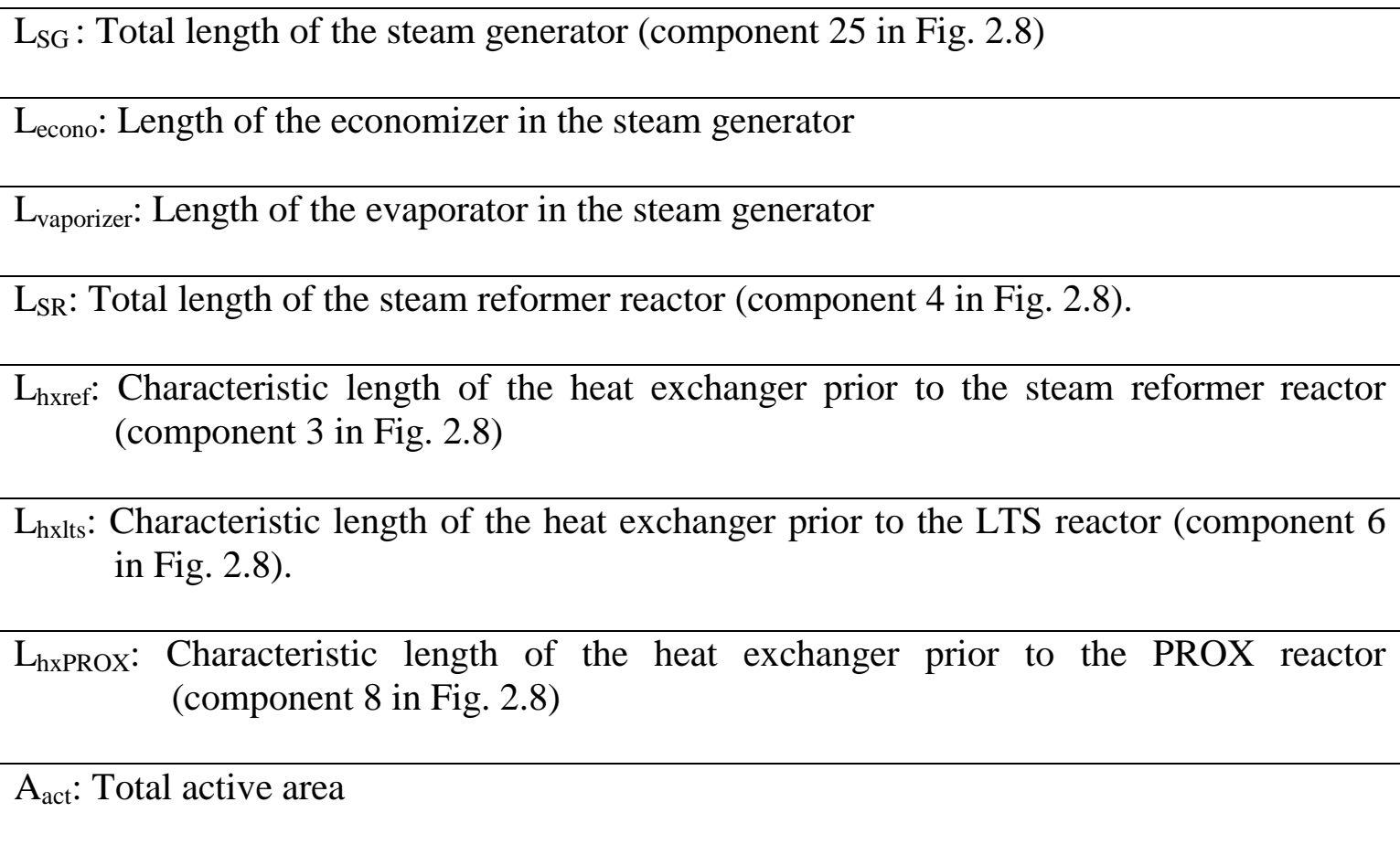


Table 5. 8: Description of the independent (operational) variables for the off-design.

\begin{tabular}{|c|c|}
\hline Variables & Range \\
\hline $\begin{array}{l}\chi_{\text {air: }} \text { Opening or closing of the valve in the air stream that } \\
\text { leads to the mixer prior to the combustion chamber (see } \\
\text { va3 in Fig. } 2.8 \text { ). }\end{array}$ & $\begin{array}{l}\text { Min.: } 0 \text { (valve closed) } \\
\text { Max.: } 1 \text { (valve wide open) }\end{array}$ \\
\hline $\begin{array}{l}\chi_{\mathrm{CH} 4} \text { : Opening or closing of the valve in the } \mathrm{CH}_{4} \text { stream that } \\
\text { leads to the mixer prior to the combustion chamber } \\
\text { (see va1 in Fig. } 2.8 \text { ); the methane that is not burned in } \\
\text { the combustion chamber is re-circulated }\end{array}$ & $\begin{array}{l}\text { Min.: } 0 \text { (valve closed) } \\
\text { Max.: } 1 \text { (valve wide open) }\end{array}$ \\
\hline $\begin{array}{l}\chi_{\text {exhaust }} \text { Opening or closing of the valve in the combustion } \\
\text { gas stream after the steam generator (see va2 in Fig. } \\
\text { 2.8); if the valve is close, all the combustion gases } \\
\text { pass through the heat exchanger (see component } 14 \\
\text { in Fig. } 2.8 \text { ); if the valve is wide open, all the } \\
\text { combustion gases pass directly through the } \\
\text { expander (see component } 22 \text { in Fig. } 2.8 \text { ) }\end{array}$ & $\begin{array}{l}\text { Min.: } 0 \text { (valve closed) } \\
\text { Max.: } 1 \text { (valve wide open) }\end{array}$ \\
\hline $\begin{array}{l}\mathrm{V}_{\text {cell }} \text { : Voltage per cell (volts) determined by the polarization } \\
\text { curve }\end{array}$ & $0.5 \leq \mathrm{V}_{\text {cell }} \leq 1$ \\
\hline $\begin{aligned} r_{\dot{m}_{a i r}}: & \text { Ratio between the corrected compressor mass flow } \\
& \text { rate at off-design and the corrected mass flow rate at } \\
& \text { design }\end{aligned}$ & $0.55 \leq r_{\dot{m}_{a i r}} \leq 1.2$ \\
\hline $\begin{array}{l}\mathrm{r}_{\mathrm{dist}}: \text { Variable that measures the distance between the ratio of } \\
\text { the pressure ratios at off-design and at design and the } \\
\text { surge line on the compressor map }\end{array}$ & $\begin{array}{l}\text { Min.: } 0(40 \% \text { of the design } \\
\text { pressure ratio) } \\
\text { Max: } 1(15 \% \text { of the surge } \\
\text { line) }\end{array}$ \\
\hline$r_{\mathrm{H}_{2} \mathrm{O} / \mathrm{CH}_{4}}$ : Moles of methane to moles of steam & $2 \leq r_{\mathrm{H}_{2} \mathrm{O} / \mathrm{CH}_{4}} \leq 6$ \\
\hline
\end{tabular}




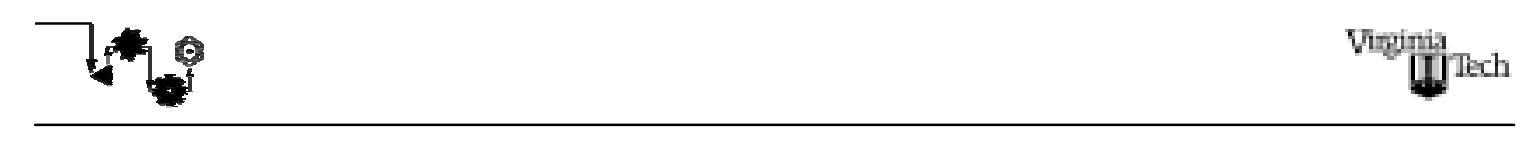

\subsection{Algorithm for the Optimization Procedure.}

This section describes the algorithm used for the optimization procedure described in sections 5.1, 5.2, and 5.3. It is as follows:

1- SS unit-level optimization problem (Problem (5.10)): Optimize the SS objective function with respect to the total active area $\left(\mathrm{A}_{\text {act }}\right)$ for different combinations of values of the coupling functions $\dot{n}_{H_{2}}, \dot{E}_{F P S}$, and $P_{\text {stack }}$, using a gradient based method, i.e. the method of feasible directions.

2- Construction of the unit-level ORSs with solutions from step 1.

3- Combined FPS unit-level/system-level optimization (Problem (5.12)): Optimize the objective function at the system-level with respect to $r_{\mathrm{H}_{2} \mathrm{O} / \mathrm{CH}_{4}}, T_{\text {steam }}, T_{P R O X}$, $n_{\mathrm{CH}_{4}}, r_{\mathrm{CH}_{4}}, r_{\text {air }}, \Delta T_{\text {ref }}$, and $P_{\text {stack }}$, using a genetic algorithm followed by a gradientbased method. Include the cost of the optimized SS (SS unit-level ORSs).

4- Identify the independent/dependent synthesis/design variables held constant during the off-design optimization ( $L_{S G}, L_{\text {econo }}, L_{\text {vaporizer }}, L_{S R}, L_{h x r e f}, L_{h x L T S}$, $L_{h x P R O X}, n_{\text {cell }}$, and $\left.A_{a c t}\right)$.

5- Optimize the operational cost with respect to $\chi_{\text {air }}, \chi_{\mathrm{CH}_{4}}, \chi_{\text {exhaust }}$, $V_{\text {cell }}, r_{\dot{m}_{\text {air }}}, r_{\text {dist }}, r_{\mathrm{H}_{2} \mathrm{O} / \mathrm{CH}_{4}}$ using a genetic algorithm followed by a gradient-based method (Problem (5.13)).

6- Calculate the total cost of the most promising designs over the entire environmental/load profile.

7- Identify the synthesis/design that minimizes the total cost of the configuration. 


Virginia Utech

\section{Results and Conclusions}

The results of the decomposed synthesis/design optimization of the fuel cell sub-system are presented in this chapter. These include a detailed description of the unit-level ORSs for the SS, a parametric study of influence of the number of residences on the optimal fuel cell sub-system synthesis/design, as well as the influence on this optimal synthesis/design of the number fuel cell subsystems manufactured per year. These results are then followed by a presentation of the thermodynamic and geometric details of the optimal synthesis/design as well as optimal off-design behavior.

\subsection{Results for the Unit-level Optimization of the SS}

Upon solving the unit-level optimization problem for the SS, Problem (5.10), a unit-level Optimum Response Surface (ORS) for each number of residences considered $(1,50$ and 100) was obtained. These unit-level ORSs are four dimensional hyper-surfaces and represent the cost of the SS $\left(C_{\text {design }}^{S S}\right)$ for a given number of residences at the synthesis/design point ${ }^{1}$ as a function of the coupling functions $\left(\dot{n}_{H_{2}}, \dot{E}_{F P S}\right.$, and $\left.P_{\text {stack }}\right)$. As an example, the hyper-surface for 50 residences is presented in Figs. 6.1a and 6.1b. Note that the hyper-surfaces obtained show a clear convex, smooth behavior. Provided that the unit-level ORSs for the FPS behave likewise, the system-level ORS will also exhibit, convex, and possible even linear behavior, so that finding the global optimum ${ }^{2}$ is likely with LGO and guaranteed with ILGO (Muñoz and Spakovsky 2000a,b,c,d; 2001a,b).

\footnotetext{
${ }^{1}$ At the synthesis/design point, the net electrical power output required per residence is $2.7 \mathrm{kWe}$ (see Table 2.1). Therefore fixing the number of residences fixes the net electrical power.

${ }^{2}$ Refer to footnote 5 in Chapter 5.
} 


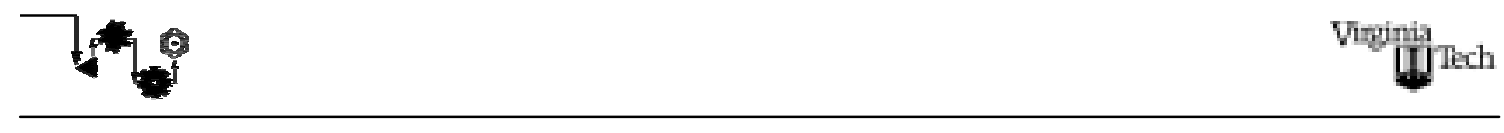

In order to understand the smooth, convex behavior of the unit-level ORSs, an analysis of the capital cost of the SS with respect to the different coupling 


$7 * 8$

Unit-level Optimum Response Surface (200000 Pa)

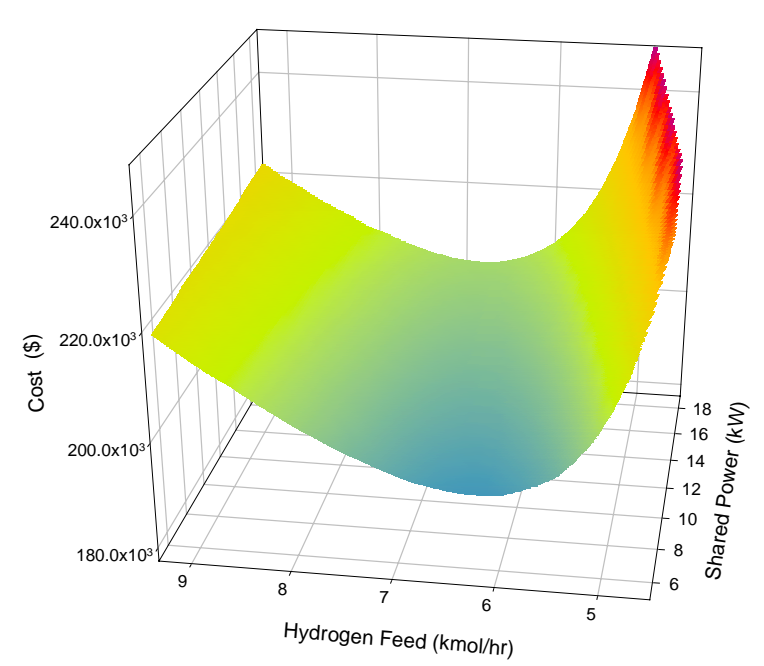

Unit-level Optimum Response Surface (250000 Pa)

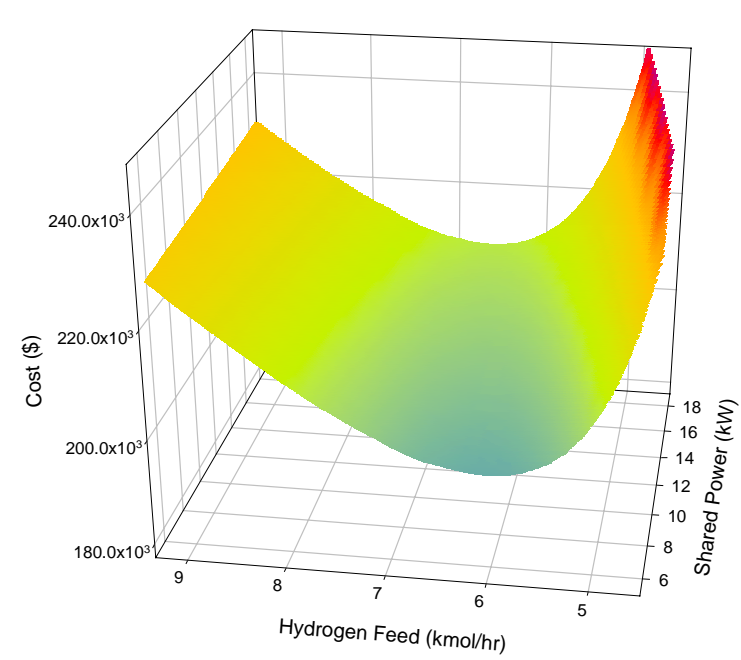

Unit-level Optimum Response System (300000 Pa)

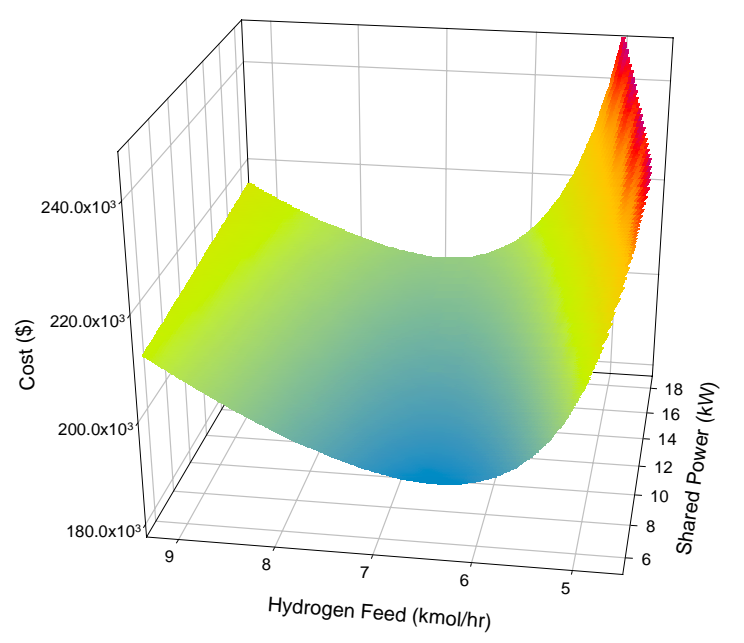

a) 


$7 * 0$

Unit-level Optimum Response Surface (400000 Pa)

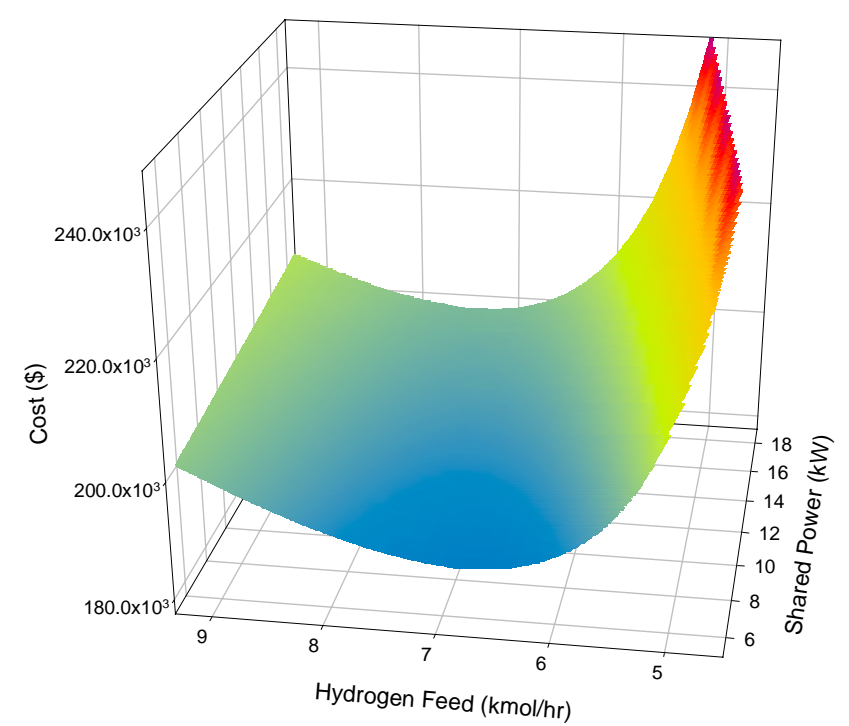

Unit-level Optimum Response Surface (350000 Pa)

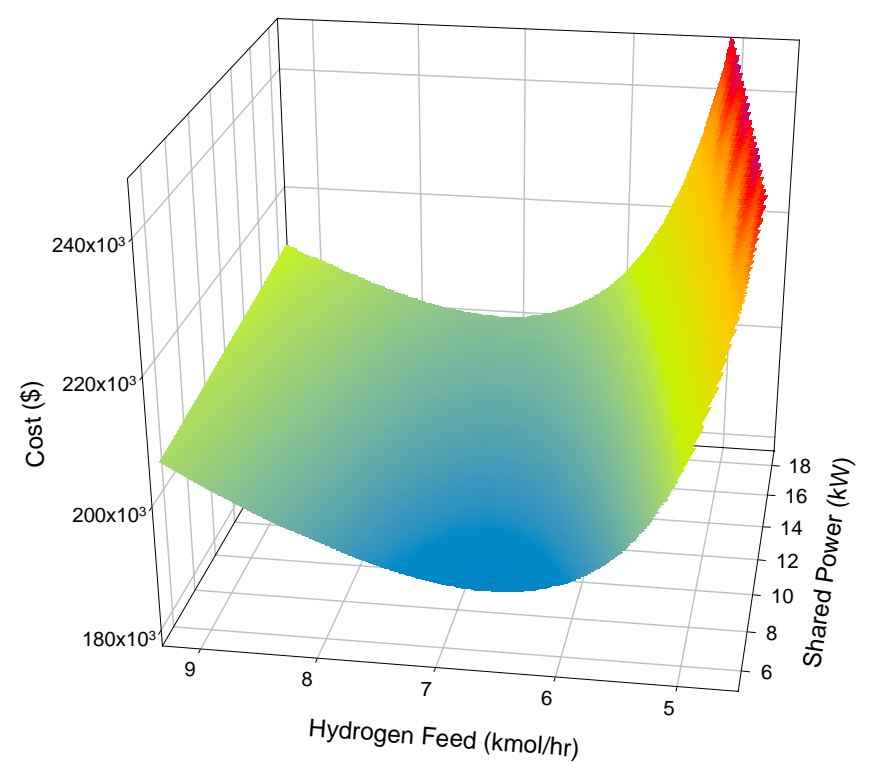

b)

Figure 6. 1: a) Unit-level ORSs for the SS at stack operating pressures of 200, 250 and $300 \mathrm{kPa}$. b) Unit-level ORSs for the SS at stack operating pressures of 350 and $400 \mathrm{kPa}$; In both cases the number of residences is set to 50 . 


$7 * 0$

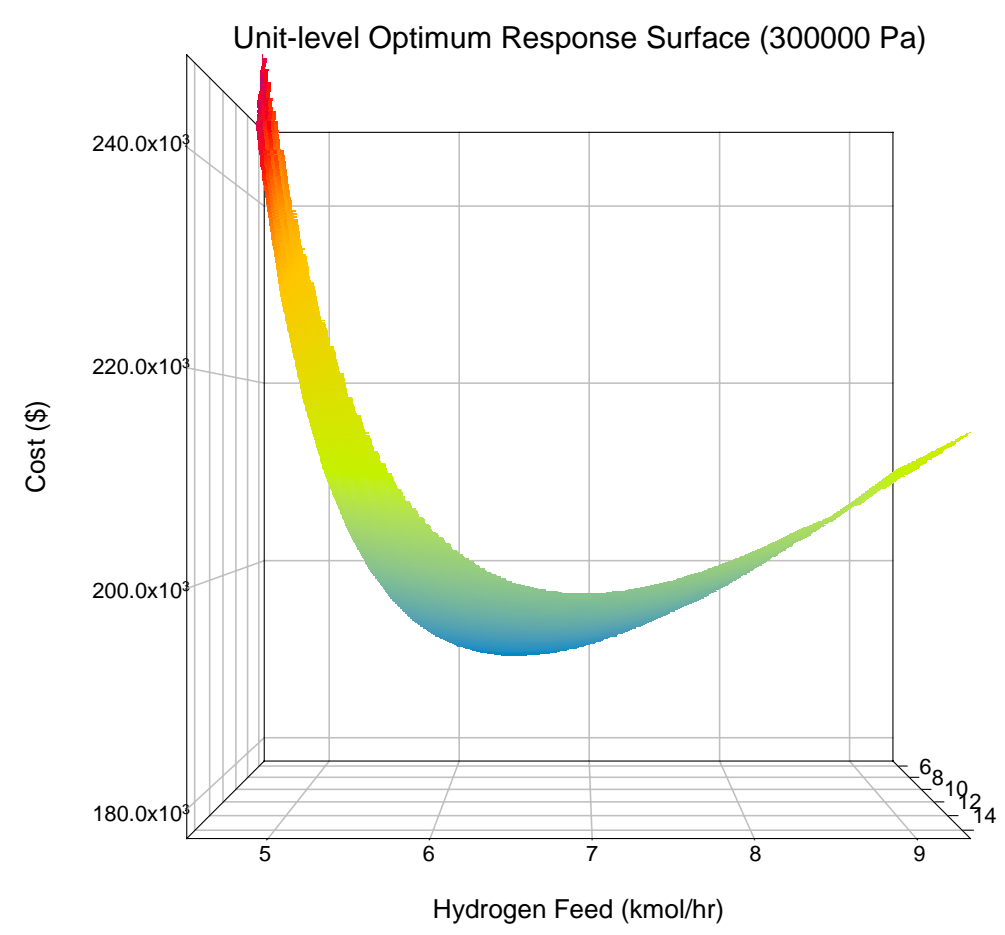

a)

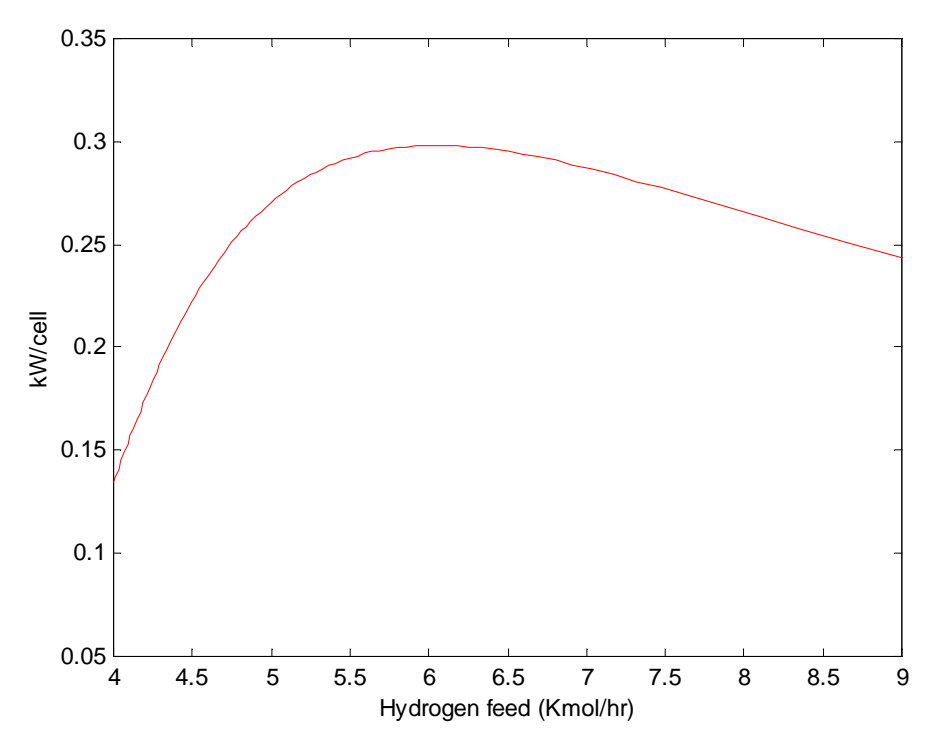

b)

Figure 6. 2: a) Frontal view of the unit-level ORS for the SS for 50 residences and at a stack pressure of $300 \mathrm{kPa}$; b) stack power density versus hydrogen feed for a gross power output of $149 \mathrm{kWe}$ and a stack pressure of $300 \mathrm{kPa}$. 


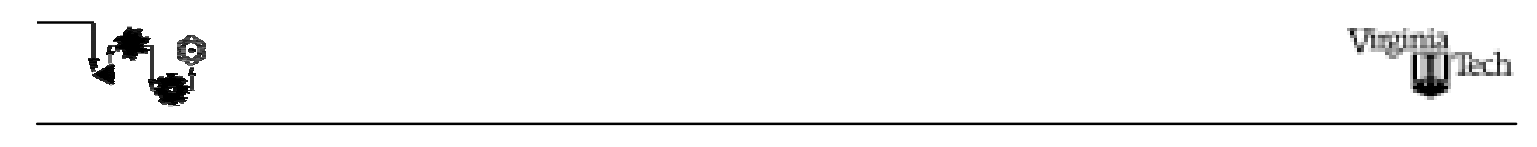

functions must be made. The first coupling function considered is the hydrogen consumed by the fuel cell stack. The variation of the cost of the SS with respect to this coupling function is shown in Fig. 6.2. Figure 6.2a is a frontal view (cost versus hydrogen feed) of the unit-level ORS at a stack pressure of $300 \mathrm{kPa}$ and 50 residences. Figure $6.2 \mathrm{~b}$ is plot of the power density versus the hydrogen that enters the stack for a given power produced in the stack (for 50 residences this is $149 \mathrm{kWe}^{3}$ of gross power output) and a fixed operating pressure $(300 \mathrm{kPa})$. Comparing both plots, one concludes that the highest cost regions of the unit-level ORS along the hydrogen axis correspond to operating points in the stack with the lowest power densities. That is to say, the unit-level ORS indicates that synthesizing/designing the stack for operation at low power densities requires a larger number of cells and therefore, a bigger and, more expensive stack for a given power output (in this case $149 \mathrm{kWe}$ ). As indicated in the discussions surrounding Problem (5.10), the SS cost is proportional to the fuel cell stack cost so that the behavior of this ORS can be explained in terms of the power density of the different operating points ${ }^{4}$. Note that the absolute minimum of all the minimum points on the unit-level ORS in Fig. 6.2 corresponds to the maximum power density at a given gross power and pressure.

The effect produced by another coupling function, the pressure of operation of the stack, on the unit-level ORSs can be explained in a fashion similar to that for the hydrogen feed. Increasing the pressure of operation results in an increasing power density for a given hydrogen feed, while at the same time the maximum power density is displaced to higher hydrogen consumptions. Those tendencies are graphically represented in Fig. 6.3 where the power density of the stack is plotted versus the hydrogen feed for a gross power of $149 \mathrm{kWe}$ and different operating pressures. This same tendency is

\footnotetext{
${ }^{3}$ Note that this gross power output corresponds to a parasitic power of $14 \mathrm{kWe}$ which includes the shared power $\dot{E}_{f p s} \approx(5.5 \mathrm{kWe})$ since for 50 residences the net power output required per residence is $2.7 \mathrm{kWe}$.

${ }^{4}$ The active area which is allowed to vary between $0.04 \mathrm{~m}^{2} /$ cell and $0.06 \mathrm{~m}^{2} /$ cell ( reasonable values according to the literature available), is found to have a unit-level optimum value of $0.06 \mathrm{~m}^{2} /$ cell for all the points on the unit-level ORSs given in Figs. 6.1 and 6.2, however is important to note that a different range for the active area might have change this result as the optimum is found at the upper boundary. This is the solution which results from solving Problem (5.10). The number of cells associated with each point on the ORSs varies, of course, depending on both the current density (i.e. hydrogen feed) and voltage per cell.
} 


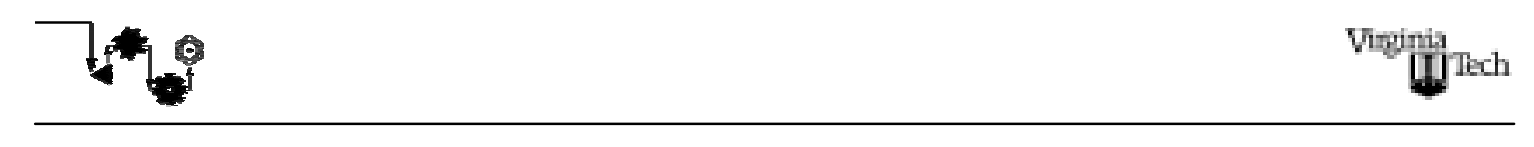

observed when the unit-level ORSs shown in Figure 6.1 are analyzed. For a given hydrogen feed, $\dot{n}_{H_{2}}$, and shared power, $\dot{E}_{f p s}$, the cost of the SS decreases as the pressure increases. Note as well that the absolute minimum of all the minimum costs on each of the unit-level ORSs is displaced to higher hydrogen consumptions when the pressure of operation increases. Therefore, the influence of two of the three coupling function, i.e. the hydrogen feed and the stack pressure of operation, on the total cost of the SS can be explained in terms of the power density of the stack.

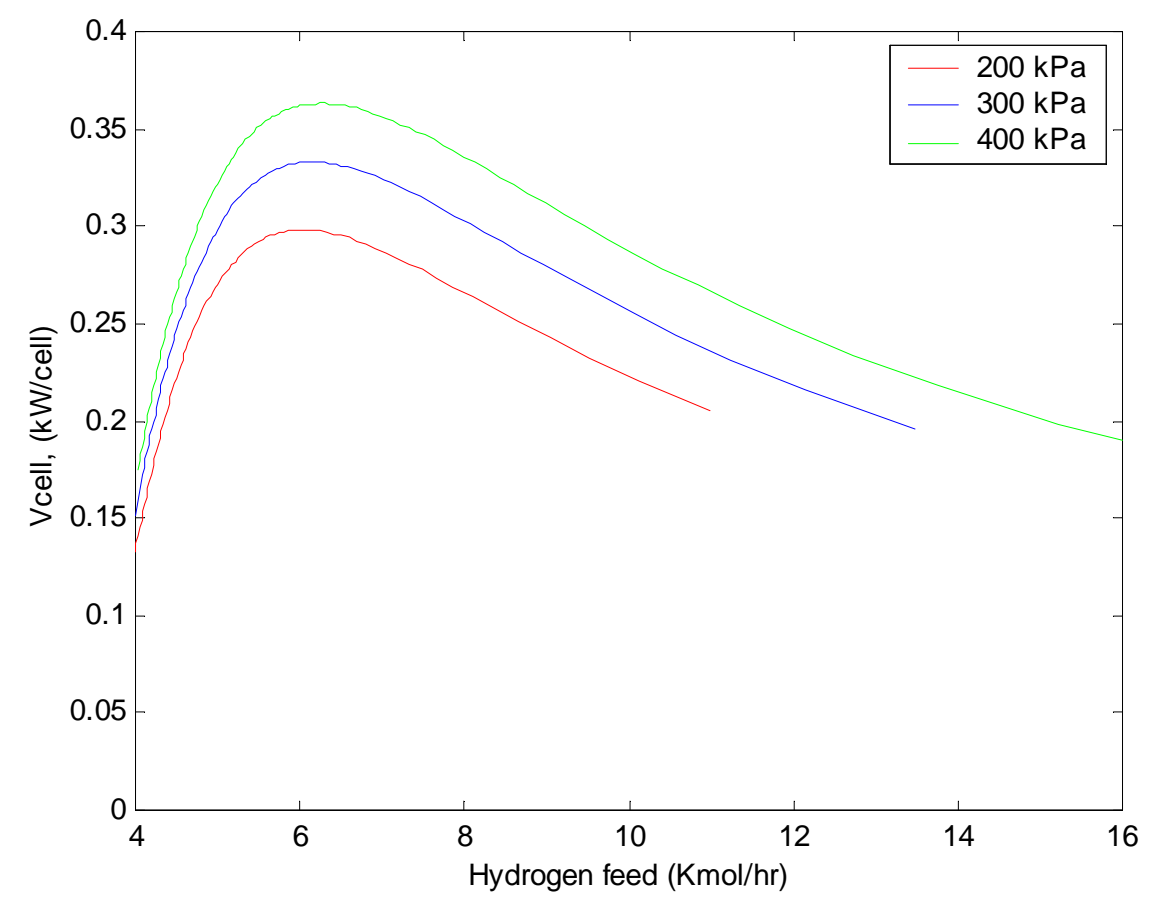

Figure 6. 3: Power density versus hydrogen feed for a gross power output of $149 \mathrm{kWe}$ and stack pressures of $200 \mathrm{kPa}, 300 \mathrm{kPa}$ and $400 \mathrm{kPa}$.

The influence of the third coupling function, i.e. the power required for running the FPS $\left(\dot{E}_{f p s}\right)$, has a predictable influence on the cost of the SS, namely, the larger the power required to run the FPS, the larger the gross power of the stack and, therefore, the larger and more expensive the capital cost of the stack and the SS. Thus, increasing the power required to run the FPS results in a general increment of the cost of the SS for 


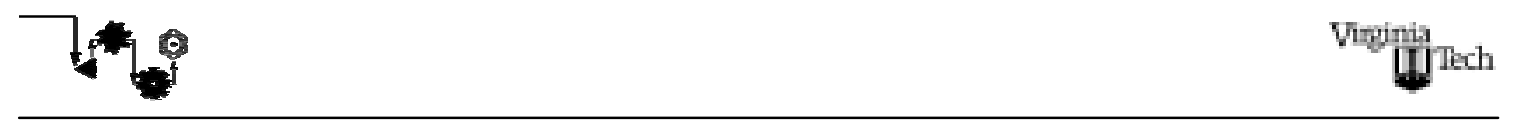

every value of the stack pressure and hydrogen feed. To illustrate this idea graphically, a lateral view of the unit-level ORS at $200 \mathrm{kPa}$ is shown for the SS in Fig. 6.4. This figure of cost versus shared power shows how increasing the shared power and, therefore, the total power output of the stack, results in increased cost for the SS.

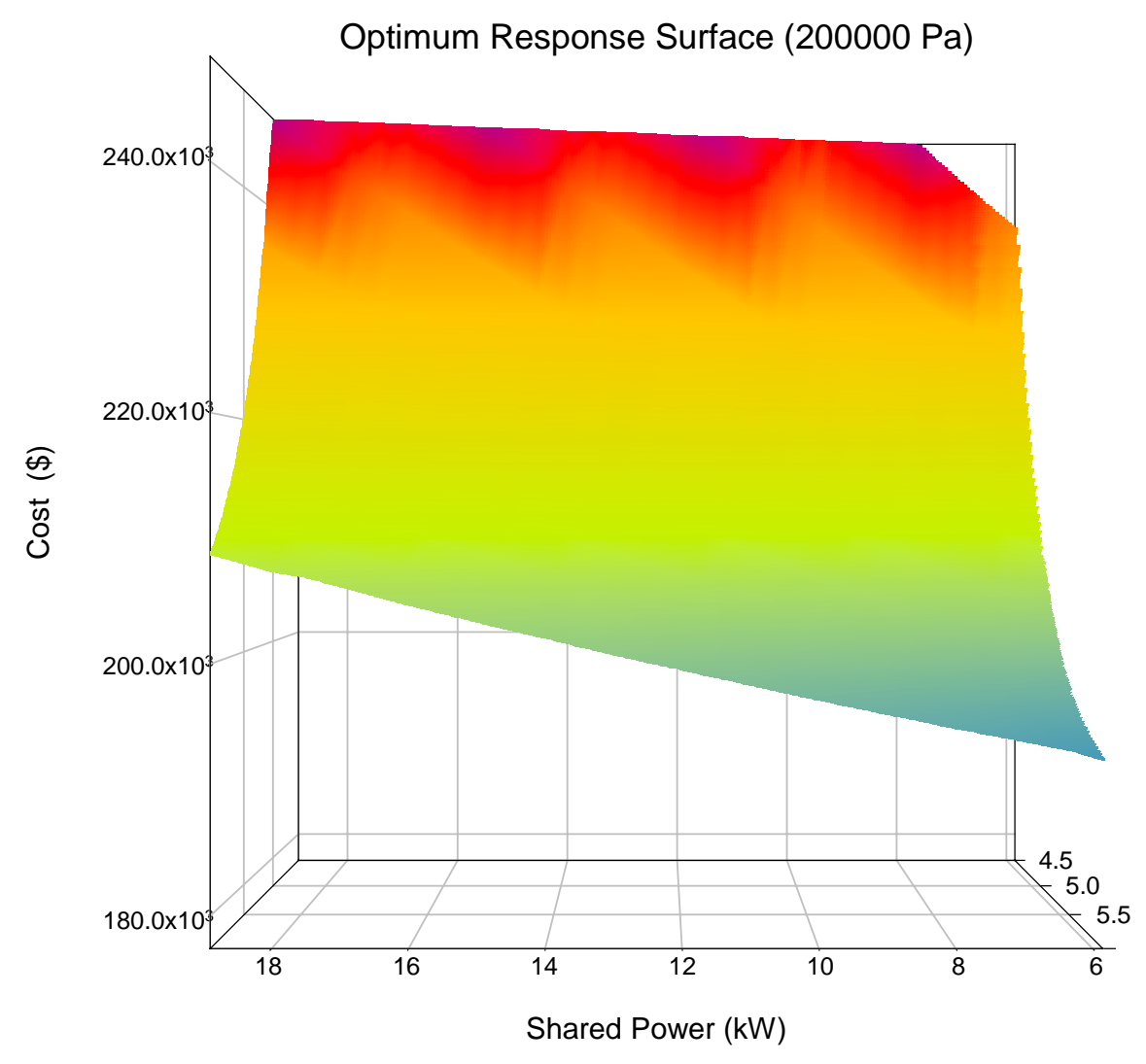

Figure 6. 4: Lateral view of the unit-level ORS for the SS for 50 residences and $200 \mathrm{kPa}$.

Figure 6.4 as all the figures presented in this section illustrate how by selecting the coupling functions wisely, the desirable convexity and smoothness of the unit-level ORS follow quite naturally. This type of behavior, however, is not limited to fuel cell sub-systems. Muñoz and Spakovsky (2000 a,b,c,d; 2001 a,b) found a similar type of behavior when analyzing a completely different set of energy sub-systems, namely, the Environmental Control and Propulsion sub-systems of a fighter aircraft. 


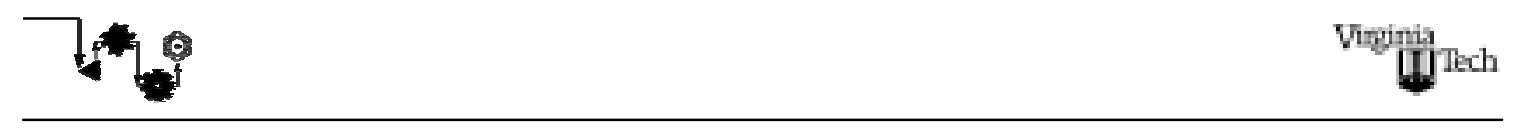

Finally, the families of unit-level ORSs found for the SS were used to optimize the entire fuel cell sub-system for a variable number of residences $(1,50$, and 100 residences). The results of this study are detailed in the following section.

\subsection{Results for the Optimization of the Fuel Cell Sub-system for a Variable Number of Residences}

As is explained in Chapter 5, in order to optimally synthesize/design the fuel cell sub-system, it is necessary to establish the synthesis/design electrical load that must be satisfied for the residences. Since the electrical load per residence is fixed at the synthesis/design point (see Table 2.1), the electrical load can be calculated as a function of the number of residences for which the fuel cell sub-system is being synthesized/designed. In order to do a sensitivity analysis of what the optimum number of residences is, the fuel cell sub-system was optimized for 1, 50, and 100 residences.

The first step in this sensitivity analysis is to determine each SS unit-level ORS for different numbers of residences by repeatedly solving Problem (5.10). As explained in Chapter 5 and in the previous section, each unit-level ORS is a function of the coupling functions $\left(\dot{n}_{\mathrm{H}_{2}}, \dot{E}_{F P S}\right.$, and $P_{\text {stack }}$ )and the independent variables for the SS (in this case a single variable $\left.A_{a c t}\right)$. In addition, as pointed out in Chapter 3, two additional variables are the number of residences (related to the net total power produced) and the number of fuel cell sub-systems manufactured per year. The latter is fixed for this sensitivity study at 1482 per year. By selecting this number, the model based on Oei et al. (1997), which was used in Chapter 3 to calculate the capital cost of the stack based on the number of units, matches the cost model in Ekdunge et al. (1998) based on gross power (again see Chapter 3).

Using the unit-level ORSs generated, the system-level Problem (5.12) was solved for a variable number of residences. The resulting optimum synthesis/design total cost in $\$ /$ residence and its breakdown for different number of residences is presented in Table 6.1. A graphical representation of the data in Table 6.1 is shown in Fig. 6.5. This data quantifies how much more expensive the synthesis/design for a single residence is 
compared with 50 and 100 residences. Note that the synthesis/design total cost has an asymptotic behavior with respect to the number of residences. Once a sufficiently large

Table 6. 1: Optimum costs for the fuel cell sub-system for different number of residences.

\begin{tabular}{|c|c|c|c|c|}
\hline $\begin{array}{c}\text { Number } \\
\text { of } \\
\text { residences }\end{array}$ & $\begin{array}{c}\text { Synthesis/design } \\
\text { total cost in } \\
\text { \$/residence }\end{array}$ & $\begin{array}{c}\text { SS capital cost } \\
\text { in \$/residence }\end{array}$ & $\begin{array}{c}\text { FPS capital cost in } \\
\text { \$/residence }\end{array}$ & $\begin{array}{c}\text { Fuel Cost } \\
\text { in } \\
\$ / \text { residence }\end{array}$ \\
\hline 1 & 97,671 & 71,291 & 9209 & 17,171 \\
\hline 50 & 25,456 & 4558 & 2900 & 17,998 \\
\hline 100 & 23,912 & 4115 & 2225 & 17,572 \\
\hline
\end{tabular}

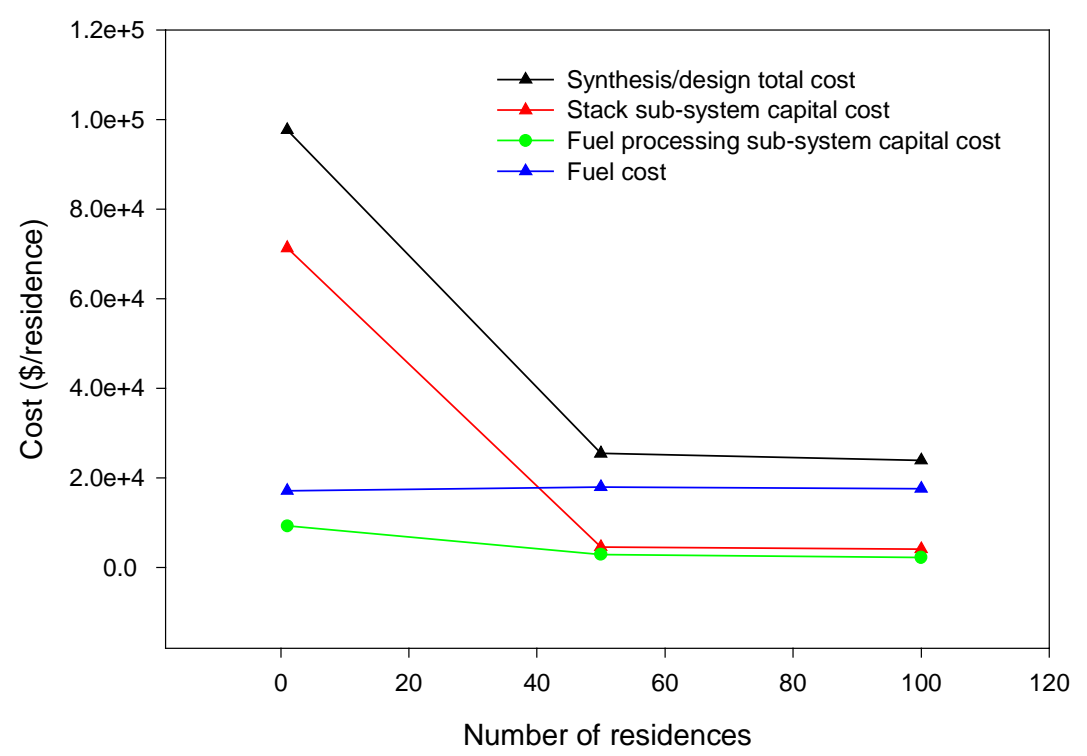

Figure 6. 5: Optimum costs of the fuel cell sub-system versus the number of residences.

number of residences have been reached, the synthesis/design cost remains almost constant at approximately $24,000 \$ /$ residence. 
In order to compare the cost of the fuel cell sub-system for producing energy or exergy $^{5}$ at the synthesis/design point, the costs of the fuel cell sub-system are given in Tables 6.2 and 6.3 in $\$ / \mathrm{kWh}^{6}$. In the first table, these cost are given on an energy basis in $\$ / \mathrm{kWh}$, while in the second table they are presented on an exergy basis in $\$ / \mathrm{kWh}^{7}$ :

Table 6. 2: Costs on an energy basis with respect to the electrical and thermal products delivered by the fuel cell sub-system for different number of residences at the synthesis/design point ${ }^{8}$.

\begin{tabular}{|c|c|c|c|c|}
\hline $\begin{array}{c}\text { Number } \\
\text { of } \\
\text { residences }\end{array}$ & $\begin{array}{c}\text { Synthesis/design } \\
\text { total cost in } \\
\mathbf{\$} / \mathbf{k W h}\end{array}$ & $\begin{array}{c}\text { SS cost in } \\
\mathbf{\$} \mathbf{k W h}\end{array}$ & $\begin{array}{c}\text { FPS cost in } \\
\mathbf{\$} \mathbf{k W h}\end{array}$ & $\begin{array}{c}\text { Fuel Cost in } \\
\mathbf{\$} \mathbf{k W h}\end{array}$ \\
\hline 1 & 0.2005 & 0.1463 & 0.0189 & 0.0352 \\
\hline 50 & 0.0574 & 0.0102 & 0.0065 & 0.0406 \\
\hline 100 & 0.0515 & 0.0088 & 0.0047 & 0.0378 \\
\hline
\end{tabular}

As expected, the $\$ / \mathrm{kWh}$ on an energy basis is less than the $\$ / \mathrm{kWh}$ on an exergy basis. In order to explain this difference, one has to look at how the products for the fuel cell sub-system are determined on an energy and on an exergy basis. To begin

\footnotetext{
${ }^{5}$ Exergy and not energy is the true measure of what the fuel cell sub-system delivers electrically and thermally since it accurately reflects how well the potential in the fuel has been utilized. Energy cannot do this since energy is a conserved quantity and, therefore, unable to capture "losses" within a system or the "quality" of the energy delivered by the system. For a more detail explanation, the reader is referred to Moran (1989).

${ }^{6}$ The total cost per $\mathrm{kWh}$ calculated at the synthesis/design point overcompensates for the operating or fuel costs since it is assumed at this point that without off-design information, the fuel cell sub-system operates at peak summer electrical load throughout its lifetime. These cost are corrected later after the off-design has been presented (see Tables 6.19 and 6.20). Also, note that all these costs per kWh (i.e. unit cost) are calculated on the basis of both products (electricity and heat) delivered by the fuel cell sub-system.

${ }^{7}$ In both cases, it is assumed that the unit price of thermal energy or of thermal exergy delivered by the fuel cell sub-system heat interaction is equivalent to the unit price of the electrical energy /exergy delivered by the fuel cell sub-system work interaction. This is a reasonable assumption based on the information available.

${ }^{8}$ See footnote 6 .
} 
Table 6. 3: Costs on an exergy basis with respect to the electrical and thermal products delivered by the fuel cell sub-system for different number of residences at the synthesis/design point ${ }^{9}$.

\begin{tabular}{|c|c|c|c|c|}
\hline $\begin{array}{c}\text { Number } \\
\text { of } \\
\text { residences }\end{array}$ & $\begin{array}{c}\text { Synthesis/design } \\
\text { total cost in } \\
\mathbf{\$} / \mathbf{k W h}\end{array}$ & $\begin{array}{c}\text { SS cost in } \\
\mathbf{\$} \mathbf{k W h}\end{array}$ & $\begin{array}{c}\text { FPS cost in } \\
\mathbf{\$} / \mathbf{k W h}\end{array}$ & $\begin{array}{c}\text { Fuel Cost in } \\
\mathbf{\$} / \mathbf{k W h}\end{array}$ \\
\hline 1 & 0.3288 & 0.2400 & 0.0310 & 0.0578 \\
\hline 50 & 0.0899 & 0.0161 & 0.0102 & 0.0636 \\
\hline 100 & 0.0834 & 0.0143 & 0.0077 & 0.0613 \\
\hline
\end{tabular}

with, exergy is defined as maximum work potential. Thus, electrical energy in the form of a work interaction is equivalent to exergy in every respect. However, the thermal energy delivered in the form of a heat interaction is not equivalent to its exergy. In fact, the exergy of a heat interaction is related to its thermal energy through the Carnot factor $\left(1-\frac{T_{o}}{T_{k}}\right)$ in the following way:

$\dot{\Omega}_{\text {heat }}=\sum_{k} \dot{Q}_{k}\left(1-\frac{T_{o}}{T_{k}}\right)$

where $\dot{Q}_{k}$ is the $\mathrm{k}^{\text {th }}$ rate of thermal energy transfer to the surroundings from the fuel cell sub-system, $T_{k}$ the corresponding temperature of transfer, To the temperature of the surroundings, and $\dot{\Omega}_{\text {heat }}$ the total rate of exergy transfer to the surroundings as a result of all the heat interactions which occur between the fuel cell sub-system and its surroundings. Therefore, the total energy in $\mathrm{kW}$ delivered by the cogeneration fuel cell sub-system is always larger than its exergy in $\mathrm{kW}$ due to the Carnot factor, which is always less than 1 . Hence, $\$ / \mathrm{kWh}$ on an exergy basis are larger than those on an energy basis.

\footnotetext{
${ }^{9}$ See footnote 6 .
} 


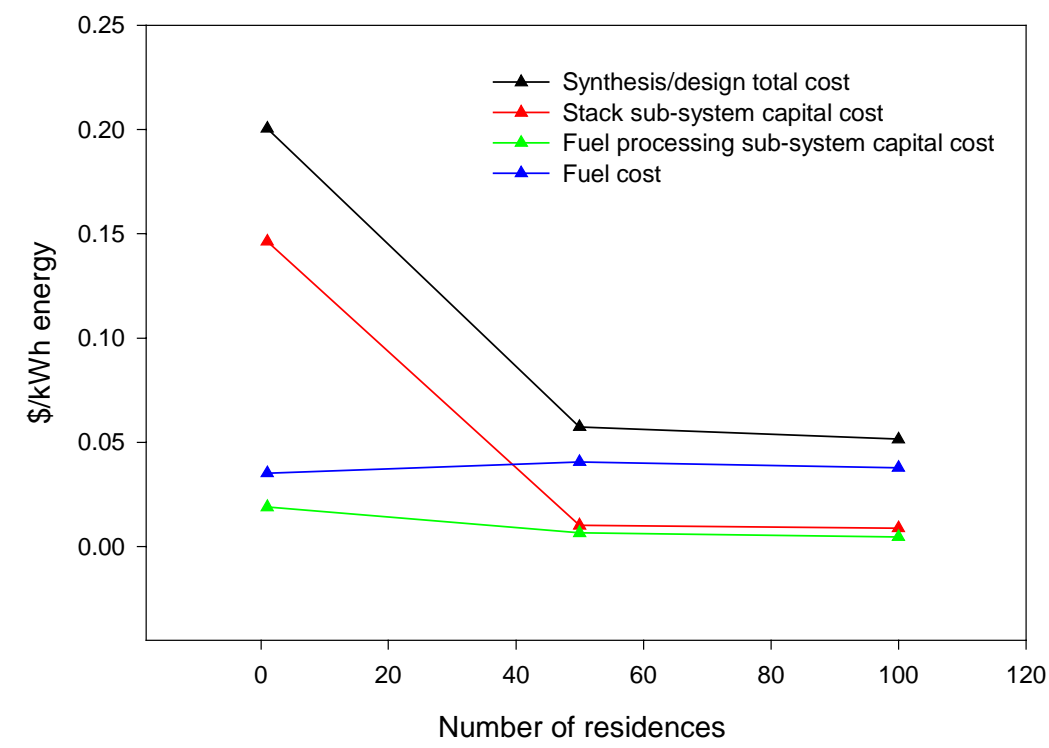

Figure 6. 6: Optimum unit cost of production at the synthesis/design point for the fuel cell sub-system in $\$ / \mathrm{kWh}$ on an energy basis versus the number of residences.

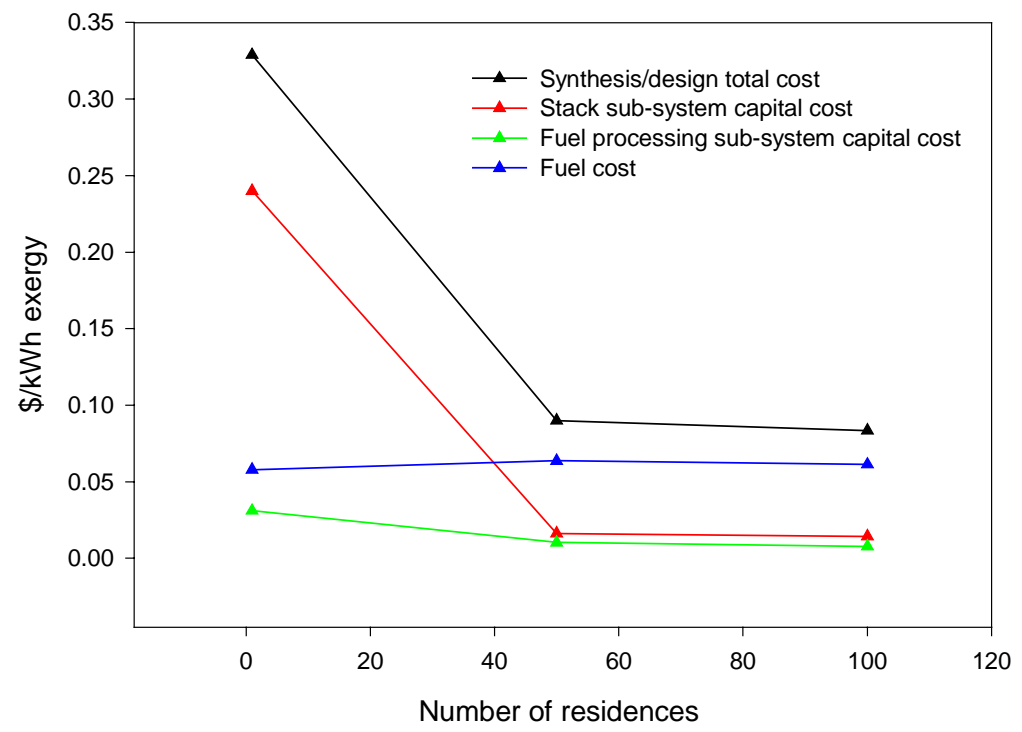

Figure 6. 7: Optimum unit cost of production at the synthesis/design point for the fuel cell sub-system in $\$ / \mathrm{kWh}$ on an exergy basis versus the number of residences. 


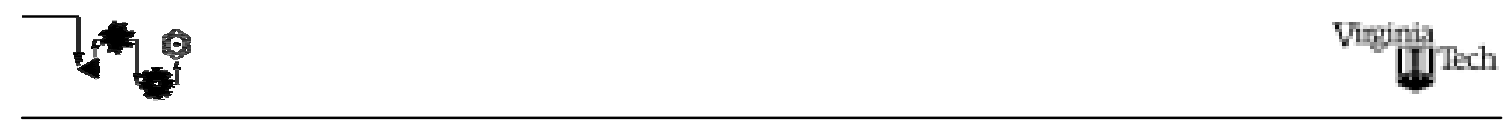

A graphical representation of the data in Tables 6.2 and 6.3 is shown in Figs. 6.6 and 6.7. Both plots have the same tendencies, that is to say, the optimum cost of producing a unit of energy or exergy when the fuel cell sub-system is synthesized/designed for a single residence is considerably larger than for 50 or 100 residences (20 / 32 cents/kWh, respectively). However, when the number of residences is increased to 50 or above, the cost in $\$ / \mathrm{kWh}$ on an energy and on an exergy basis exhibits asymptotic behavior ${ }^{10}$, averaging approximately 5.4 / 8.6 cents/kWh, respectively. Note that only three points have been used in this analysis and that therefore no conclusions can be drawn from intermediate points. The values of the electrical energy and amounts of heat transfer for each number of residences used in the calculations of the unit cost are presented in Table 6.4 .

The same tendencies observed in Figs. 6.5 through 6.7 for the optimum synthesis/design holds for all feasible simulations of the fuel cell sub-system. That is to say, the capital cost, especially the capital cost of the stack, dominates the total synthesis/design cost when the fuel cell sub-system is synthesized/designed for a single residence (see Fig 6.8). However, the fuel cost becomes the primary contributor to the total synthesis/design cost for a large number (50 or above) of residences (see Figs. 6.9 to 6.10). It is interesting to observe that this total cost (the black curve in Figs. 6.8 to 6.10) descends monotonically when plotted against system efficiency ${ }^{11}$. Therefore, the minimum total synthesis/design cost for 1482 manufactured units is found at the maximum system electrical efficiency that can be achieved by the configuration ${ }^{12}$ regardless of the number of residences. In Fig. 6.11 the system electrical efficiency for the optimum synthesis/design for different number of residences is plotted. The fact that the maximum system electrical efficiency achieved for 1, 50 and 100 residences is almost constant (about 40\%) indicates that the fuel cell sub-system configuration itself has a maximum efficiency independent of the size of the fuel cell sub-system. The value of this

\footnotetext{
${ }^{10}$ Of course, since only three points are used to define the curves, the 50 residences threshold is at best approximate. A more detailed sensitivity analysis might indicate a lower threshold.

11 The definition used for system efficiency is net electrical power output divided by the rate of fuel consumed times its lower heating value (LHV).

12 Note that this conclusion is subject to change once the optimal off-design information is taken into account. As will be seen later in this chapter, this indeed turns out to be the case.
} 
maximum is establish on the basis of 25,000 plus simulations at the synthesis/design point for which no feasible solution with a system electrical efficiency higher than this value was found.

Table 6. 4: Optimum work and heat interactions of the fuel cell sub-system at the synthesis/design point.

\begin{tabular}{|l|c|c|c|}
\hline Number of residences & 1 & 50 & 100 \\
\hline Net electric power $(\mathrm{kWe})$ & 2.7 & 135 & 270 \\
\hline $\begin{array}{l}\text { Thermal power from the stack } \\
\text { at 343 K in kW }\end{array}$ & 2.238 & 102.128 & 231.6 \\
\hline $\begin{array}{l}\text { Thermal power from the HX } \\
\text { prior to the stack (component } \\
10, \text { Fig. 2.8) in kW }\end{array}$ & $0.154($ at 397 K) & $9.95($ at $405 \mathrm{~K})$ & $17.28($ at $400 \mathrm{~K})$ \\
\hline $\begin{array}{l}\text { Thermal power of the PROX } \\
\text { (component 9, Fig. 2.8) in kW }\end{array}$ & $0.476($ at $451 \mathrm{~K})$ & $5.97($ at $467 \mathrm{~K})$ & $11.05($ at $457 \mathrm{~K})$ \\
\hline Total energy delivered $(\mathrm{kW})$ & 5.56 & 253 & 529.9 \\
\hline Total exergy delivered $(\mathrm{kW})$ & 3.39 & 161.5 & 327.2 \\
\hline
\end{tabular}

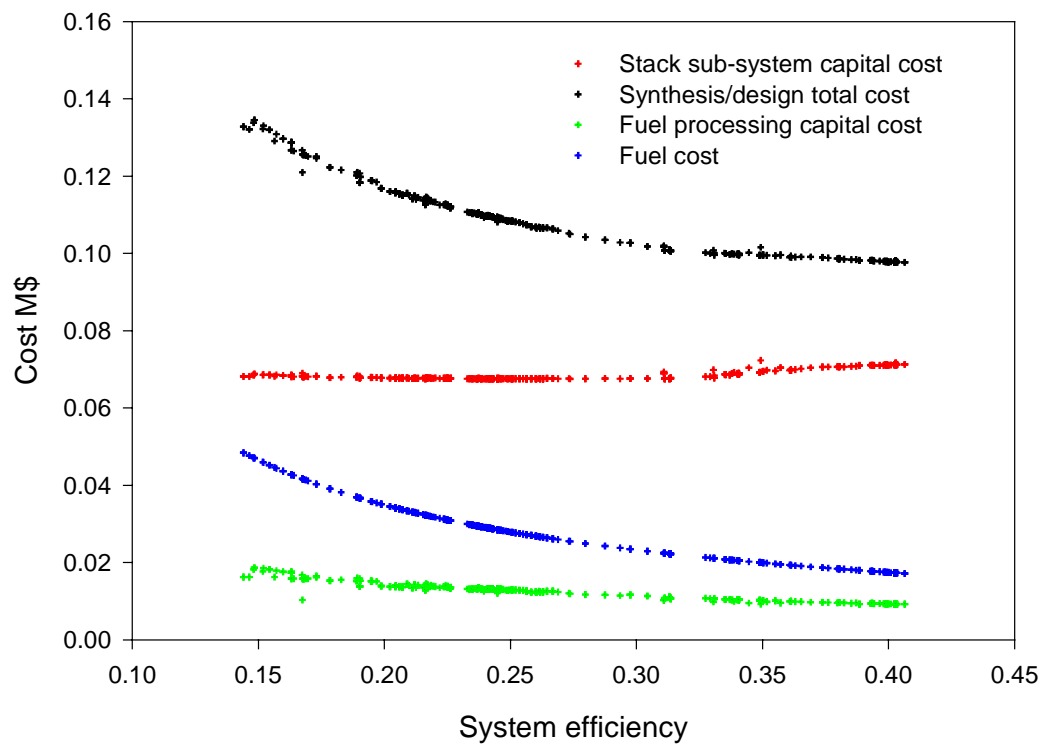

Figure 6. 8: Costs of the fuel cell sub-system for a single residence in millions of dollars versus system efficiency for a complete range of feasible fuel cell sub-system simulations. 


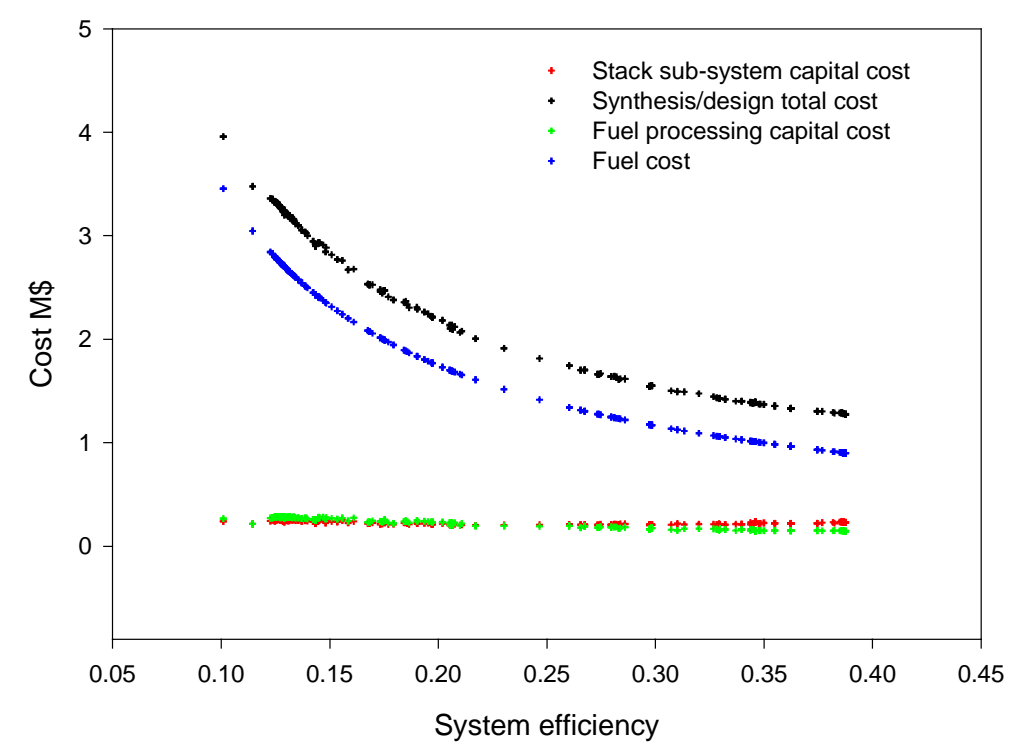

Figure 6. 9: Costs of the fuel cell sub-system for 50 residences in millions of dollars versus system efficiency for a complete range of feasible fuel cell subsystem simulations.

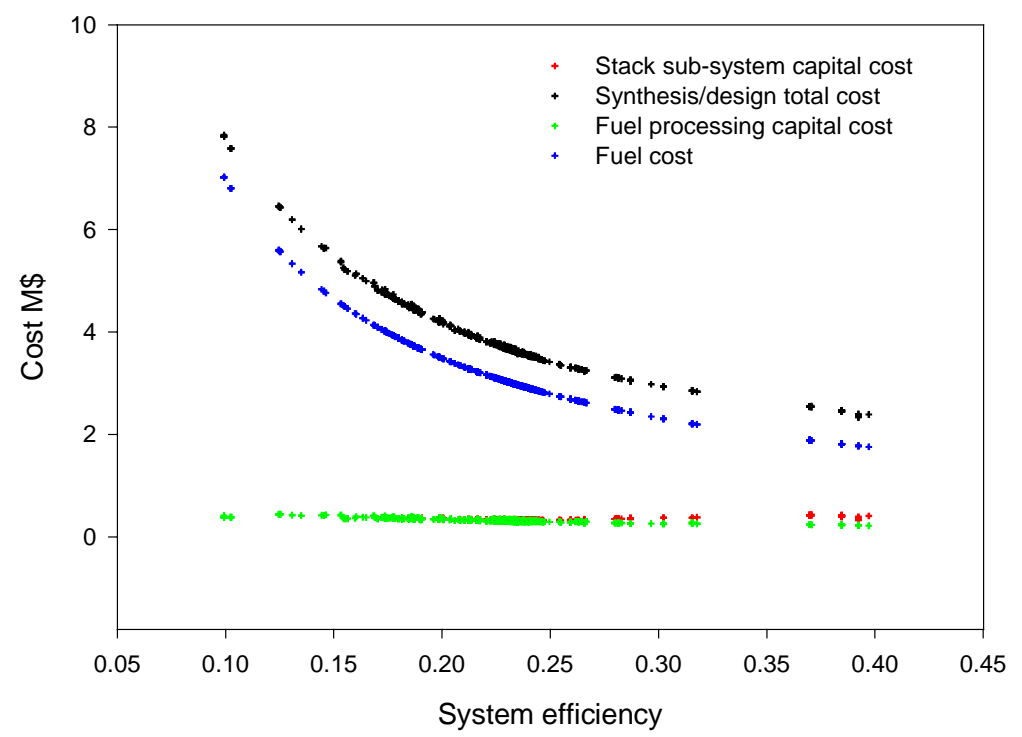

Figure 6. 10: Costs of the fuel cell sub-system for 100 residences in millions of dollars versus system efficiency for a complete range of feasible fuel cell subsystem simulations. 

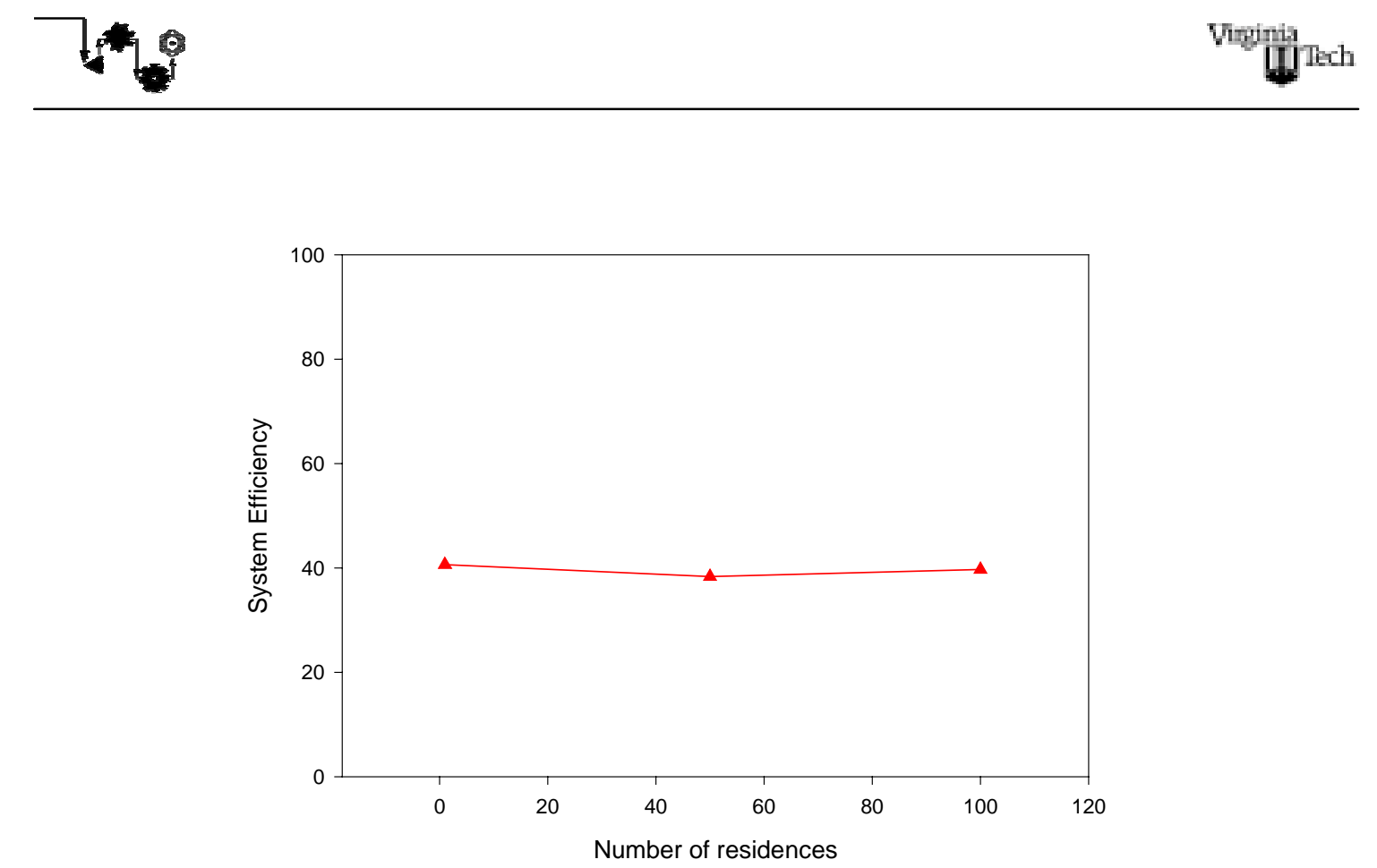

Figure 6. 11: System efficiency of the optimum synthesis/design versus the number of residences.

Another important result of this sensitivity study is the fact that the optimum net electrical power output of the fuel cell sub-system at the synthesis/design point and the optimum rate of fuel consumed at the synthesis/design point have an almost perfectly linear behavior when plotted with respect to the number of residences for which the fuel cell sub-system is synthesized/designed (Figs. 6.12 and 6.13). This result is consistent with the fact that the system electrical efficiency remains almost constant for the optimum synthesis/design independent of the size of the fuel cell sub-system (Fig. 6.11). Furthermore, if one looks at the values for the independent variables for the optimum synthesis/design for different number of residences (see Table 6.5), one can observe that the values for independent variables such as temperature, active cell area, or stack pressure tend to have relatively similar values at the optimum conditions independent of the size 


7.0

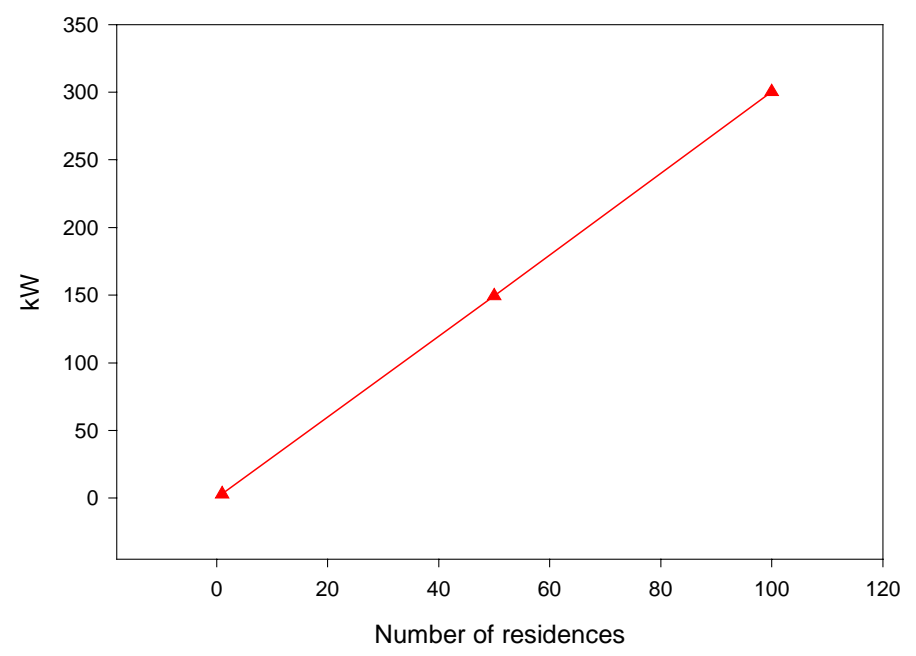

Figure 6. 12: Optimum net power output at the synthesis/design point of the fuel cell sub-system versus the number of residences.

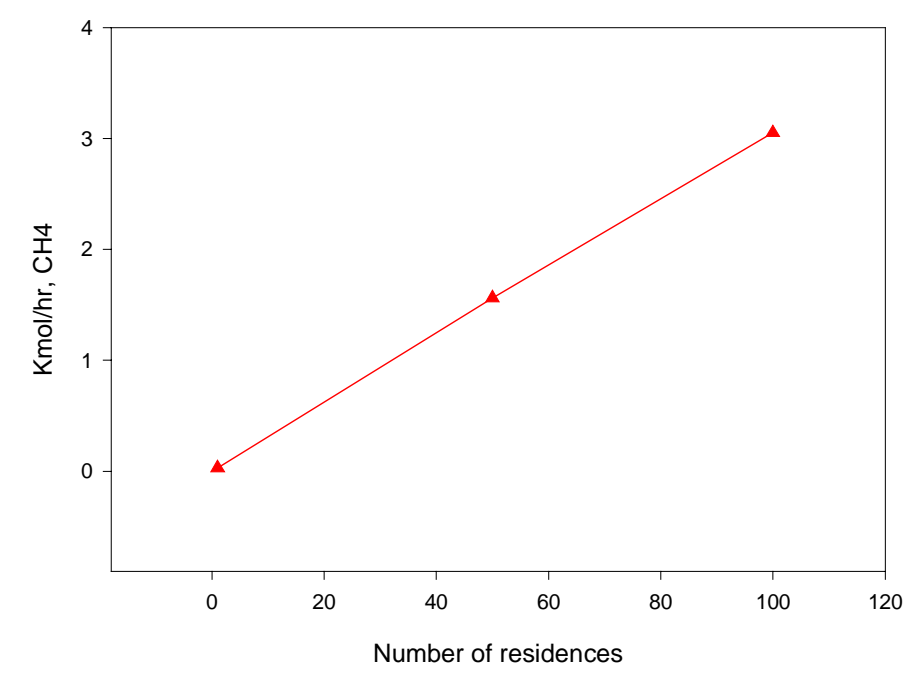

Figure 6. 13: Optimum rate of methane consumption at the synthesis/design point versus the number of residences.

of the fuel cell sub-system. Fluctuations in these variable values exhibit no more than a $9.3 \%$ difference and as little as a $0 \%$ from the arithmetic mean of the three optimizations shown in Table 6.5. However, other values such as the air to fuel/steam ratio that is used 
in the combustor or the steam to methane ratio do not appear to follow such a clear cut pattern.

As to the dependent geometric variable values associated with each optimum synthesis/design, details are given in Fig. 6.14. These values are plotted versus the number of residences. Some of the geometry behaves linearly with respect to changes in

Table 6. 5: Optimum synthesis/design values of the independent variables for 1, 50 and 100 residences.

\begin{tabular}{|c|c|c|c|}
\hline $\begin{array}{c}\text { Independent } \\
\text { variables }\end{array}$ & single residence & $\mathbf{5 0}$ residences & 100 residences \\
\hline $\mathrm{r}_{\mathrm{h} 2 \mathrm{och} 4}$ & 3.08 & 4.37 & 4.5 \\
\hline $\mathrm{T}_{\text {steam }}$ & $432^{\circ} \mathrm{C}$ & $450^{\circ} \mathrm{C}$ & $417^{\circ} \mathrm{C}$ \\
\hline $\mathrm{T}_{\text {prox }}$ & $178^{\circ} \mathrm{C}$ & $194^{\circ} \mathrm{C}$ & $184^{\circ} \mathrm{C}$ \\
\hline $\mathrm{T}_{\text {lts }}$ & $237^{\circ} \mathrm{C}$ & $200^{\circ} \mathrm{C}$ & $217^{\circ} \mathrm{C}$ \\
\hline $\mathrm{T}_{\text {reformer }}$ & $703^{\circ} \mathrm{C}$ & $748^{\circ} \mathrm{C}$ & $693{ }^{\circ} \mathrm{C}$ \\
\hline $\mathrm{n}_{\text {ch4 }}$ & $0.035 \mathrm{kmol} / \mathrm{hr}$ & $1.56 \mathrm{kmol} / \mathrm{hr}$ & $3.06 \mathrm{kmol} / \mathrm{hr}$ \\
\hline $\mathrm{r}_{\text {ch4 }}$ & 0.22 & 0.33 & 0.38 \\
\hline $\mathrm{r}_{\text {air }}$ & 3.96 & 3 & 3.78 \\
\hline$\Delta \mathrm{T}_{\text {ref }}$ & $243^{\circ} \mathrm{C}$ & $245^{\circ} \mathrm{C}$ & $219{ }^{\circ} \mathrm{C}$ \\
\hline $\mathrm{P}_{\text {stack }}$ & $249 \mathrm{kPa}$ & $216 \mathrm{kPa}$ & $250 \mathrm{kPa}$ \\
\hline $\mathrm{A}_{\text {act }}$ & $600 \mathrm{~cm}^{2}$ & $600 \mathrm{~cm}^{2}$ & $600 \mathrm{~cm}$ \\
\hline
\end{tabular}

the number of residences (see Fig. $6.14 \mathrm{a}, \mathrm{c}$, and d) which is related to the fact that several thermodynamic properties such as temperature, pressure and certain flow rates exhibit similar behavior when the optimum synthesis/design is plotted versus the number of residences. However, important geometric variables such as the characteristic length of the heat exchanger prior to the steam reformer reactor (component 3 in Fig. 2.8) or that of the heat exchanger prior to the LTS reactor (component 6 in Fig. 2.8) do not show such 


$7 * 8$

Characteristic geometry of the steam generator vs the number of residences

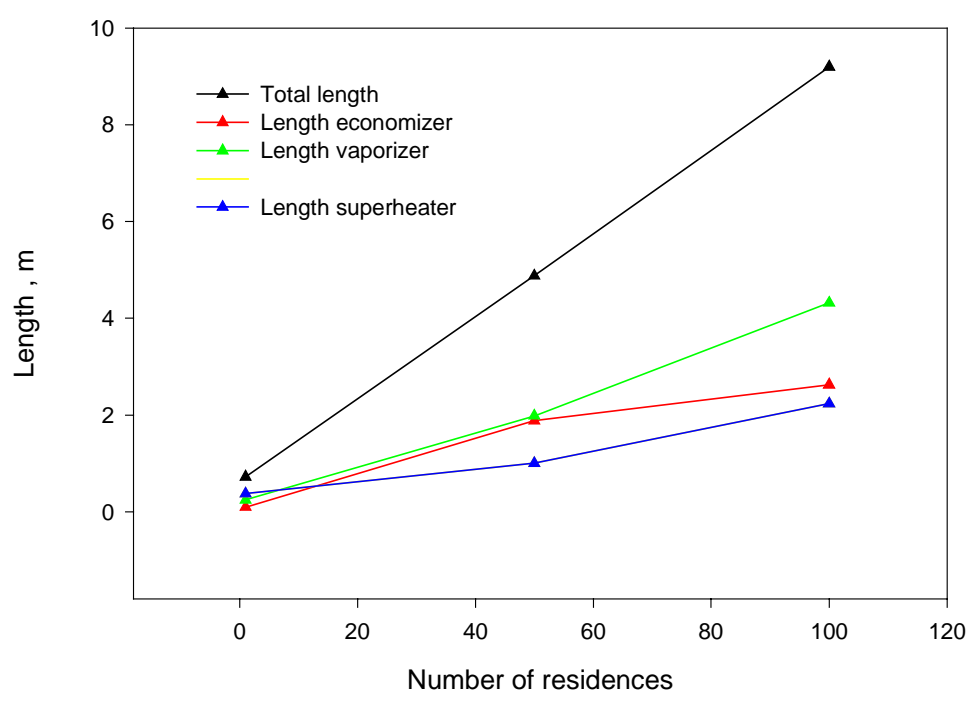

a)

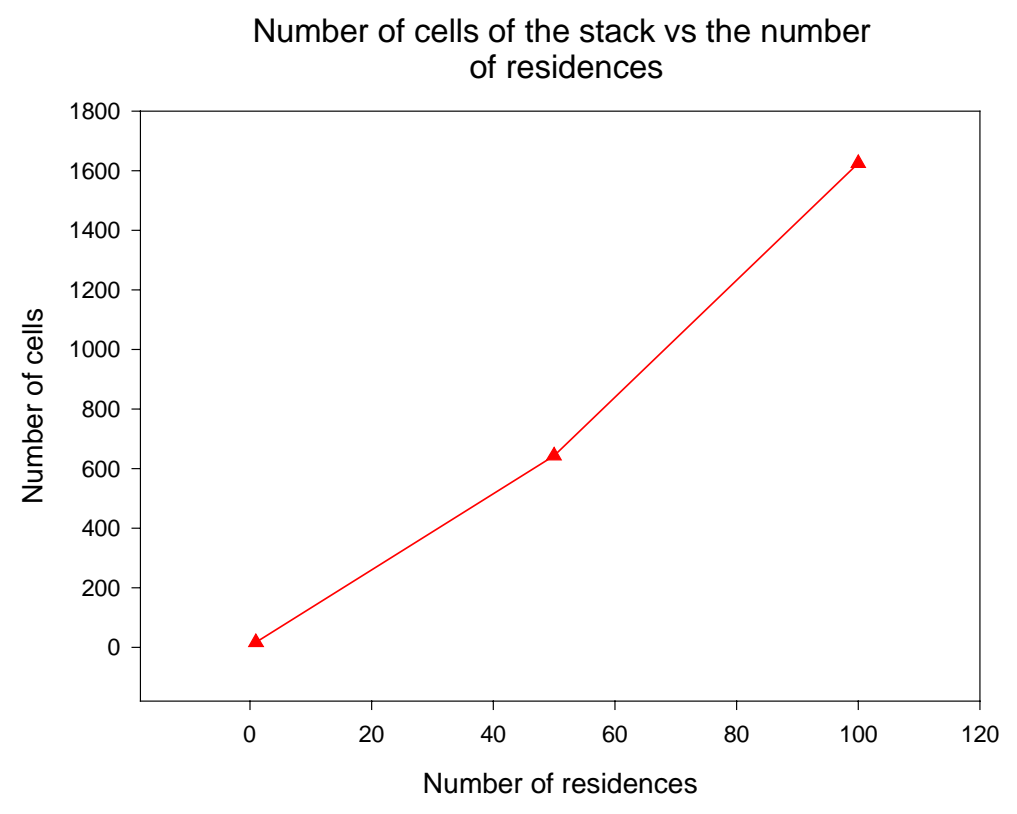

b) 


$7 * 8$

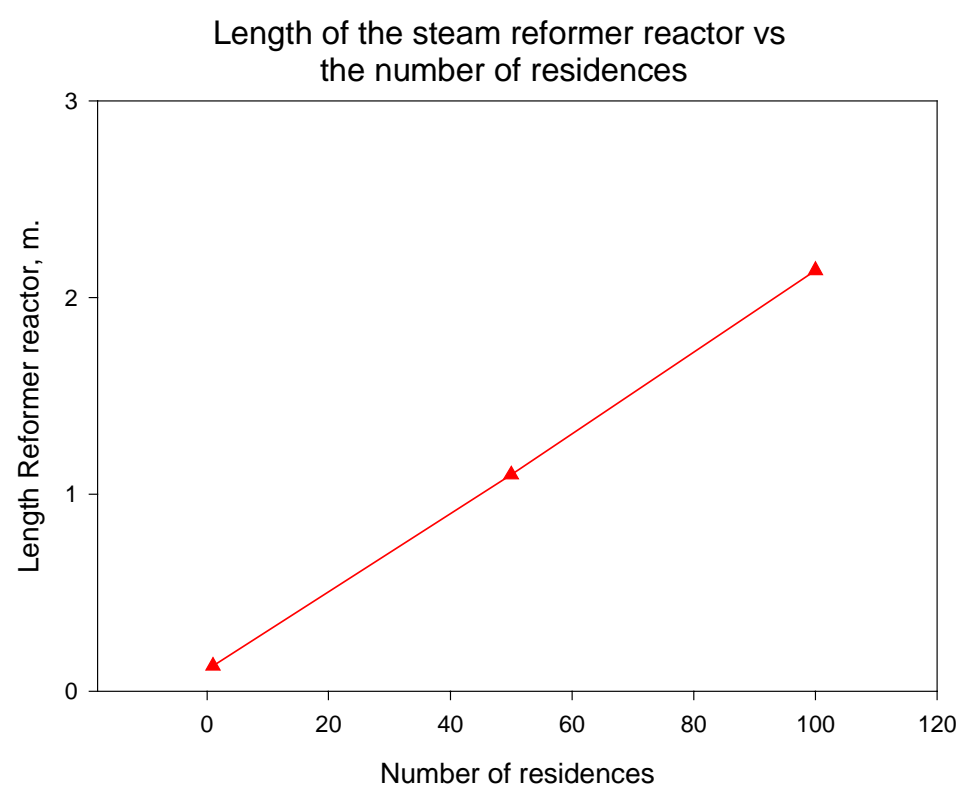

c)

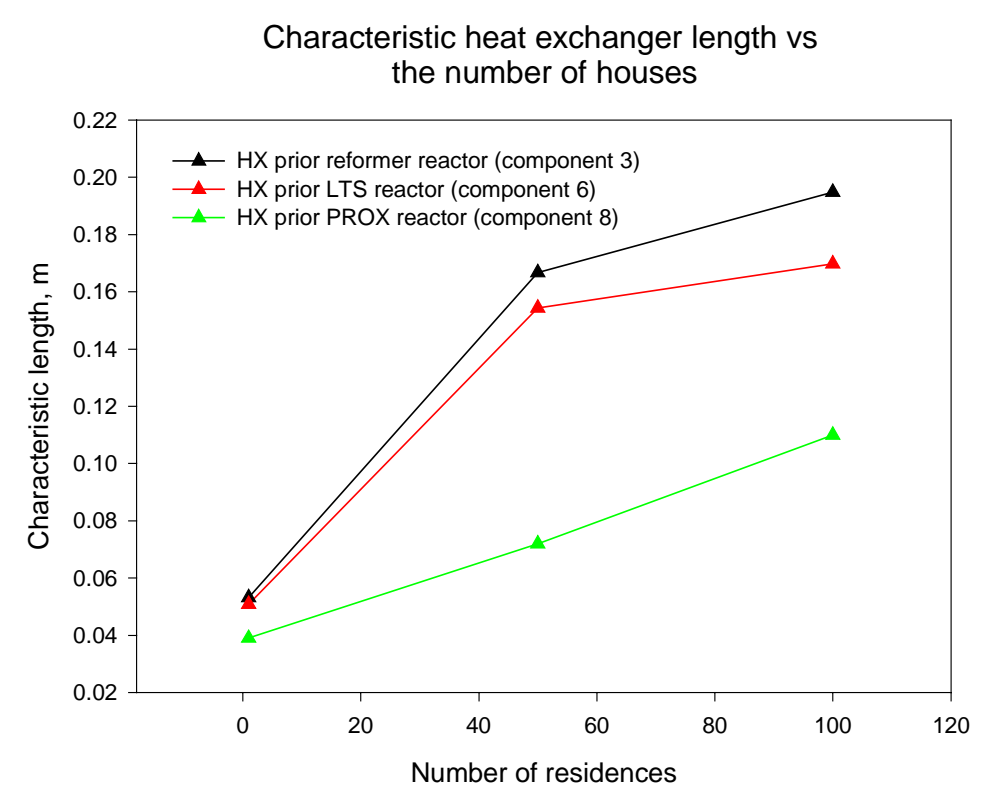

d)

Figure 6. 14: Characteristic lengths of the a) steam generator, c) steam reformer reactor and d) heat exchangers as well as b) the number of cells of the stack versus the number of residences for which the fuel cell sub-system is synthesized/designed. 
linear behavior (see Fig. 6.14d). These, in particular can be explained by the fact that the steam to methane ratio for the synthesis/design of 50 and 100 residences is considerably different than the optimum value of this ratio for a single residence (see Table 6.5).

Of course, all the results shown in this section were obtained for 1482 fuel cell subsystem units manufactured per year. Altering this number will have an effect on these results which have shown in general that the fuel cell sub-system is more economical when built for a relatively large number of residences, e.g., 50 rather than a single residence. However, increasing the number of residences even further, e.g., to 100 residences, only reduces the cost by a very small percentage. In the next section, the number of residences for which the fuel cell sub-system is synthesized/designed is fixed at 50, and the number of units manufactured is varied in order to see the effect that this parameter has on the optimal synthesis/design of the fuel cell sub-system.

\subsection{Results for the Optimization of the Fuel Cell Sub-system for a Variable Number of Units Manufactured per Year}

The system-level optimization problem for the fuel cell sub-system was solved for 50 residences and three different number of units manufactured per year $(100,1482$, and 10,000). The optimal $\operatorname{cost}^{13}$ results of this sensitivity study are summarized in Table 6.6. As expected, costs reduce considerably when the number of units manufactured per year increases. For a small number of units produced, the capital costs of the SS and FPS are the main contributors to the total optimum cost. However, when the number of units manufactured is increased, the fuel consumed by the fuel cell sub-system becomes by far the biggest contributor to the total optimal synthesis/design cost. These tendencies are shown in Fig. 6.15, which is a graphical representation of the data provided in Table 6.6. Furthermore, the costs in this table in terms of the products delivered by the fuel cell system are given in $\$ / \mathrm{kWh}$ on an energy basis in Table 6.7 and on an exergy basis in Table 6.8. As with the previous sensitivity study, the unit costs on an exergy basis are higher than those on an energy basis. The values of the electrical energy and amounts of

\footnotetext{
${ }^{13}$ Again, keep in mind that this optimal cost is defined only with respect to the synthesis/design point. The optimal off-design information, which is taken into account later in this chapter, will affect this cost.
} 
heat transfer used in the calculations of these unit costs with 1482 and 10,000 units are those given previously for 50 residences in Table 6.4. The values of the electrical energy and amounts of heat transfer for 100 units manufactured differ from the ones of 1482 and 10,000 as the optimum is found with a different synthesis/design. The values for the work and heat interactions are summarized in Table 6.9.

Table 6. 6: Optimum cost at the synthesis/design point of the fuel cell sub-system for different number of fuel cell sub-system units manufactured per year.

\begin{tabular}{|c|c|c|c|c|}
\hline $\begin{array}{c}\text { Number of } \\
\text { units } \\
\text { manufactured } \\
\text { per year }\end{array}$ & $\begin{array}{c}\text { Synthesis/design } \\
\text { total cost in } \\
\$ / \mathbf{u n i t}\end{array}$ & $\begin{array}{c}\text { SS capital cost } \\
\text { in } \$ / \text { unit }\end{array}$ & $\begin{array}{c}\text { FPS capital } \\
\text { cost in \$/unit }\end{array}$ & $\begin{array}{c}\text { Fuel cost in } \\
\$ / \text { unit }\end{array}$ \\
\hline 100 & $6,343,983$ & $3,067,428$ & $2,268,078$ & $1,008,477$ \\
\hline 1,482 & $1,272,834$ & 227,906 & 145,019 & 899,909 \\
\hline 10,000 & 912,338 & 35,254 & 21,262 & 855,822 \\
\hline
\end{tabular}

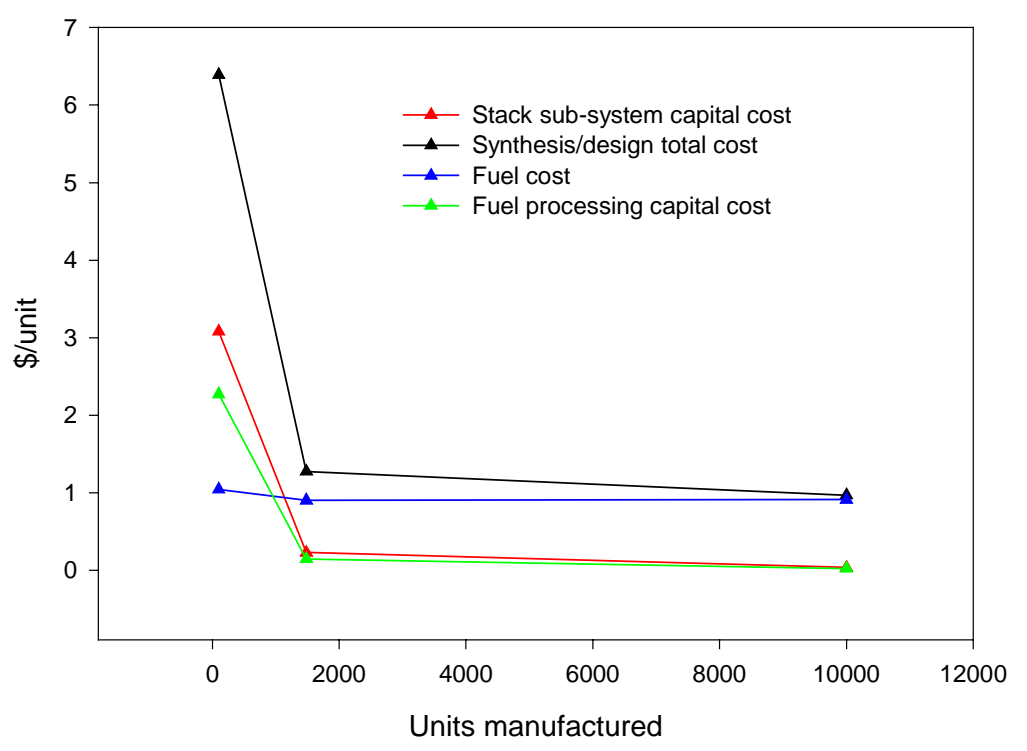

Figure 6. 15: Optimum costs at the synthesis/design point of the fuel cell sub-system in \$/unit versus the number of units manufactured per year. 
Table 6. 7: Costs on an energy basis with respect to the electrical and thermal products delivered by the fuel cell sub-system for different number of fuel cell subsystem units manufactured per year.

\begin{tabular}{|c|c|c|c|c|}
\hline $\begin{array}{c}\text { Number of } \\
\text { units } \\
\text { manufactured }\end{array}$ & $\begin{array}{c}\text { Synthesis/design } \\
\text { total cost in } \\
\$ / \mathrm{kWh} \\
\end{array}$ & $\begin{array}{l}\text { SS capital cost } \\
\text { in } \$ / k W h\end{array}$ & $\begin{array}{c}\text { FPS capital } \\
\text { cost in } \$ / k W h\end{array}$ & $\begin{array}{c}\text { Fuel Cost in } \\
\$ / k W h\end{array}$ \\
\hline 100 & 0.2405 & 0.1163 & 0.0860 & 0.0382 \\
\hline 1,482 & 0.0574 & 0.0102 & 0.0065 & 0.0406 \\
\hline 10,000 & 0.0411 & 0.0015 & 0.0009 & 0.0386 \\
\hline
\end{tabular}

Table 6. 8: Costs on an exergy basis with respect to the electrical and thermal products delivered by the fuel cell sub-system for different number of fuel cell subsystem units manufactured per year.

\begin{tabular}{|c|c|c|c|c|}
\hline $\begin{array}{c}\text { Number of } \\
\text { units } \\
\text { manufactured }\end{array}$ & $\begin{array}{c}\text { Synthesis/design } \\
\text { total cost in } \\
\mathbf{\$} / \mathbf{k W h}\end{array}$ & $\begin{array}{c}\text { SS capital cost } \\
\text { in } \mathbf{\$} / \mathbf{k W h}\end{array}$ & $\begin{array}{c}\text { FPS capital } \\
\text { cost in } \mathbf{\$} / \mathbf{k W h}\end{array}$ & $\begin{array}{c}\text { Fuel Cost in } \\
\mathbf{\$} \mathbf{k W h}\end{array}$ \\
\hline 100 & 0.4259 & 0.2059 & 0.1523 & 0.0677 \\
\hline 1,482 & 0.0902 & 0.0161 & 0.0102 & 0.0638 \\
\hline 10,000 & 0.0646 & 0.0024 & 0.0015 & 0.0606 \\
\hline
\end{tabular}


Table 6. 9: Optimum work and heat interactions of the fuel cell sub-system for different number of fuel cell sub-system units manufactured per year.

\begin{tabular}{|l|c|c|c|}
\hline Units manufactured & 100 & 1482 & 10,000 \\
\hline Net electric power $(\mathrm{kWe})$ & 135 & 135 & 135 \\
\hline $\begin{array}{l}\text { Thermal power from Stack at } \\
343 \mathrm{~K} \text { in kW }\end{array}$ & 152.2 & 102.128 & 102.128 \\
\hline $\begin{array}{l}\text { Thermal power from the HX } \\
\text { prior stack (component 10 Fig. } \\
2.8) \text { ) in kW }\end{array}$ & $8.86($ at 394 K) & $9.95($ at $405 \mathrm{~K})$ & $9.95($ at $405 \mathrm{~K})$ \\
\hline $\begin{array}{l}\text { Thermal power of the PROX } \\
\text { (component 9 Fig. } 2.8) \text { in kW }\end{array}$ & 4.99 (at 445 K) & $5.97($ at $467 \mathrm{~K})$ & $5.97($ at $467 \mathrm{~K})$ \\
\hline Total energy delivered $(\mathrm{kW})$ & 301 & 253 & 253 \\
\hline Total exergy delivered $(\mathrm{kW})$ & 170 & 161.5 & 161.5 \\
\hline
\end{tabular}

Now, in order to see the effects of varying the number of units manufactured per year on the system electrical efficiency, plots of cost versus efficiency are given in Figs 6.16 to 6.18 for the complete range of feasible solutions used in determining the optimal

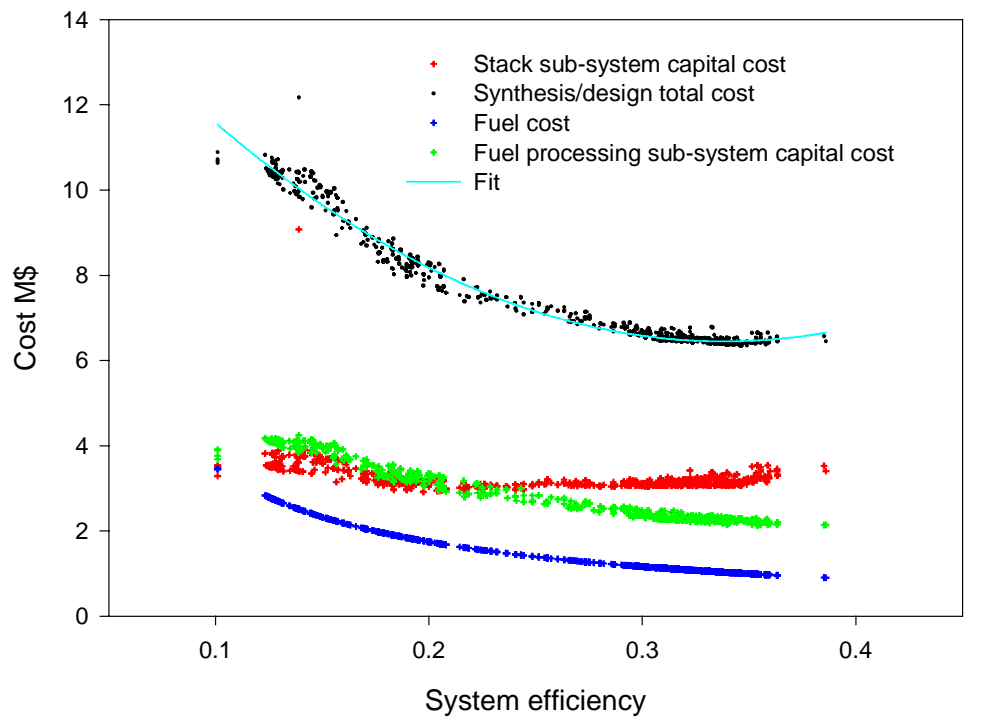

Figure 6. 16: Costs of the fuel cell sub-system for 100 units manufactured per year in millions of dollars versus system efficiency for a complete range of feasible fuel cell sub-system simulations. 


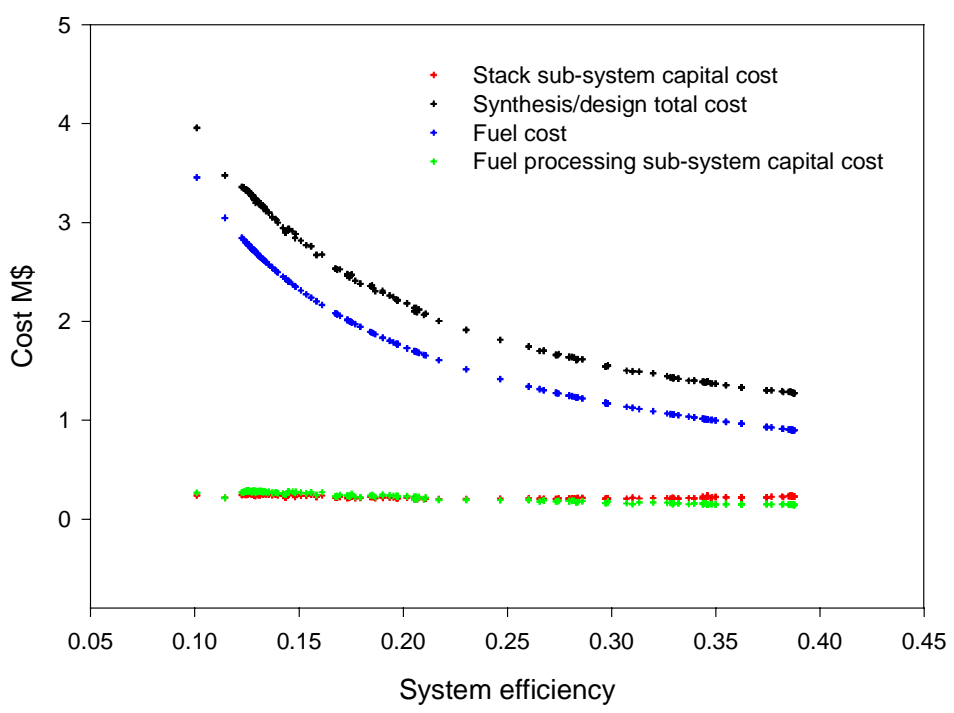

Figure 6. 17: Costs of the fuel cell sub-system for 1482 units manufactured per year in millions of dollars versus system efficiency for a complete range of feasible fuel cell sub-system simulations.

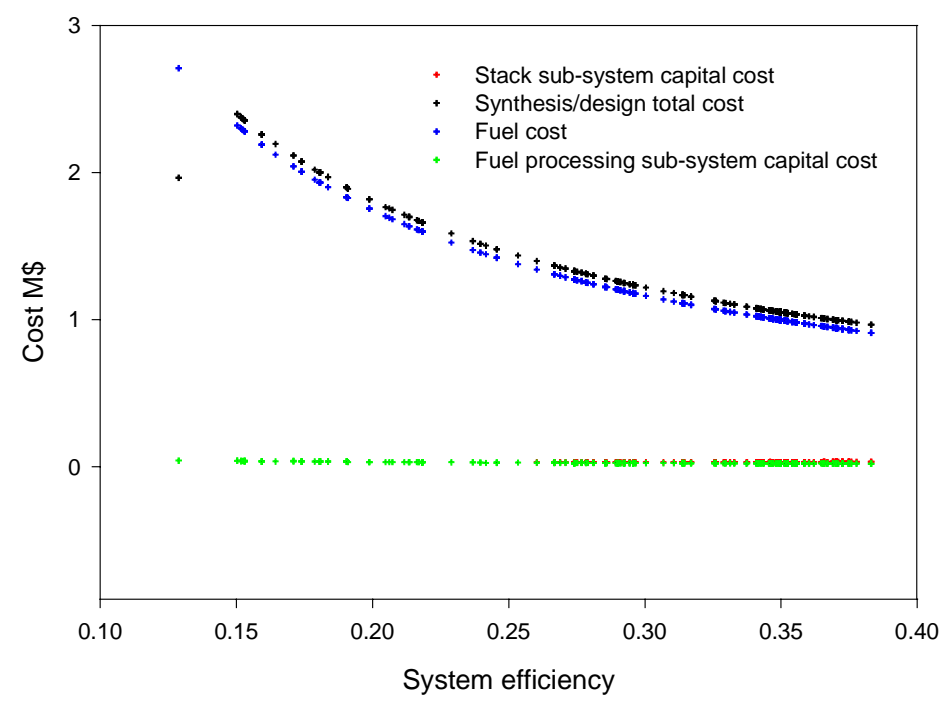

Figure 6. 18: Costs of the fuel cell sub-system for 10,000 units manufactured per year in millions of dollars versus system efficiency for a complete range of feasible fuel cell sub-system simulations. 
fuel cell sub-system synthesis/design. The obvious effect is that of changing the importance of the different types of cost involved. For example, the smaller the number of units manufactured per year, the more dominant the capital costs of the SS and the FPS in determining the total synthesis/design cost. Note that for the optimization problems which assume 1482 units per year (Fig. 6.17) and 10,000 units per year units (Fig. 6.18), the optimum synthesis/design (minimum total synthesis/design cost) is found at the maximum system efficiency ${ }^{14}$. However, for 100 units per year, the optimum synthesis/design is not found at the maximum system efficiency of $38.7 \%$ but at a system efficiency of $34.5 \%$. This is because the SS capital cost has the tendency to increase at higher system efficiencies.

Finally, both the sensitivity analysis presented in this section and the one given in the previous section lead qualitatively and quantitatively to the conclusion that based on the cost functions employed, optimal fuel cell sub-system synthesis/design is attractive with a minimum of about 50 residences. Many fewer than this number raises the cost significantly while many more gains little in terms of reduced costs. Another important conclusion is that the fuel cell sub-system has the potential at least at the synthesis/design point of producing electrical and thermal energy at prices lower than 10 cents/kWh on an exergy basis and 6 cents/kWh on an energy basis for 1482 or greater units manufactured per year. Based on these conclusions, details of the thermodynamic and geometric characteristics of the optimal fuel cell sub-system synthesis/design for 50 residences and 1482 units are presented in the next section.

\subsection{Thermodynamics and Geometry Characteristics of the Optimal Fuel Cell Sub-system at the Synthesis/Design Point for 50 Residences and 1482 Units.}

\subsubsection{Thermodynamic Characteristics}

\footnotetext{
${ }^{14}$ See footnote 13 .
} 


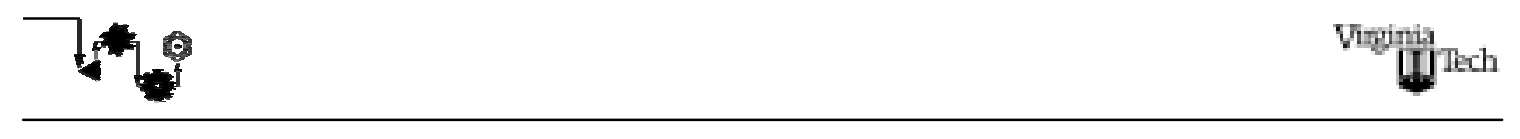

Every simulation of the fuel cell sub-system generates detailed thermodynamic and geometric data that corresponds to a particular sub-system synthesis/design. This section presents and discusses this data for the optimum synthesis/design ${ }^{15}$ of the fuel cell sub-system for 50 residences and 1482 manufactured units per year.

The thermodynamic details of this particular optimal synthesis/design are presented in Figs. 6.19 and 6.20 and Tables 6.10 and 6.11. In Fig. 6.19, the stream numbers, temperatures, and pressures of this particular synthesis/design are presented. Corresponding molar flow rates are summarized in Tables 6.10 and 6.11. The work consumed/produced (mechanical/electrical energy exchange) by the compressors/expander and the fuel cell stack together with the thermal energy exchanged in the heat exchangers are presented in Fig. 6.20. These thermodynamics details allow one to have some insight into the operation of the system at the synthesis/design point. Two aspects of this operation are discussed in some detail below: the conversion of methane to reformate and the mechanical/electrical balance within the configuration. Other aspects of the configuration like the water balance or the relative humidities of the streams were not object of a detailed study in this thesis work, however the information for such studies is available in the data generated in the simulations of the fuel cell subsystem.

\footnotetext{
${ }^{15}$ The thermodynamic information presented in section 6.4.1 is for the optimal synthesis/design determined based on the synthesis/design point alone. When optimal off-design information is taken into account as it is later in this chapter, it turns out that the optimal solution is actually one of the near optimum solutions determined at the synthesis/design point. Section 6.4.2 presents geometric information for both of these solutions.
} 


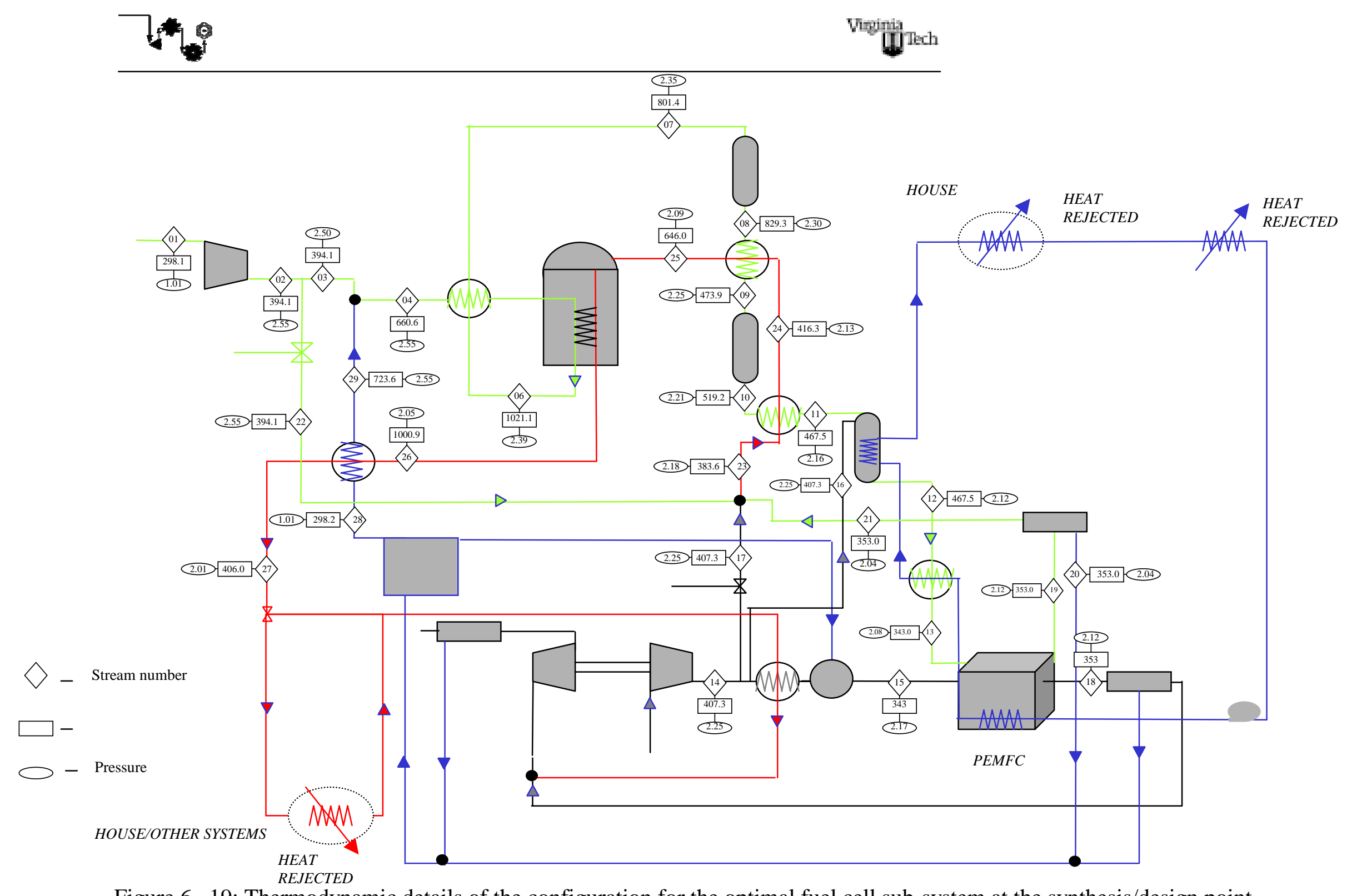

Figure 6. 19: Thermodynamic details of the configuration for the optimal fuel cell sub-system at the synthesis/design point. 
Table 6. 10: Optimum molar flow rates, temperatures, and pressures for streams 1 to 20 of Fig. 6.19.

\begin{tabular}{|l|l|c|c|c|c|c|c|c|c|c|c|}
\hline Stream number & & $\mathbf{1}$ & $\mathbf{2}$ & $\mathbf{3}$ & $\mathbf{4}$ & $\mathbf{5}$ & $\mathbf{6}$ & $\mathbf{7}$ & $\mathbf{8}$ & $\mathbf{9}$ & $\mathbf{1 0}$ \\
\hline Temperature & {$[\mathbf{K}]$} & 298.1 & 394.1 & 394.1 & 660.6 & 906.3 & 1021.1 & 801.4 & 829.3 & 473.9 & 519.2 \\
\hline Pressure & {$[\mathbf{b a r}]$} & 1.01 & 2.55 & 2.55 & 2.55 & 2.49 & 2.39 & 2.35 & 2.30 & 2.25 & 2.21 \\
\hline $\mathbf{H}_{\mathbf{2}}$ & {$[\mathbf{k m o l} / \mathbf{h}]$} & 0.000 & 0.000 & 0.000 & 0.000 & 0.000 & 4.115 & 4.115 & 4.343 & 4.343 & 4.671 \\
\hline $\mathbf{N}_{\mathbf{2}}$ & {$[\mathbf{k m o l} / \mathbf{h}]$} & 0.000 & 0.000 & 0.000 & 0.000 & 0.000 & 0.000 & 0.000 & 0.000 & 0.000 & 0.000 \\
\hline $\mathbf{O}_{\mathbf{2}}$ & {$[\mathbf{k m o l} / \mathbf{h}]$} & 0.000 & 0.000 & 0.000 & 0.000 & 0.000 & 0.000 & 0.000 & 0.000 & 0.000 & 0.000 \\
\hline $\mathbf{C O}$ & {$[\mathbf{k m o l} / \mathbf{h}]$} & 0.000 & 0.000 & 0.000 & 0.000 & 0.000 & 0.577 & 0.577 & 0.349 & 0.349 & 0.021 \\
\hline $\mathbf{C O}_{\mathbf{2}}$ & {$[\mathbf{k m o l} / \mathbf{h}]$} & 0.000 & 0.000 & 0.000 & 0.000 & 0.000 & 0.596 & 0.596 & 0.824 & 0.824 & 1.152 \\
\hline $\mathbf{C H}_{\mathbf{4}}$ & {$[\mathbf{k m o l} / \mathbf{h}]$} & 1.563 & 1.563 & 1.174 & 1.174 & 1.174 & 0.001 & 0.001 & 0.001 & 0.001 & 0.001 \\
\hline $\mathbf{H}_{\mathbf{2}} \mathbf{T}$ & {$[\mathbf{k m o l} / \mathbf{h}]$} & 0.000 & 0.000 & 0.000 & 5.142 & 5.142 & 3.374 & 3.374 & 3.145 & 3.145 & 2.818 \\
\hline Total molar flow rate & {$[\mathbf{k m o l} / \mathbf{h}]$} & 1.563 & 1.563 & 1.174 & 6.317 & 6.317 & 8.663 & 8.663 & 8.663 & 8.663 & 8.663 \\
\hline
\end{tabular}

\begin{tabular}{|l|l|c|c|c|c|c|c|c|c|c|c|}
\hline Stream number & & $\mathbf{1 1}$ & $\mathbf{1 2}$ & $\mathbf{1 3}$ & $\mathbf{1 4}$ & $\mathbf{1 5}$ & $\mathbf{1 6}$ & $\mathbf{1 7}$ & $\mathbf{1 8}$ & $\mathbf{1 9}$ & $\mathbf{2 0}$ \\
\hline Temperature & {$[\mathbf{K}]$} & 467.5 & 467.5 & 343.0 & 407.3 & 343.0 & 407.3 & 407.3 & 353.0 & 353.0 & 353.0 \\
\hline Pressure & {$[\mathbf{b a r}]$} & 2.16 & 2.12 & 2.08 & 2.25 & 2.17 & 2.25 & 2.25 & 2.08 & 2.08 & 2.04 \\
\hline $\mathbf{H}_{\mathbf{2}}$ & {$[\mathbf{k m o l} / \mathbf{h}]$} & 4.671 & 4.607 & 4.607 & 0.000 & 0.000 & 0.000 & 0.000 & 0 & 0.691 & 0.000 \\
\hline $\mathbf{N}_{\mathbf{2}}$ & {$[\mathbf{k m o l} / \mathbf{h}]$} & 0.000 & 0.159 & 0.159 & 23.940 & 14.794 & 0.159 & 8.987 & 14.79 & 0.159 & 0.000 \\
\hline $\mathbf{O}_{\mathbf{2}}$ & {$[\mathbf{k m o l} / \mathbf{h}]$} & 0.000 & 0.000 & 0.000 & 6.477 & 4.002 & 0.043 & 2.431 & 2.001 & 0.000 & 0.000 \\
\hline $\mathbf{C O}$ & {$[\mathbf{k m o l} / \mathbf{h}]$} & 0.021 & 0.000 & 0.000 & 0.000 & 0.000 & 0.000 & 0.000 & 0.000 & 0.000 & 0.000 \\
\hline $\mathbf{C O}_{\mathbf{2}}$ & {$[\mathbf{k m o l} / \mathbf{h}]$} & 1.152 & 1.173 & 1.173 & 0.000 & 0.000 & 0.000 & 0.000 & 0.000 & 1.173 & 0.000 \\
\hline $\mathbf{C H}_{\mathbf{4}}$ & {$[\mathbf{k m o l} / \mathbf{h}]$} & 0.001 & 0.001 & 0.001 & 0.000 & 0.000 & 0.000 & 0.000 & 0.000 & 0.001 & 0.000 \\
\hline $\mathbf{H}_{\mathbf{2}} \mathbf{T}$ & {$[\mathbf{k m o l} / \mathbf{h}]$} & 2.818 & 2.881 & 2.881 & 0.000 & 0.000 & 0.000 & 0.000 & 3.927 & 2.881 & 2.593 \\
\hline Total molar flow rate & {$[\mathbf{k m o l} / \mathbf{h}]$} & 8.663 & 8.822 & 8.822 & 30.417 & 18.796 & 0.203 & 11.419 & 20.7 & 4.906 & 2.593 \\
\hline
\end{tabular}




7 *

Table 6. 11: Optimum molar flow rates, temperatures and pressures for streams 21 to 29 in Fig. 6.19.

\begin{tabular}{|c|c|c|c|c|c|c|c|c|c|c|}
\hline Stream number & & 21 & 22 & 23 & 24 & 25 & 26 & 27 & 28 & 29 \\
\hline Temperature & [K] & 353.0 & 394.1 & 383.6 & 416.3 & 646.0 & 1100 & 406.0 & 298.2 & 723.6 \\
\hline Pressure & [bar] & 2.04 & 2.55 & 2.18 & 2.13 & 2.09 & 2.05 & 2.01 & 2.60 & 2.55 \\
\hline $\mathbf{H}_{2}$ & {$[\mathrm{kmol} / \mathrm{h}]$} & 0.691 & 0.000 & 0.691 & 0.691 & 0.691 & 0.000 & 0.000 & 0.000 & 0.000 \\
\hline $\mathbf{N}_{2}$ & {$[\mathrm{kmol} / \mathrm{h}]$} & 0.159 & 0.000 & 9.147 & 9.147 & 9.147 & 9.147 & 9.147 & 0.000 & 0.000 \\
\hline $\mathbf{O}_{2}$ & {$[\mathrm{kmol} / \mathrm{h}]$} & 0.000 & 0.000 & 2.431 & 2.431 & 2.431 & 0.862 & 0.862 & 0.000 & 0.000 \\
\hline $\mathrm{CO}$ & {$[\mathrm{kmol} / \mathrm{h}]$} & 0.000 & 0.000 & 0.000 & 0.000 & 0.000 & 0.000 & 0.000 & 0.000 & 0.000 \\
\hline $\mathrm{CO}_{2}$ & {$[\mathrm{kmol} / \mathrm{h}]$} & 1.173 & 0.000 & 1.173 & 1.173 & 1.173 & 1.561 & 1.561 & 0.000 & 0.000 \\
\hline $\mathrm{CH}_{4}$ & {$[\mathrm{kmol} / \mathrm{h}]$} & 0.001 & 0.388 & 0.388 & 0.388 & 0.388 & 0.000 & 0.000 & 0.000 & 0.000 \\
\hline $\mathbf{H}_{2} \mathbf{O}$ & {$[\mathrm{kmol} / \mathrm{h}]$} & 0.288 & 0.000 & 0.288 & 0.288 & 0.288 & 3.512 & 3.512 & 5.142 & 5.142 \\
\hline Total molar flow rate & {$[\mathrm{kmol} / \mathrm{h}]$} & 2.313 & 0.388 & 14.11 & 14.119 & 14.119 & 15.08 & 15.08 & 5.142 & 5.142 \\
\hline
\end{tabular}




$7 * 0$

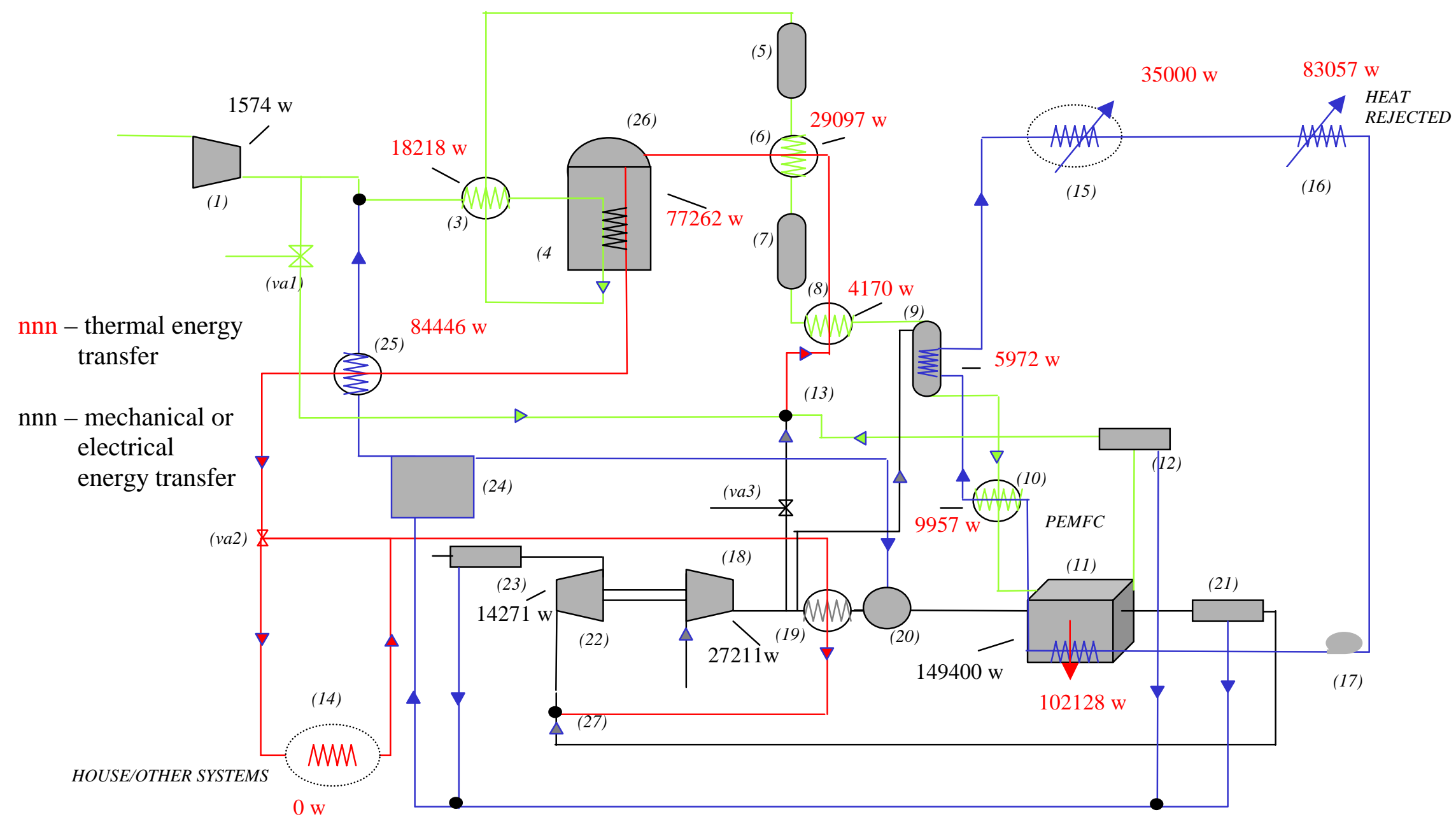

Figure 6. 20: Mechanical/electrical exchanges and thermal energy exchanges within and from the configuration for the optimal fuel cell sub-system at the synthesis/design point (50 residences, 1482 units manufactured per year). 

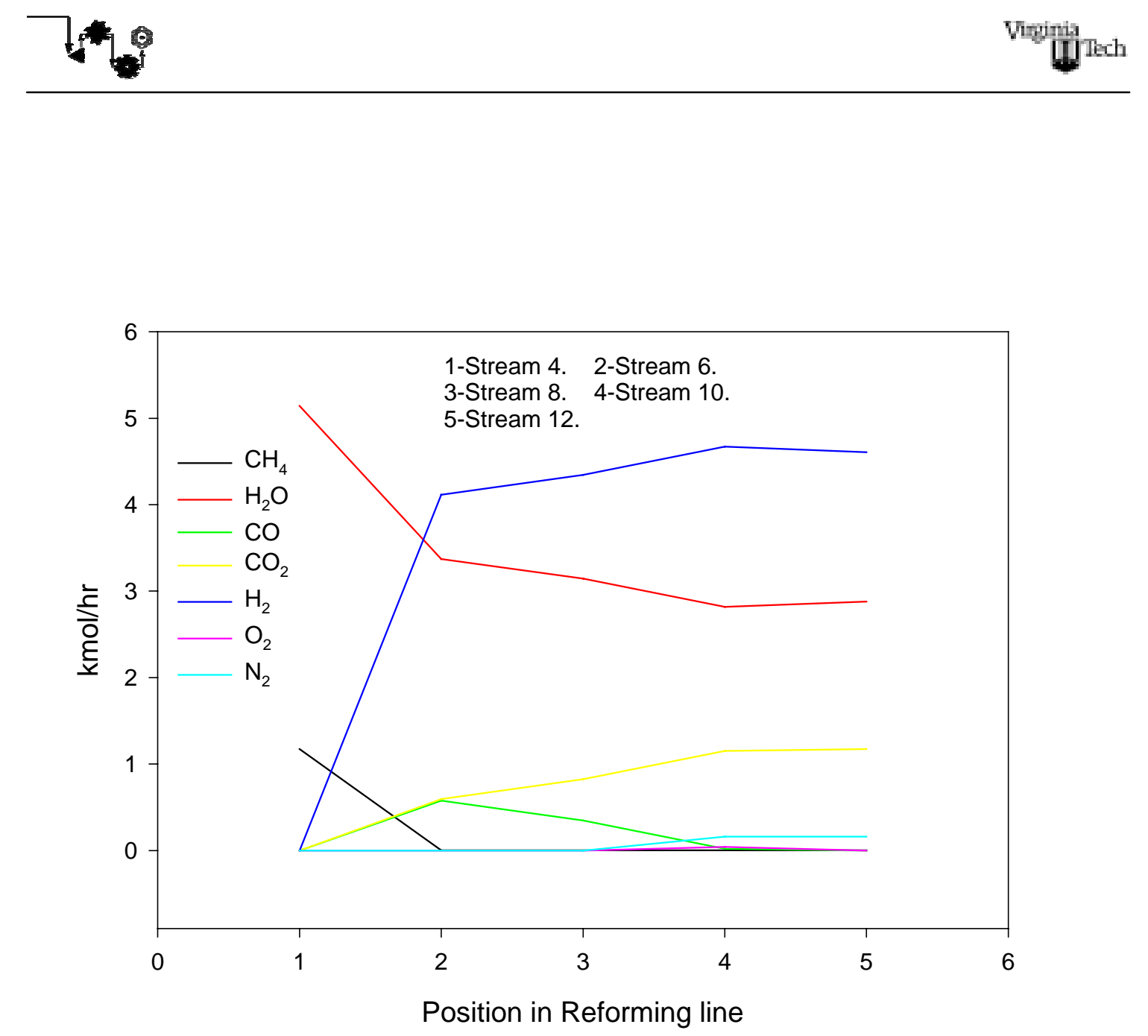

Figure 6. 21: Conversion of the methane to reformate in the FPS for the optimum fuel cell sub-system at the synthesis/design point (50 residences, 1482 units manufactured per year).

In Fig 6.21, the chemical composition of the methane/reformate at different stages of the FPS is presented. From this data, it is evident that most of the conversion of the methane and steam into hydrogen is achieved in the steam reformer reactor. However, the HTS and LTS play a two-fold strategic role. They first increase the concentration of hydrogen in the reformate and second decrease the concentration of carbon monoxide. As was explained in Chapter 2, the presence of carbon monoxide in the reformate that enters the stack poisons the Pt catalyst in the cells so that the concentration of carbon monoxide must be decreased to a few ppm (parts per million). As shown in Fig. 6.21, the PROX 


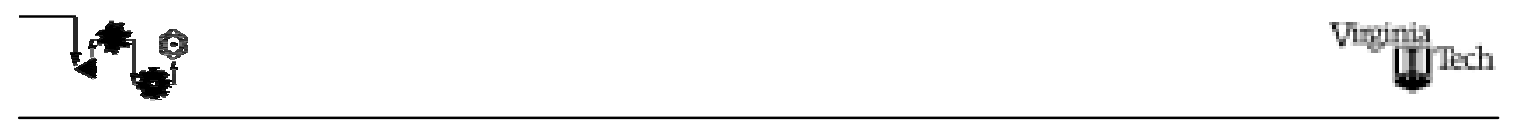

reactor performs this reduction although at the expense of decreases in hydrogen concentration $^{16}$.

Another important feature of the configuration is the mechanical/electrical energy balance shown in Fig. 6.20. The parasitic work needed to optimally run the methane and air compressors at the synthesis/design point is $28.78 \mathrm{kWe}$, which represents $21.3 \%$ of the total net power output (135kWe). However, the expander (component 22 in Fig. 2.8) recovers an important part of this energy $(14.21 \mathrm{kWe})$ by expanding the combustion gases and the air before exhausting them to the atmosphere. This fact reduces the parasitic work loses to $11 \%$ of the total net power output, which represents an important improvement in performance for the configuration.

\subsubsection{Geometric Characteristics}

The detailed geometry for the optimal fuel cell sub-system at the synthesis/design point for 50 residences and 1482 units manufactured per year is summarized in Tables 6.12 through 6.15. That for the optimal fuel cell sub-system based on the synthesis/design point and for optimal off-design information is summarized in Tables 6.16 through 6.19.

Table 6. 12: Geometry for the heat exchangers of the optimal fuel cell sub-system at the synthesis/design point.

\begin{tabular}{|l|c|c|c|}
\hline \multicolumn{1}{|c|}{ Variable } & $\begin{array}{c}\text { Heat exchanger } \\
\text { (component 3) }\end{array}$ & $\begin{array}{c}\text { Heat } \\
\text { exchanger } \\
\text { (component 6) }\end{array}$ & $\begin{array}{c}\text { Heat } \\
\text { exchanger } \\
\text { (component 8) }\end{array}$ \\
\hline Characteristic length $^{17}(\mathrm{~mm})$ & 167 & 155 & 72 \\
\hline Number of plates & 13 & 12 & 6 \\
\hline $\begin{array}{l}\text { Ratio of heat transfer area to } \\
\text { volume }\left(\mathrm{mm}^{2} / \mathrm{mm}^{3}\right)\end{array}$ & 1204 & 1204 & 1204 \\
\hline Fin height $(\mathrm{mm})$ & 6.35 & 6.35 & 6.35 \\
\hline $\begin{array}{l}\text { Hydraulic diameter of the } \\
\text { conduits }(\mathrm{mm})\end{array}$ & 3.08 & 3.08 & 3.08 \\
\hline
\end{tabular}

16 In reality, typically additional processes downstream of the PROX reactor such a pressure-swing absorption (PSA) or metal or polymer membranes are needed to reduce the $\mathrm{CO}$ concentration down to a few ppm.

${ }^{17}$ For the compact heat exchangers of the configuration, the same length in the three spatial dimensions is assumed. This length is taken as the characteristic dimension of the heat exchanger. 


70

Table 6. 13: Optimum geometry for the steam generator based only on the synthesis/design point.

\begin{tabular}{|l|c|}
\hline \multicolumn{1}{|c|}{ Varible } & Steam Generator (component 25) \\
\hline Number of tubes & 30 \\
\hline Outer tube diameter $(\mathrm{mm})$ & 19 \\
\hline Tube thickness $(\mathrm{mm})$ & 3 \\
\hline Baffle spacing $(\mathrm{mm})$ & 243.8 \\
\hline Pitch $(\mathrm{mm})$ & 24.7 \\
\hline Shell diameter $(\mathrm{mm})$ & 380 \\
\hline Tube passes & 4 \\
\hline Shell passes & 1 \\
\hline Economizer characteristic length $(\mathrm{mm})$ & 1888 \\
\hline Evaporator characteristic length $(\mathrm{mm})$ & 1986 \\
\hline Superheater characteristic length $(\mathrm{mm})$ & 1005 \\
\hline Total length of the tubes $(\mathrm{mm})$ & 4879 \\
\hline
\end{tabular}

Table 6. 14: Optimum geometry for the steam reformer reactor based only on the synthesis/design point.

\begin{tabular}{|l|c|}
\hline \multicolumn{1}{|c|}{ Variable } & Steam Reformer (component 4) \\
\hline Number of tubes & 25 \\
\hline Pitch $(\mathrm{mm})$ & 24 \\
\hline Shell diameter $(\mathrm{mm})$ & 140 \\
\hline Total length $(\mathrm{mm})$ & 1100 \\
\hline Characteristic diameter of the catalyst $(\mathrm{mm})$ & 2.5 \\
\hline
\end{tabular}

Table 6. 15: Optimum geometry for the fuel cell stack based on the synthesis/design point only.

\begin{tabular}{|l|c|}
\hline \multicolumn{1}{|c|}{ Variable } & Stack (component 11) \\
\hline Number of cells & 643 \\
\hline Active area per cell $\left(\mathrm{m}^{2}\right)$ & 0.06 \\
\hline
\end{tabular}


Table 6. 16: Geometry for the heat exchangers of the optimal fuel cell sub-system determined based on the synthesis/design point and off-design information.

\begin{tabular}{|l|c|c|c|}
\hline \multicolumn{1}{|c|}{ Variable } & $\begin{array}{c}\text { Heat exchanger } \\
\text { (component 3) }\end{array}$ & $\begin{array}{c}\text { Heat } \\
\text { exchanger } \\
\text { component 6) }\end{array}$ & $\begin{array}{c}\text { Heat } \\
\text { exchanger } \\
\text { (component 8) }\end{array}$ \\
\hline Characteristic length (mm) & 167 & 172 & 114 \\
\hline Number of plates & 13 & 14 & 9 \\
\hline $\begin{array}{l}\text { Ratio of heat transfer area to } \\
\text { volume }\left(\mathrm{mm}^{2} / \mathrm{mm}^{3} \text { ) }\right.\end{array}$ & 1204 & 1204 & 1204 \\
\hline Fin height (mm) & 6.35 & 6.35 & 6.35 \\
\hline $\begin{array}{l}\text { Hydraulic diameter of the } \\
\text { conduits (mm) }\end{array}$ & 3.08 & 3.08 & 3.08 \\
\hline
\end{tabular}

Table 6. 17: Optimum geometry for the steam generator based on the synthesis/design point and off-design.

\begin{tabular}{|l|c|}
\hline \multicolumn{1}{|c|}{ Variable } & Steam Generator (component 25) \\
\hline Number of tubes & 30 \\
\hline Outer tube diameter $(\mathrm{mm})$ & 19 \\
\hline Tube thickness $(\mathrm{mm})$ & 3 \\
\hline Baffle spacing $(\mathrm{mm})$ & 228.2 \\
\hline Pitch $(\mathrm{mm})$ & 24.7 \\
\hline Shell diameter $(\mathrm{mm})$ & 380 \\
\hline Tube passes & 4 \\
\hline Shell passes & 1 \\
\hline Economizer characteristic length $(\mathrm{mm})$ & 1373 \\
\hline Evaporator characteristic length $(\mathrm{mm})$ & 1819 \\
\hline Superheater characteristic length $(\mathrm{mm})$ & 916 \\
\hline Total length of the tubes $(\mathrm{mm})$ & 4108 \\
\hline
\end{tabular}




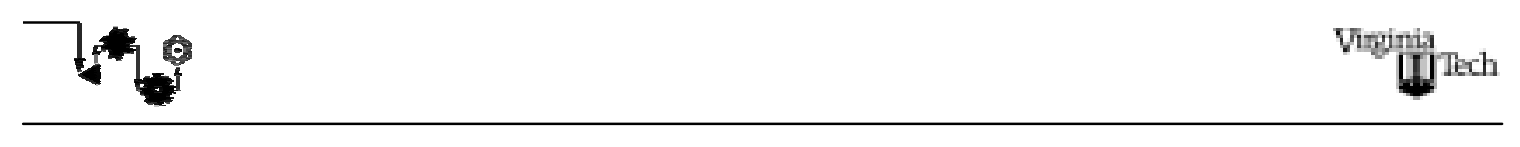

Table 6. 18: Optimum geometry for the steam reformer reactor based on the synthesis/design point and off-design.

\begin{tabular}{|l|c|}
\hline \multicolumn{1}{|c|}{ Variable } & Steam Reformer (component 4) \\
\hline Number of tubes & 25 \\
\hline Pitch $(\mathrm{mm})$ & 24 \\
\hline Shell diameter $(\mathrm{mm})$ & 140 \\
\hline Total length $(\mathrm{mm})$ & 1015 \\
\hline Characteristic diameter of the catalyst $(\mathrm{mm})$ & 2.5 \\
\hline
\end{tabular}

Table 6. 19: Optimum geometry for the fuel cell stack based on the synthesis/design point and off-design.

\begin{tabular}{|l|c|}
\hline \multicolumn{1}{|c|}{ Variable } & Stack (component 11) \\
\hline Number of cells & 605 \\
\hline Active area per cell $\left(\mathrm{m}^{2}\right)$ & 0.06 \\
\hline
\end{tabular}

The geometric variable values are calculated as dependent variables. That is to say, for every optimal or near-optimal combination of independent and coupling function variables (see Table 5.2) for the fuel cell sub-system, feasible geometric variable values are calculated.

As mentioned in Chapter 3, an equilibrium model as opposed to a kinetic rate model is used for the steam reformer. Such an equilibrium model leads to an oversizing of the reactor component since, in fact, equilibrium is achieved somewhere within the interior of the steam methane reformer model. Thus, the real size required for the steam reformer is $60 \%$ to $50 \%$ of the length $(1100 \mathrm{~mm})$ calculated in this thesis work. Work presently underway at Virginia Tech has moved to a kinetic rate based model in order to correct this oversizing of the optimal steam reformer. Finally. The geometric data of Tables 6.12 through 6.14 is graphically represented in Figs. 6.22 through 6.26. Obviously, the data of Tables 6.16 through 6.19 could easily be substituted in these figures. 


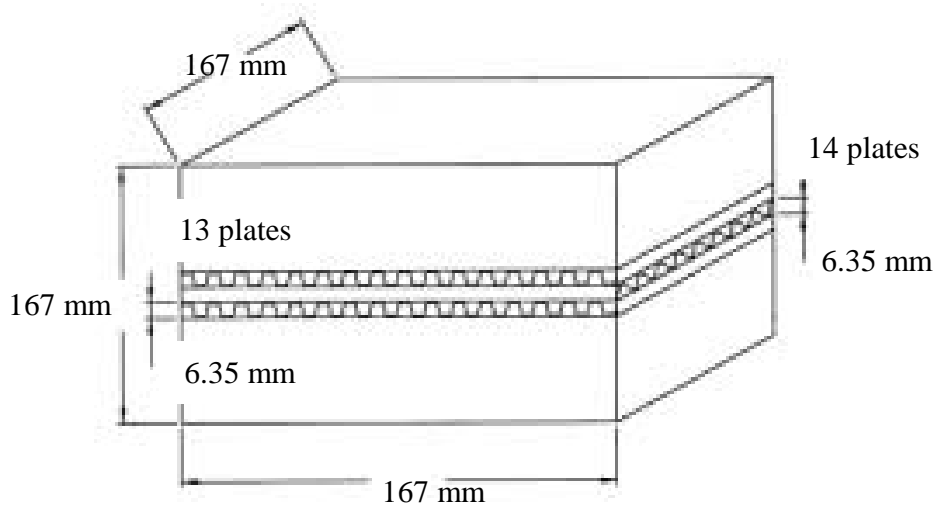

Figure 6. 22: Graphical representation of the geometric data of Table 6.12 for the heat exchanger prior to the steam reformer reactor (component 3 in Fig 2.8).

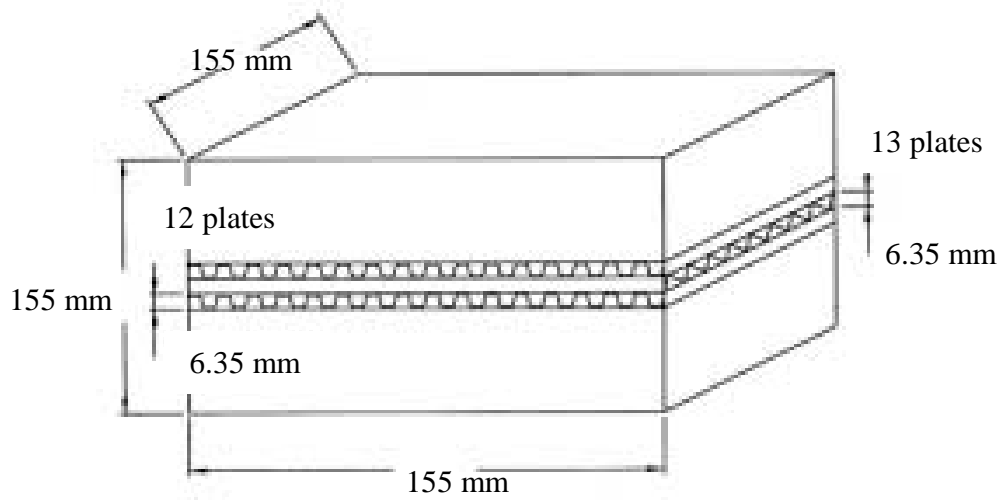

Figure 6. 23: Graphical representation of the geometric data of Table 6.12 for the heat exchanger prior to the LTS reactor (component 6 in Fig 2.8).

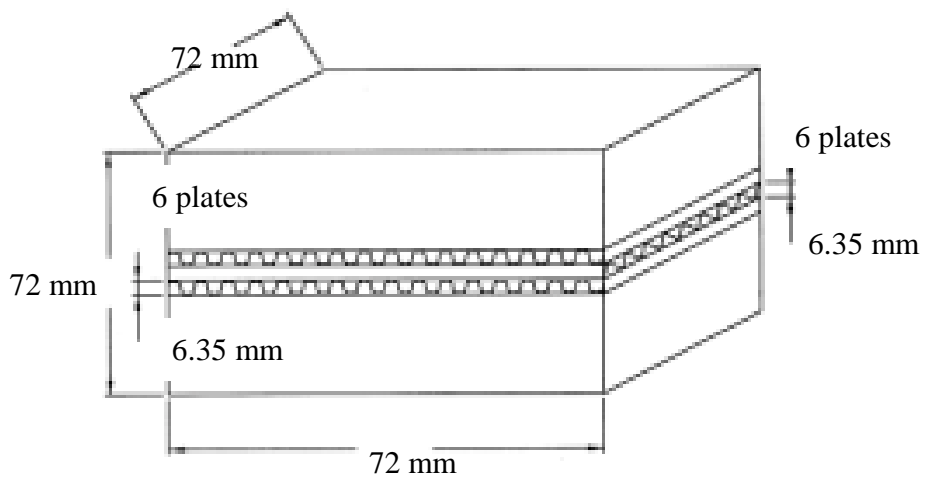

Figure 6. 24: Graphical representation of the geometric data of Table 6.12 for the heat exchanger prior to the PROX reactor (component 8 in Fig 2.8). 


70
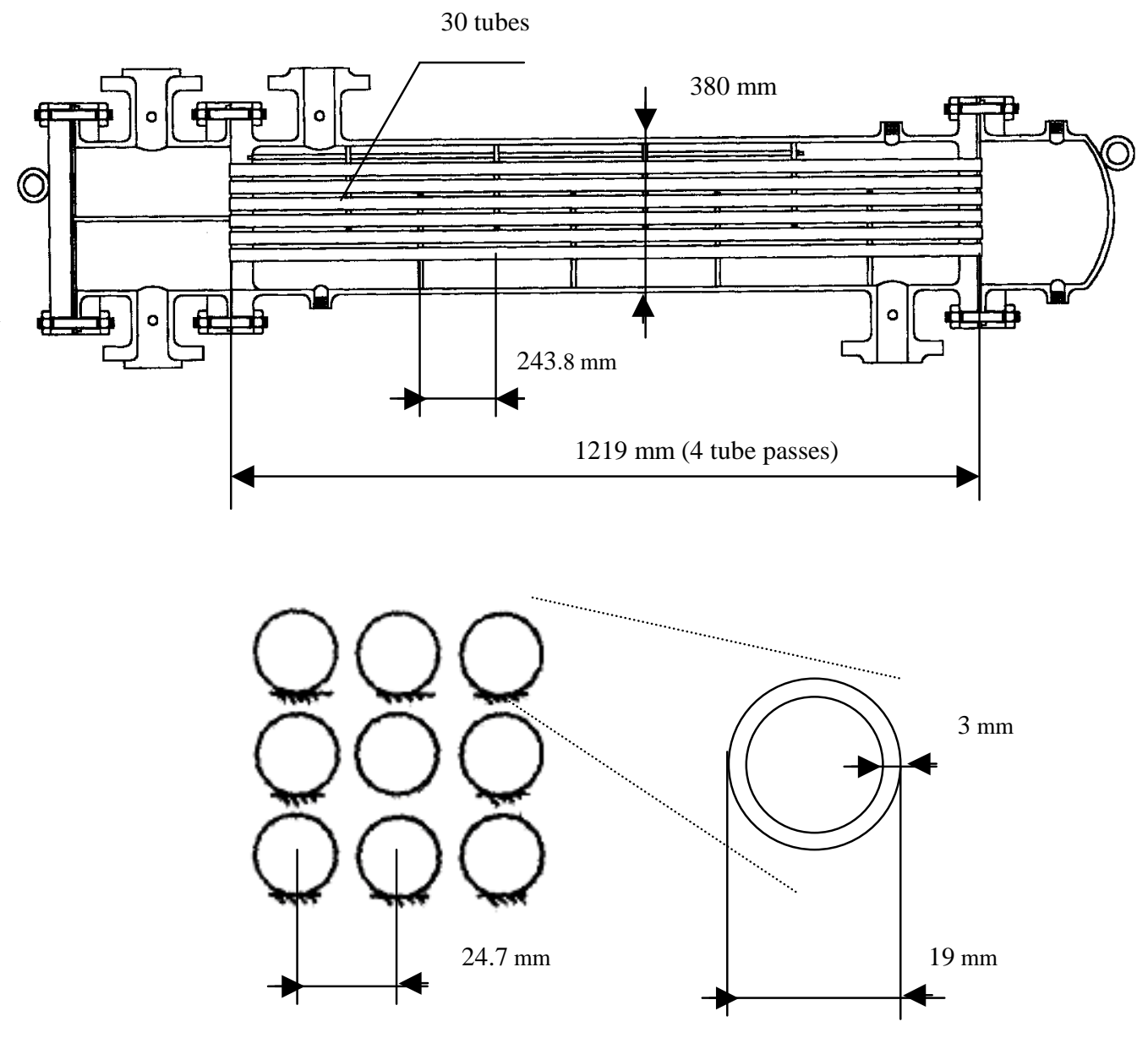

Figure 6. 25: Graphical representation of the geometric data of Table 6.13 for the steam generator (component 25 in Fig 2.8). 


70

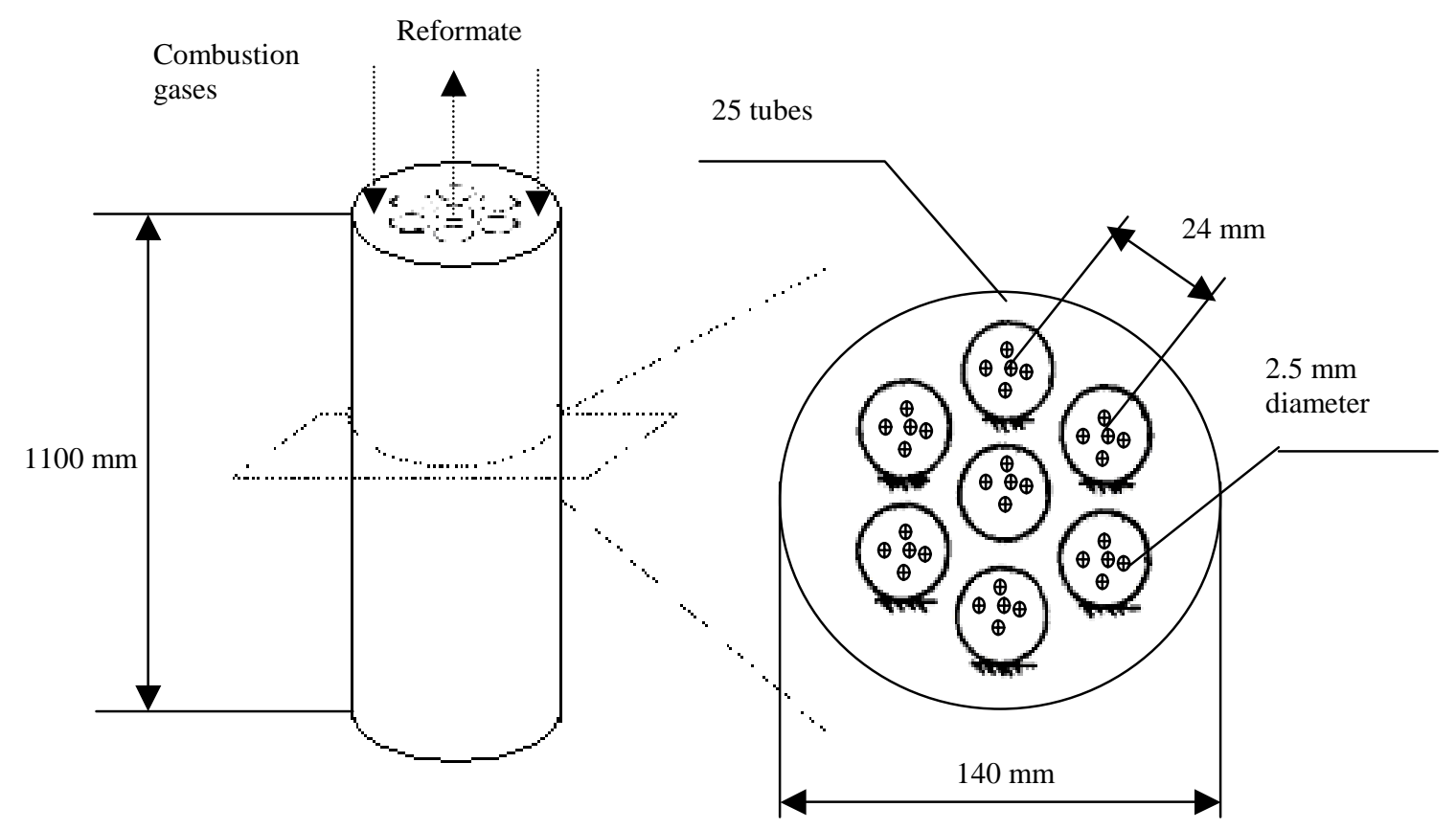

Figure 6. 26: Graphical representation of the geometric data of Table 6.14 for the steam reformer reactor (component 4 in Fig 2.8).

\subsection{Off-design Optimization of the Most Promising Syntheses/designs (50 Residences, 1482 Units)}

The main characteristics of the most promising syntheses/designs for the systemlevel optimization of the fuel cell sub-system for 50 residences and 1482 units manufactured per year are summarized in Table 6.20. This table shows how the two best and the $5^{\text {th }}$ best ${ }^{18}$ syntheses/designs are quite close so that their off-design behavior may help in

\footnotetext{
${ }^{18}$ The $5^{\text {th }}$ best as opposed to $3^{\text {rd }}$ or $4^{\text {th }}$ best synthesis/design was chosen since its configuration in terms of size of the stack and that of the FPS was the most different from that of the optimum and $2^{\text {nd }}$ best syntheses/designs. It, thus, offered the greatest possibility of being affected positively or negatively once the optimal off-design behavior was taken into account.
} 


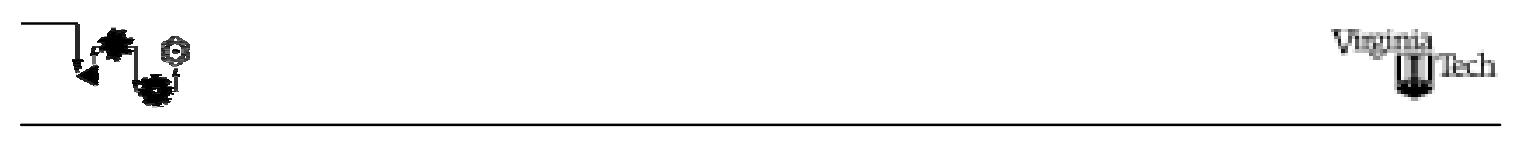

Table 6. 20: Most promising syntheses/designs.

\begin{tabular}{|l|l|l|l|}
\hline \multicolumn{1}{|c|}{ Parameter } & $\begin{array}{l}\text { Optimum } \\
\text { synthesis } \\
\text { /design }\end{array}$ & $\begin{array}{l}\mathbf{2}^{\text {nd }} \text { best } \\
\text { synthesis } \\
\text { /design }\end{array}$ & $\begin{array}{l}\mathbf{5}^{\text {th }} \text { best } \\
\text { synthesis } \\
\text { /design }\end{array}$ \\
\hline Total methane consumed (kmol/hr) & 1.56 & 1.58 & 1.67 \\
\hline Hydrogen consumed (kmol/hr) & 4.6 & 4.8 & 4.84 \\
\hline Power to run the FPS (w) & 5,495 & 6,702 & 6,120 \\
\hline Electrical system efficiency (\%) & 38.7 & 38.24 & 36.2 \\
\hline SS capital cost (\$) & 227,906 & 222,363 & 217,425 \\
\hline FPS capital cost (\$) & 145,019 & 151,780 & 153,044 \\
\hline Fuel cost (\$, over 10 years) & 899,909 & 912,168 & 962,965 \\
\hline Synthesis/design total cost (\$) & $1,272,834$ & $1,286,311$ & $1,333,434$ \\
\hline
\end{tabular}

determining which is the best synthesis/design when the total cost of the configuration is evaluated over the entire environmental/load profile. The results for the optimal offdesign for the optimum synthesis/design at the synthesis/design point are shown in Table 6.21 while those for the $2^{\text {nd }}$ and $5^{\text {th }}$ best syntheses/designs are shown in Tables 6.22 and 6.23. Tables 6.24 and 6.25 tabulate total unit costs based on two products (electricity and heat) for all three syntheses/designs. 
Table 6. 21: Summary of performance for the optimum synthesis/design over the entire environmental/load profile.

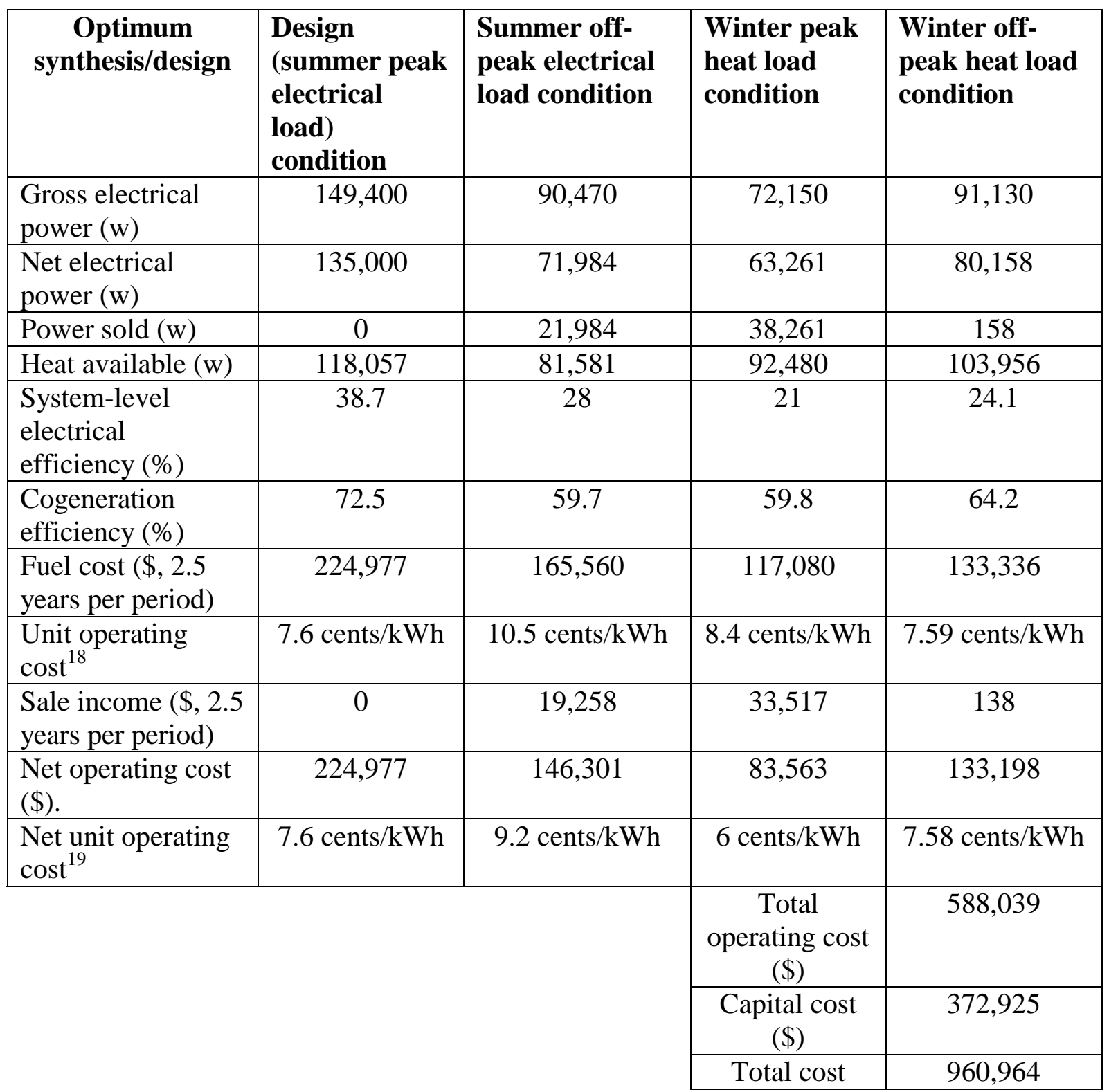

\footnotetext{
${ }^{18}$ These unit costs unlike the ones given in Tables 6.2, 6.3, 6.24 and 6.25 are calculated on the basis of a single product (i.e. electricity) delivered by the fuel cell sub-system. This is done in order to compare this unit cost with the unit sale price for electricity to the electric utility grid which itself is determined on the basis of a single product, namely, electricity..

${ }^{19}$ See footnote 18 .
} 
Table 6. 22: Summary of performance for the $2^{\text {nd }}$ best synthesis/design over the entire environmental/load profile.

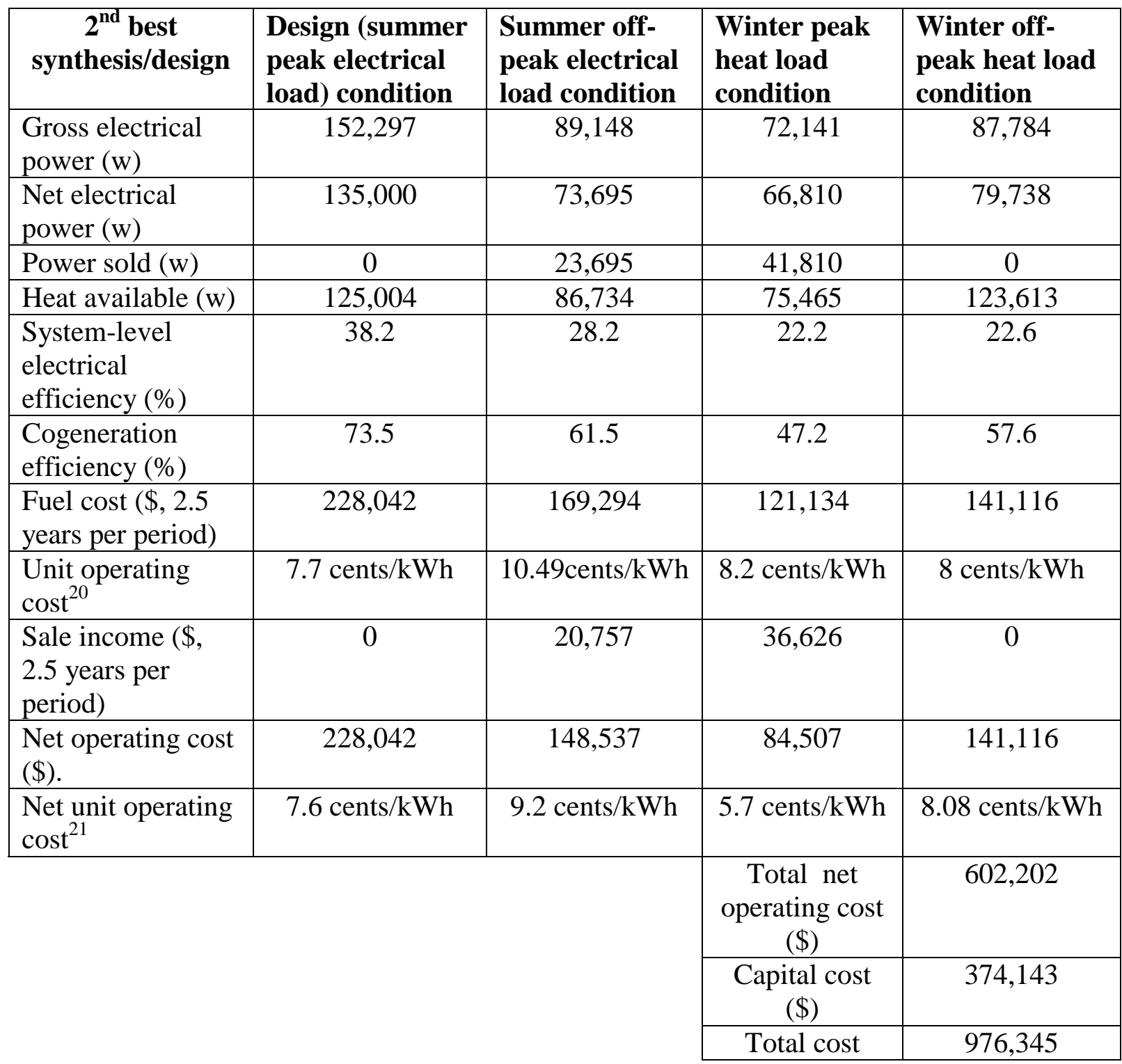

\footnotetext{
${ }^{20}$ See footnote 18 .

${ }^{21}$ See footnote 18 .
} 
Table 6. 23: Summary of performance for the fifth best synthesis/design over the entire environmental/load profile.

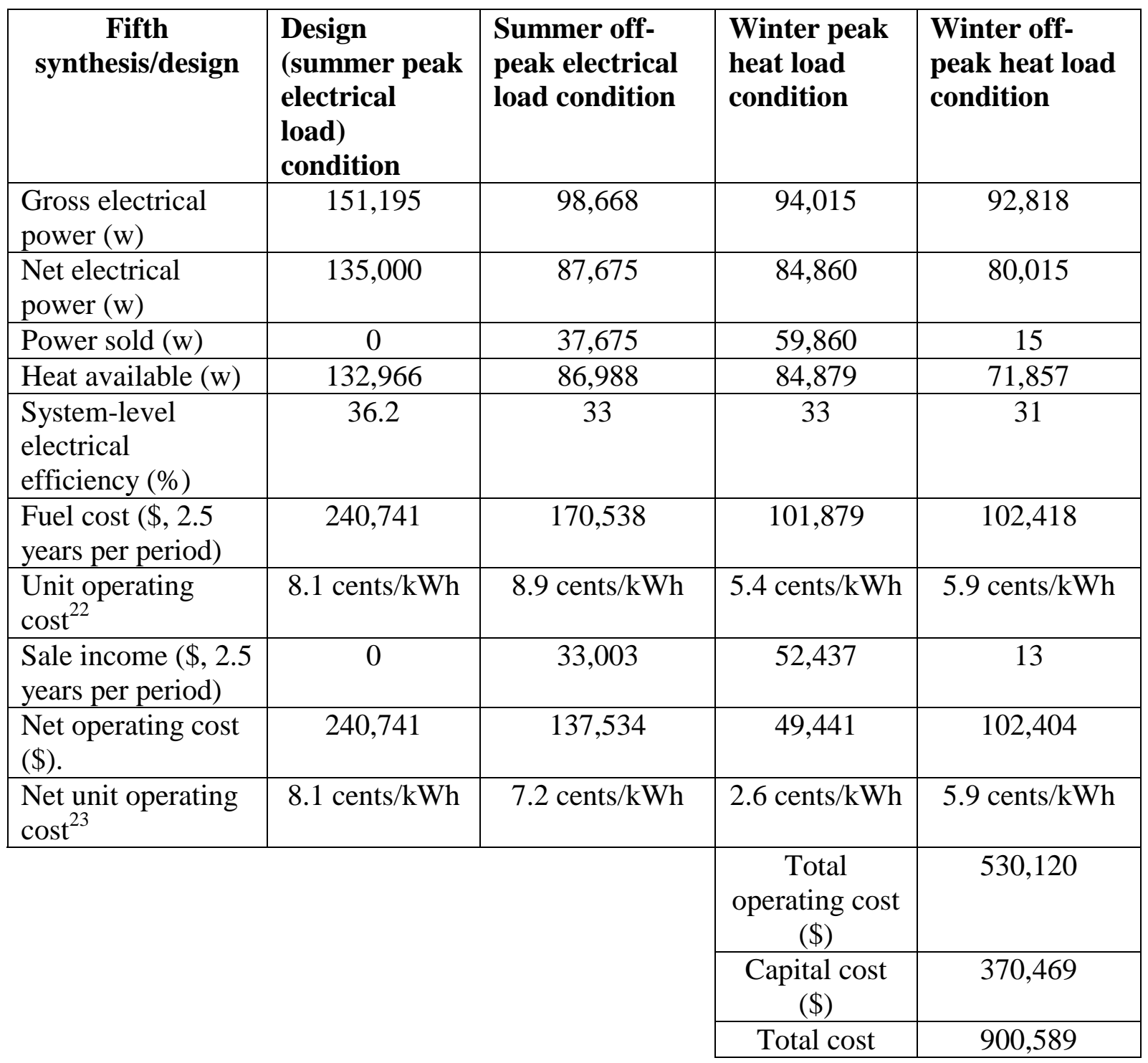

${ }^{22}$ See footnote 18 .

${ }^{23}$ See footnote 19 . 


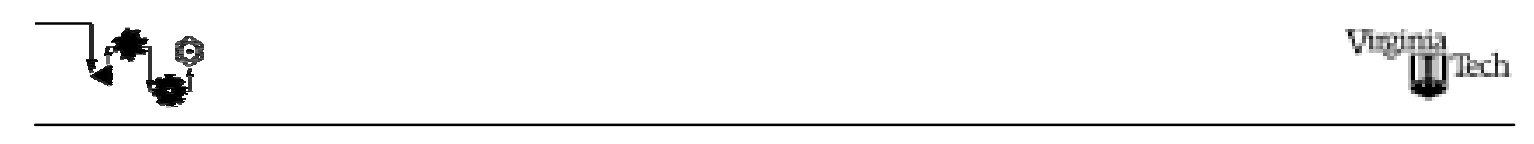

Table 6. 24: Total unit costs on an energy basis for the most promising synthesis/designs.

\begin{tabular}{|l|l|l|l|}
\cline { 2 - 4 } \multicolumn{1}{c|}{} & $\begin{array}{l}\text { Optimum } \\
\text { Synthesis } / \text { design }\end{array}$ & $\begin{array}{l}\mathbf{2}^{\text {nd }} \text { best } \\
\text { synthesis } \\
\text { /design }\end{array}$ & $\begin{array}{l}\mathbf{5}^{\text {th }} \text { best } \\
\text { synthesis/design }\end{array}$ \\
\hline Total unit cost $(\$ / \mathrm{kWh})$ & 0.0587 & 0.0582 & 0.054 \\
\hline
\end{tabular}

Table 6. 25: Total unit costs on an exergy basis for the most promising synthesis/designs.

\begin{tabular}{|l|c|l|l|}
\cline { 2 - 4 } \multicolumn{1}{c|}{} & $\begin{array}{l}\text { Optimum } \\
\text { Synthesis } \\
\text { /design }\end{array}$ & $\begin{array}{l}\mathbf{2}^{\text {nd }} \text { best } \\
\text { synthesis } \\
\text { /design }\end{array}$ & $\begin{array}{l}\mathbf{5}^{\text {th }} \text { best } \\
\text { synthesis/design }\end{array}$ \\
\hline Total unit cost $(\$ / \mathrm{kWh})^{24}$ & 0.0836 & 0.0886 & 0.0834 \\
\hline
\end{tabular}

Three main conclusions arise from an analysis of the off-design behavior of these three syntheses/designs. The first that taking the optimal off-design information into account, the total cost of the second best synthesis/design $(\$ 976,345)$ is greater than that for the optimum synthesis/design $(\$ 960,964)$. However, the $5^{\text {th }}$ best synthesis/design evaluated at the synthesis/design point has a lower total cost $(\$ 900,589)$ than either of the other two when the entire environmental/load profile is considered. This somewhat surprising conclusion is based on the fact that the fuel cell sub-system decreases its performance at small thresholds of electrical power produced. In Fig 6.27 the optimum system electrical efficiency for the optimum synthesis/design is plotted versus the electrical load for the summer environmental conditions. Note that only two optimum points are available for this plot (Summer peak and Summer off-peak load conditions). However, the third point at full load is obtained based on the fact that the system electrical efficiency remains almost constant between approximately $60 \%$ and $100 \%$

\footnotetext{
${ }^{24}$ In order to calculate the total unit cost on an exergy basis the heat exchanger of the combustion gases (component 14 in Fig 2.8) was assumed to have a constant temperature at operation of $250{ }^{\circ} \mathrm{C}$. The rest of the thermal energy produced for the fuel cell sub-system was assumed to be produced at the average temperature of the PROX and the stack for every operating segment. This assumption resembles to a good approximation the operation of the fuel cell sub-system.
} 

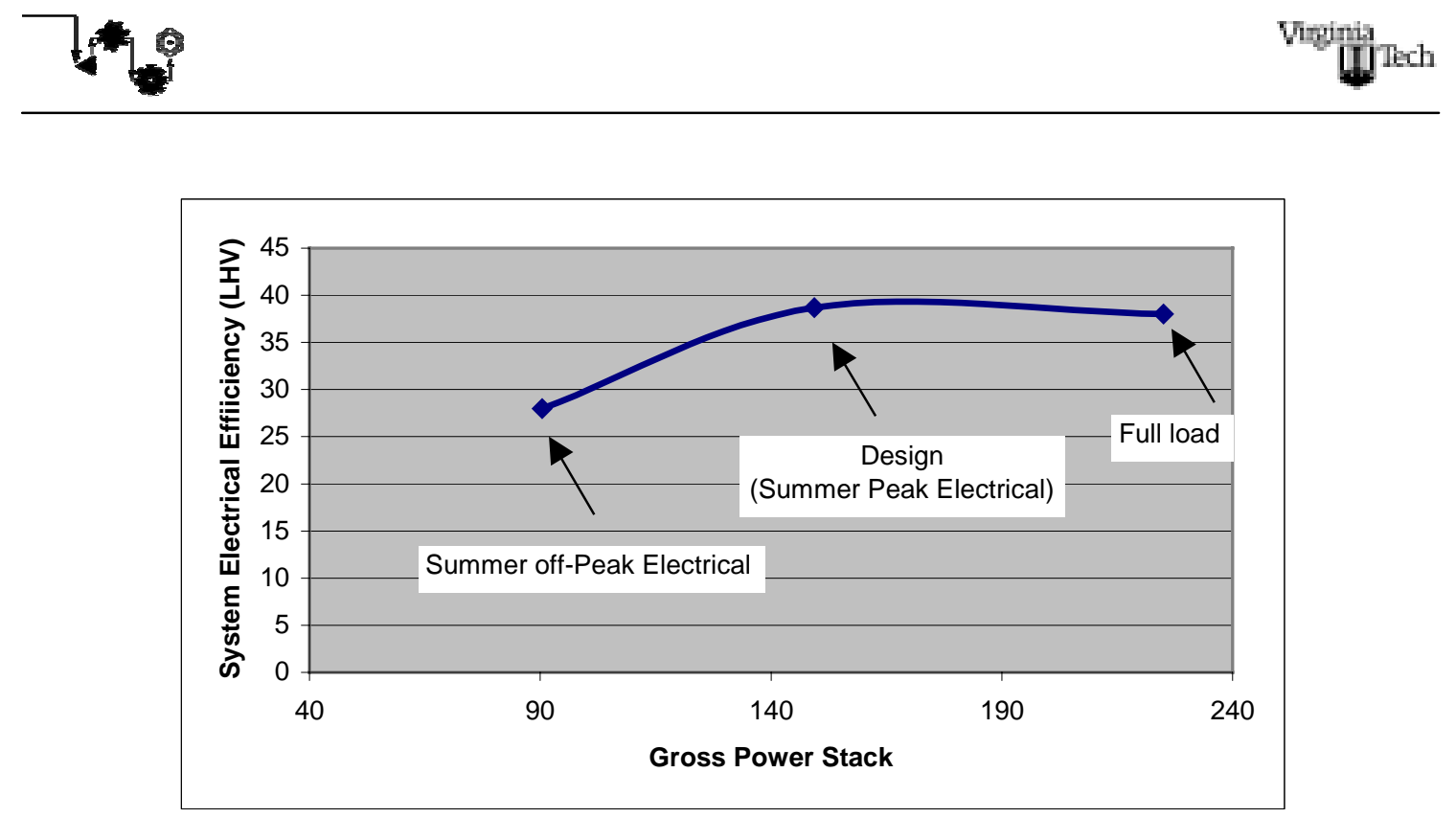

Figure 6. 27: System electrical efficiency based on LHV versus gross power of the stack for the optimum synthesis/design at the different summer load conditions.

of full load ${ }^{25}$, decreasing slightly close to full load. Note that at the synthesis/design point, the fuel cell sub-system is operating at maximum system electric efficiency, which is achieved at approximately $65 \%$ of full load. At the summer off-peak load condition, the optimum for operation is found at the smallest partial load achieved during summer load conditions, which is approximately $40 \%$ of full load. Similar behavior is found for winter conditions (see Fig. 6.28). That is to say, optimum operation under winter offdesign conditions has a relatively small system electrical efficiency. Thus, one may conclude from these figures that operating at maximum system electrical efficiency (approximately $65 \%$ of full load) at the synthesis/design point may not be optimal since

\footnotetext{
${ }^{25}$ Full load was estimated at the maximum power density (About $0.33 \mathrm{kWe} / \mathrm{cell}$ ) and an operating pressure of $350 \mathrm{kPa}$.
} 

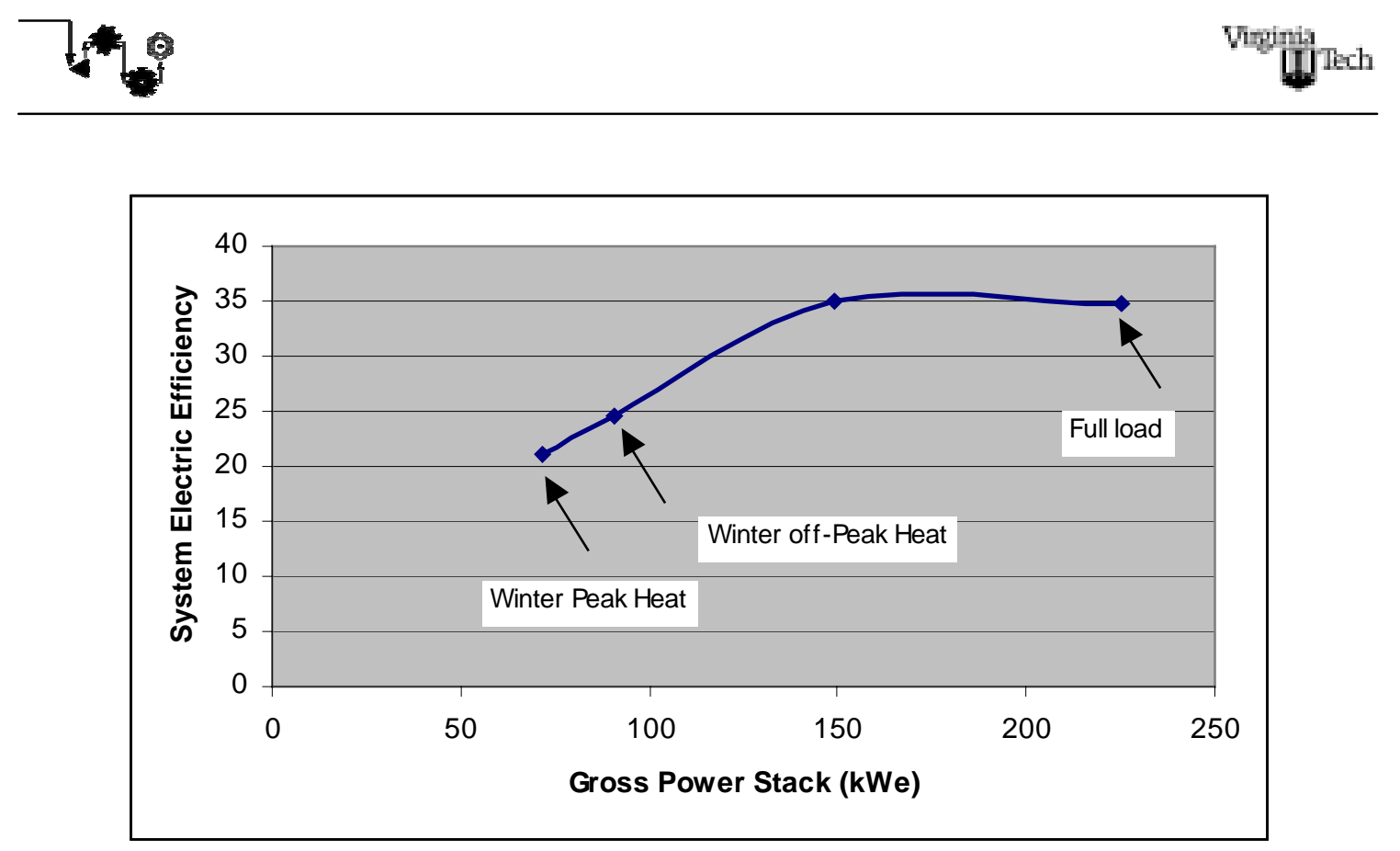

Figure 6. 28: System electrical efficiency (LHV) versus gross power of the stack for the optimum synthesis/design at the different winter load conditions.

It entails a penalty in terms of decreasing system electrical efficiency when optimum operation at off-design is found at small thresholds of electrical power produced. The optimum and $2^{\text {nd }}$ best syntheses/designs follow this behavior while the $5^{\text {th }}$ best synthesis/design does not. The latter, therefore, turns out to be the best overall synthesis/design. Values for the operational variables of the fifth synthesis/design are summarized in Table 6.26.

The second conclusion drawn from an analysis of the off-design behavior is that the configuration of Fig. 2.8 is not able to regulate its operation below a minimum threshold production of electric power (i.e. approximately $35 \%$ of the maximum gross power). The off-design optimization has the tendency to minimize the net electric power output of the fuel cell sub-system. That is to say, the option of selling electricity to the grid (see Problem (5.13)) is, according to the optimization results, not really 
Table 6. 26 Optimum values of the operational variables for the fifth design.

\begin{tabular}{|l|c|c|c|}
\hline Operational variable & $\begin{array}{l}\text { Summer off-peak } \\
\text { electrical load } \\
\text { condition }\end{array}$ & $\begin{array}{l}\text { Winter peak heat } \\
\text { load condition }\end{array}$ & $\begin{array}{l}\text { Winter off-peak } \\
\text { heat load } \\
\text { condition }\end{array}$ \\
\hline$\chi_{\text {air }}$ & 0.708 & 0.705 & 0.688 \\
\hline$\chi_{\mathrm{CH}_{4}}$ & 0.429 & 0.431 & 0.327 \\
\hline$\chi_{\text {exhaust }}$ & 0.737 & 0.8 & 0.95 \\
\hline$V_{\text {cell }}$ & 0.78 & 0.78 & 0.79 \\
\hline$r_{\dot{m}_{\text {air }}}$ & 0.81 & 0.81 & 1.11 \\
\hline$r_{\text {dist }}$ & 0.94 & 0.94 & 0.8 \\
\hline$r_{\mathrm{H}_{2} \mathrm{O} / \mathrm{CH}_{4}}$ & 2.74 & 2.8 & 3.59 \\
\hline
\end{tabular}

economical at any load condition due to the fact that the production cost per $\mathrm{kWh}$ (ranging between 5.4 and 10.5 cents/ $\mathrm{kWh}^{26}$ ) is higher than the sale price of 4 cents/kWh. Nonetheless, electricity is sold under two load conditions (summer off-peak electrical and winter peak heat) to the grid due to the fact that the fuel cell sub-system produces an excess of electricity since it cannot be regulated at these load conditions to a level of production sufficiently low to avoid this. This is seen in Tables 6.21 to 6.23. In contrast, at the winter off-peak load condition, the power sold is effectively zero, while that at the summer peak electrical load condition is identically zero.

To examine more closely the conclusion surrounding the summer off-peak and winter peak heat loads, the net operating cost for the summer off-peak electrical condition is plotted in Fig. 6.29 versus the power sold to the grid for all the feasible simulations used to determine the optimum operating point for the optimum synthesis/design at that particular load condition. It is clear that the less electrical power sold to the grid, the less the net operating cost associated with that particular load condition. The same conclusion applies to the winter peak heat load condition. However, in both cases the fuel cell subsystem does not have a feasible simulation which operates with zero power sold to the grid (i.e. satisfies only the electrical power demand of the residences). There are two

\footnotetext{
${ }^{26}$ See footnote 18 .
} 
possible explanations for this. The first is that the simulation built for off-design is not sufficiently robust to produce sufficiently small electrical outputs. Although possible, it seems unlikely given the fact that a fairly detailed validation process was used to ensure the robustness of the simulation. The other more likely explanation is that the fuel cell sub-system syntheses/designs presented in Tables 6.21 to 23 are not able to operate at the relatively small electrical outputs required. The data at off-design conditions indicates that for all three syntheses/designs, the physical and convergence constraints imposed on the fuel cell sub-system cannot be met when the net power is less than approximately 70 $\mathrm{kWe}$ at the summer off-peak electrical load condition and approximately $60 \mathrm{kWe}$ at the winter peak heat load condition.

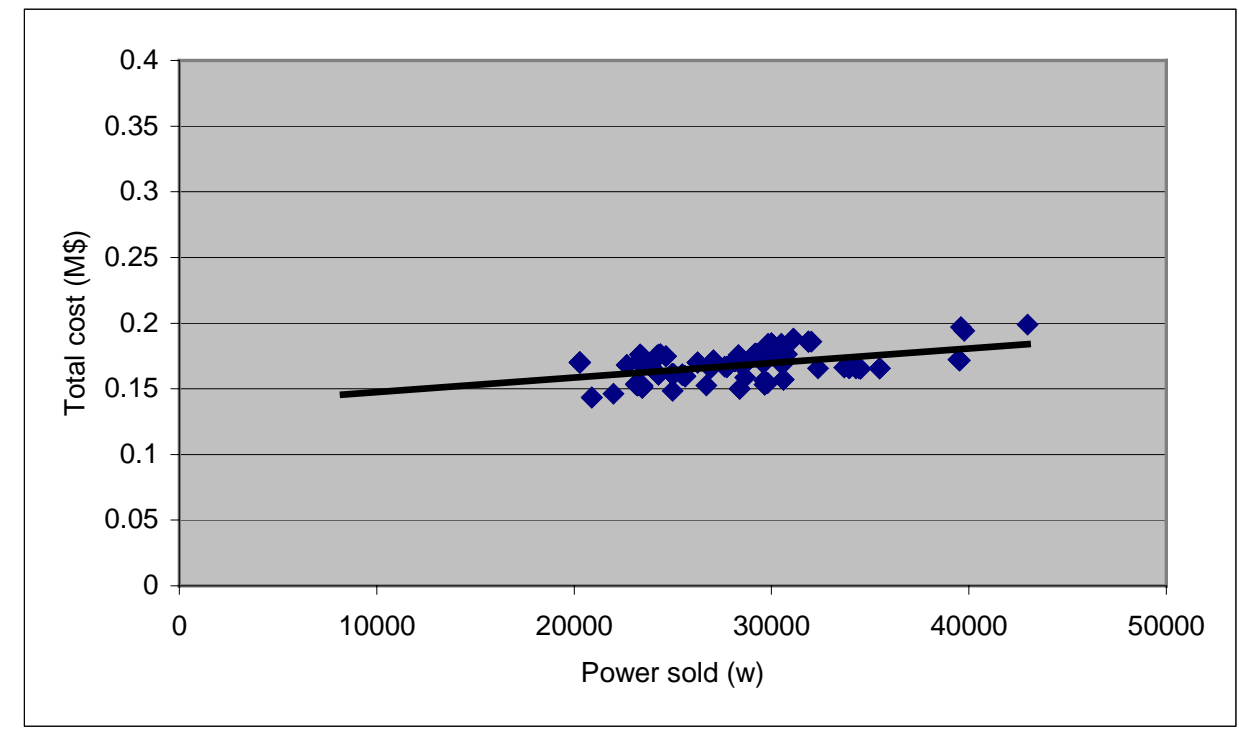

Figure 6. 29: Total cost versus power sold for all the feasible runs at the summer offpeak electric load condition for the optimum synthesis/design shown in Table 6.21. 


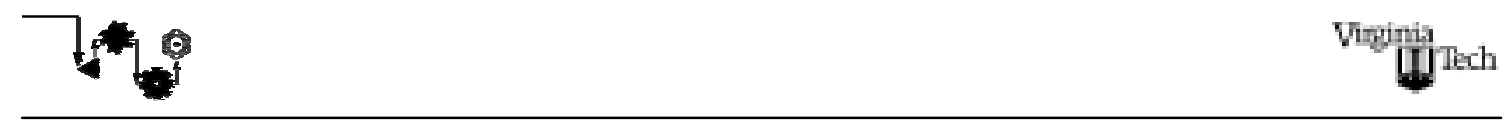

Finally, the last conclusion based on an analysis of off-design performance is that the fuel cell sub-system is unable by itself to satisfy the heating loads of the residences (see Table 2.1). In Fig. 6.30, the net electrical power produced by the fuel cell sub-system

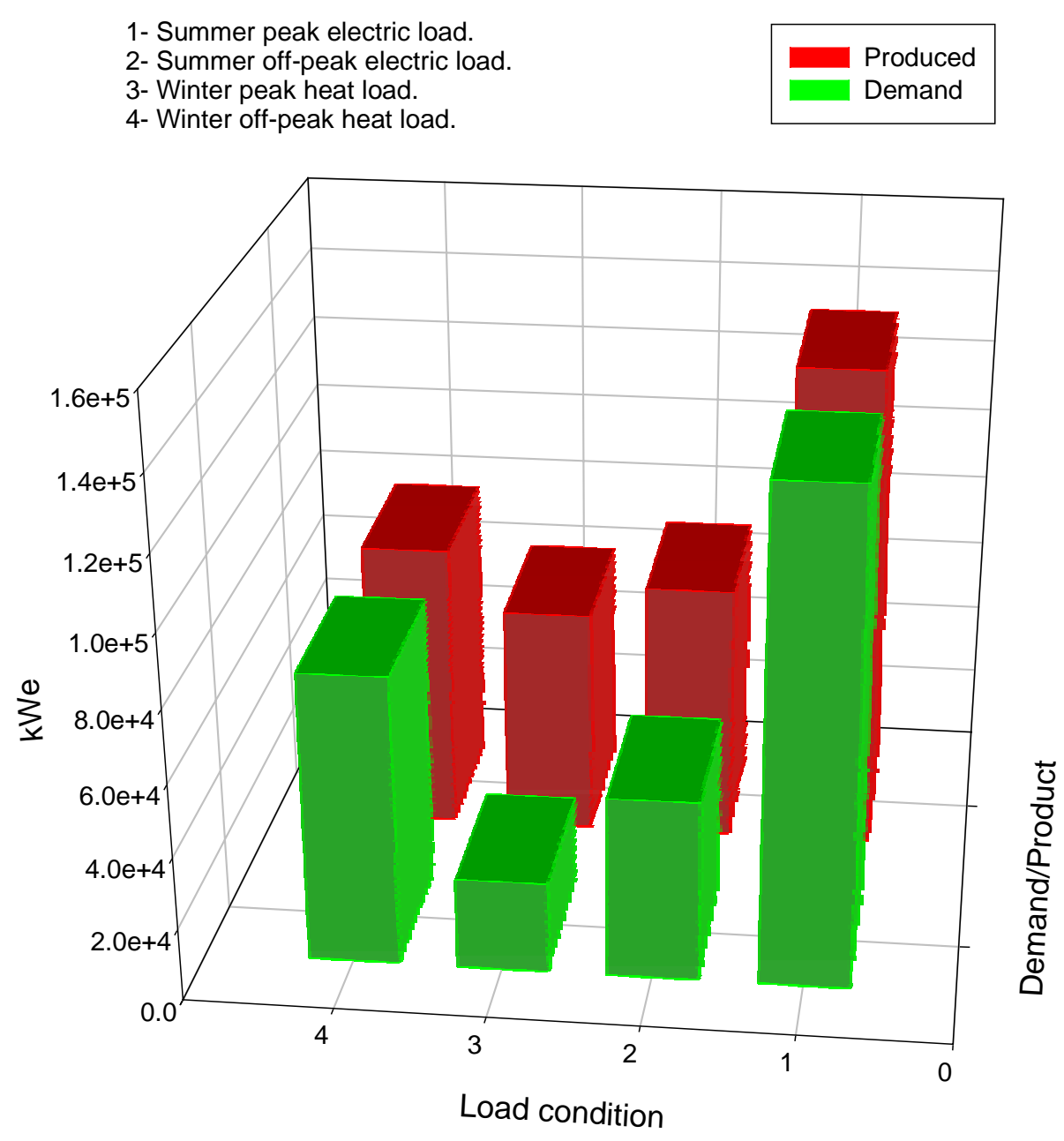

Figure 6. 30: Comparison of the electrical production and the electrical demand over the entire environmental/load profile.

at the optimum synthesis/design point is compared with the electrical demands for each of the four time segments considered in this thesis work. The fuel cell sub-system meets the electrical demands at all load conditions. This result is coherent with the fact that the synthesis/design point is taken at the maximum electrical demand. In Fig. 6.31 the heat 
produced by the fuel cell sub-system at the optimum synthesis/design point is compare with the heating demands for each of the four time segments. These results show how the heat demand is only satisfied at the summer load conditions. At the winter load conditions, the heat produced by the fuel cell sub-system is clearly insufficient. This fact obviously

1- Summer peak electric load.

2- Summer off-peak electric load.

3- Winter peak heat load.

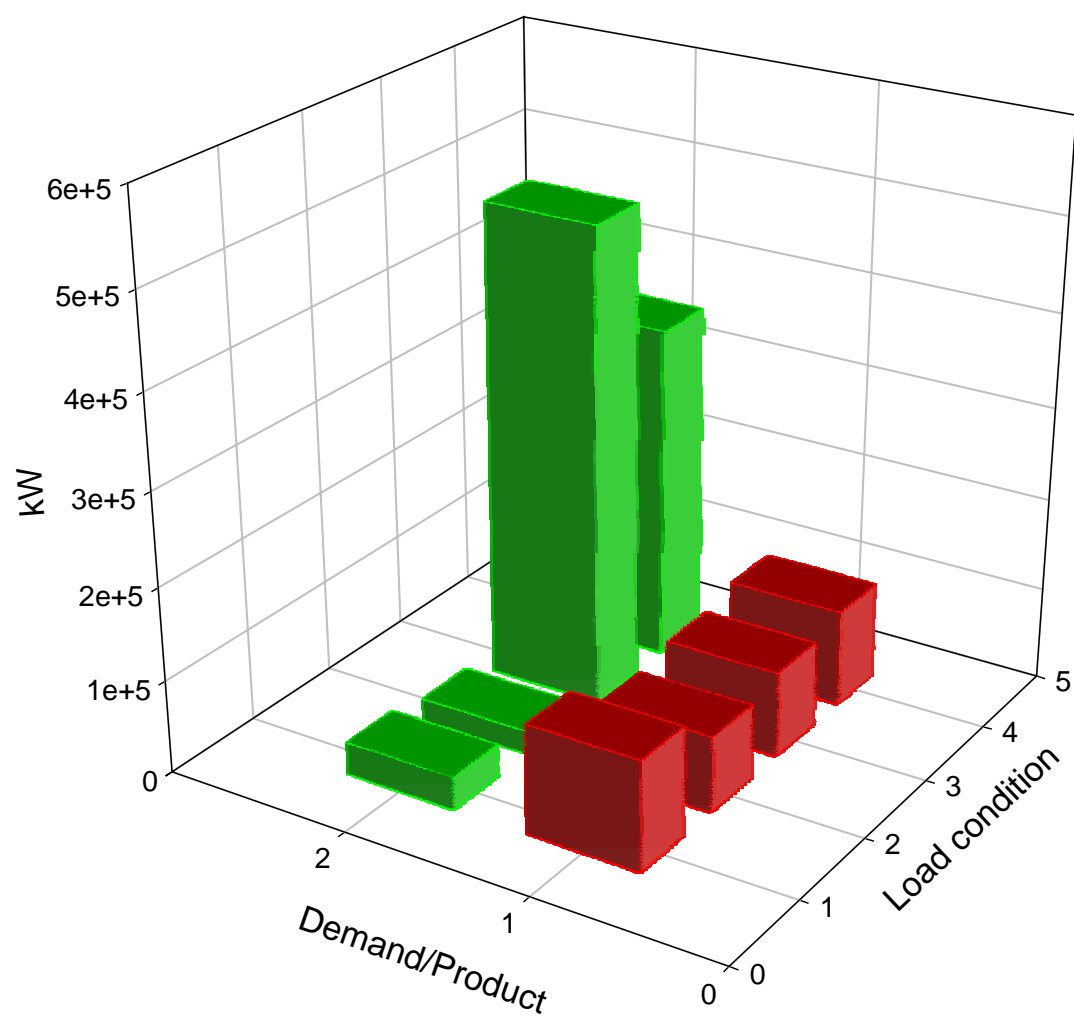

Figure 6. 31: Comparison of the heat production and the heat demand over the entire environmental/load profile.

points to the need for an additional sub-system in the configuration (e.g., a heat pump) in order to provide the additional thermal energy required. Work to include an absorption 
heat pump is currently underway in the complementary M.S. thesis work mentioned earlier in this thesis.

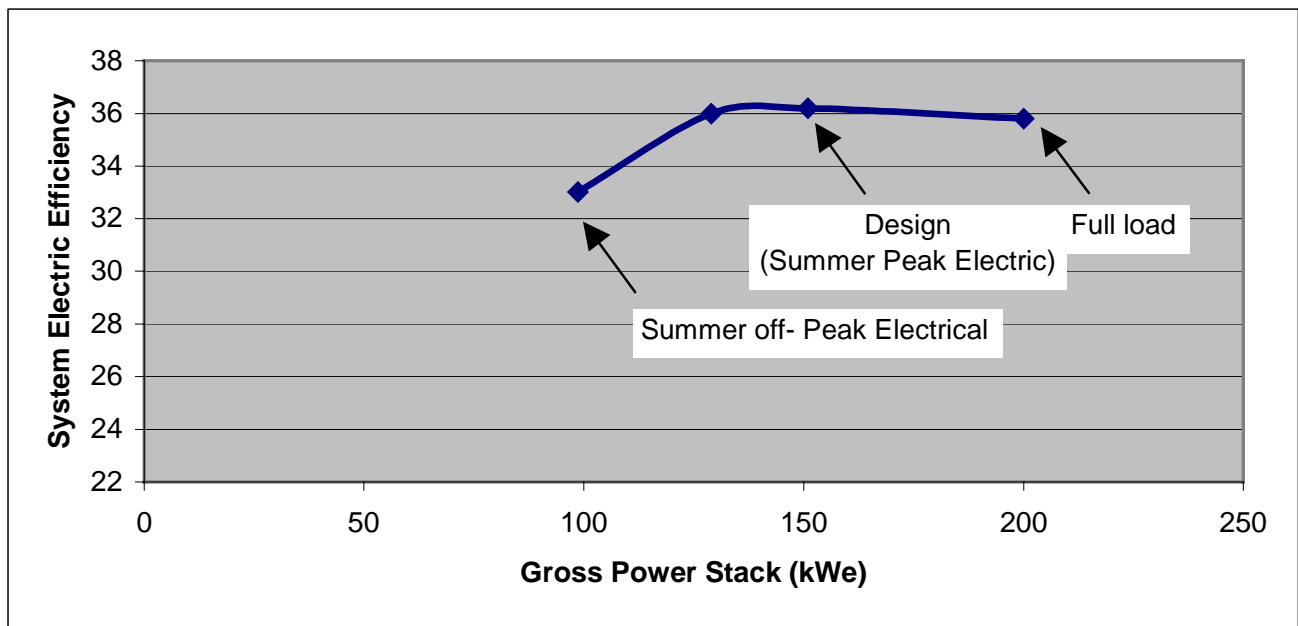

Figure 6. 32 System electrical efficiency based on LHV versus gross power of the stack for the optimum synthesis/design and off-design at the different summer load conditions.

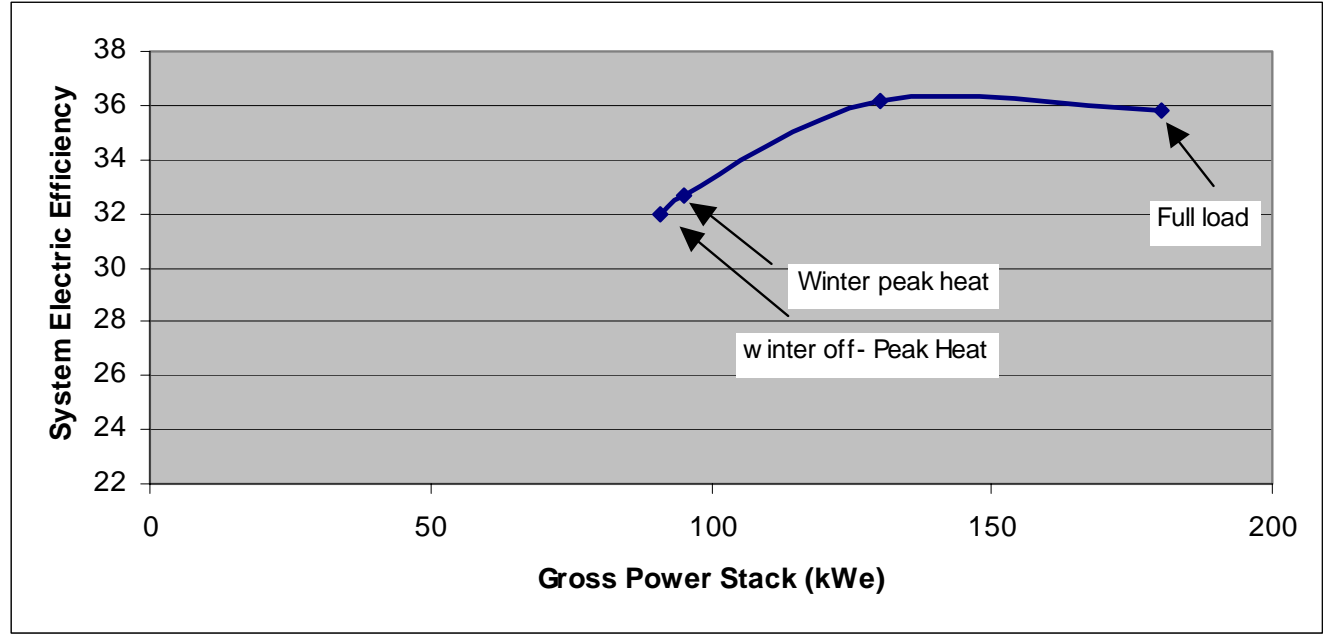

Figure 6. 33 System electrical efficiency (LHV) versus gross power of the stack for the optimum synthesis/design and off-design at the different winter load conditions. 


\section{Conclusions and Recommendations for Future work}

The conclusions and recommendations for future work are summarized in the following points:

1- Time decomposition and physical decomposition (e.g., LGO) are useful tools for simplifying the overall synthesis/design optimization problem of energy conversion systems in general and fuel cell sub-systems in particular. Even though LGO was the approach applied in this thesis work, it would be interesting in future work to apply ILGO as outlined in Chapter 4. ILGO could greatly decrease the computational time required for the optimization and sensitivity analyses which were done here. It would furthermore be interesting to determine and graphically represent the unit-level ORS for the FPS in order to show that as expected its behavior is just as smooth and convex as is that for the unit-level ORS of the SS. This, of course, would underscore why using ILGO is more effective than using LGO.

2- The optimization strategy followed in this thesis work allows one to analyze the fuel cell sub-system not only at the system level (e.g., with respect to the synthesis/design total cost or system efficiencies) but also at the component level (e.g., with respect to the detailed geometry of the components). 


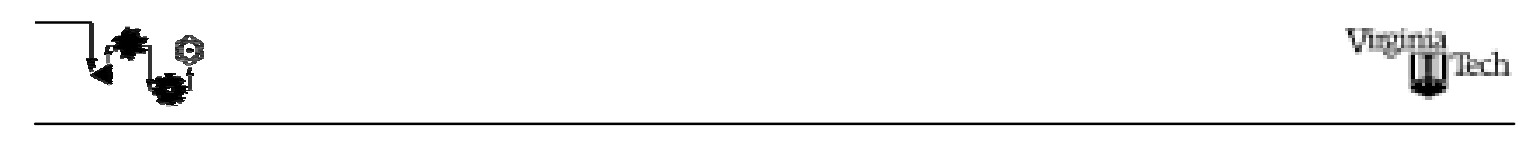

3- Wisely selecting the coupling functions quite naturally leads to the desirable convexity and smoothness of the unit-level ORSs and, thus, to the systemlevel ORS.

4- The optimum total synthesis/design cost for the fuel cell sub-system tends to decrease as the number of residences for which the fuel cell sub-system is synthesized/designed increases. The fuel cell sub-system is, thus, more economical for a relatively large cluster of residences (i.e. about 50). However little is gained in terms of reduced cost by increasing this number much above 50. Note of course that this conclusion is restricted to the fact that only three different number of residences were studied.

5- The optimum total synthesis/design cost for the fuel cell sub-system tends to decrease as the number of units manufactured per year increases. Achieving a unit cost of power production less expensive than 10 cents/kWh on an exergy basis requires the manufacture of approximately more than 1500 units per year. Of course this conclusion as well as the second above depend greatly on the cost functions available. Future work should improve these functions since the cost information available at the time that they were developed was relatively meager. More detailed information on costs has since become available and is currently being used to improve these functions in the other M.S. thesis work already mentioned several times. This improvement along with the kinetically as opposed to equilibrium based models should lead to a more accurate and detailed prediction of the optimal fuel cell sub-system synthesis/design.

6- The simulation of the fuel cell sub-system under synthesis/design and offdesign conditions (especially off-design) is a complex problem due to the presence of several chemical components (up to seven) and the wide range of load conditions at which the fuel cell sub-system must operate. Therefore, 


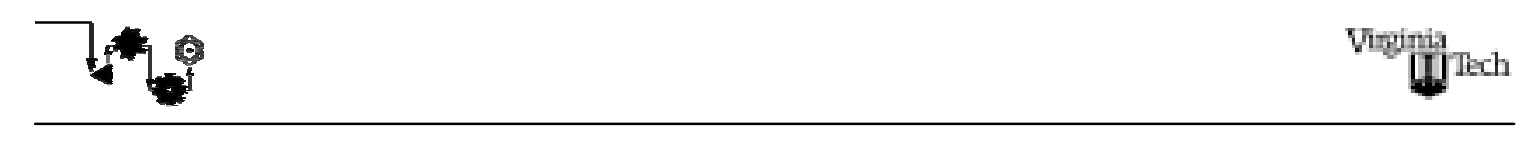

further improving the robustness of the code is an important issue. In this thesis work, the different components of the configuration are solved sequentially as opposed to simultaneously. Future work should try solving the synthesis/design and off-design systems of equations simultaneously. This will require implementing some very efficient non-linear equation solvers, which are both robust and relatively fast. This work is currently underway as part of the other M.S. thesis work already mentioned, which is implementing a set of non-linear solvers using the gPROMS environment. gPROMS not only can improve the robustness of the simulation code as mentioned but will as well allow more flexibility in selecting the independent variables of the simulation.

7- The fuel cell sub-system configuration in this study was not able to operate at relatively small electrical outputs. The fact that no feasible simulations at offdesign with net power outputs less than approximately $70 \mathrm{kWe}$ at the summer off-peak electrical load condition and approximately $60 \mathrm{kWe}$ at the winter peak heat load condition were found after more than 25,000 simulations of the $230 \mathrm{kWe}$ rated fuel cell sub-system suggest that the configuration does not operate at partial electrical loads smaller than approximately $35 \%$ of the maximum electrical load.

8- The fuel cell sub-system is not able by itself to satisfy the winter heat demands. This fact clearly points to the need for integrating the fuel cell subsystem with another sub-system such as a heat pump in order to increase heat production in winter. Work is currently underway as part of the other M.S. thesis work mentioned earlier to incorporate an absorption heat pump subsystem. This will allow greater flexibility in meeting combined heat and electrical loads throughout the year. 


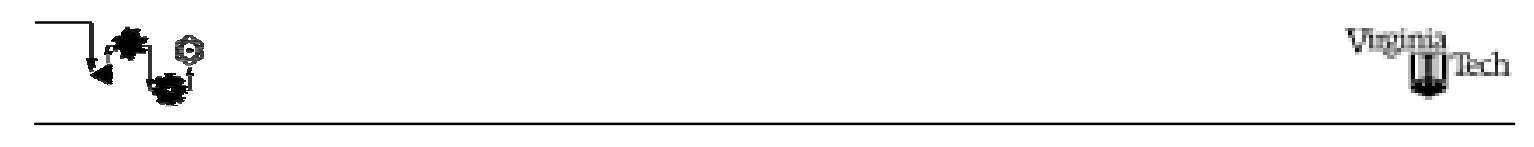

9- According to the cost functions available and the syntheses/designs studied, operating at maximum system electrical efficiency (approximately 65\% of full load) at the synthesis/design point is an optimum solution. However, this has a penalty in terms of decreasing the system electrical efficiency when the optimum operation under off-design conditions is found at small thresholds of electrical power produced. The consequence as seen in the results presented is that a synthesis/design close to the optimum but not operating at maximum system electrical efficiency at the synthesis/design point becomes the best synthesis/design ${ }^{1}$ because it out performs the others at off-design (see Figs 6.32 and 6.33).

\footnotetext{
${ }^{1}$ Obviously, if we had expanded the number of feasible near-optimum solutions at the synthesis/design point, which were evaluated optimally at off-design, another near-optimum solution may have become the optimum with respect to both the synthesis/design point and off-design. Of course, this can always be done but was not done in this work due to time constraints. Furthermore, this would not need to be done at all if time decomposition had not been used but then one would lose the advantages, which come with its application.
} 


\section{References}

ADELMAN, S. T., HOFFMAN, M. A., BAUGHN, J. W., 1995, A Methane-Steam

Reformer for a Basic Chemically Recuperated Gas Turbine, Journal of Engineering for Gas Turbines and Power. Vol. 117 January.

ALATIQUI, I.M., 1991, Dynamic simulation and adaptive control of an industrial Steam reformer Gas, Computers Chemical Enginnering, vol 15, n. 3 147-155.

ARTHUR D. LITTLE, 1994, Multi-Fuel reformers for fuel cells used in transportation, U.S. Dept. of Energy, May.

BARBIR, F., GOMEZ, T. 1997, Efficiency and Economics of proton exchange membrane (PEM) fuel cells, Int. Journal Hydrogen Energy, vol.22 n. 10/11 pp. 10271037.

BARBIR, F., 1999, Trade-off Design Analysis of Operating Pressure and Temperature in PEM Fuel Cell Systems, Proceedings of the ASME, Advanced Energy Systens Division, ASME.

BASYE, L., SWAMINATHAN, S., 1997, Hydrogen Production Costs, Department of Energy, USA, (DOE/GO/10170-778). 
BEJAN, A., TSATSARONIS, G., et al., 1996, Thermal Design and Optimization, John Wiley and Sons, New York.

BESSETTE, N. F., 1995, Prediction of Solid Oxide Fuel Cell Power System Performance Through Multi-level Modeling, Journal of Energy Resources Technology, vol. 117, 307-317.

CLEGHORN, S.J., 1996, PEM Fuel Cells for Transportation and Stationary Power Generation Applications, $11^{\text {th }}$ World Hydrogen Energy Conference, Stuttgart, Germany.

EKDUNGE, P., RABERG, M., 1998, The Fuel Cell vehicle analysis of energy use, emissions and cost, Int. Journal Hydrogen Energy, vol.23 n. 5 pp. 381-385.

EL-SAYED Y., 1989 A Decomposition Strategy for Thermoeconomic Optimization, ASME Application, Journal of Energy Resources Technology, vol. 111, pp1-15.

FARRY, M., 1998, Ethane from Associated Gas Still the Most Economical, The Oil and Gas journal, June $8^{\text {th }}$.

GLEASON, K. J., WRIGHT, J.D., 1999, Solid Oxide Fuel Cell Residential Cogeneration, Joint DOE / EPRI / GRI Fuel Cell Technology Review Conference 3-5 August, Chicago.

GUNES, M.B., ELLIS, M.W., 2001, Status of Fuel Cell Systems for Combined Heat and Power Applications in Buildings, ASHRAE Transactions 
INBODY, M.A., HEDSTROM J.C., TAFOYA, J., STROH, K.R. VANDERGORGH, N.E., 1998, Transient Carbon Monoxide Control for PEM Fuel Cell Systems, 1998 Fuel Cell Seminar, Palm Springs, California.

INCROPERA and DEWITT, 1990, Influence coefficients for fully developed lamina flow in a circular tube annulus with uniform heat flow maintain at both surfaces of $3^{\text {rd }}$ edition.

iSIGHT version 5 User's Guide, 1999, Engineous Software Inc., Morrisville, N.C.

JIANGUO, X., GILBERT, F. F., 1989, Methane Steam Reforming, Methanation and Water-Gas Shift: I. Intrinsic Kinetics, AIChE Journal, vol. 35, n.1,.

JIANGUO, X., GILBERT, F. F., 1989, Methane Steam Reforming: II. Diffusional Limitations and Reactor Simulation, AIChE Journal, vol. 35, n.1, .

JORGENSEN, C., 2000, Hydrogen Production, EMI internal document, Blacksburg, Virginia.

KAYS, W.M. and LONDON, A.L., 1998, Compact Heat Exchangers, $\underline{\text { Krieger }}$ Publishing Company, Malabar, FL.

KORDESCH, K., SIMADER, G., 1996, Fuel Cells and Their Applications, VCH Publishers, I.N.C.,

LIU, H., KAKAC, S., 1998, Heat exchangers: Selection, Rating, and Thermal Design, CRC Press. 
LINDSTROM, O., LAVERS, W., 1997, Cost Engineering of Power Plants with Alkaline Fuel Cells, Int. Journal Hydrogen Energy, vol.22 n. 8 pp. 815-823.

LOMAX, F. D., 2001, Application of Concurrent Development Practices to Petrochemical Equipment Design, Ph.D. dissertation, Mechanical Engineering Department, Virginia Polytechnic Institute and State University, Blacksburg, Virginia.

MEZIOU, A. M., 1994, Identification and Control of an Industrial Steam-Reforming Plant, The Canadian Journal of chemical Engineering, vol. 72 .

MORAN, M.J., SHAPIRO, H.N., 1994, Fundamentals of Engineering Thermodynamics, Ed John Wiley adn Sons.

MUNOZ, J.R., VON SPAKOVSKY, M.R, 2001a, A The Use of Decomposition Approach for the Large Scale Synthesis/Design Optimization of Highly Coupled, Highly Dynamic Energy Systems, International Journal of Applied Thermodynamics, March, vol. 4, no. 1 .

MUNOZ, J.R., VON SPAKOVSKY, M.R, 2001b, The Application of Decomposition to the Large Scale Synthesis/Design Optimization of Aircraft Energy Systems, International Journal of Applied Thermodynamics, June, vol. 5, no.1.

MUNOZ, J.R., VON SPAKOVSKY, M.R, 2000a, The Use of Decomposition for the Large-Scale Synthesis / Design Optimization of Highly Coupled, Highly Dynamic Energy Systems - Theory, International Mechanical Engineering Congress and Exposition - IMECE'2000, ASME, Orlando, Nov. 5-10, AES-Vol. 40. 
MUNOZ, J.R., VON SPAKOVSKY, M.R, 2000b, The Use of Decomposition for the Large-Scale Synthesis / Design Optimization of Highly Coupled, Highly Dynamic Energy Systems - Application, International Mechanical Engineering Congress and Exposition -IMECE'2000, ASME, Orlando, Nov. 5-10, AES-Vol. 40.

MUNOZ, J.R., VON SPAKOVSKY, M.R, 2000c, Decomposition in Energy System Synthesis / Design Optimization for Stationary and Aerospace Applications, $\underline{8}^{\text {th }}$ AIAA/NASA/USAF/ISSMO Symposium on Multidisciplinary Analysis and Optimization, Long Beach, CA, September 6-8.

MUNOZ, J.R., VON SPAKOVSKY, M.R, 2000d, An Integrated Thermoeconomic Modeling and Optimization Strategy for Aircraft / Aerospace Energy System Design, Efficiency, Costs, Optimization, Simulation and Environmental Aspects of Energy Systems (ECOS'00), Twente University, ASME, Netherlands, July 5-7.

MURRAY, A., SNYDER, T., 1985, Steam-Methane Reformer Kinetic Computer model with Heat Transfer and Geometry Options, Ind. Eng. Chemical Process Design. Dec. ,24, 286-294, 1985.

NEWSOME, D.S., 1980, The Water-Gas Shift Reaction, Catalysis Review - Science and Engineering, vol. 21, no. 2, pp. 275-318.

ODGEN. J. M., 1996, Hydrogen energy Systems studies, Priceton University for US department of energy, August.

OEI, D., 1997, Direct Hydrogen fueled Pronton Exchange Membrane Fuel Cell system for transportation applications, Ford Motor Company for U.S. Department of Energy, July 1997. 
THOMAS, C., 1995, Technology Development Goals for automotive Fuel Cell Power Systems, Hydrogen vs. Methanol: a comparative Assessment for fuel cell electric vehicles, Argonne National Laboratory, July.

THOMAS, S., ZALBOWITZ, M., Fuel Cells: Green Power, Los Alamos National Laboratory, www.education.lanl.gov/resources/fuelcells.

VALERO, A., LOZANO, M., 1994, Application of the Exergetic Cost Theory to the CGAM problem, Energy- The international Journal, Vol. 19, No 3, pp. 365-381.

VON SPAKOVSKY, M.R, 1994, Application of Engineering Functional Analysis to the Analysis and Optimization of the CGAM Problem, Energy-The international Journal, vol 19, No3, pp 343-364, Pergamon, Great Britain.

WILSON, M.S., ZAWODZINSKI, C., GOTTESFELD, S., LANDGREBE, A.R., 1996, Stationary Power Aplications for Polymer Electrolyte Fuel Cells, U.S. Dept. of Energy.

TSATSARONIS, G., Y. PISA, J., 1994, Exergoeconomic Evaluation and optimization of Energy Systems-Application to the CGAM Problem, Energy-The international Journal, Vol. 19, No 3, pp. 287-321. 


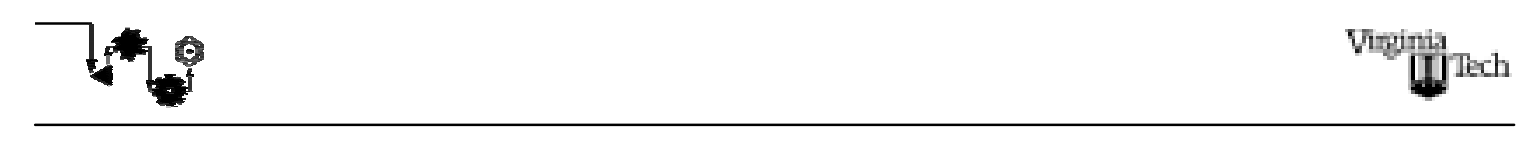

\section{Appendix A}

\section{Heat exchangers model}

The heat exchangers used are compact with cross flow and unmixed fluids (see Figs. 6.22 to 6.24). The main reference for this particular model is Liu et al. (1998). The model uses the effectiveness-NTU method in order to relate the geometry of the heat exchangers with the thermodynamic properties at any moment of the operation. The correlation used in order to establish a relation between the effectiveness, the number of transfer units and the ratio of heat capacities is the classic relation for cross flow (single pass) arrangement with both fluids unmixed.

$\varepsilon=1-\exp \left[\left(\frac{1}{C_{r}}\right)(N T U)^{0.22}\left\{\exp \left[-C_{r}(N T U)^{0.78}\right]-1\right\}\right]$

where the heat capacity ratio is express as

$$
C_{r}=\frac{C_{\min }}{C_{\max }}
$$

where $C_{\min }$ and $C_{\max }$ are the minimum and maximum heat capacities, respectively, from the heat capacities of the cold and hot streams. The number of transfer units is calculated as

$$
N T U=\frac{U A}{C_{\min }}
$$

where $U, A$ are the overall heat transfer coefficient and A the heat transfer area. The product $\mathrm{UA}$ is express as 


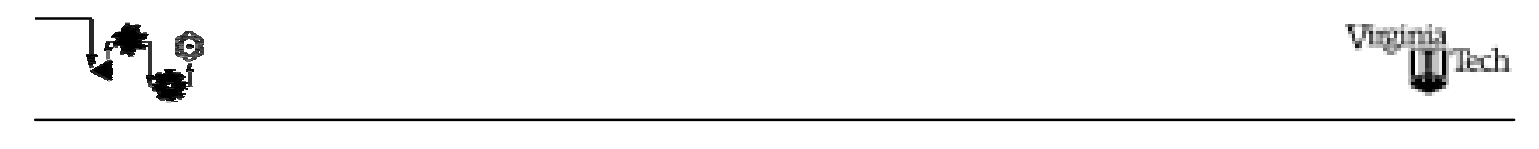

$$
U A=\frac{1}{\frac{1}{\eta_{o h} A_{h} h_{h}}+\frac{1}{\eta_{o c} A_{c} h_{c}}}
$$

where $\eta_{o}, A$ and $h$ are the outside overall surface efficiency, the heat transfer area and the heat transfer coefficient respectively. The subscript ' $h$ ' indicates that the magnitude corresponds to the 'hot' side and ' $c$ ' indicates that the magnitude corresponds to the 'cold' side. In the model used in the simulation of the fuel cell sub-system the 'cold' and the 'hot' side are assumed to be identical. Therefore for both sides the overall surface efficiency is related to the fin efficiency $\left(\eta_{f}\right)$ in the following terms

$$
\eta_{o}=1-\frac{A_{f}}{A}\left(1-\eta_{f}\right)
$$

where $A_{f}$ is the secondary surface area. The fin efficiency is defines as

$$
\eta_{f}=\frac{\tanh (m l)}{m l}
$$

where $l$ is the fin length and the factor $m$ is defined as a function of the heat transfer coefficient, the thermal conductivity of the fin material $\left(k_{f}\right)$ and the fin thickness $\left(t_{f}\right)$ in the following terms

$$
m=\sqrt{\frac{2 h}{k_{f} t_{f}}}
$$

the fin length is calculated as a function of the fin thickness and the plate spacing $(b)$

$$
l=\frac{b}{2}-t_{f}
$$

The heat transfer coefficient for each side is calculated as

$$
h=j \cdot G \cdot c_{p} \cdot P_{r}^{-2 / 3}
$$

where $G$ is the mass velocity, $P_{r}$ the Prandtl number and $j$ the Colburn factor. The expression used to calculate the mass velocity is

$$
G=\frac{\dot{m}}{A_{o}}
$$




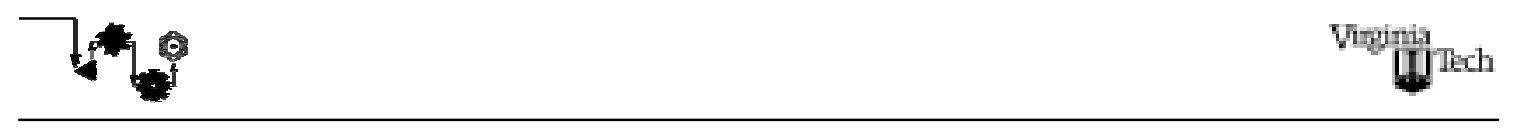

where the mass flow rate $(\dot{m})$ is divided by the minimum free flow area $\left(A_{o}\right)$, which is defined as

$$
A_{o}=\frac{D_{h} A}{4 L}
$$

where $L$ is the characteristic length of the heat exchanger and $D_{h}$ the hydraulic diameter of the conducts. Finally the calculation of the heat transfer area is done through the parameter $V$, which has a slight different definition for the 'cold' and 'hot' side

$V_{p_{c}}=L_{c} L_{h} b_{c} N_{p}$

$V_{p_{h}}=L_{c} L_{h} b_{h}\left(N_{p}+1\right)$

and through the heat transfer surface area density $(\beta)$

$A=\beta V_{p}$

\section{HTS and LTS reactor model}

The model used for the HTS and LTS reactor is in the same fashion as the thermodynamic model used for the steam reactor reformer (Eqs. (3.2) through (3.10)). In this case the overall reaction is

$$
x_{1} \mathrm{CH}_{4}+x_{2} \mathrm{H}_{2} \mathrm{O}+x_{3} \mathrm{CO}_{2}+x_{4} \mathrm{CO}+x_{5} \mathrm{H}_{2} \Rightarrow a \mathrm{CH}_{4}+b \mathrm{H}_{2} \mathrm{O}+c \mathrm{CO}_{2}+d \mathrm{CO}+e \mathrm{H}_{2}
$$

where $x_{1}, x_{2}, x_{3}, x_{4}$ and $x_{5}$ are the number of moles entering the reactor and $a, b, c, d$, and $e$ are the moles of product for the equilibrium composition at the outlet conditions of the reactor. The latter represent five unknowns whose determination requires a system of five linearly independent equations. Three of these are formed by the three atomic balances, which result from the overall reaction, namely

$$
\begin{aligned}
& x_{1}+x_{3}+x_{4}=a+c+d \\
& 4 x_{1}+2 x_{2}+2 x_{5}=4 a+2 b+2 e \\
& x_{2}+2 x_{3}+x_{4}=b+2 c+d
\end{aligned}
$$




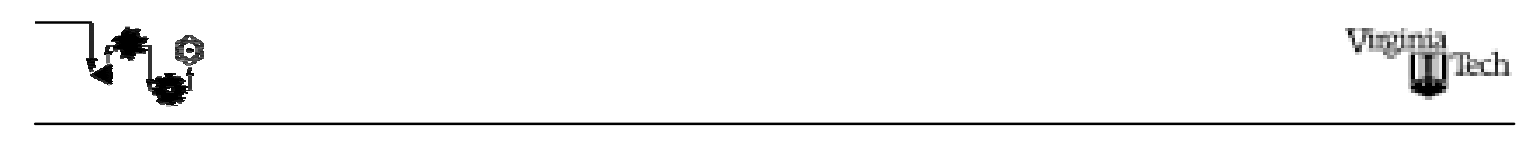

An additional equation is obtain from the fact that the methane flow rate does not change in the reactor as the only reaction taking place in the HTS and LTS reactors is the water-gas shift (see Table 2.5).

$$
x_{1}=a
$$

The additional equation required is that based on the conditions of thermodynamic chemical equilibrium associated with the stoichiometric equilibrium reactions of water-gas shift taking place in the HTS and LTS reactors. This thermodynamic chemical equilibrium condition is given in general terms by (Eq. (3.5)). For the stoichiometric equilibrium water gas-shift reaction is expressed as

$$
\left.K_{p}(T)\right|_{w g s}=\left(\frac{y_{\mathrm{CO}_{2}} y_{\mathrm{H}_{2}}}{y_{\mathrm{CO}} y_{\mathrm{H}_{2} \mathrm{O}}}\right)\left(\frac{P}{P_{o}}\right)^{1+1-1-1}
$$

where in this case the Gibbs free energy of reaction used to determine $\left.K_{p}(T)\right|_{w g s}$ is given by

$$
\left.\Delta G^{o}(T)\right|_{w g s}=\left(h_{\mathrm{CO}_{2}}+h_{\mathrm{H}_{2}}-h_{\mathrm{CO}}-h_{\mathrm{H}_{2} \mathrm{O}}\right)-T \cdot\left(s_{\mathrm{CO}_{2}}^{o}+s_{\mathrm{H}_{2}}^{o}-s_{\mathrm{CO}}^{o}-s_{\mathrm{H}_{2} \mathrm{O}}^{o}\right)
$$

and $h_{i}$ and $s_{i}^{o}$ are the total enthalpy and absolute entropy for the $\mathrm{i}^{\text {th }}$ component of the reformate exiting the reactor. For a given outlet HTS or LTS temperature $T$ and pressure $P$ as well as inlet composition, the outlet composition $a, b, c, d$, and $e$ for the HTS or LTS reactor is calculated using Eqs. (A.15) through (A.21).

\section{Compressors/Expander model}

In this section the model used for the compressors of the fuel cell sub-system is presented. The model for the expander was applied in the same fashion.

In design conditions the outlet temperatures of the compressor is calculated based in a fixed isentropic efficiency $\left(\eta_{c}, 70 \%\right)$ in the following terms 


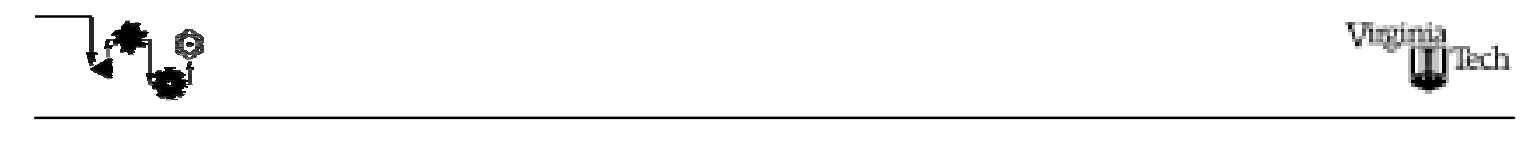

$T_{\text {out }}=T_{\text {in }}\left(1+\frac{1}{\eta_{c}}\left[\left(P_{r}\right)^{\frac{\gamma-1}{\gamma}}-1\right]\right)$

where $P_{r}$ is the pressure ratio express as

$$
\frac{P_{\text {out }}}{P_{\text {in }}}
$$

the duty of the compressor is calculated with the following energy balance

$$
\dot{E}_{\text {comp }}=\dot{m}\left(h^{\text {out }}-h^{\text {in }}\right)
$$

where $\mathrm{h}$ is the enthalpy of the fluid compressed evaluated at the outlet $\left(h^{\text {out }}\right)$ and at the inlet of the compressor $\left(h^{\text {in }}\right)$.

For the off-design simulation code the model of the compressors presented is substituted with a simplified non-dimensional map for small centrifugal compressors. The non-dimensional map establish a linear relation between the maximum ratio of the pressure ratio at design conditions and the pressure ratio at off-design conditions $\left(P R r_{\max }\right)$, (this ratio corresponds to $15 \%$ of the surge line) and the ratio of corrected mass flow rates at design conditions and off-design conditions $(\mathrm{cmr})$

$$
P R r_{\max }=0.3+0.7 \mathrm{cmr}
$$

In order to allow the compressor to operate at a variable distance of the surge line the difference between the minimum (0.4) and the maximum value of $P R r$ is multiply times a variable that takes values between 0 and $1(O p)$.

$$
\Delta P R r=\left(P R r_{\max }-0.4\right) O p
$$

Finally the value of $P R r$ at operation is calculated as

$$
P R_{\text {operation }}=(\Delta P R r+0.4) P R_{\text {design }}
$$




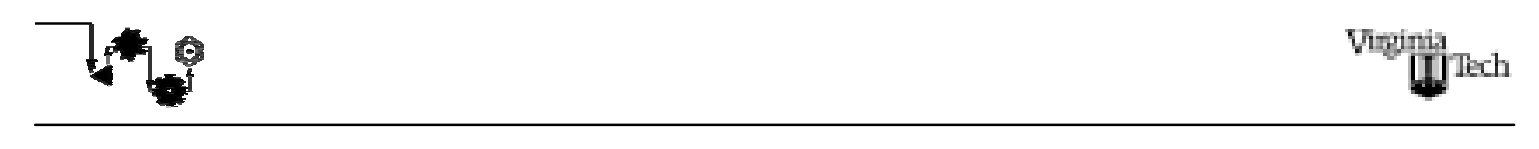

\section{Vita}

Borja Oyarzábal Alonso was born in Bilbao, Spain on April 23 ${ }^{\text {rd }}, 1977$. He joined the Centro Politécnico Superior (CPS) of engineers in Zaragoza in 1995 after graduating from Colegio Montearagon with honors. Working towards his degree at CPS, he completed a three months stay as a research assistant in the Austrian Academy of Science in Leoben, Austria. Pursuing his degree at CPS he also attended the Nottingham Trent University (NTU). He received a first class, honors Bachelor in Science from the NTU in July 1999. At that time he was also awarded with the departmental prize of best mechanical engineer of the year at NTU. After an academic semester in Spain he joined the Energy Management Institute at Virginia Polytechnic and State University (VPI) for his senior project. In August 2000 he joined the Master of Science program at VPI. He received his second Bachelor in Science of Mechanical Engineering from CPS in March 2001. Upon completion of his degree of Masters of Science in Mechanical Engineering (August 2001) from VPI he will join the Global Risk Management Solution group of PricewaterhouseCoopers as a consultant in Madrid, Spain. 